\title{
DIE DEFLECTION MODELING: EMPIRICAL VALIDATION AND TECH TRANSFER
}

\author{
Project DE-FC07-97ID13576
}

\section{FINAL REPORT}

\author{
R. Allen Miller, Professor \\ Industrial, Welding and Systems Engineering \\ Center for Die Casting \\ The Ohio State Univerisity \\ 210 Baker Systems Building \\ 1971 Neil Avenue \\ Columbus, $\mathrm{OH} 43210$ \\ Phone: 614-292-7067 \\ Fax: 614-292-7852
}

May 28, 2003 



\section{TABLE OF CONTENTS}

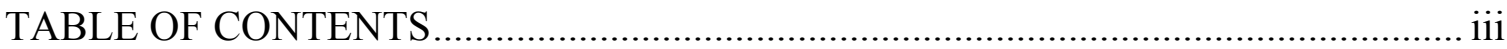

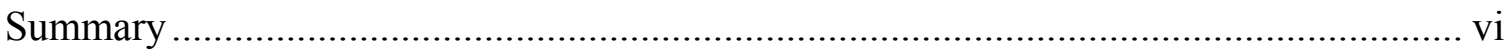

1. Parametric Study of the Effect of Structural Die and Machine Variables on Die Deflections

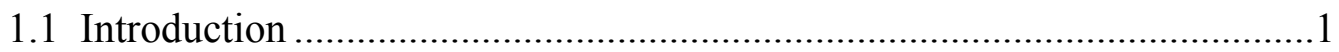

1.2 Approach for the Analysis..................................................................

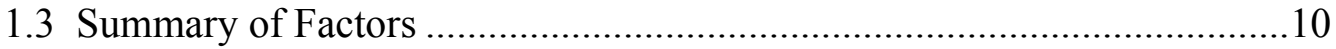

1.4 Simulation Procedures.............................................................................

1.5 Computational Array and Response Surfaces ............................................11

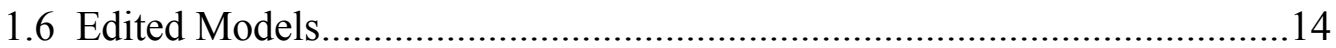

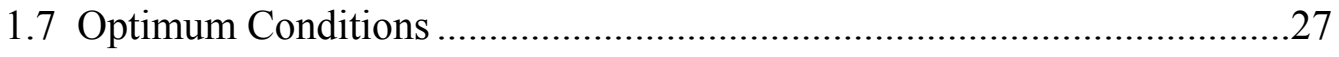

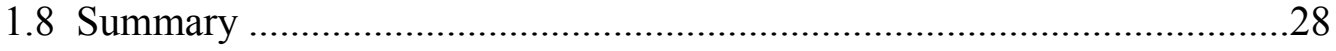

2. Explanation of Factors Determining Parting Plane Separation ......................................31

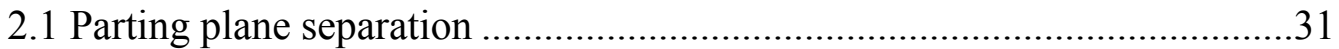

2.2 Factors causing parting plane separation....................................................4

3. Measurement of Deflection on the Cover Side and Ejector Side ….............................45

3.1 Estimating the rigid body motion .................................................................45

2.2 Extracting the data for calculation of rigid body motion ............................46

3.3 Regression analysis for the cover and ejector side...................................50

3.4 Distortion of the dies along dimensions parallel to parting plane:...............51

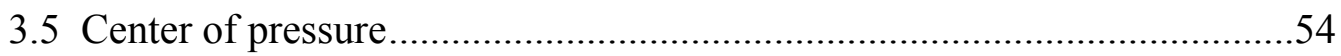

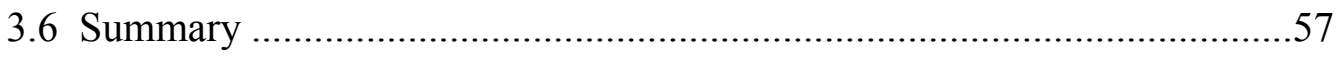

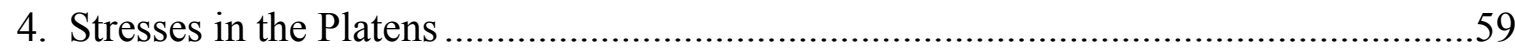

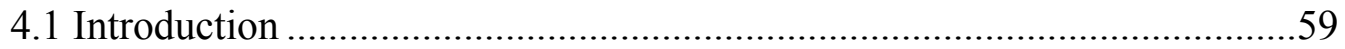

4.2 Contact pressure between the die and the platen........................................59

4.3 Compressive stresses in the platens............................................................62

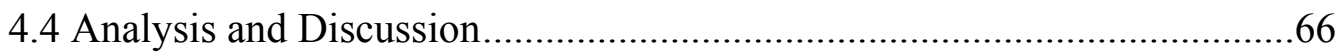


5. Effects of Backplate and Proud Inserts on Separation

5.1 Introduction .69

5.2 Effect of adding the backplate to the ejector die 69

5.3 Proud inserts . .71

5.4 Summary 85

6. Two Cavity Die..... .87

6.1 Introduction and Model Setup..... 87

6.2 Results and Analysis 89

6.3 Summary .96

7. Conclusions. .97

APPENDIX A Separation s, contact pressure and compressive stress plots for all cases.99

APPENDIX A.1 Plots for Case 1 ...... . .99

APPENDIX A.2 Plots for Case 2 . 102

APPENDIX A.3 Plots for Case 3 . 105

APPENDIX A.4 Plots for Case 4. 108

APPENDIX A.5 Plots for Case 5. 111

APPENDIX A.6 Plots for Case 6. 114

APPENDIX A.7 Plots for Case 7 117

APPENDIX A.8 Plots for Case 8 120

APPENDIX A.9 Plots for Case 9 123

APPENDIX A.10 Plots for Case 10. 126

APPENDIX A.11 Plots for Case 11 129

APPENDIX A.12 Plots for Case 12 132

APPENDIX A.13 Plots for Case 13 135

APPENDIX A.14 Plots for Case 14. 138

APPENDIX A.15 Plots for Case 15 141

APPENDIX A.16 Plots for Case 16. 144

APPENDIX A.17 Plots for Case 17. 147

APPENDIX A.18 Plots for Case 18 150

APPENDIX A.19 Plots for Case 19 153

APPENDIX A.20 Plots for Case 20 156 
APPENDIX A.21 Plots for Case 21.

APPENDIX A.22 Plots for Case 22 ….......................................................162

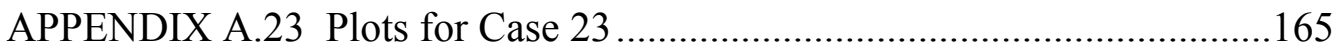

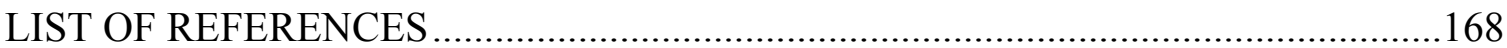




\section{SUMMARY}

This report summarizes computer modeling work that was designed to help understand how the die casting die and machine contribute to parting plane separation during operation. Techniques developed in earlier research [8] were applied to complete a large computational experiment that systematically explored the relationship between the stiffness of the machine platens and key dimensional and structural variables (platen area covered, die thickness, platen thickness, thickness of insert and the location of the die with respect to the platen) describing the die/machine system. The results consistently show that there are many significant interactions among the variables and it is the interactions, more than the individual variables themselves, which determine the performance of the machine/die system. That said, the results consistently show that it is the stiffness of the machine platens that has the largest single impact on die separation.

Attempts were made to analyze the cover and ejector contributions to overall parting separation. For the cases studied, the cover side contribution was dominant and the factors controlling cover side distortion naturally correspond to those controlling total separation. The ejector contribution is smaller and the design of ejector rails and pillars is critical to minimizing die separation. Since the details of the ejector side design were not controlled in the experiments, the data do not illuminate the situation. Ejector side design remains a subject of further study.

A small two cavity die was analyzed with a small computational experiment using three representative cases. Other than the differences in thermal loads and pressure distribution, the results for single and double cavity dies are quite similar. The same basic factors of machine stiffness and good ejector side design control the parting plane separation. 


\section{PARAMETRIC STUDY OF THE EFFECT OF STRUCTURAL DIE AND MACHINE VARIABLES ON DIE DEFLECTIONS}

\subsection{Introduction}

Designing the dies for die casting is largely still an art, rather than science, and depends on the experience of the die designer. Die designers tend to determine the size and shape of the individual components based on experience and/or rules of thumb. There is limited literature available for the structural design of dies and computer aided engineering tools for die casting focus primarily on thermal and process issues. The mechanical design of components is not addressed with the same level of completeness as other aspects of the process. Die designers tend to follow their own guidelines learned over time based on their own and others' experience. With recent developments in mathematical modeling (FEM) and computing capability, including graphics, storage, and speed, there is ample opportunity for designers to simulate and analyze their designs before production. The application of basic mechanical computer aided engineering (CAE) tools enables the designers to analyze the displacement and distortion of dies due to mechanical and thermal loads thus enabling better dimensional control of the part and fewer operating problems.

The work reported here builds on early modeling work by Ahuett-Garza [8] and others. In this particular research, the sensitivity and response of die deflection to variation in key die and machine variables was studied. The objectives of this work are:

- To understand the effect of die and machine variables on maximum parting plane separation. Parting plane separation controls across parting plane dimensions and is an indicator of die flash problems.

- To identify the primary machine variables that most affect the deflections.

- To establish guidelines for die design and machine selection.

Based on the sensitivity analysis, equations for the response surface relating each variable to parting plane separation are developed and used to help provide insight into the physical principles that control die distortion and separation. In addition to the response surfaces, numerous other analyses of separation, pressure, and stress are used to provide insight.

\subsection{Approach for the Analysis}

The approach for sensitivity analysis was developed by Chayapati's [2] and continued by several others including Tewari [6] and Kulkarni [7]. A hypothetical box shaped casting sized to fit on an 800-ton machine was selected by the NADCA Computer Modeling Committee for use in this study. The dimensions of the casting are shown in Figure 1.1. Inserts and dies were designed for the given part in such away that key parameters could be adjusted without affecting the insert. Schematics of the die are shown in Figure 1.2. The die parameters that were used in the study are:

1. Die Footprint, A. As shown in Figure 1.2, the die shoe is square with dimension A on each side. A is varied so that the die size covers from $30 \%$ to $80 \%$ of the platen. The relationship between the die and the platen is shown in Figure 1.3. 
2. Die Thickness, B. The cover and ejector dies are assumed to be the same thickness (neglecting the effects of the rails on the ejector side which are 6" thick in all cases.

3. Die Insert to Shoulder Ratio, D. The insert thickness is $D^{\prime \prime}$ and the shoulder thickness is $D^{\prime}$. The die thickness is $B=D^{\prime}+D^{\prime \prime}$. The variable used in the analysis is the ratio $\mathrm{D}$, defined as $D=\frac{B-D^{\prime \prime}}{B}=\frac{D^{\prime}}{B}$

The other variables considered are the machine platen thickness and the position of the die on the platen. These variables will be addressed shortly.

The design of the die was setup so that the insert length and width are held constant for all cases considered while the length and width of the shoe are adjusted according to values of the variable A. The number, size and location of pillars on the ejector side is a function of the size of the die shoe.

A schematic of the layout of the machine platen is shown in Figure 1.3. The die mounting area 44 inches square and is defined by the center lines of the tie bars. Die sizes that are considered in this study range from $30 \%$ of the platen area covered to about $80 \%$. The $80 \%$ level corresponds to a die that fits inside the tie bars without cutouts in the corner of the die.

The position of the die on the platen is constrained by the shot hole in the die and the cover platen. The effect of the constraint for small, nominal and large dies is shown in Figures $1.4 \mathrm{a}-\mathrm{c}$. In all cases, the top position is constrained by the shot hole in the platen and corresponds to 1.25 " inches above the nominal position which corresponds to the geometric center. The lowest position feasible depends on both the die size and the shot hole. The smallest die can be lowered 9.5 inches while the largest die can be lowered only 2.5 inches.

Figure 1.5 illustrates the configuration of the die on the machine and the components that were modeled. As noted, the cover and ejector platens were explicitly modeled along with the die holder blocks and inserts. Tie bars were explicitly modeled and the clamping mechanism was modeled via displacements of springs with stiffness computed to approximate the machine toggle mechanism.

Figure 1.5 also shows the boundary conditions that were used in the model. By having an explicit tie bar as shown in this figure, the lateral movement of the ejector platen is restrained. Restraining the movement of the model in the vertical direction is accomplished using the ' $\mathrm{Y}$ ' restraint on a couple of nodes. A ' $\mathrm{Y}$ ' restraint would represent the bolting of the platen to the machine foundation. The tie bar loads may also be reasonably balanced.

The clamping tonnage is applied by means of a displacement boundary condition on the ends of the spring elements that represent the stiffness of the toggle mechanism in the machine. The rear platen is not explicitly modeled; instead the nodes at the end of the tiebars are restricted in all six degrees of freedom. The bolting of the inserts to the die holder blocks is represented by a multi-point constraint (tied nodes) of the nodes at the corners of the insert. The clamping of the holder blocks to the platens is represented by a multi-point constraint (tied nodes) of the nodes at the corners of the die holder blocks. 


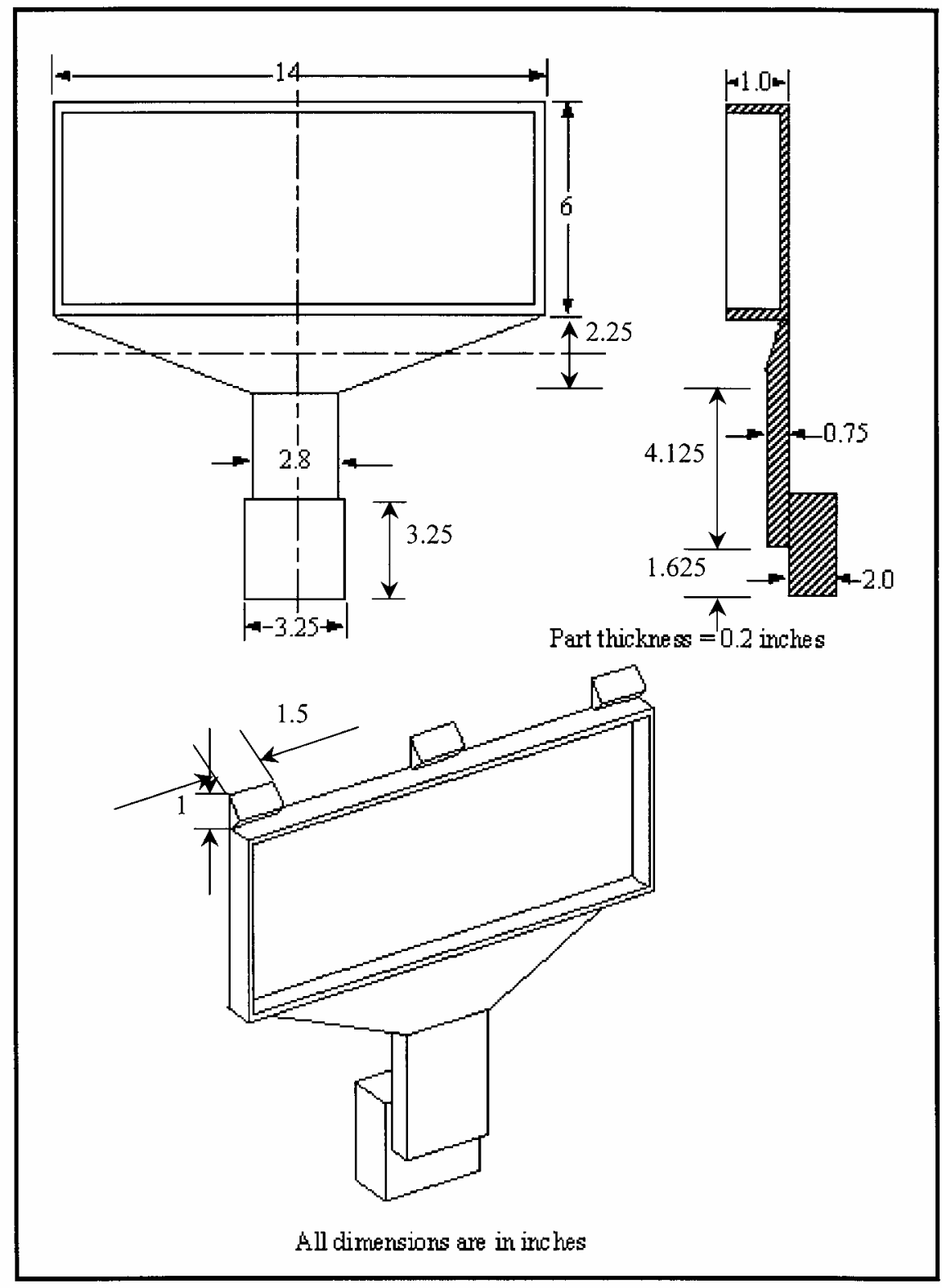

Figure 1.1: Casting used for 800 ton machine parametric study 


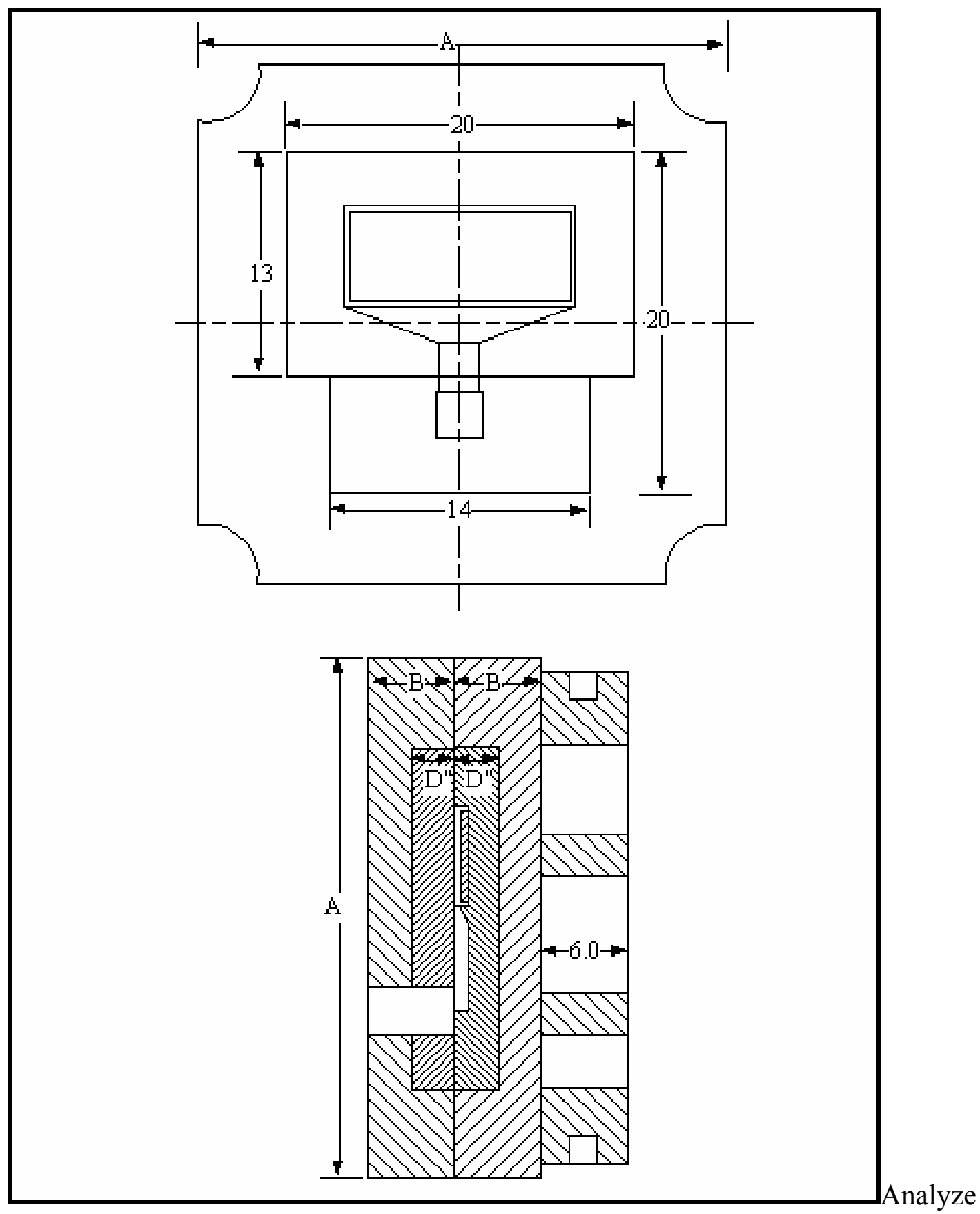

Figure 1.2: Schematic of the Die 


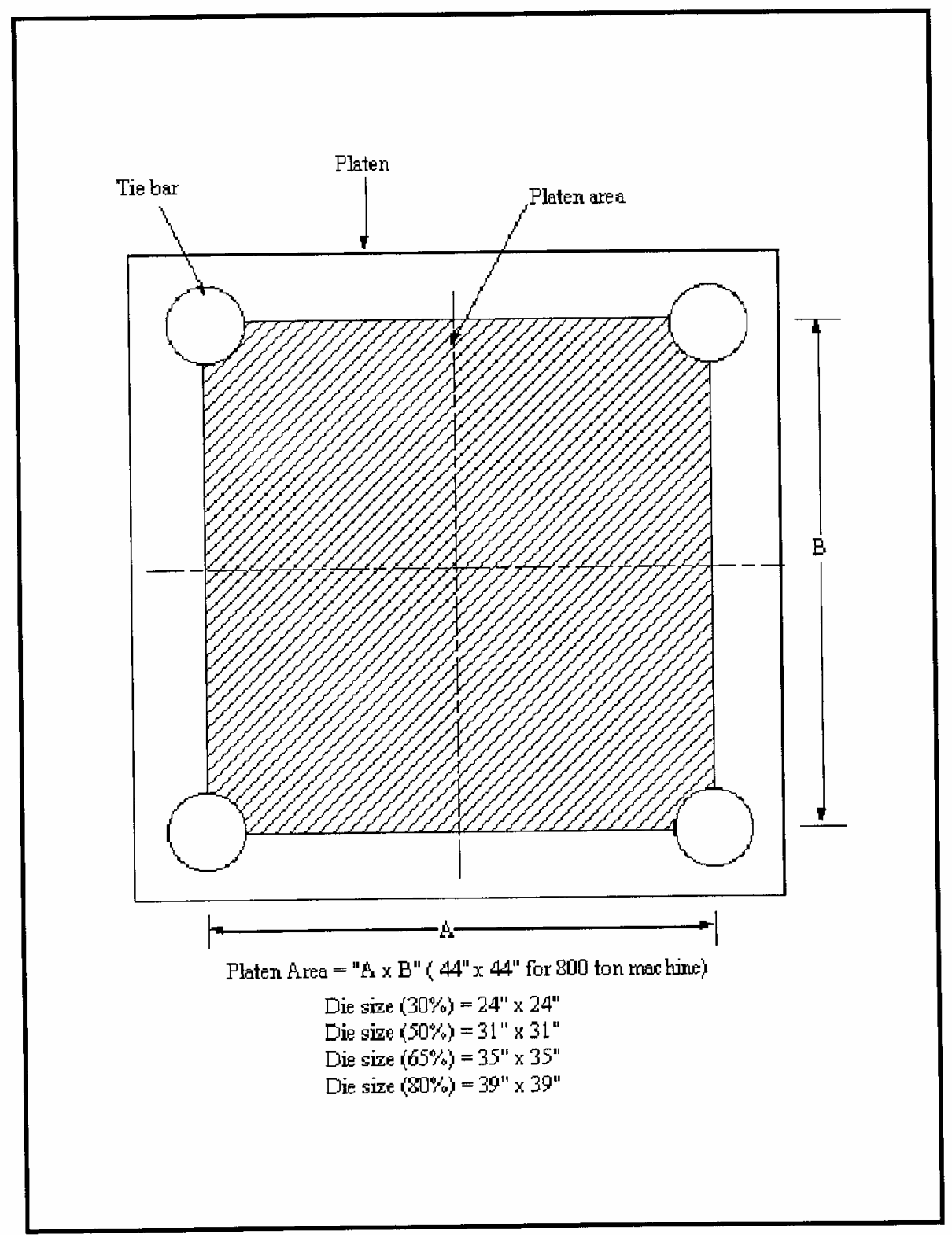

Figure 1.3 Machine Platen Layout 

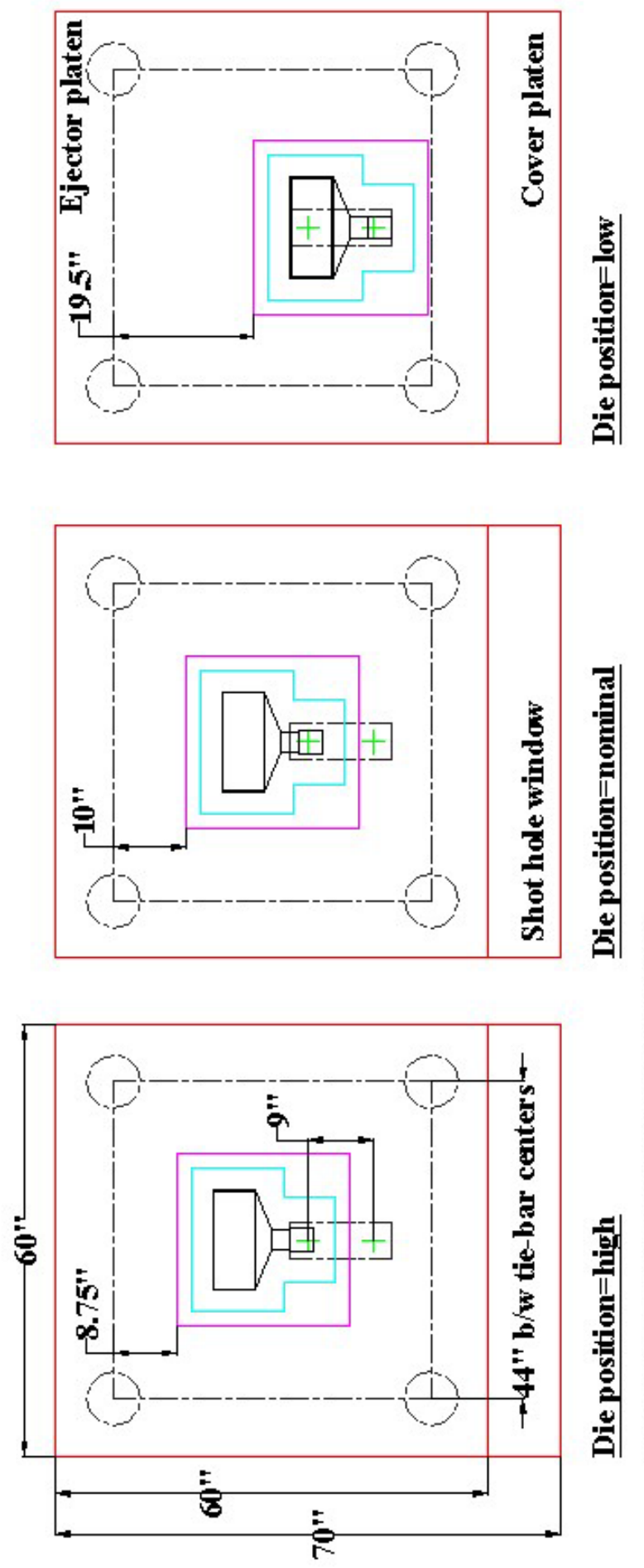

8
8
0
0
0
0
0
0
0
0
0
0
0
0
0
0
0

Figure 1.4a: Small die ( $30 \%$ Platen area covered) at different positions on the platens 

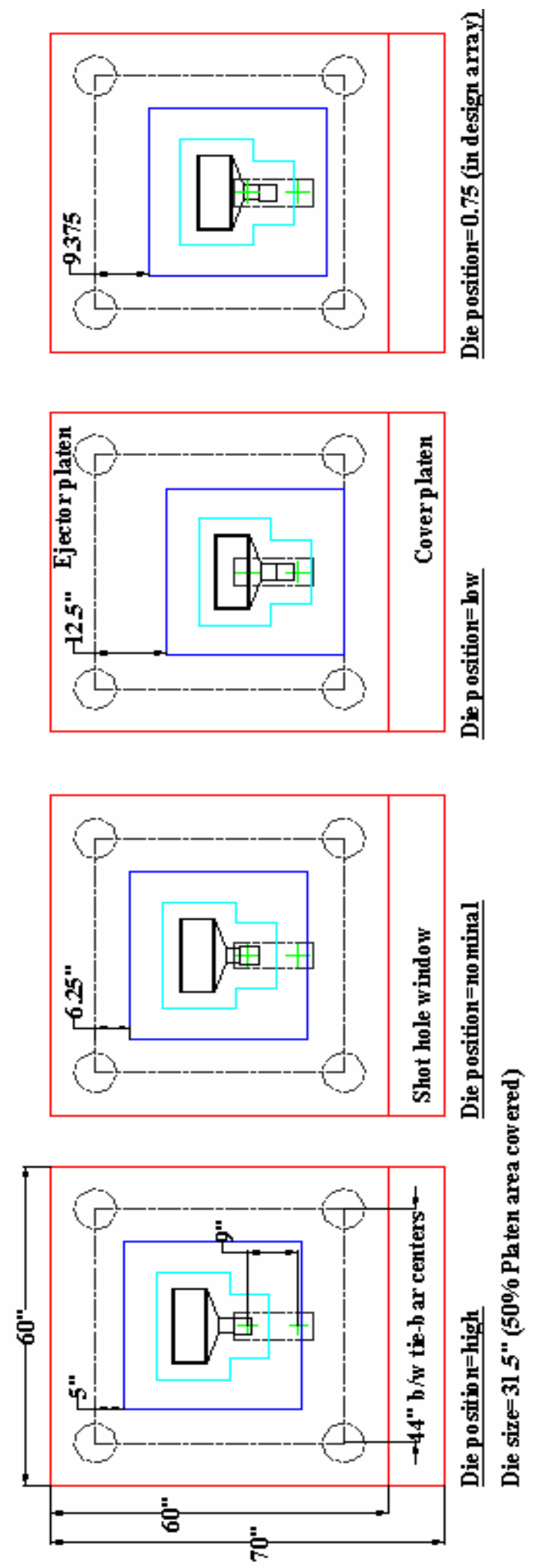

Figure 1.4b: Medium die (50\% Platen area covered) at different positions on the platen 


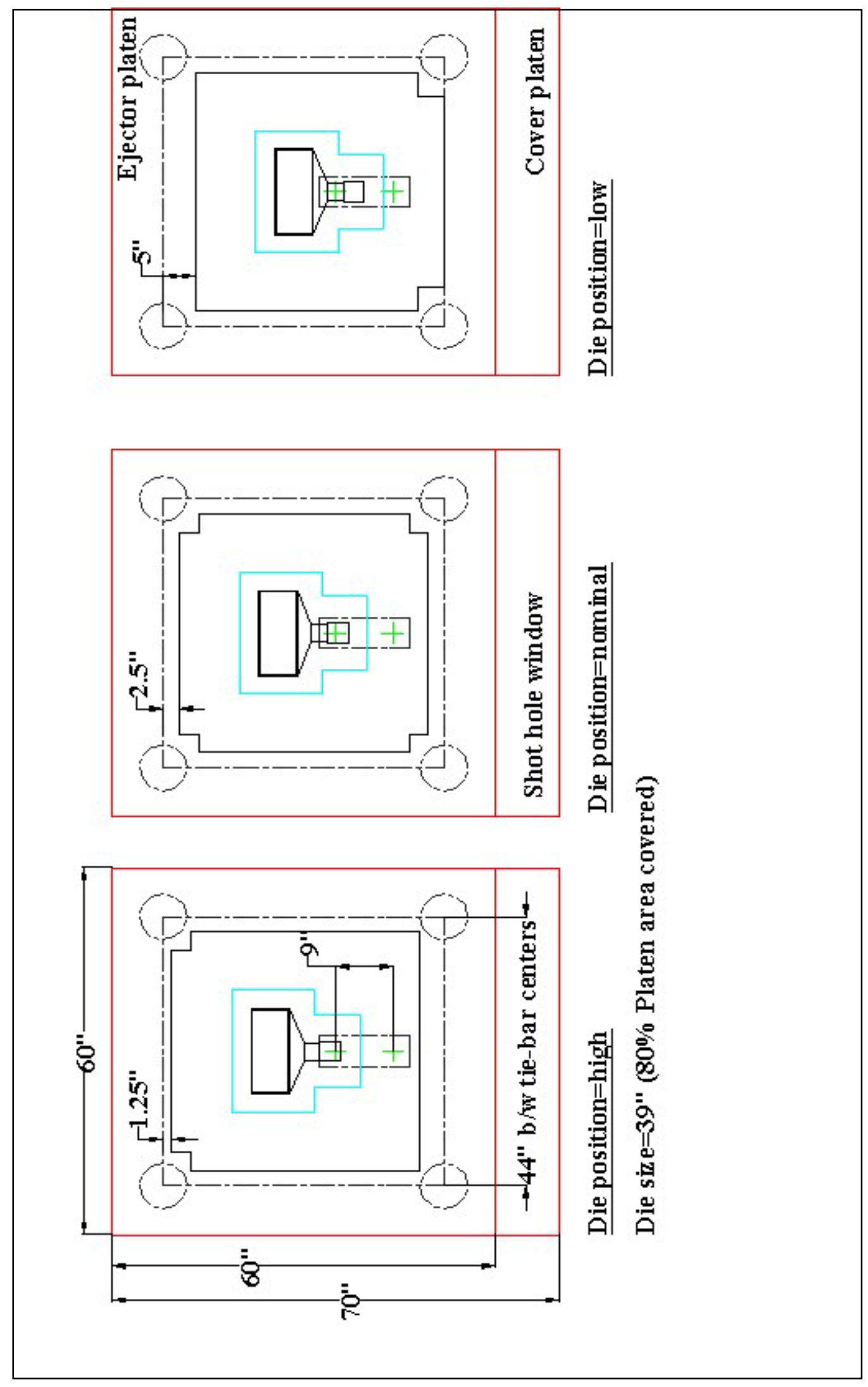

Figure 1.4c: Large die (80\% Platen area covered) at different positions on the platen 


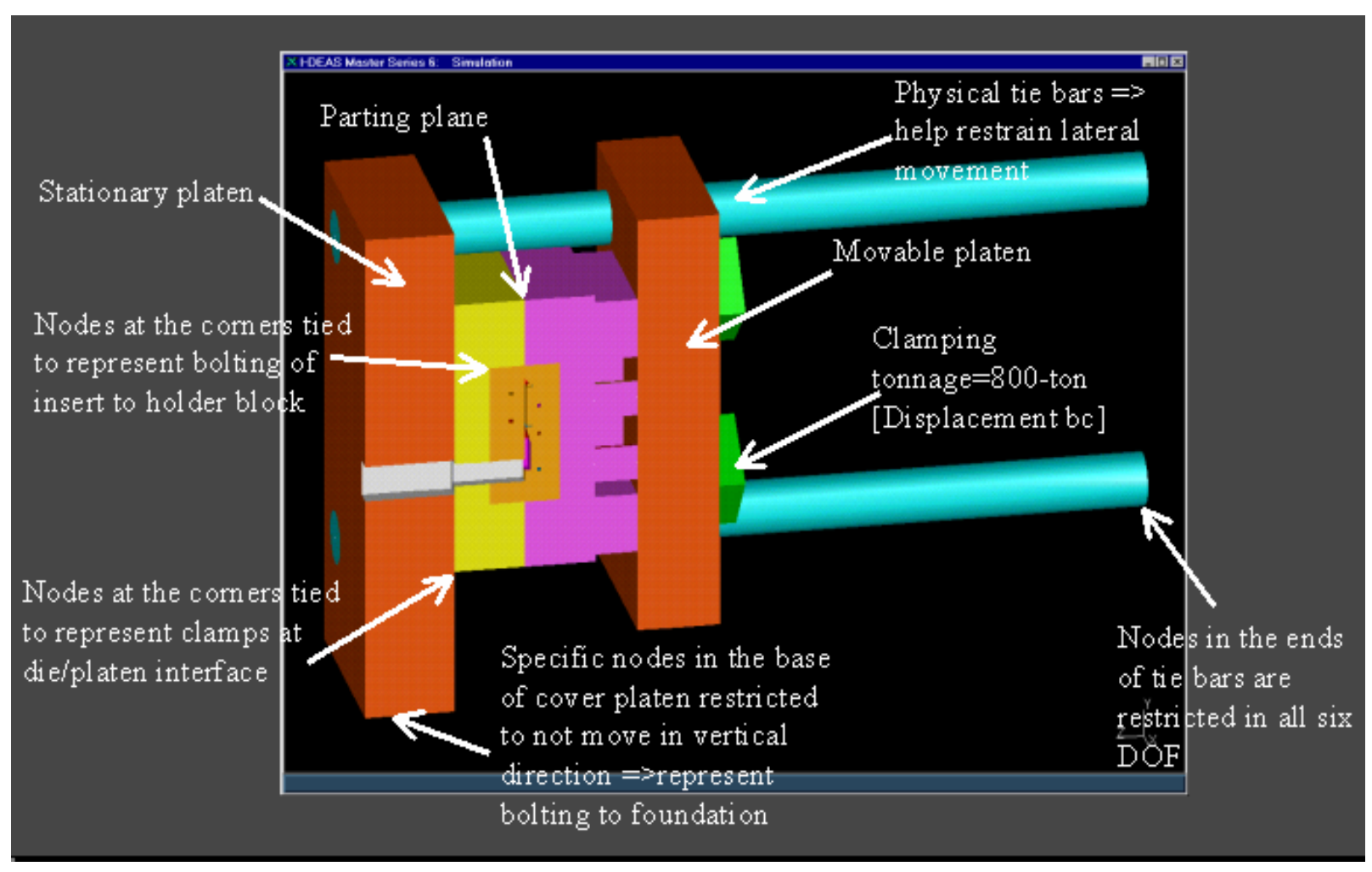

Figure 1.5 Schematic of the Machine/Die Model 


\subsection{Summary of Factors}

The variables considered and the ranges described in the previous section are summarized in the following table.

\begin{tabular}{|c|c|c|c|}
\hline Factor & Factor Description & Low & High \\
\hline A & Die Size & 24 in. & 39 in. \\
\hline B & Die Thickness & 5 in. & 10 in. \\
\hline C & Platen Thickness & 9 in. & 14.5 in. \\
\hline D & Thickness Ratio $^{1}$ & 0.4 & 0.5 \\
\hline E & Die location $^{2}$ & -7.1 in. & 3.6 in. \\
\hline D $^{\prime}$ & Shoulder Thickness $^{3}$ & 2.0 in. & 5.0 in. \\
\hline D" $^{\prime \prime}$ & Insert Thickness $^{4}$ & 2.5 in. & $6.0 \mathrm{in.}$ \\
\hline
\end{tabular}

Table 1. 1: Definition of Variables

The die sizes are designed for platen area coverage of $30 \%, 40 \%, 50 \%, 65 \%$ and $80 \%$. The factor E represents the location of the die as the distance between the die center of pressure and the platen centerline. The nominal position places the die centerline in line with the platen centerline. The die center of pressure is about 2.38 " above the platen centerline at nominal. A positive $\mathrm{E}$ means that the die center of pressure is located above the platen centerline, and a negative $\mathrm{E}$ indicates that the die center of pressure is located below the platen centerline. The maximum travel possible by any die is limited by the size of the shot hole window and the size of the die as shown in Figure 1.4. In case of a large die the movement in downward direction is limited by the size of the die since the bottom of the die hits the lower tie bars center before it could move as much as the shot hole window allows. But in case of a small die the die could move downward as much as the shot hole window allows and still not hit the lower tie bar centers.

\subsection{Simulation Procedures}

For each case considered, a 10 cycle solidification simulation was run and the insert and die temperatures at the instant of part ejection in the $10^{\text {th }}$ cycle were obtained from an

${ }^{1} D^{\prime}+D^{\prime \prime}=B$ in all cases. The variable used in the construction of the computational array is the ratio $D=\frac{B-D^{\prime \prime}}{B}$

2 The die location is constrained by the die size as summarized in the previous section. The location is defined as the distance from the die center of pressure from the platen geometric center.

3 See note 1 above

4 See note 1 above. 
ABAQUS thermal simulation. The uncoupled thermal-stress simulation was then performed for cycles 1 and 10 alone (since the analysis is uncoupled, the results can be obtained by superposition). These methods give reliable deflection information with less computation time and with lower memory requirements compared to coupled analyses.

We assume that the intensification pressure is applied shortly after the cavity is filled. The loads due to intensification tend to be the maximum mechanical loads (neglecting the impact spike). Thus, the deflections at $0.1 \mathrm{sec}$ into the intensification are used for analysis and comparison. However, the designer can gain quick understanding of the parting plane shape at part ejection, if the simulation is run until the point when the part is ejected. In the current research, for each of the cycles 1 and 10, simulation of the entire cycle was completed.

For each of the runs with the thermal and the stress simulation, the die temperatures were viewed in the I-DEAS post processor and the stress results were viewed in both IDEAS and ABAQUS post processors. The I-DEAS post processor was used to check the tiebar loads while the ABAQUS post processor was used for viewing the deflection/distortion, parting plane pressure and separation plots. ABAQUS is used extensively for post processing due to its speed and ability in processing contour plots.

The data analyzed for each case includes the contact pair separation, contact pressures, Von-mises stresses, nodal displacements etc. To evaluate the designs, the parting plane separation was chosen as a metric for comparison. Also, separations at such locations may result in flashing, a condition in which the metal spills out from the cavity. The excess metal must be removed from the part, die, or both. This trimming operation leads to the additional cost of trimming dies, and the reduction in production time. It should however be noted that the process might still be good if the parting plane is properly shut, irrespective of the die opening. The contact pressures on the parting plane and the die/platen interface were also studied to understand the die behavior for different runs.

\subsection{Computational Array and Response Surfaces}

An experimental array was designed to computationally study the effects and interactions of the above variables on maximum parting plane separation. Response surfaces were then constructed for the above variables.

The analysis was performed in several stages. Initially, an array was designed for 15 runs. This 15 run array was designed with the help of Allen et al [3] using the low cost response surface methodology. The initial results consisting of the 15 simulation runs were analyzed by Chayapati [2]. The initial results generally made sense, but there were some problems with the polynomial response surfaces in a few regions of the parameter space (separations predicted by interpolation were negative) and additional runs were required to fill in missing data and eliminate the problems. In total another 16 cases were run for a total of 31 .

The factor settings for all 31 cases considered are shown in Table 1.2. Also included are the results for maximum separation and the contribution to maximum separation attributed to the cover and ejector die sides respectively. The separation values are recorded in thousandths of an inch. The technique used to separate the total into the components will be discussed in a later section. 


\begin{tabular}{|c|c|c|c|c|c|c|c|c|}
\hline Run & A & B & C & D & E & Cover & Ejector & Max Sep \\
\hline 1 & 39 & 5 & 9 & 0.5 & 3.6334 & 14.590 & 5.228 & 19.818 \\
\hline 2 & 39 & 10 & 9 & 0.5 & -0.1166 & 7.727 & 6.457 & 14.184 \\
\hline 3 & 24 & 10 & 14.5 & 0.5 & -7.1166 & 8.505 & 6.396 & 14.901 \\
\hline 4 & 24 & 5 & 14.5 & 0.4 & -7.1166 & 5.552 & 4.451 & 10.004 \\
\hline 5 & 24 & 5 & 9 & 0.4 & 3.6334 & 6.626 & 2.299 & 8.924 \\
\hline 6 & 39 & 5 & 14.5 & 0.5 & -0.1166 & 5.155 & 3.304 & 8.459 \\
\hline 7 & 39 & 5 & 9 & 0.4 & -0.1166 & 14.185 & 5.417 & 19.602 \\
\hline 8 & 24 & 10 & 9 & 0.4 & -7.1166 & 8.310 & 8.022 & 16.331 \\
\hline 9 & 24 & 10 & 9 & 0.5 & 3.6334 & 7.405 & 4.695 & 12.100 \\
\hline 10 & 24 & 5 & 14.5 & 0.5 & 3.6334 & 3.832 & 1.294 & 5.126 \\
\hline 11 & 31.5 & 7.5 & 11.75 & 0.5 & -3.8666 & 4.987 & 4.493 & 9.480 \\
\hline 12 & 31.5 & 7.5 & 9 & 0.45 & 2.3834 & 8.073 & 4.424 & 12.498 \\
\hline 13 & 24 & 5 & 11.75 & 0.45 & 2.3834 & 4.254 & 2.168 & 6.422 \\
\hline 14 & 31.5 & 10 & 11.75 & 0.4 & -0.7416 & 7.999 & 6.343 & 14.342 \\
\hline 15 & 39 & 7.5 & 14.5 & 0.45 & 3.6334 & 4.651 & 6.341 & 10.993 \\
\hline 16 & 27.8 & 8.75 & 13.1 & 0.425143 & 3.0084 & 4.873 & 4.043 & 8.916 \\
\hline 17 & 39 & 8.75 & 10.4 & 0.43 & 3.0084 & 8.448 & 4.026 & 12.474 \\
\hline 18 & 35.3 & 7.5 & 13.1 & 0.45 & -1.9666 & 6.002 & 3.403 & 9.405 \\
\hline 19 & 31.5 & 10 & 11.8 & 0.45 & 2.3834 & 7.020 & 4.392 & 11.412 \\
\hline 20 & 35.3 & 10 & 14.5 & 0.43 & 3.0084 & 5.018 & 6.338 & 11.355 \\
\hline 21 & 35.3 & 5 & 13.1 & 0.43 & 3.0084 & 5.806 & 4.171 & 9.977 \\
\hline 22 & 35.3 & 8.75 & 13.1 & 0.5 & 2.3834 & 7.339 & 3.579 & 10.918 \\
\hline 23 & 31.5 & 5 & 14.5 & 0.5 & 2.3834 & 4.176 & 3.873 & 8.049 \\
\hline 24 & 24 & 5 & 9 & 0.4 & -7.1166 & 5.488 & 3.137 & 8.625 \\
\hline 25 & 24 & 5 & 14.5 & 0.4 & 3.6334 & 3.119 & 2.732 & 5.851 \\
\hline 26 & 24 & 5 & 14.5 & 0.5 & -7.1166 & 2.404 & 3.278 & 5.682 \\
\hline 27 & 24 & 5 & 9 & 0.5 & -1.7416 & 4.893 & 3.849 & 8.743 \\
\hline 28 & 24 & 10 & 14.5 & 0.4 & 3.6334 & 4.594 & 9.058 & 13.652 \\
\hline 29 & 31.5 & 5 & 14.5 & 0.45 & 3.6334 & 2.238 & 4.744 & 6.982 \\
\hline 30 & 24 & 5 & 9 & 0.5 & -7.1166 & 4.689 & 5.658 & 10.346 \\
\hline 31 & 24 & 5 & 11.75 & 0.5 & 3.6334 & 2.273 & 4.697 & 6.970 \\
\hline
\end{tabular}

Table 1.2: The array of variables with the maximum parting plane separation as the response

A plot of the total separation results is shown in Figure 1.6. The results are extracted immediately after the application of intensification pressure in the tenth cycle. Clearly, there is considerable variability with the maximum separation ranging from a low of 5.126 thousandths (case 10) to a high of 19.818 (case 1). The surprising fact is that the minimum separation result occurs with the smallest, thinnest die and the worst result occurs with a large die. Much of the discussion that follows is designed to explain these apparent anomalies. 


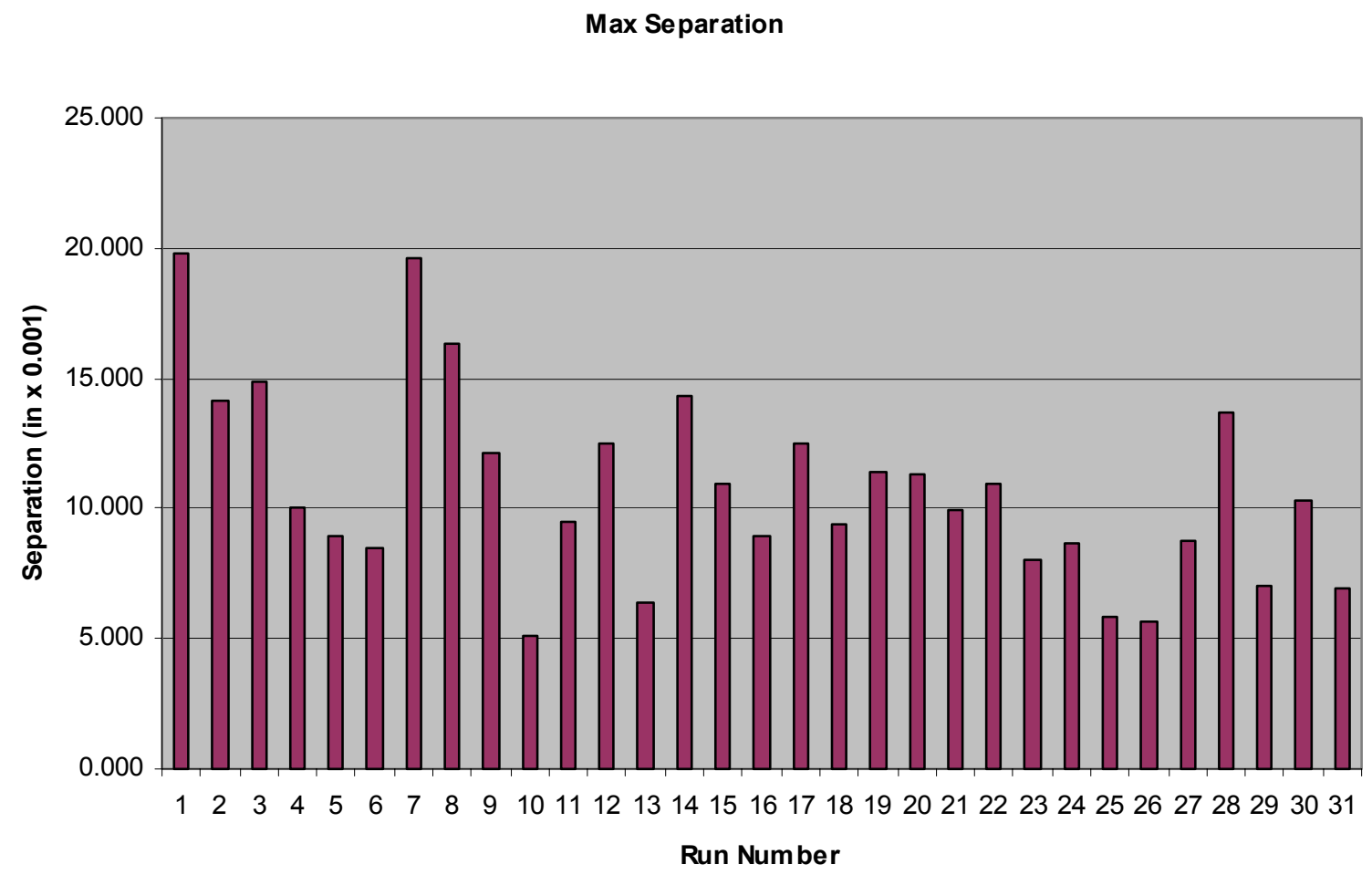

Figure 1.6 Maximum separation at the parting plane at intensification, Cycle 10

A full quadratic response surface model was fit to the total separation data. This means that a polynomial model with all first and second order terms (including cross product terms) based on the five independent variables was fit. The results are summarized in Table 1.3 below. The estimation was performed using scaled data which means that the range of the independent variables was scaled to $[-1,+1]$ so that the magnitude of the coefficients can be easily interpreted. The first column of the table identifies the coefficient that is estimated, the second column contains the estimated value. The $3^{\text {rd }}$ column is the standard error of the estimate, the $4^{\text {th }}$ is the $t$ statistic used for testing the significance of the estimate and last column is the level at which the results are significant. Small values of $p$ mean that the coefficient is significantly different from 0 (i.e., meaningful and contributes to the result). Larger values of $p$ suggest the term is not contributing to explaining the results. There are several terms, particularly $\mathrm{E}$ (die position), $\mathrm{A}^{*} \mathrm{~A}$ (die footprint area), $\mathrm{B} * \mathrm{~B}$ (die thickness squared), $\mathrm{E}^{*} \mathrm{E}$ (position squared), $\mathrm{A}^{*} \mathrm{E}$ (die size times die position), and $\mathrm{B}^{*} \mathrm{D}$ (die thickness by ratio which equals the shoulder thickness) are very large. There $\mathrm{C}^{*} \mathrm{C}$ (platen thickness squared) and $\mathrm{A}^{*} \mathrm{D}$ (die size by ratio) are marginal. We will edit the model to eliminate the terms that are not significant to provide a little better description of the result. 


\begin{tabular}{|c|c|c|c|c|}
\hline Term & Coef & SE Coef & $T$ & $\mathbf{P}$ \\
\hline Constant & 9.526 & 0.7162 & 13.302 & 0.000 \\
\hline A & 1.704 & 0.9037 & 1.886 & 0.089 \\
\hline$B$ & 1.435 & 0.2960 & 4.846 & 0.001 \\
\hline $\mathrm{C}$ & -1.414 & 0.3271 & -4.324 & 0.002 \\
\hline $\mathrm{D}$ & -1.196 & 0.3450 & -3.467 & 0.006 \\
\hline$E$ & -0.479 & 0.9801 & -0.489 & 0.635 \\
\hline$A^{*} A$ & -0.048 & 0.6104 & -0.079 & 0.939 \\
\hline$B^{*} B$ & 0.574 & 0.6654 & 0.862 & 0.409 \\
\hline $\mathrm{C}^{*} \mathrm{C}$ & 0.874 & 0.6139 & 1.423 & 0.185 \\
\hline$D^{*} D$ & 1.429 & 0.7219 & 1.980 & 0.076 \\
\hline$E^{*} E$ & 0.545 & 1.1888 & 0.458 & 0.656 \\
\hline$A^{*} B$ & -1.599 & 0.3475 & -4.601 & 0.001 \\
\hline$A^{*} C$ & -1.042 & 0.3395 & -3.071 & 0.012 \\
\hline$A^{*} D$ & -0.530 & 0.3456 & -1.533 & 0.156 \\
\hline$A^{*} E$ & 0.806 & 0.9954 & 0.810 & 0.437 \\
\hline $\mathrm{B}^{*} \mathrm{C}$ & 1.131 & 0.3135 & 3.609 & 0.005 \\
\hline$B^{*} D$ & -0.309 & 0.3070 & -1.007 & 0.337 \\
\hline $\mathrm{B}^{*} \mathrm{E}$ & -0.849 & 0.3517 & -2.415 & 0.036 \\
\hline$C^{*} D$ & -0.760 & 0.3256 & -2.333 & 0.042 \\
\hline$C^{*} E$ & -0.502 & 0.3604 & -1.393 & 0.194 \\
\hline$D^{*} E$ & 0.676 & 0.3523 & 1.920 & 0.084 \\
\hline
\end{tabular}

Table 1.3 Estimated Regression Coefficients for Maximum Separation (Cover + Ejector)

\subsection{Edited Models}

As described previously, the full quadratic model that was used to fit the polynomial response surface has several terms that are not statistically significant. The terms that have a large $p$ value are terms whose coefficients are not significantly different from zero given the standard error of the coefficient. By sequentially eliminating the terms with high $p$ values, a model that provides the best explanatory power is obtained. The results of this editing process are summarized in Table 1.4 below. Compared to the unedited model, the standard error and adjusted $\mathrm{R}^{2}$ are very comparable although the raw $\mathrm{R}^{2}$ is slightly lower. 


\begin{tabular}{|l|l|l|l|l|}
\hline Term & Value & Std.Error & $\mathbf{t}$ & $\mathbf{p}$ \\
\hline Intercept & 10.3545 & 0.4102 & 25.2444 & 0.0000 \\
\hline$A$ & 0.9883 & 0.3058 & 3.2319 & 0.0044 \\
\hline$B$ & 1.1719 & 0.2801 & 4.1831 & 0.0005 \\
\hline$C$ & -1.7490 & 0.2711 & -6.4511 & 0.0000 \\
\hline$D$ & -0.7422 & 0.2507 & -2.9605 & 0.0080 \\
\hline$D^{*} D$ & 1.6327 & 0.5425 & 3.0093 & 0.0072 \\
\hline$A^{*} B$ & -1.9343 & 0.3133 & -6.1738 & 0.0000 \\
\hline$A^{*} C$ & -1.2429 & 0.2899 & -4.2874 & 0.0004 \\
\hline$A^{*} E$ & 1.4315 & 0.3171 & 4.5145 & 0.0002 \\
\hline$B^{*} C$ & 0.8825 & 0.2678 & 3.2961 & 0.0038 \\
\hline$B^{*} E$ & -0.6891 & 0.3273 & -2.1051 & 0.0488 \\
\hline$C^{*} D$ & -0.6266 & 0.2940 & -2.1312 & 0.0464 \\
\hline \multicolumn{5}{|l}{} \\
\multicolumn{5}{|l}{} \\
\end{tabular}

Table 1.4 Estimated Regression Coefficients for Max Separation (Ejector + Cover): Edited Model

Because of the number of independent variables, it is difficult to establish a graphical picture of the entire parameter space. The best we can do is a set of contour plots that give a partial picture. The following figures, Figures $1.7-1.17$ show the response surface in the region of a nominal die. The same scale is used for all of the plots. Dark blue denotes small separation values, lighter green colors denote large separation

Figure 1.7 shows the interaction between the die size and die thickness. This contour plot has been plotted with the other variables at nominal settings. The characteristics of the plot are interesting and illustrate the type of interactions that occur. The settings are listed at the top of the Figure. Separation is minimized at the lower left corner which is the smallest, thinnest die. Roughly $2 / 3$ of the way across the die thickness axis at about 0.3 , the nature of the plot changes and the separation remains relatively constant if the die thickness increases. Separation increases if the die thickness is small. Basically, what this says is that the best performance is with a small, thin die, but if the die is large, then a thicker die is the better choice.

The interaction between die size and platen thickness is shown in Figure 1.8. The best condition is a small die and a thick platen. The contour plot has a very consistent gradient illustrating that thicker platens reduce separation no matter what the die size. Thick platens imply more rigid machines and hence less platen bow and better support to the cavity. Also, if the platen is thin, small dies work much better than large dies. Following the contour line starting at the lower left corner shows that a small die on the thinnest platen (lower left corner) is equivalent to a moderately large die ( 0.5 die size, roughly $60 \%$ platen area covered) on the thickest platen.

The interaction between die size and thickness ratio is shown in Figure 1.9. It suggests that a ratio slightly above nominal is the best choice and the pattern is not sensitive 
to die size. The figure also suggests that for a particular thickness ratio, large dies have higher values of separation than small dies.

Figure 1.10 shows the interaction between die size and die location. The figure shows the infeasible region that gets bigger as the die size gets bigger. This is because the a large die cannot move too far down before it hits the lower tie bars, where as for the small dies the downward movement is limited by the shot hole window instead of the lower tie bars. This figure suggests that a small die mounted high works best, but the sensitivity to location is quite low.

Figure 1.11 shows the interaction between die thickness and platen thickness. It suggests that a thin die-thick platen combination results in lowest separation but the sensitivity to die thickness is less than sensitivity to platen thickness. Also, sensitivity to platen thickness decreases with die thickness.

Figure 1.12 shows the interaction between die thickness and thickness ratio. The results are relatively insensitive to both variables, but a ratio close to nominal is the best and a thin die is preferred for minimizing separation.

Figure 1.13 shows the interaction between die thickness and die location. The results are also relatively insensitive, but they do show increasing separation with increasing die thickness.

The interaction between platen thickness and thickness ratio is shown in Figure 1.14. The gradient with respect to platen thickness is strong and shows that separation decreases with platen thickness.

The interaction between platen thickness and die location is shown in Figure 1.15. The pattern shows complete insensitivity to die location (all higher order terms with respect to location have been edited out of the model).

The interaction between thickness ration and die location is shown in Figure 1.16. The pattern again shows complete insensitivity to die location.

Overall, the patterns suggest that platen thickness is the dominate factor, the one with the highest gradients. Die thickness can be important because of interactions with other parameters, particularly with die size. There seems to be an optimum thickness ratio somewhere near the nominal value and the results are largely insensitive to die location. 


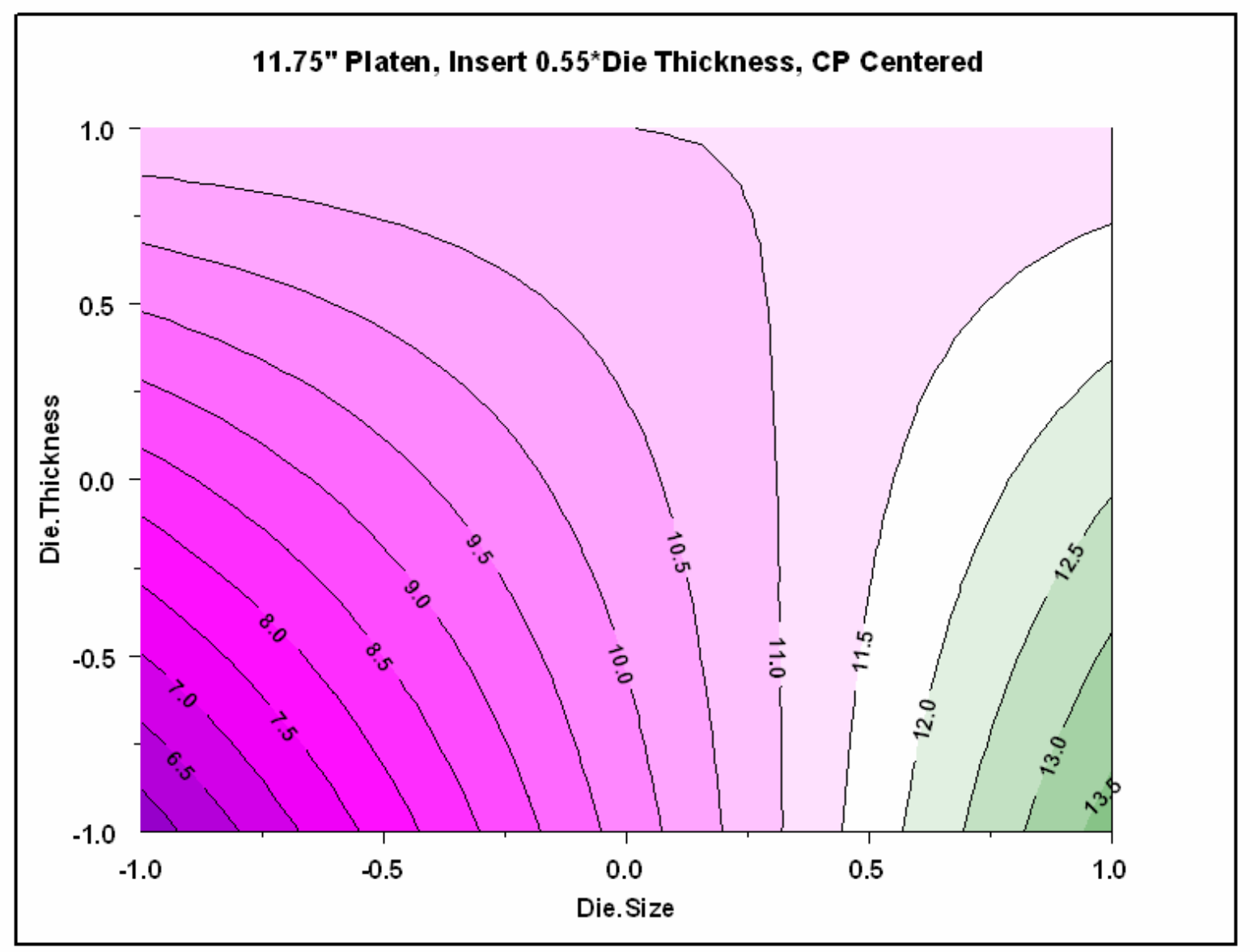

Die size:

$-1=30 \%$ platen area

$0=50 \%$ platen area

$1=80 \%$ platen area

Die Thickness:

$-1=5$ "

$0=7.5$

$1=10 "$

Note: Separation given in $0.001 "$

Figure 1.7: Interaction between die size and die thickness 


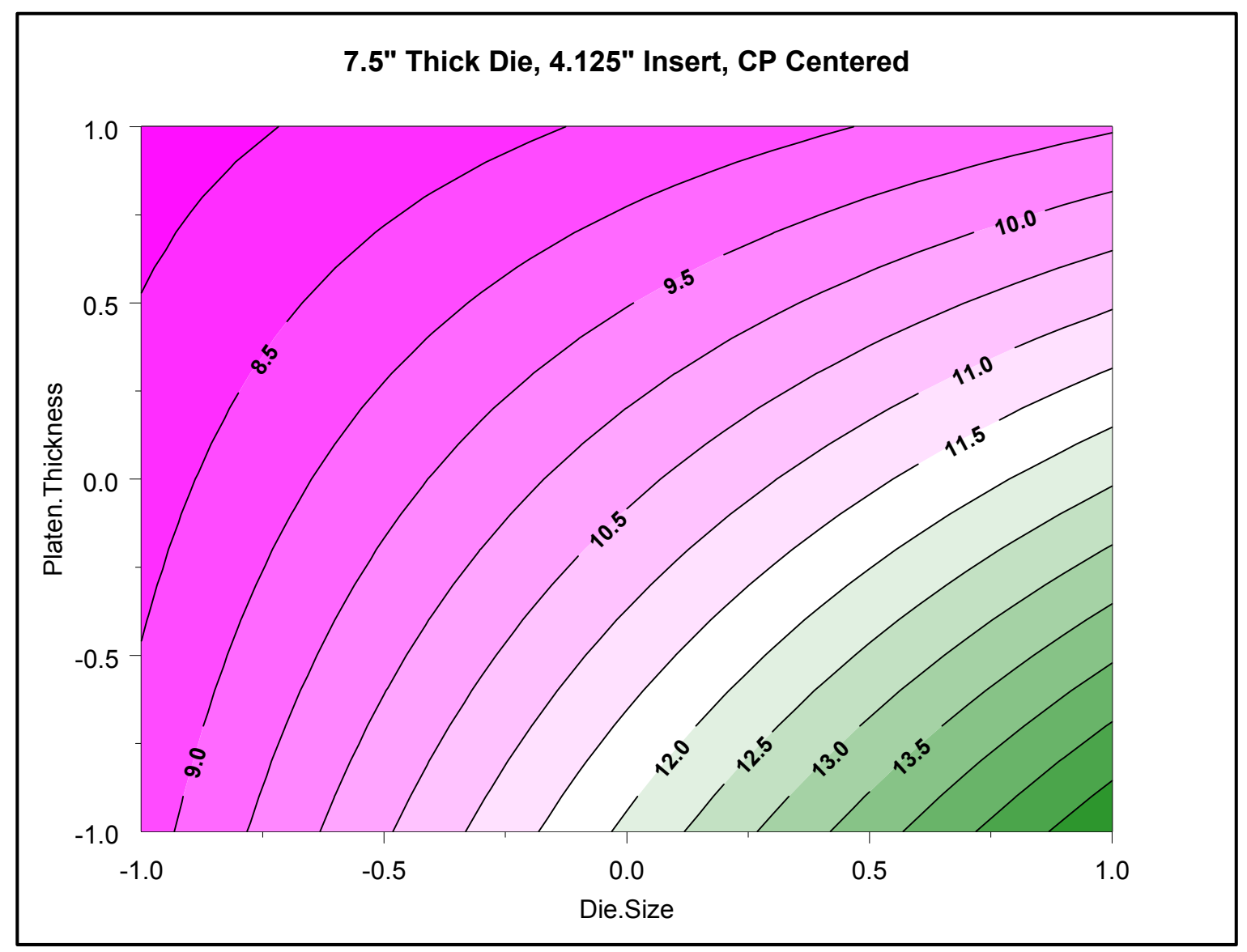

$$
\begin{aligned}
& \text { Die size: } \\
& -1=30 \% \text { platen area } \\
& 0=50 \% \text { platen area } \\
& 1=80 \% \text { platen area }
\end{aligned}
$$

Platen Thickness:

$$
\begin{aligned}
& -1=9 " \\
& 0=11.75 " \\
& 1=14.5 "
\end{aligned}
$$

Note: Separation given in $0.001 "$

Figure 1.8: Interaction between die size and platen thickness 


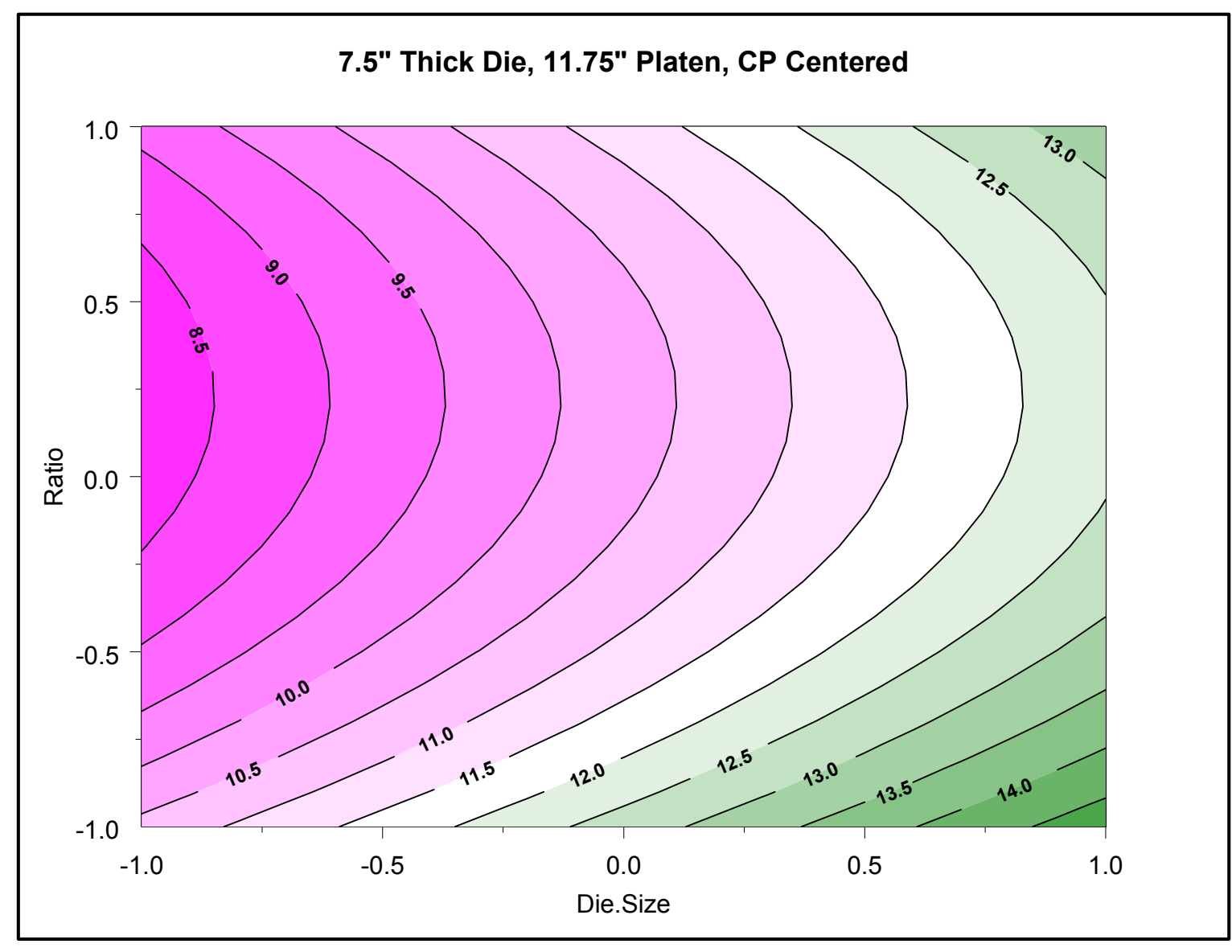

\section{Die size: \\ $-1=30 \%$ platen area \\ $0=50 \%$ platen area \\ $1=80 \%$ platen area}

Thickness ratio:

$$
\begin{aligned}
-1 & =0.40 \\
0 & =0.45 \\
1 & =0.50
\end{aligned}
$$

Note: Separation given in $0.001 "$

Figure 1.9: Interaction between die size and thickness ratio 


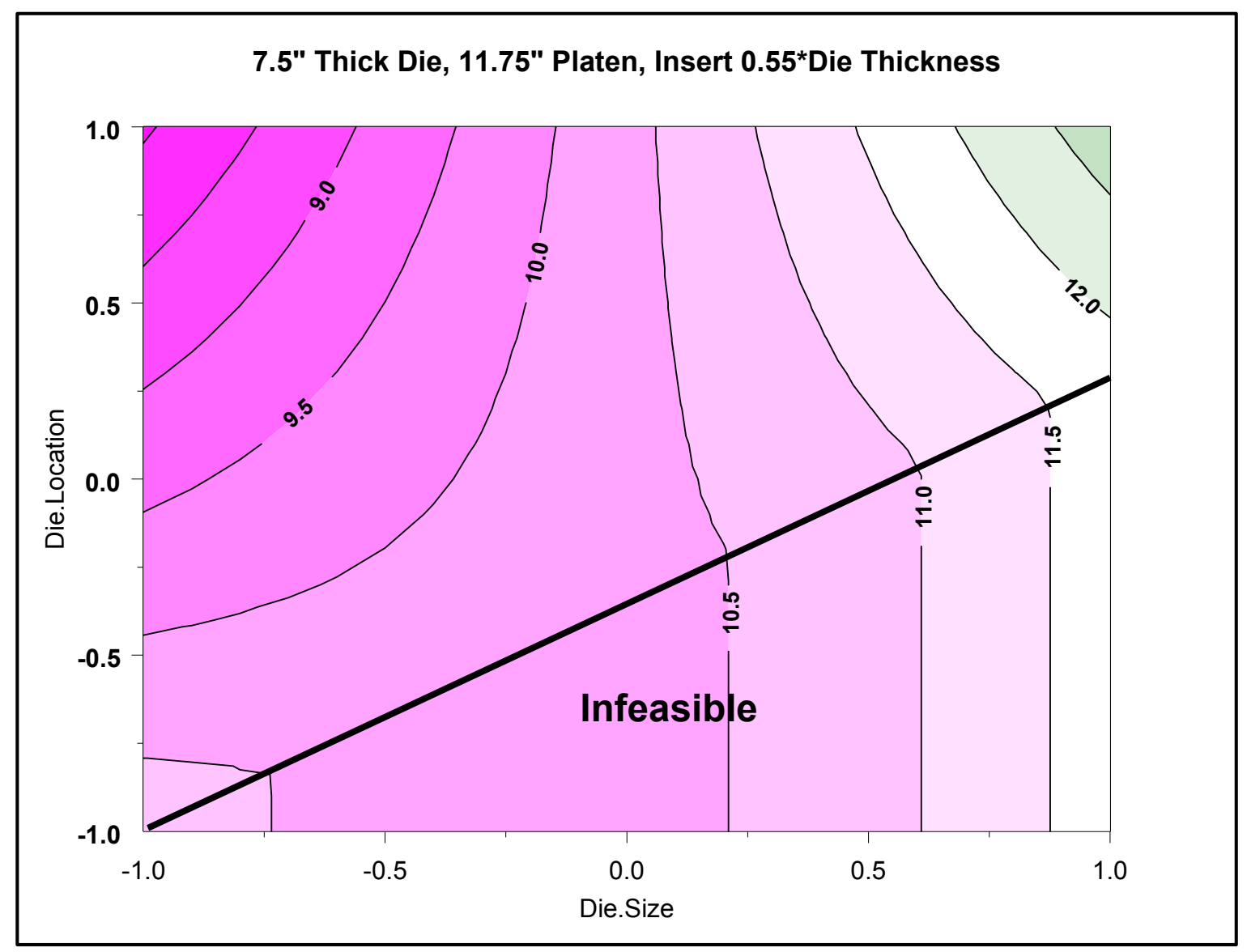

Die size:

$-1=30 \%$ platen area

$0=50 \%$ platen area

$1=80 \%$ platen area

Die Location:

$-1=$ Lowest possible

$0=$ Nominal

$1=$ Highest Possible

Note: Separation given in $0.001 "$

Figure 1.10: Interaction between Die size and Die location 


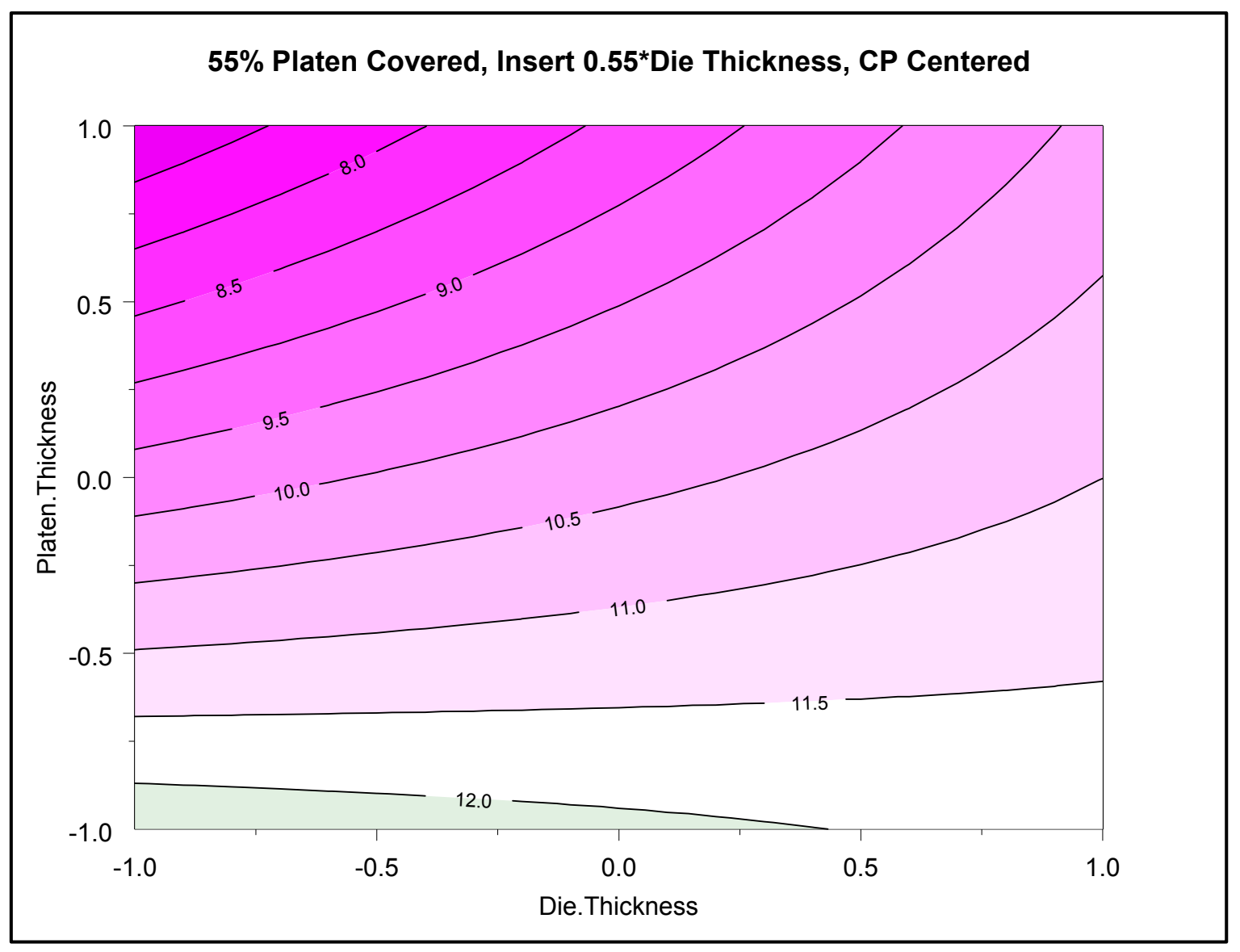

Die Thickness:

$-1=5$ "

$0=7.5 \%$

$1=10$ "

Platen Thickness:

$-1=9$ "

$0=11.75$

$1=14.5^{\prime}$

Note: Separation given in 0.001 "

Figure 1.11: Interaction between die thickness and platen thickness 


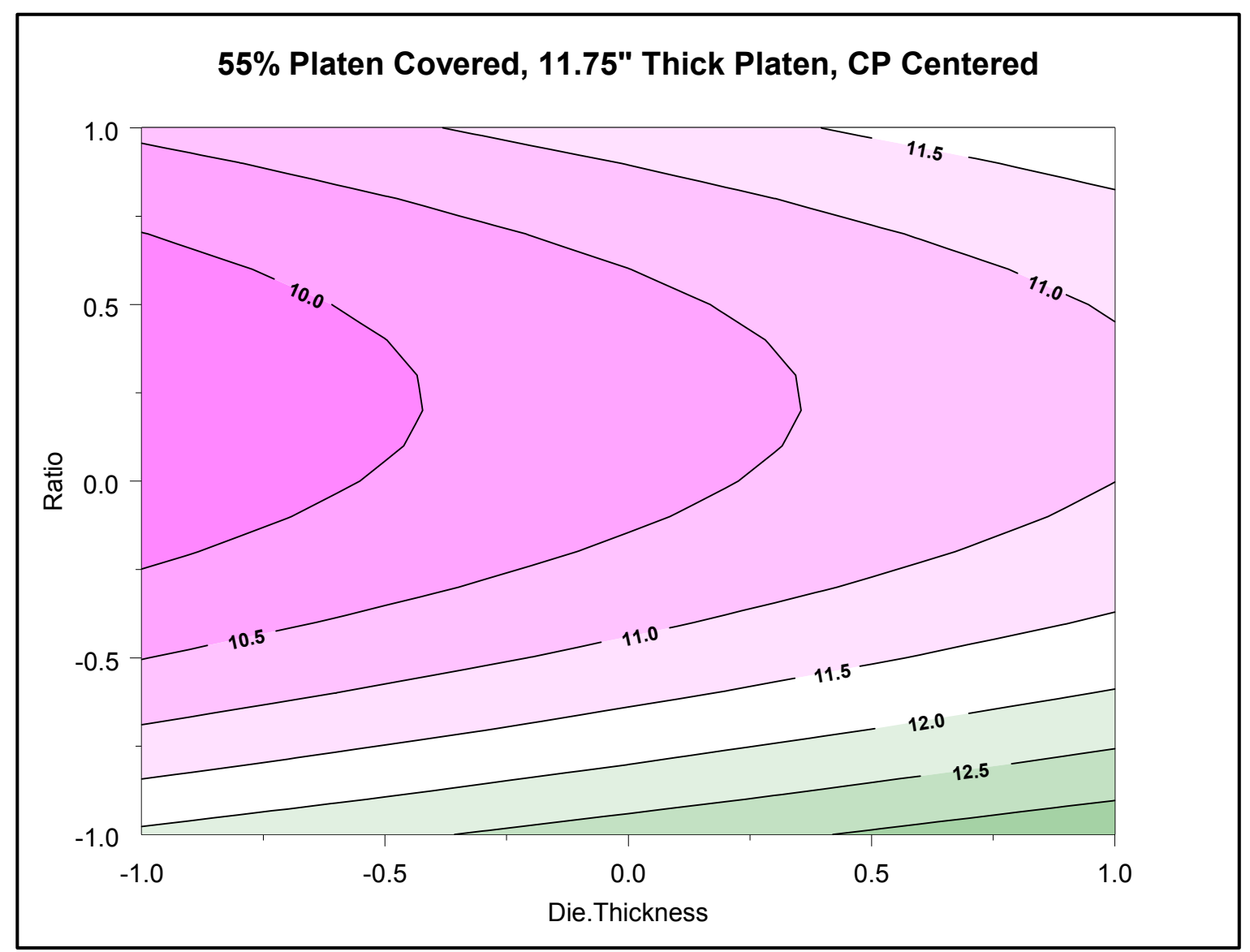

Die Thickness:

$-1=5$ '

$0=7.5$ "

$1=10 "$

Thickness ratio:

$-1=0.40$

$0=0.45$

$1=0.50$

Note: Separation given in $0.001 "$

Figure 1.12: Interaction between Die thickness and thickness ratio 


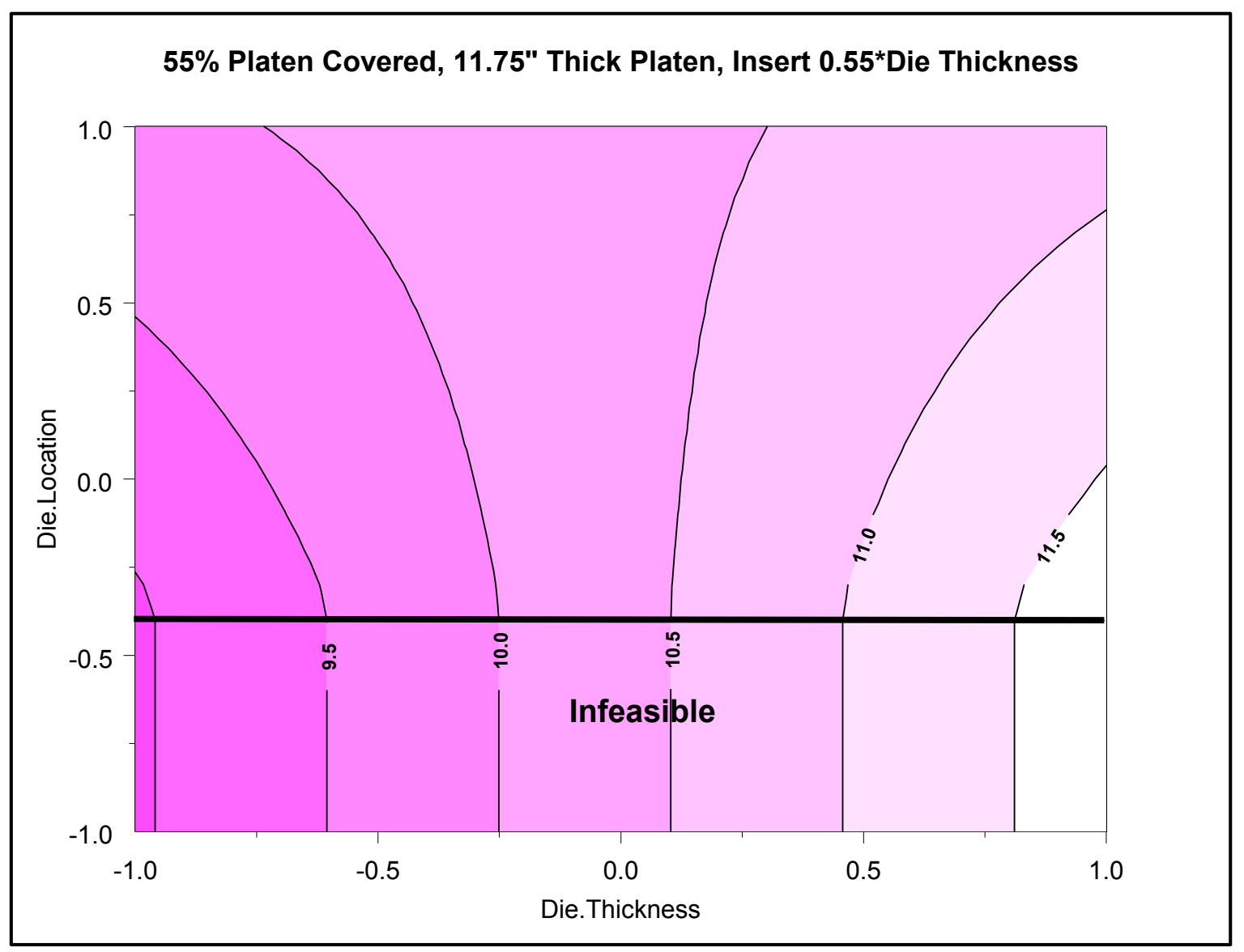

Die Thickness:

$$
\begin{aligned}
-1 & =5 " \\
0 & =7.5 " \\
1 & =10 "
\end{aligned}
$$

Die Location:

$-1=$ As low as possible

$0=$ Nominal

$1=$ As high as possible

Note: Separation given in 0.001 "

Figure 1.13: Interaction between die thickness and die location 


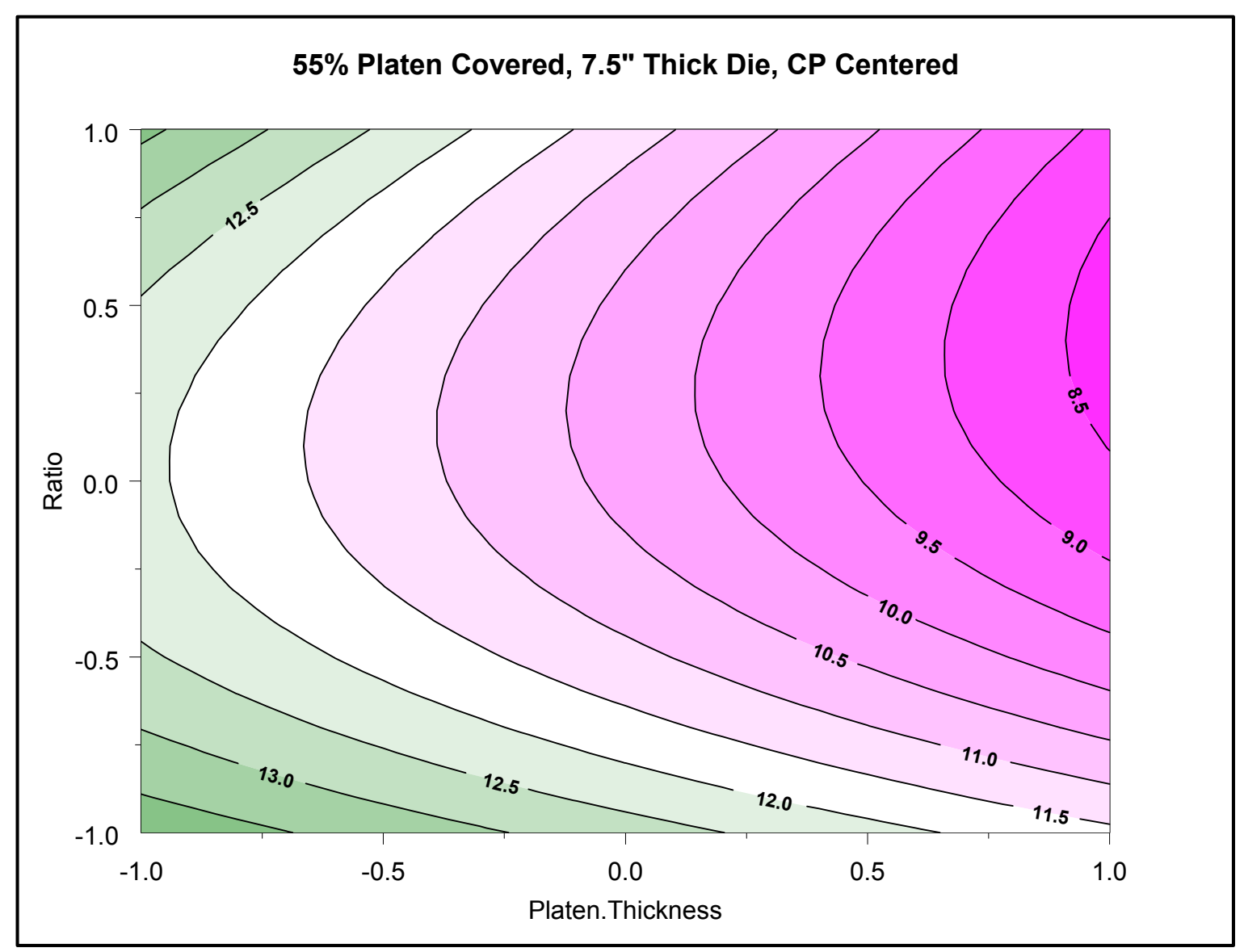

Platen Thickness:
$\begin{aligned} & -1=9 " \\ & 0=11.75 " \\ & 1=14.5 "\end{aligned}$
Thickness ratio:
$-1=0.40$
$0=0.45$
$1=0.50$
Note: Separation given in $0.001 "$

Figure 1.14: Interaction between platen thickness and thickness ratio 


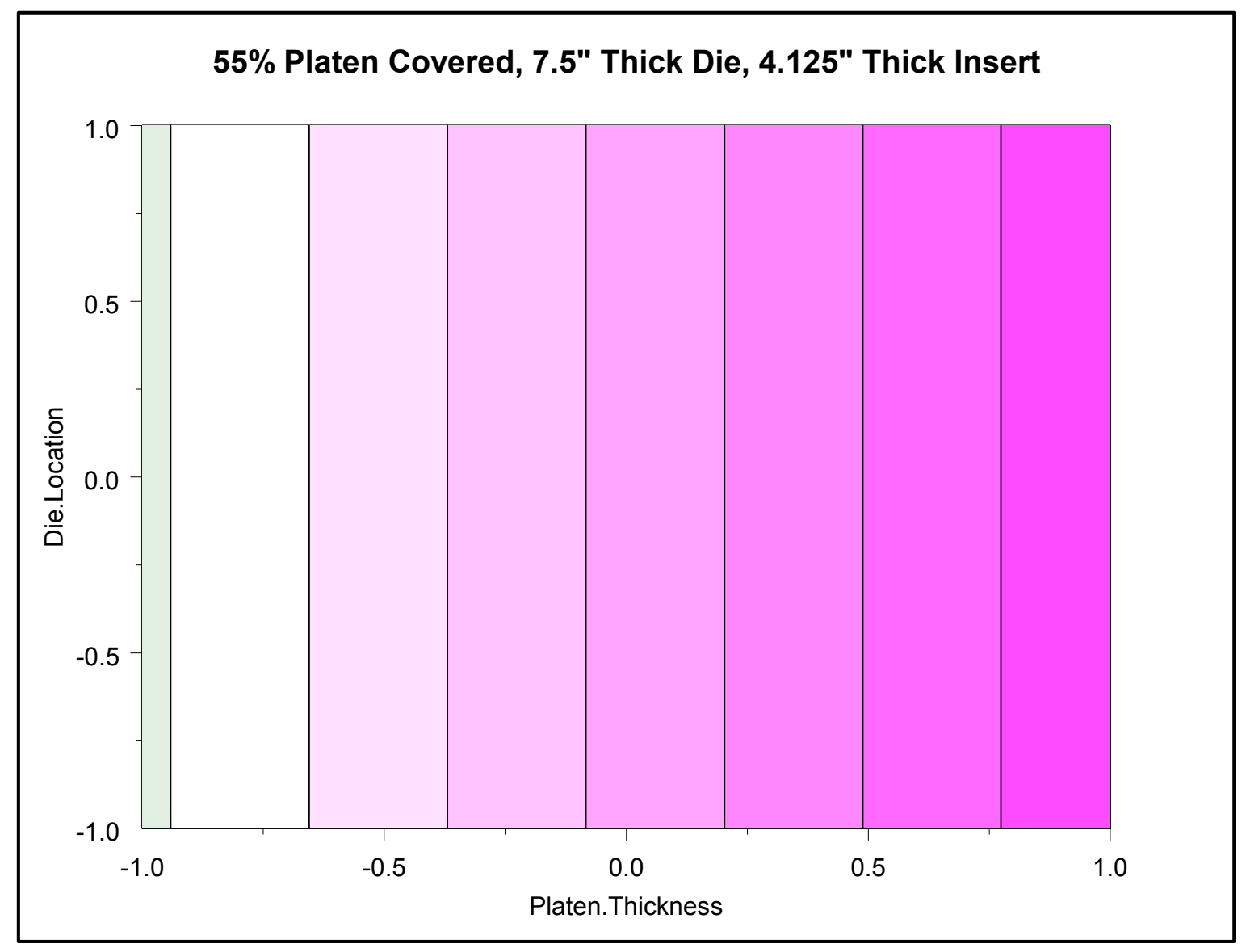

$$
\begin{aligned}
& \text { Platen Thickness: } \\
& \begin{array}{l}
-1=9 " \\
0=11.75 " \\
1=14.5 "
\end{array} \\
& \text { Die Location: } \\
& \begin{array}{l}
-1=\text { As low as possible } \\
0=\text { Nominal } \\
1=\text { As high as possible }
\end{array}
\end{aligned}
$$

Note: Separation given in $0.001 "$

Figure 1.15: Interaction between platen thickness and die location 


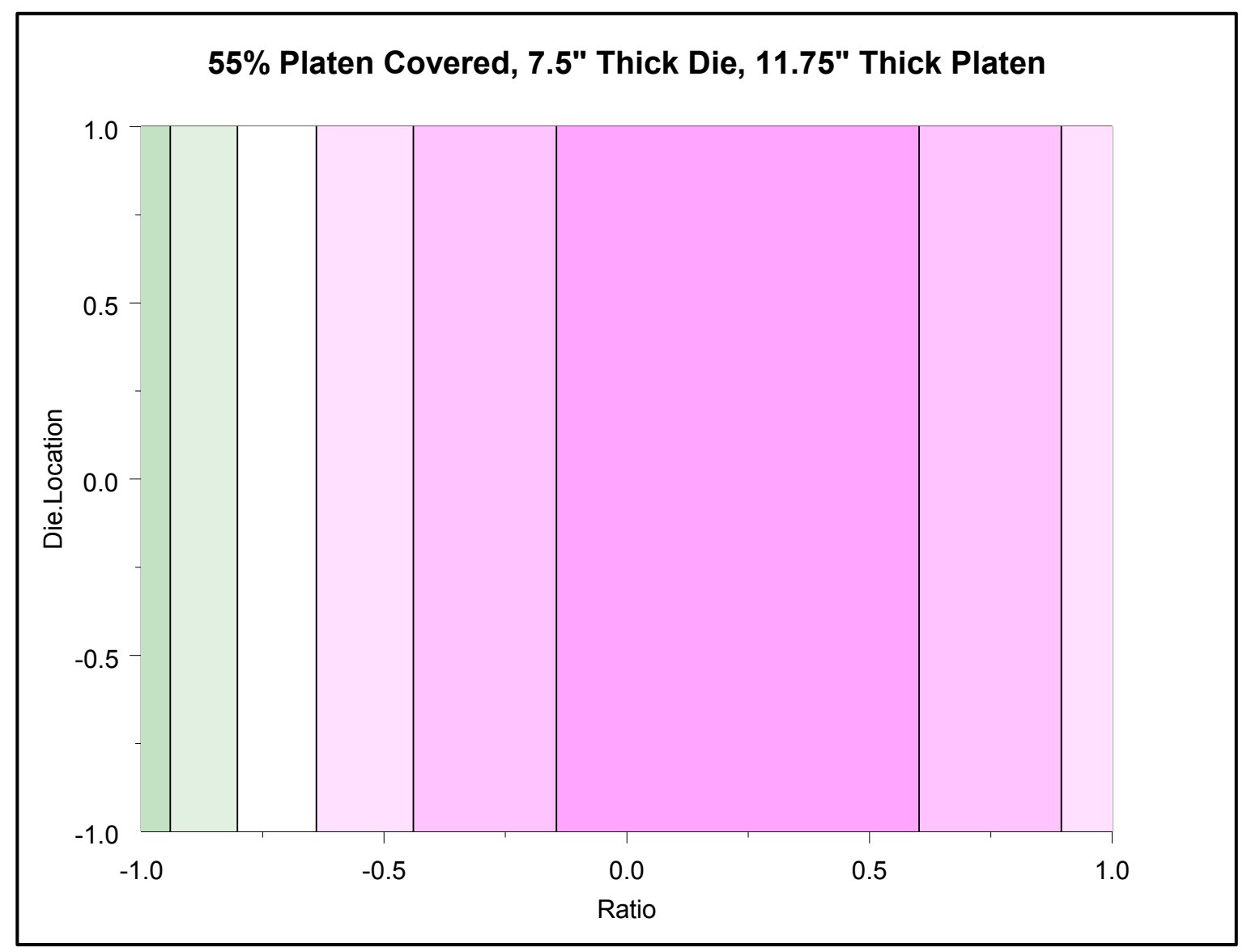

Thickness ratio:

$-1=0.40$ or less die steel

$0=0.45$ or medium die steel

$1=0.50$ or more die steel

Die Location:

$-1=$ As low as possible

$0=$ Nominal

$1=$ As high as possible

Note: Separation given in $0.001 "$

Figure 1.16: Interaction between thickness ratio and die location 


\subsection{Optimum Conditions}

We can use the polynomial model to minimize the maximum separation as a function of the parameters. Performing the optimization produces the following set of parameters. The edited model was used. The predicted maximum separation is about 0.0038 ”.

\begin{tabular}{|l|l|}
\hline Parameter & Description \\
\hline Die Size $=24 "$ & Smallest die \\
\hline Die Thickness = 5" & Thinnest die \\
\hline Platen Thickness = 14.5" & Thickest platen \\
\hline Insert $=2.645^{\prime \prime}$ & \\
\hline Shoulder $=2.355^{\prime \prime}$ & \\
\hline Location $=1.2$ " $^{\prime \prime}$ & Center of pressure slightly above platen center \\
\hline Max Separation = 0.0038" & \\
\hline
\end{tabular}

Table 1.5 Optimum Parameters Based on Edited Model

As an illustration of the effect of the interactions, if the die size is constrained to be large, and the optimization repeated, the results are as shown in Table 1.6

\begin{tabular}{|l|l|}
\hline Parameter & Description \\
\hline Die Size $=39 "$ & Largest die (set as a constraint \\
\hline Die Thickness = 10" & Thickest die \\
\hline Platen Thickness = 14.5" & Thickest platen \\
\hline Insert $=5.29 "$ & \\
\hline Shoulder $=4.71 "$ & \\
\hline Location $=-2.5 "$ & Center of pressure below platen center \\
\hline Max Separation $=0.0084 "$ & \\
\hline
\end{tabular}

Table 1.6 Optimum Parameters Based on Edited Model With Die Constrained to be Large

The main difference is that the best die in this case is thick. The separation is also considerably larger at 0.0084 ".

If the platen is constrained at the nominal dimension and the die is constrained to be large, the results are very similar, as shown in Table 1.7, but the separation jumps to 0.0107'. 


\begin{tabular}{|l|l|}
\hline Parameter & Description \\
\hline Die Size $=39 "$ & Largest die (set as a constraint) \\
\hline Die Thickness = 10" & Thickest die \\
\hline Platen Thickness = 11.75" & Nominal platen (set as a constraint) \\
\hline Insert $=5.39 "$ & \\
\hline Shoulder $=4.61 "$ & \\
\hline Location $=-2.5 "$ & Center of pressure below platen center \\
\hline Max Separation = 0.0107" & \\
\hline
\end{tabular}

Table 1.7 Optimum Parameters Based on Edited Model Large Die and Nominal Platen

\subsection{Summary}

The results obtained from the simulation runs and from the regression models suggest that the rigidity of the machine is the dominant factor in influencing die deflections. A thick platen invariably works better than the thin platen with respect to parting plane separations. A large die on a thick platen is insensitive to the die thickness and the same holds true for a small die on a thin platen.

Small or medium sized dies (platen area covered ranging from $40 \% 50 \%$ ) seem to be the optimal setting as far as dies size is concerned. In general, small dies result in a lower separation as compared to large dies. Thin dies as compared to thick dies are more compliant to mechanical loads and hence result in lower separation at parting plane. The effects due to thermal loads seem to get ironed out, making thin dies more compliant. A large, thick die works better than a large, thin die and a small, thin die works better than a small, thick die.

A thin insert usually works better in a large die, irrespective of the die thickness. If the platen is thick the die insert should be thin to get the maximum support from the platens. As far as the inserts are concerned, the results point to the fact that an insert should never be made overly thick. The results suggest that the performance is the best when insert thickness is close to the thickness of steel behind it.

This study so far suggests that the thicker the die steel behind the insert for a particular die size and die thickness, the better is the support provided to the cavity, and hence lower the value of separation. The key to reducing the parting plane separation is by having uniformly supported ejector and cover die.

In case of a die located high on the machine, the cold center of pressure is located above the geometric center of platen. After 10 cycles when the dies heat up, the center of pressure tends to shift downwards. So, if the dies are mounted high having cold center of pressure above the platen center, after the heat growth the center of pressure moves near the center of platen, which is better in terms of uniformity of support behind the dies. That's why, a die located on or above the platen center is an optimal setting for low separation. Note that this conclusion is very geometry dependent and applies only for this case. Thin dies located low perform better than thick dies located low, due to less platen bow and the 
consequent wrapping of the platen around the die. A thick platen-thin die combination works better than a thick die-thin platen combination. 



\section{EXPLANATION OF FACTORS DETERMINING PARTING PLANE SEPARATION}

The results of the response surface presented in the previous chapter are somewhat counter intuitive. The fact that a small footprint die produces the smallest separation is definitely not something that was anticipated. The objective in this chapter of the report is to provide more insight into the fundamental reasons why these results make sense.

\subsection{Parting plane separation}

Separation at the parting plane results due to the fact that the dies and inserts tend to distort due to the combined effect of clamping, intensification and heat growth. Much of our intuition about the performance of dies seems to be based on reasoning about rigid structures and the die/die casting machine is far from rigid. A few cases have been picked from the array in order to explain our observations about the factors that cause parting plane separations.

Figures 2.1a and $2.1 \mathrm{~b}$ are distortion plots that provide a degree of insight into the behavior of the system. The red objects depict the initial position of the platens and die prior to the application of loads and the white objects are after loading. Case 10 is the best case observed in the array, Case 7 one of the worst. Case 10 is a small thin die on a thick platen; Case 7 is a large thin die on a thin platen. The lack of support from the thin platen is obvious as is the lack of ejector side support for Case 7. As we shall see with detailed examinations of three cases, it is the variation in support and the degree to which the clamping force from the machine reaches the parting surface that determines the separation.

Figures $2.2-2.10$ show parting plane separation and contact pressure, both ejector and cover side, for cases 10,7 and 2 . The units on the separation plots are meters. The units on the contact pressure plots are newtons $/$ meter $^{2}$ or pascals. In combination, these plots provide clues as to the behavior of the dies in the three cases. Similar plots for 23 of the 31 cases are provided in Appendix A along with some additional stress plots. In all of the plots, separation is the local distance between the cover and ejector parting surfaces measured along the direction of the tie bars. Contact pressure is the surface pressure between the die surface and the platen surface at the point in question.

Case 10 (best case in terms of maximum parting plane separations -0.0051 ") has a die size of 24", die thickness 5", platen thickness 14.5", thickness ratio 0.5 and die is mounted as high as it can possibly mounted. Case 7 (one of the worst cases in terms of parting plane separations - 0.0196") has a die size of 39", die thickness 5", platen thickness 9", thickness ratio 0.4 and die mounted as low as it can be mounted for a large die. Case 2 (an intermediate case in terms of parting plane separations - 0.0141") has a die size of 39", die thickness 10", platen thickness 9", thickness ratio 0.5 and the die is mounted as low as it can be mounted for a large die. The cases 10 and 7 were chosen for the study because of the fact that they are two extremes, in terms of maximum parting plane separations. Case 2 was chosen, as it was similar to case 7 except for the thickness ratio and die thickness. 


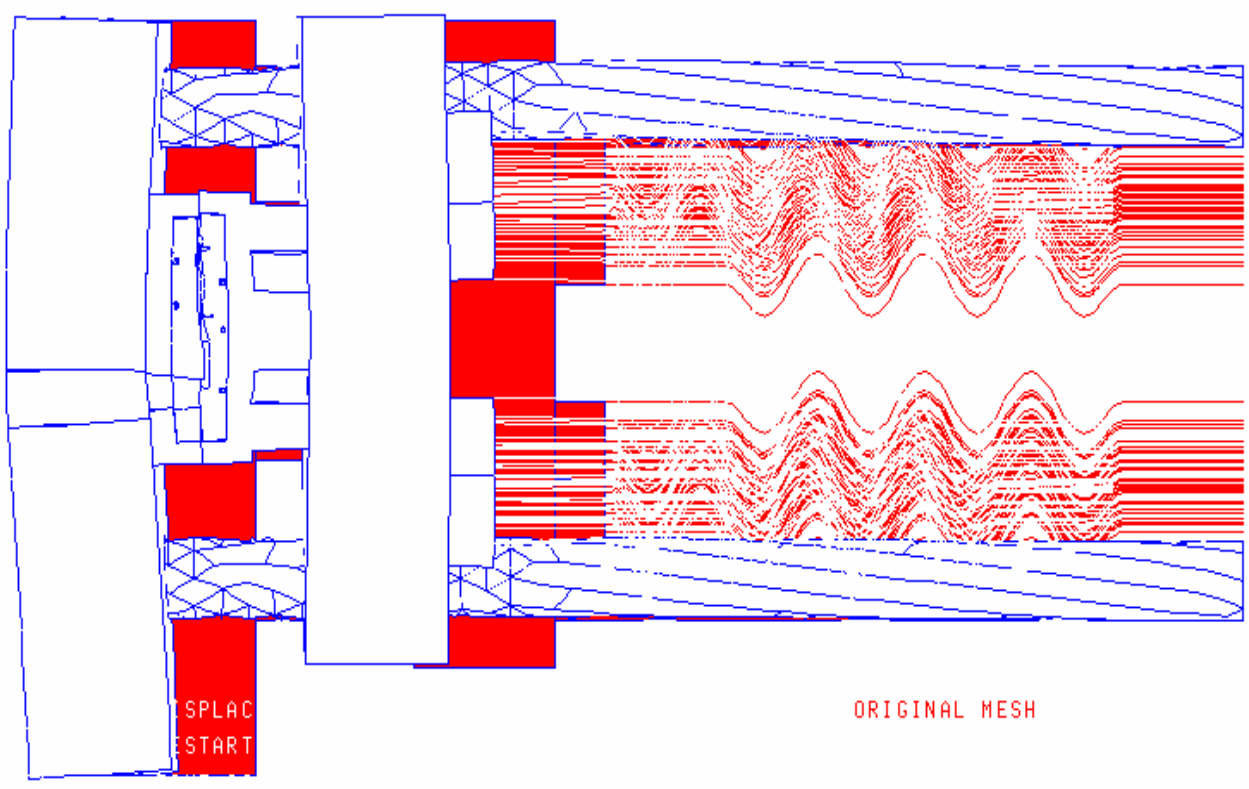

Figure 2.1a: Deformed structure for Case10

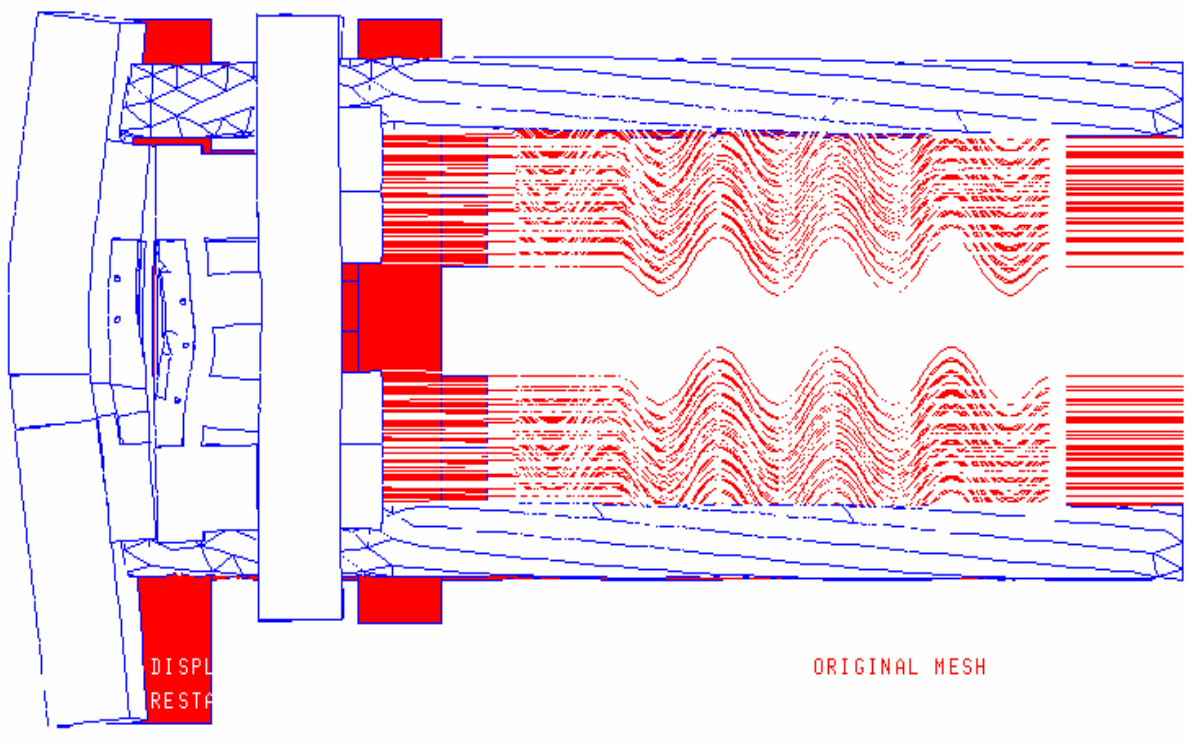

Figure 2.1b: Deformed structure for Case7 
Specifications for case 10:

- $\operatorname{Die} \operatorname{size}(\mathrm{A}): 24 "$

- Die thickness (B): 5"

- Platen thickness (C): 14.5"

- Thickness ratio (D): 0.5 (Insert thickness: 2.5", Shoulder thickness: 2.5")

- Die Location (E): High as possible

- Max. Separation:0. 0051”

\begin{tabular}{|c|r|}
\hline COPEN & VALUE \\
\hline & $-5.44 \mathrm{E}-19$ \\
& $+1.00 \mathrm{E}-05$ \\
& $+2.00 \mathrm{E}-05$ \\
- & $+3.00 \mathrm{E}-05$ \\
- & $+4.00 \mathrm{E}-05$ \\
- & $+5.00 \mathrm{E}-05$ \\
- & $+6.00 \mathrm{E}-05$ \\
- & $+00 \mathrm{E}-05$ \\
- & $+8.00 \mathrm{E}-05$ \\
- & $+9.00 \mathrm{E}-05$ \\
- & $+1.00 \mathrm{E}-04$ \\
- & $+1.10 \mathrm{E}-04$ \\
- & $+1.20 \mathrm{E}-04$ \\
$+1.30 \mathrm{E}-04$ \\
\hline
\end{tabular}

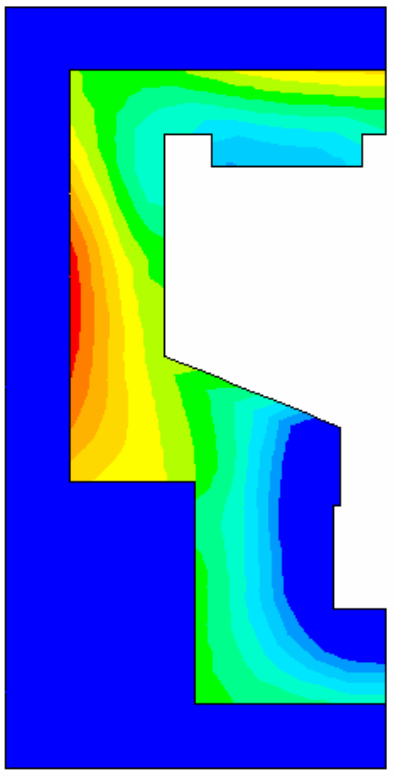

Figure 2.2 Parting plane separation for case 10

Red is maximum separation, Blue is no separation. 

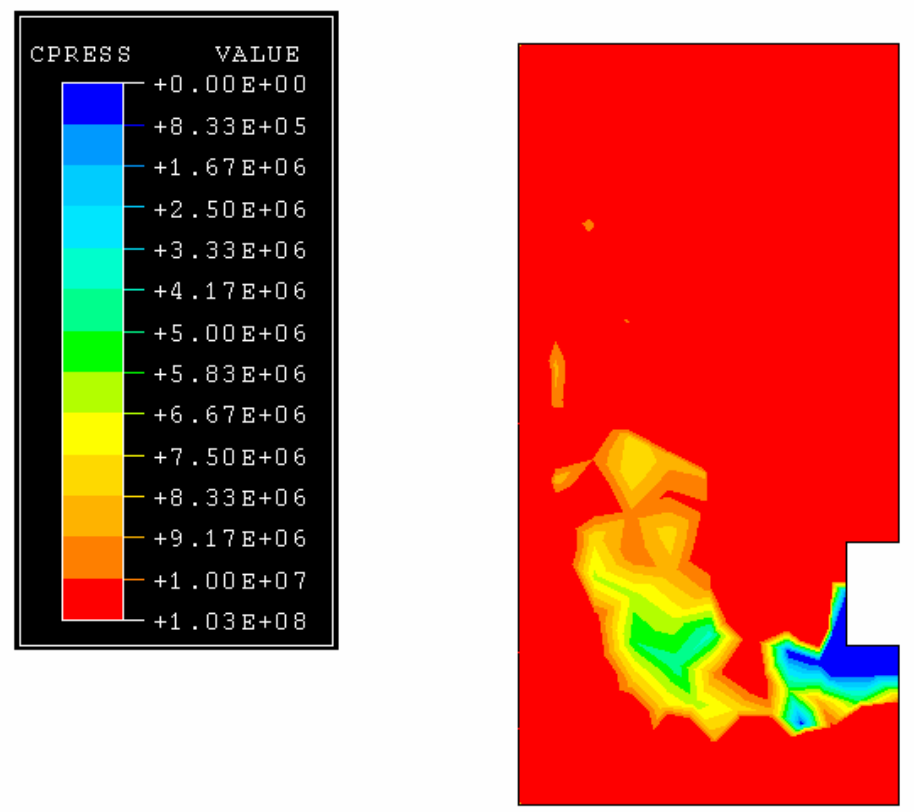

Figure 2.3: Contact pressure at the back of the cover die for case 10

\begin{tabular}{|c|c|}
\hline \multirow{15}{*}{ CPRESS } & VALUE \\
\hline & 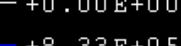 \\
\hline & $+8.33 \mathrm{E}+05$ \\
\hline & $-+1.67 \mathrm{E}+06$ \\
\hline & $-+2.50 \mathrm{E}+06$ \\
\hline & $-+3.33 \mathrm{E}+06$ \\
\hline & $-+4.17 \mathrm{E}+06$ \\
\hline & $-+5.00 \mathrm{E}+06$ \\
\hline & $-+5.83 \mathrm{E}+06$ \\
\hline & $-+6.67 \mathrm{E}+06$ \\
\hline & $-+7.50 \mathrm{E}+06$ \\
\hline & $-+8.33 \mathrm{E}+06$ \\
\hline & $-+9.17 \mathrm{E}+06$ \\
\hline & $-+1.00 \mathrm{E}+07$ \\
\hline & $-+1.33 \mathrm{E}+08$ \\
\hline
\end{tabular}

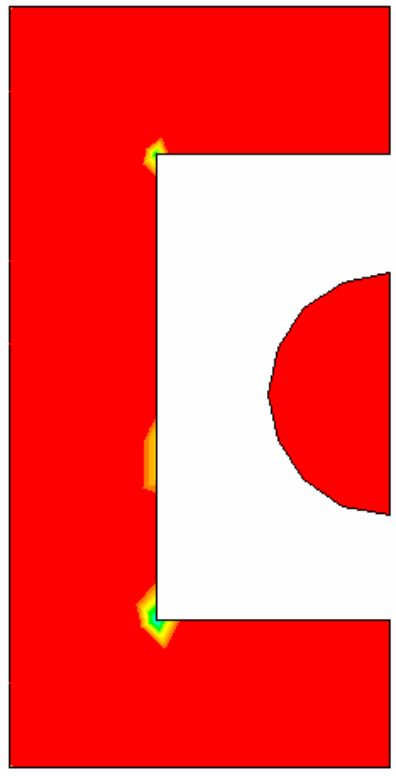

Figure 2.4: Contact pressure at the back of the ejector die for case 10

Red is maximum pressure, Blue is no pressure. 


\section{Specifications for case 7:}

- Die size (A): 39”

- Die thickness (B): 5"

- Platen thickness (C): 9"

- Thickness ratio (D): 0.4 (Insert thickness: 3", Shoulder thickness: 2")

- Die Location (E): Low as possible

- Max. Separation: 0. 0197"

\begin{tabular}{|c|r|}
\hline COPEN & VALUE \\
\hline & $-3.88 E-19$ \\
$+3.83 E-05$ \\
$+7.65 E-05$ \\
$-1.15 E-04$ \\
$-+1.53 E-04$ \\
$-+1.91 E-04$ \\
$-+2.30 E-04$ \\
$-+2.68 E-04$ \\
$-+3.06 E-04$ \\
$-+3.44 E-04$ \\
$-+3.83 E-04$ \\
$-4.21 E-04$ \\
$-4.59 E-04$ \\
$+4.97 E-04$ \\
\hline
\end{tabular}

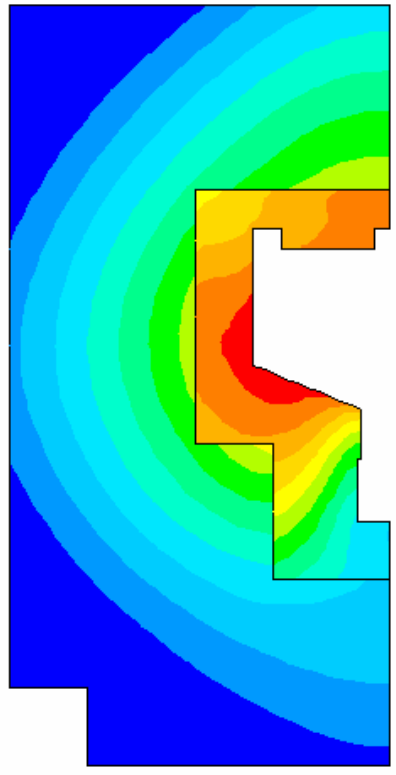

Figure 2.5: Parting plane separation for case 7

Red is maximum separation, Blue is no separation. 

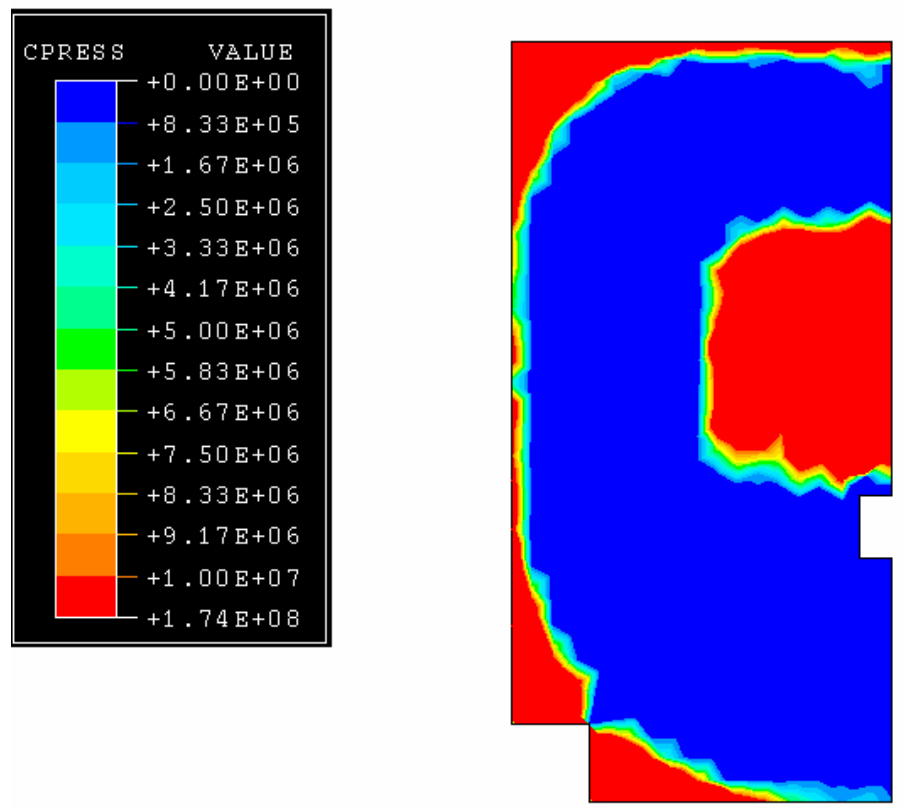

Figure 2.6: Contact pressure at the back of the cover die for case 7
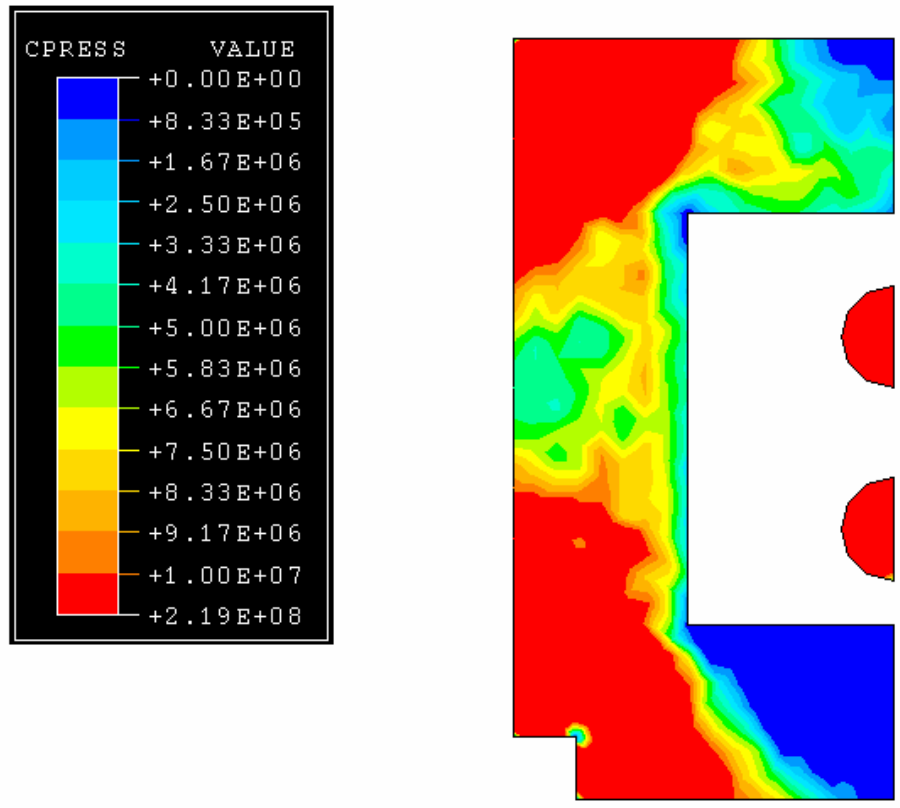

Figure 2.7: Contact pressure at the back of the ejector die for case 7

Red is maximum pressure, Blue is no pressure. 


\section{Specifications for case 2:}

- $\quad \operatorname{Die} \operatorname{size}(\mathrm{A})$ : 39"

- Die thickness (B):10"

- Platen thickness (C): 9"

- Thickness ratio (D): 0.5 (Insert thickness: 5", Shoulder thickness: 5")

- Die Location (E): Low as possible

- Max. Separation:0. 0141”

\begin{tabular}{|c|r|}
\hline \multicolumn{1}{|c|}{ COPEN } & VALUE \\
\hline & $-4.86 \mathrm{E}-19$ \\
$+2.77 \mathrm{E}-05$ \\
$-5.54 \mathrm{E}-05$ \\
$-+8.31 \mathrm{E}-05$ \\
$-+1.11 \mathrm{E}-04$ \\
$-+1.38 \mathrm{E}-04$ \\
$-+1.66 \mathrm{E}-04$ \\
$-1.94 \mathrm{E}-04$ \\
$-+2.22 \mathrm{E}-04$ \\
$-+2.49 \mathrm{E}-04$ \\
$-+2.77 \mathrm{E}-04$ \\
$-3.05 \mathrm{E}-04$ \\
$+3.32 \mathrm{E}-04$ \\
$+3.60 \mathrm{E}-04$ \\
\hline
\end{tabular}

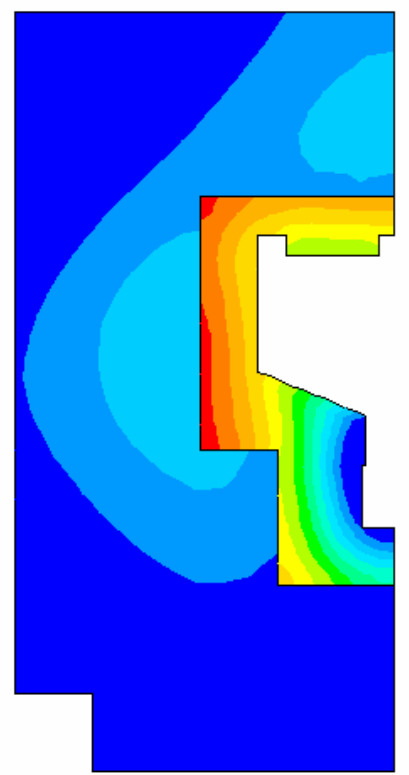

Figure 2.8: Parting plane separation for case 2

Red is maximum separation, Blue is no separation. 

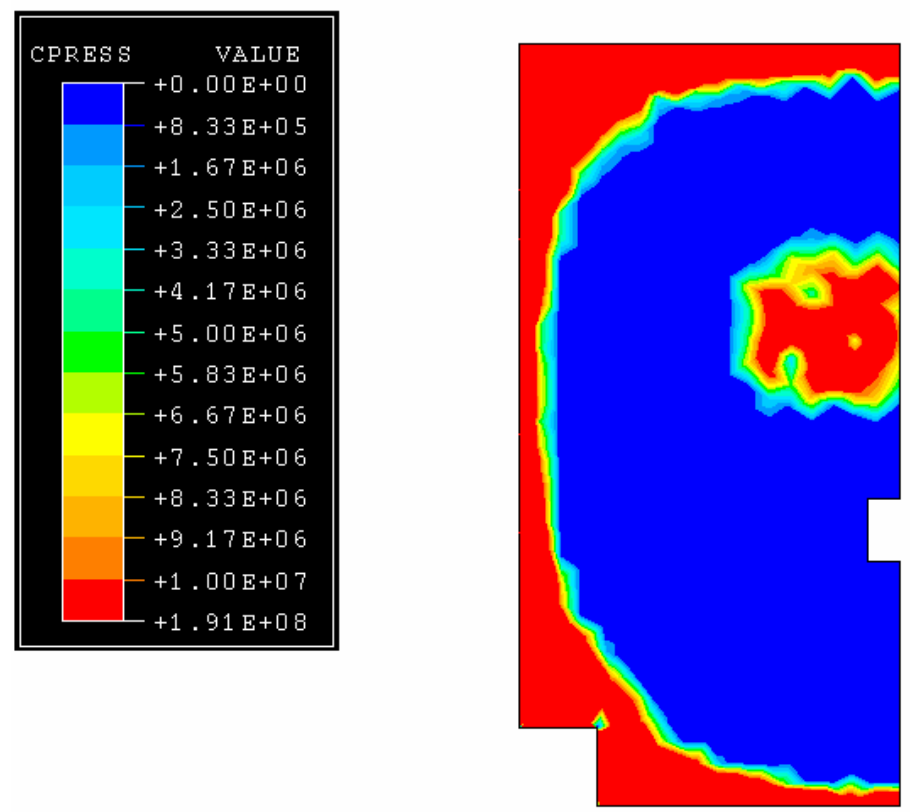

Figure 2.9: Contact pressure at the back of the cover die for case 2
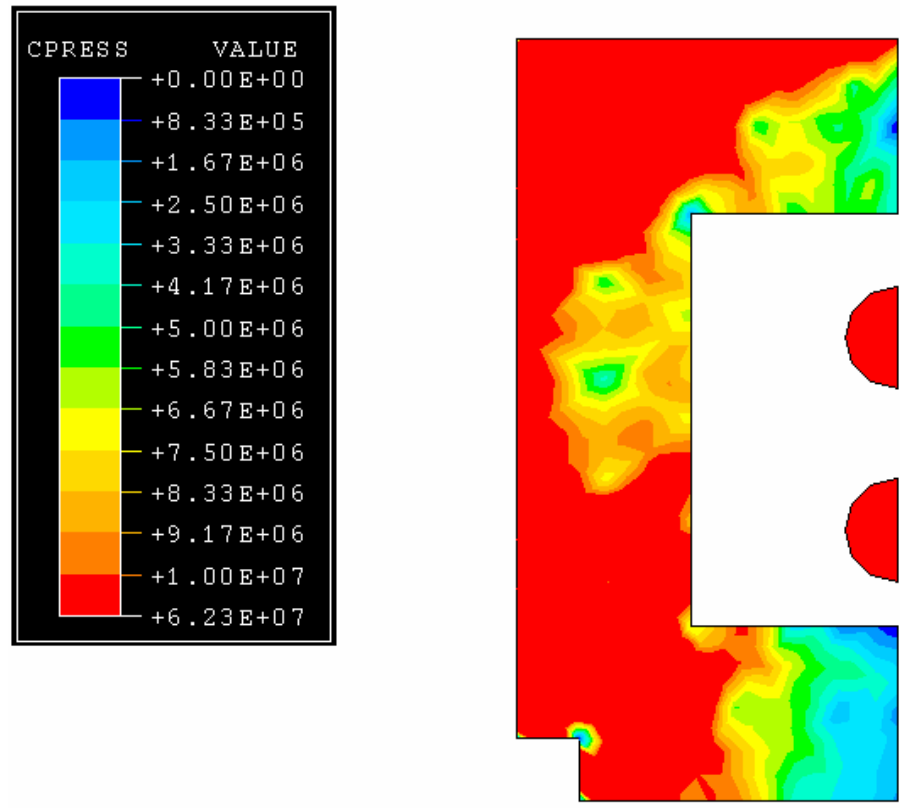

Figure 2.10: Contact pressure at the back of the ejector die for case 2

Red is maximum pressure, Blue is no pressure. 
It can be observed from Figure 2.2 that in case 10 the holder blocks are in perfect contact and only the inserts open up near the edge to produce parting plane separation. Figures 2.3 and 2.4 show that the contact between the die and the platens is very uniform which means that the tendency of the die to bend is controlled by the platen. The separation pattern suggests that differential heat growth with more growth near the biscuit area and around the cavity results in contact along the cavity and a crowning of the insert.

In case 7, as shown in Figure 2.5, the inserts opens up due to the cavity pressure and lack of sufficient support, producing an "oil can" effect and significant parting plane separation. Along with the inserts, the holder blocks also open up by a small amount clearly shown by the light blue patches on the parting plane of the dies. The lack of support is shown by Figure 2.6. There is a window frame type effect with the die periphery in contact with the platen, and contact immediately behind the cavity (note the red patches). Even though the die has large surface area, only a small fraction is carrying the load to the platen. The ejector side contact pressure plot, Figure 2.7, shows that the pillars are in full contact, but much of the rest of the die shoe is not resulting in non-uniform support.

In case 2, as shown by Figure 2.8, the separation pattern is closer to that of case 10 although the separation magnitude is larger. The pattern similarity comes about from the improved support provided by the thicker die. Figure 2.9 shows a similar window frame pattern of contact pressure, but the patch behind the cavity is smaller indicating that the stiffer die is carrying more of the load and bridging the bowed platen to some degree.

When the clamping load is applied on the dies, the nature of support behind the cover die, i.e. of the cover platen is such that it is bound to bend. The magnitude of bending depends on several other factors such as platen thickness, location of the dies, pressure and heat growth magnitudes, etc. Four tie bars support the cover platen at the four corners and the load acts in the middle of the platen. The bowing of the cover platen is inherent due to this kind of support mechanism. When the intensification is applied, the insert is pushed into the die pocket. So, even though the holder blocks are in contact with each other, the ejector and cover inserts are pushed into the respective die pockets generating parting plane separation, even though the holder blocks might remain in perfect contact with each other as in Figure 2.2a (case 10). But, if there is insufficient support directly behind the cavity, it might push the dies hard enough to open the dies as shown in Figure 2.2b (case 7). In case 7, it can be seen from the specifications that it is a large thin die mounted on a thin platen, which means that there is neither enough die steel behind the insert nor enough steel in the platen to support the insert against the cavity pressure.

The movement of the insert on the ejector side can be observed in Figure $2.3 \mathrm{a}, \mathrm{b}$ and c for cases 10, case 2 and case 7 respectively. Figure 2. a, b and c show how far back the insert pushes into the holder block. Figure 2.4 is a different view of the same data. The insert movement is less if there is sufficient support from the pillars and/or the die shoulder. 

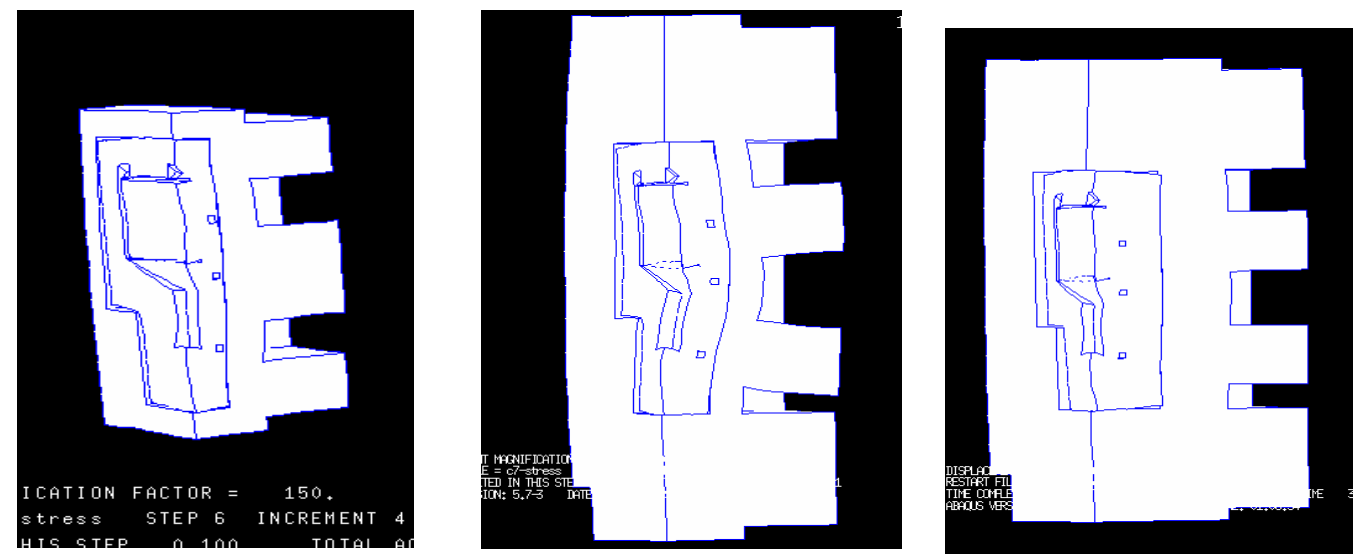

Figure 2.11 Ejector Side Movement and Distortion, Cases 10, 7 and 2.
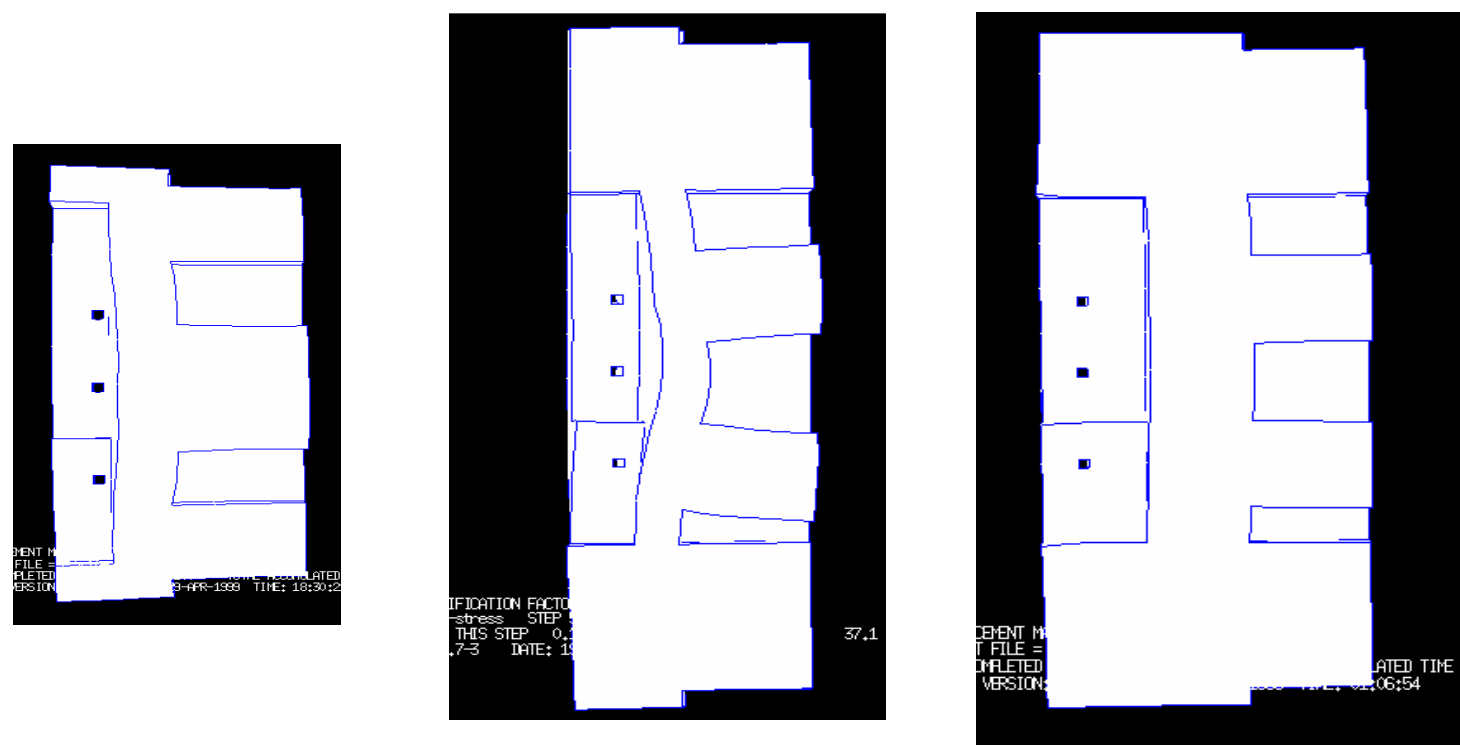

Figure 2.12 Ejector Side Movement

In case of a small die, the insert is better supported at the back by both the ejector box and the ejector pillar. This can be seen from Figure 2.12 and Figure 2.13 which shows the layout of the pocket and the pillars. In case of a small die, there is better support from the ejector box as it is closer to the cavity and it bears most of the load applied by the insert onto the ejector die. The single large pillar is also directly behind the cavity. Whereas with a large die, the ejector box is farther away from the cavity and most of the load has to taken by the pillars. If the shoulder is not sufficient and there is minimal support from the rails, the intensification pressure may distort the pocket, causing further movement of the insert away from the parting plane as observed in case 7 . Hence we observe less separation in case of a die, which is small, as in. case10, and in case of a die which has good support at the back of the ejector die as in case 2, as compared to the die which neither has support from the ejector box, which is usually the case with larger dies nor from the steel behind the insert as in case 7. 
Figure 2.14 provides distortion plots of the cover inserts for the 3 cases analyzed. The contribution of the cover platen is apparent in these figures and the pictures correspond quite well to the contact pressure plots. With the stiffer platen, the small die distorts relatively little. The large thin die on the thin platen distorts considerably because of the platen bow. The large thick die compensates to some degree for the lack of support from the thin platen, but it shows additional bending compared to the small die due the additional distance from the cavity to the edge of the die that provides additional leverage. 

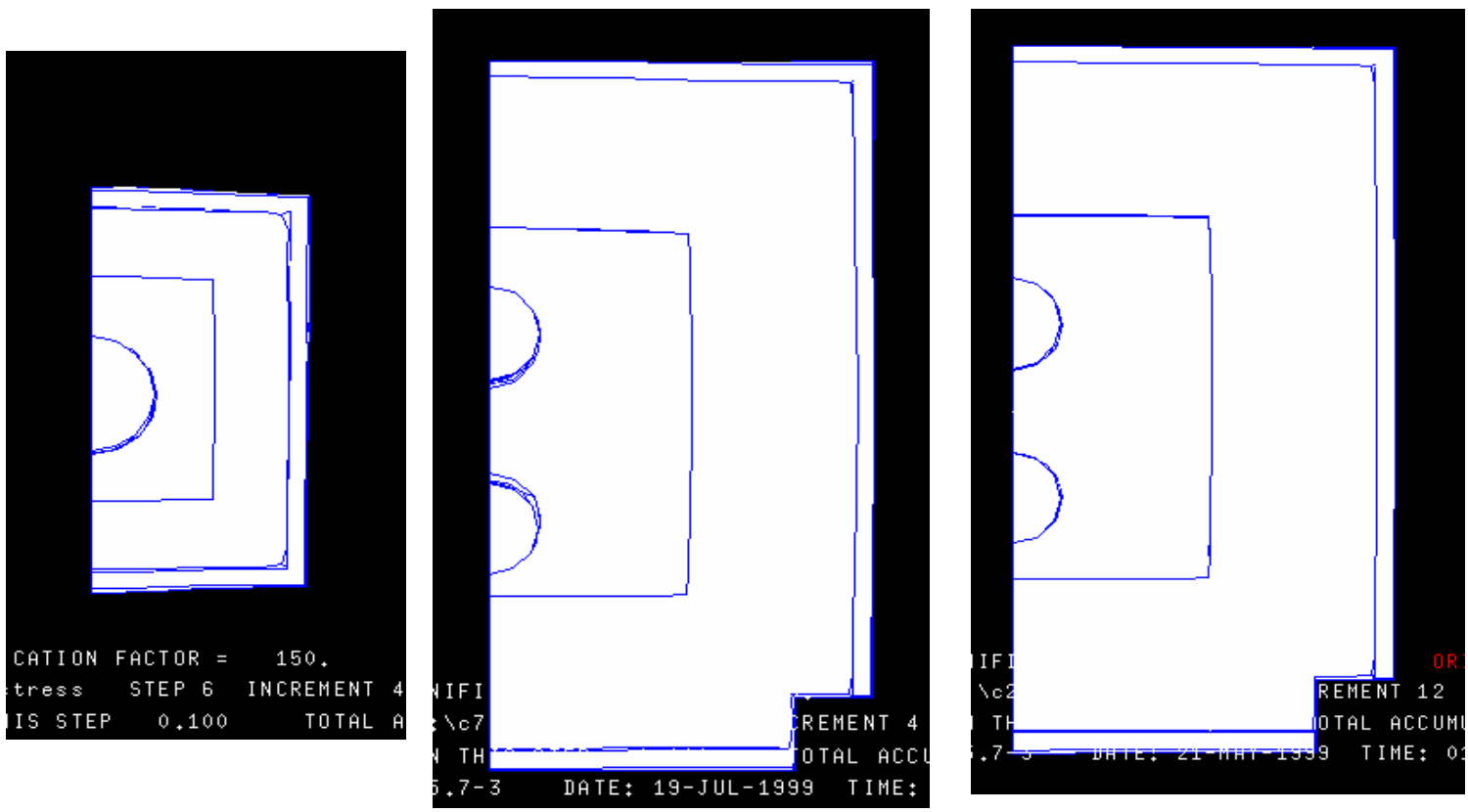

Figure $2.13 \mathrm{a}$
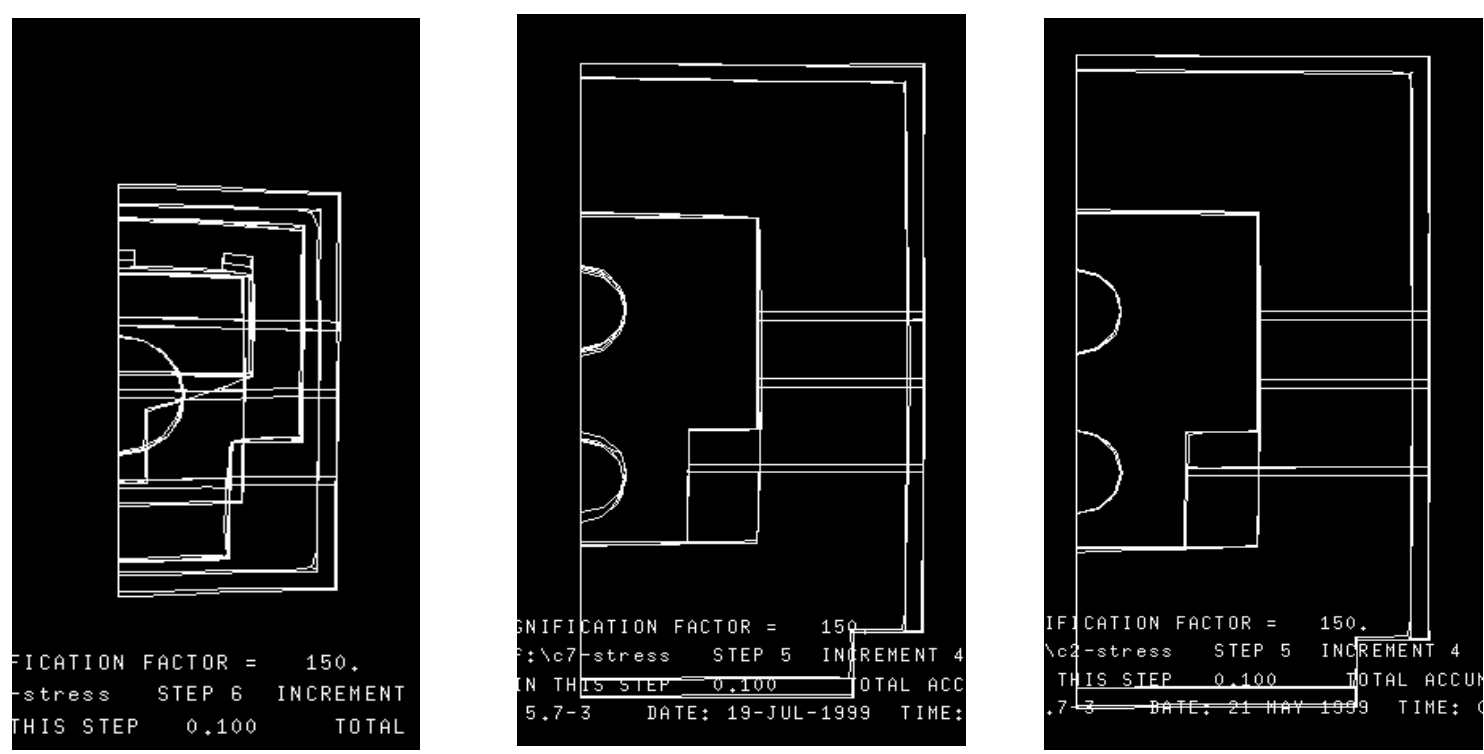

Figure $2.13 b$

Figure 2.5a and $\mathrm{b}$ : Showing the location of the support block and ejector box behind the ejector die, 

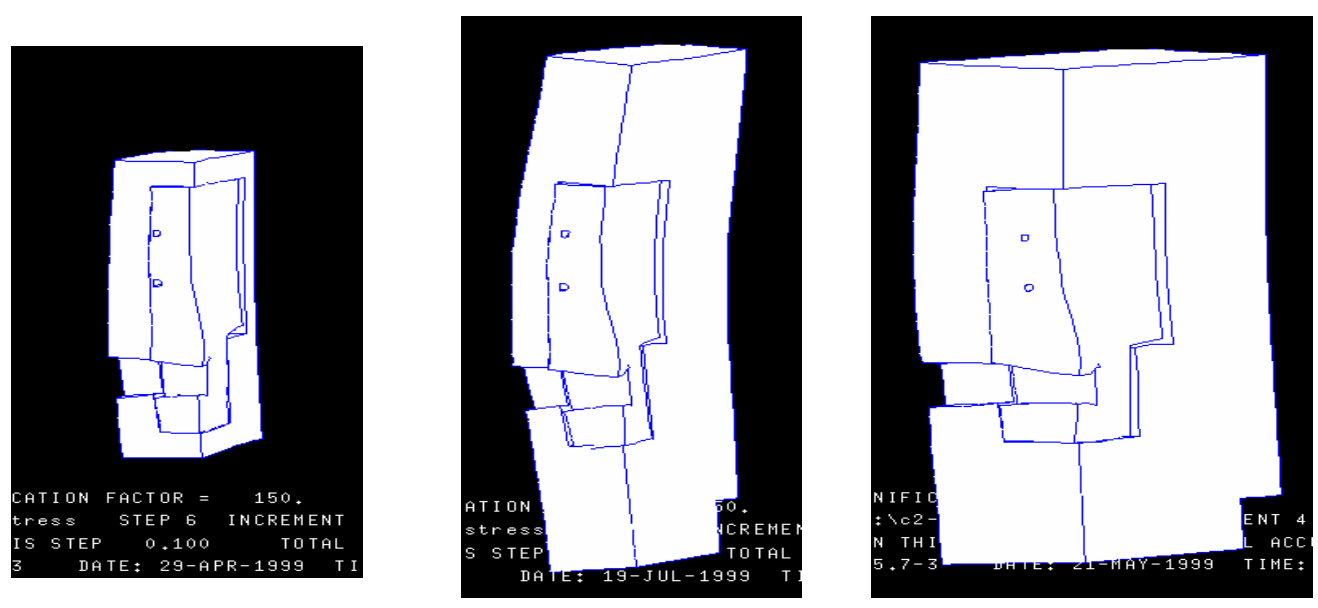

Figure 2.14 a: Cover Side Movement and Distortion
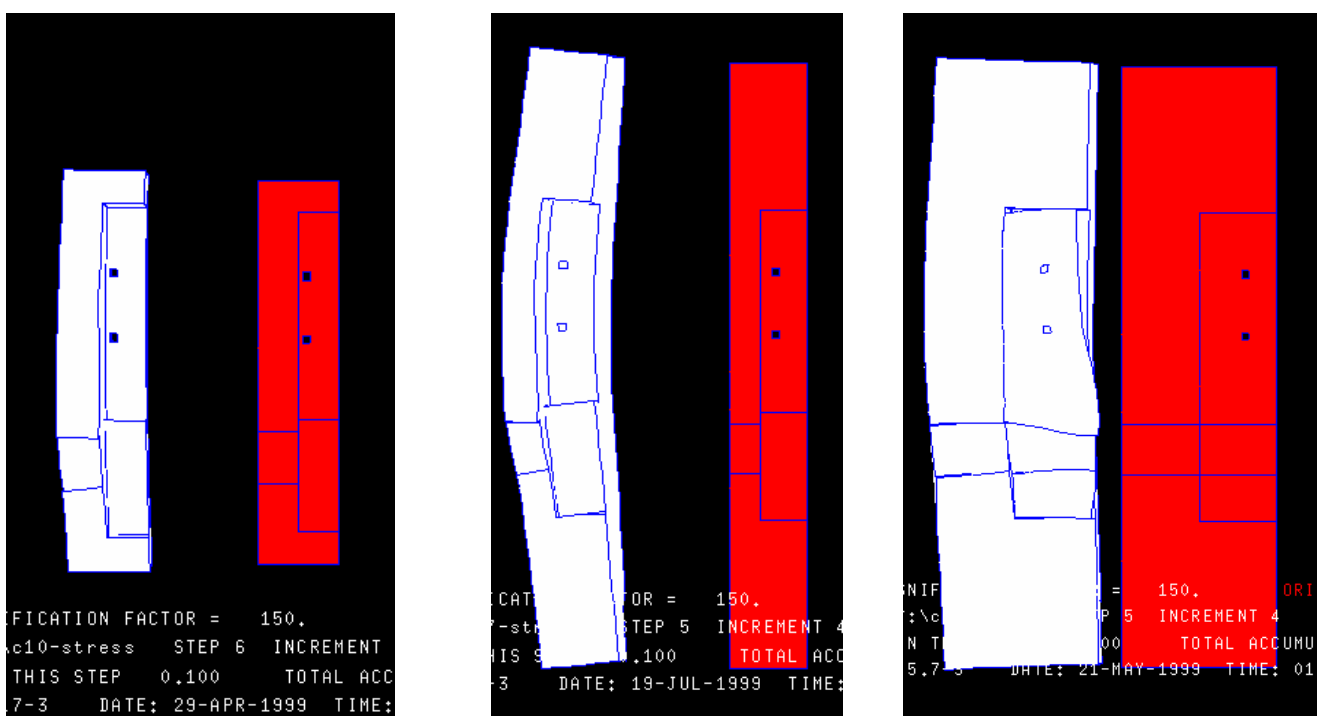

Figure 2.14 b: Cover Side Movement Compared to Initial Position (red). 


\subsection{Factors causing parting plane separation}

The parting plane separation is due to a combination of factors including:

- Limited support for the insert from rails or pillars on the ejector side.

- The bowing of the platen due to clamp and pressure loads.

- Distortion of the die shoe and insert.

- Thermal distortion of the insert and shoe.

- Compression of the insert into the die pocket by cavity pressure.

One of the observations during this study was that the compression phenomena is more prominent in case of a thick die rather than in case of thin die. This can be explained in part by the principles of strain. The formula for strain is

Strain $(\Delta \mathrm{l} / \mathrm{L})=$ Force $(\mathrm{F}) /($ Area $(\mathrm{A}) *$ Young's Modulus $(\mathrm{E}))$

If $\mathrm{L}$ is the shoulder thickness i.e. steel behind the insert and $\Delta \mathrm{l}$ be the change in shoulder thickness due to the ramming of the insert.

Basically, $\quad \Delta \mathrm{l} / \mathrm{L}=\mathrm{F} /(\mathrm{A} * \mathrm{E})$

$$
\Delta \mathrm{l}=\left(\mathrm{F}^{*} \mathrm{~L}\right) /\left(\mathrm{A}^{*} \mathrm{E}\right)
$$

Here the pressure acting on the cavity i.e. cavity pressure is constant and acting on a constant area so the force acting on the die insert and hence on the die pocket, is also constant. E is young's modulus, which is also constant for the material. So, the equation reduces to:

$$
\Delta \mathrm{l}=\mathrm{k} * \mathrm{~L}
$$

where, $\mathrm{k}$ is the constant of proportionality as all the factors are constant.

There fore, $\quad \Delta \mathrm{l} \propto \mathrm{L}$.

This says that more the thickness of the die more is the squeezing of the die due to insert and hence, more pronounced is the effect. For the pressures and die sizes that we are using for this study, the differences are on the order of $1-2$ thousands of an inch. The assumption here is that the foundation (shoe) provides uniform support and it does not. 


\section{MEASUREMENT OF DEFLECTION ON THE COVER SIDE AND EJECTOR SIDE}

\subsection{Estimating the rigid body motion}

As seen in previous sections, the cover side behaves quite differently compared to the ejector side. Hence, it is necessary to measure and study the deflections on the cover side and ejector side separately. However, data from the simulation cannot be used directly for measuring the separations on the cover and the ejector sides. The tiebars stretch under the action of the clamping force, causing rigid body translation and some degree of rotation in addition to distortion of the die. Both the cover die parting surface and the ejector die surface are distorted and displaced from their nominal positions. Since Abaqus can extract only the relative difference between the two and not the difference from the initial position, it is essential to remove the effective rigid body motion from the data in order to independently determine the distortion on each side of the die.

The approximation that we use to characterize the motion is described by the following equation:

$$
\begin{aligned}
& X_{f}=X_{s} * \text { Trans }+E \text { where } \\
& X_{s}=\left[\begin{array}{llll}
x_{s} & y_{s} & z_{s} & 1
\end{array}\right]=\text { starting coordinates before application of loads } \\
& X_{f}=\left[\begin{array}{llll}
x_{f} & y_{f} & z_{f} & 1
\end{array}\right]=\text { ending coordinates after loads } \\
& \text { Trans = a rigid body transformation matrix } \\
& E=\text { non rigid body component of the resulting coordinates }
\end{aligned}
$$

The transformation matrix is of the form:

$$
\text { Trans }=\left[\begin{array}{cc}
R & \underline{0} \\
T & 1
\end{array}\right]
$$

where $\mathrm{R}$ is a $3 \times 3$ rotation matrix and $\mathrm{T}$ is a translation matrix. The translation matrix is the simpler of the two and is of the form:

$$
T=\left[\begin{array}{lll}
\Delta x & \Delta y & \Delta z
\end{array}\right]
$$

The rotation matrix is the composition of rotation about each axis,

$$
R=\operatorname{Rotx} * \operatorname{Roty} * \operatorname{Rotz}
$$

with each rotation matrix defined by the angle of rotation around each access. Specifically, 


$$
\begin{aligned}
\text { Rotx } & =\left[\begin{array}{ccc}
1 & 0 & 0 \\
0 & \cos (\theta) & -\sin (\theta) \\
0 & \sin (\theta) & \cos (\theta)
\end{array}\right] \\
\text { Roty } & =\left[\begin{array}{ccc}
\cos (\phi) & 0 & \cos (\phi) \\
0 & 1 & 0 \\
-\sin (\phi) & 0 & \cos (\phi)
\end{array}\right] \\
\operatorname{Rotz} & =\left[\begin{array}{ccc}
\cos (\gamma) & \sin (\gamma) & 0 \\
-\sin (\gamma) & \cos (\gamma) & 0 \\
0 & 0 & 1
\end{array}\right]
\end{aligned}
$$

The assumption is that since the distortion is small, it can be represented as a linear additive component. An affine structure is used to accommodate both rotation and translation and this is the reason that the array of coordinates is expressed with 4 components. The inclusion of the 1 in the $4^{\text {th }}$ position allows the translation to be included as well as rotation about the origin.

The net result is that the transformation involves 6 unknowns ( 3 components of the translation matrix, and 3 rotation angles). From the simulation we compute the coordinates of several nodes on each side of the die before and after the application of all of the loads of interest. These nodes provide data that populate two arrays, one for the initial coordinates, one for the final coordinates. The 6 unknowns are estimated by least squares (minimizing the sum square of components of E). A Mathcad program was written to compute the values estimates.

\subsection{Extracting the data for calculation of rigid body motion}

Choosing the right nodes from the model is important for estimating the rigid body motion. It is helpful to pick those nodes, which show minimal deformation under mechanical and thermal loads. Thus, nodes on the parting surface of the die block, which remain in contact, are picked. In addition 100 random nodes are picked from the ejector and cover die.

The nodes that are in contact can be found from the data file that is written by the ABAQUS solver. The values of the final co-ordinates and the displacements of the nodes are obtained during post processing. To improve precision, the final co-ordinates are recalculated using the input node co-ordinates and the displacements. A program was written to pick random nodes from the nodeset. The outputs of the code are the initial and the final values of the co-ordinates of the nodes, which are in contact on the parting surface and the nodes that are randomly picked from the nodeset.

Using the transformed co-ordinates, the values for separation on the cover and the ejector side are found by subtracting the initial and transformed values in the Z-direction. The results are included in Table 1.2. A plot comparing the individual cover and ejector side data by run is shown in Figure 3.1. The main thing the plot shows is that there is considerable variability and that cover side separation (the maroon bars) tend to dominate the ejector side. The two cases ( 1 and 7 ) with very high separation both have very high cover 
separation. Both of these cases are large thin dies on thin platens. Figures 3.2 and 3.3 plot the cover and ejector data separately and order the results. Note that the best overall case, case 10 , is not the best from the cover side but is considerably better than the others on the ejector side.

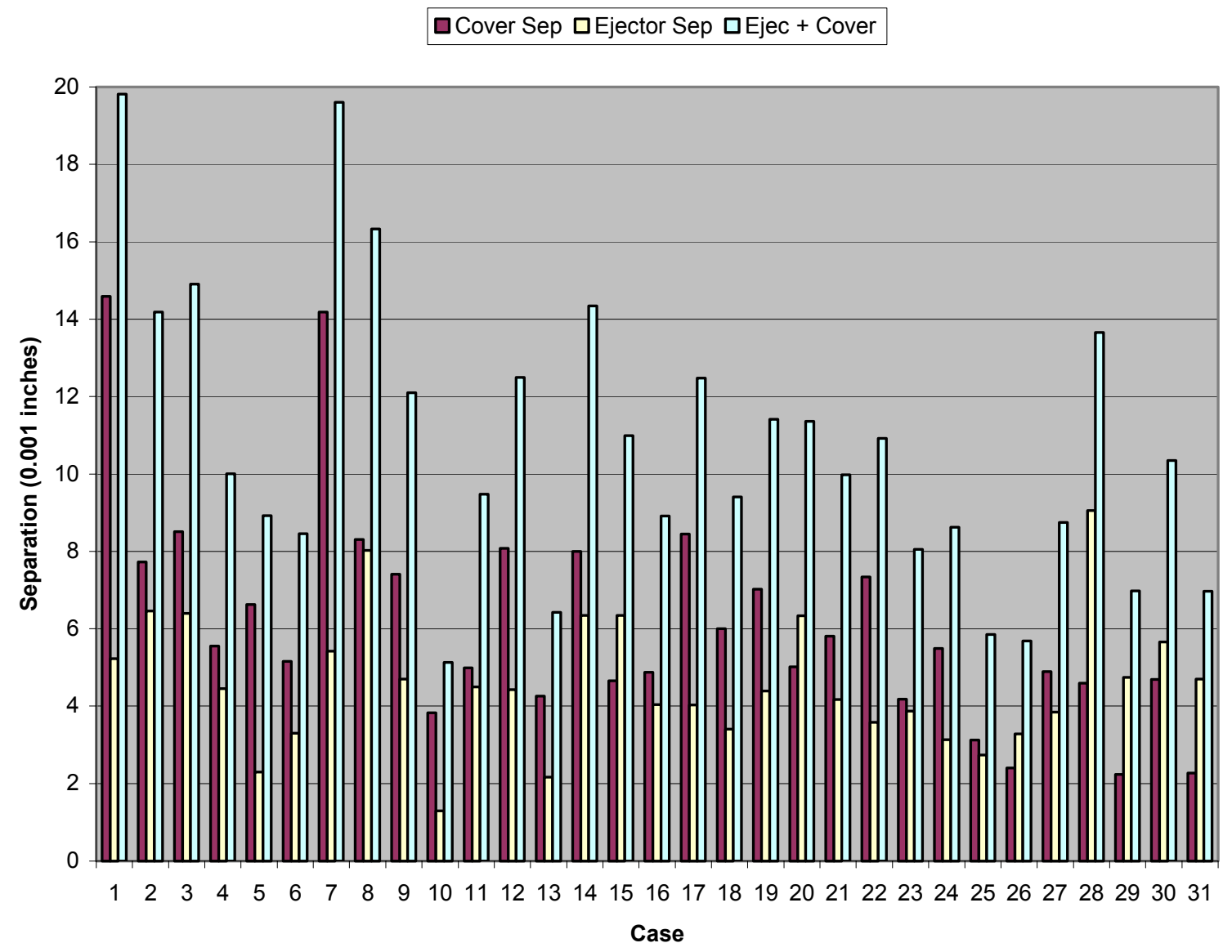

Figure 3.1 Comparison of Maximum Separation with Cover and Ejector Separation 


\section{Cover Separation}

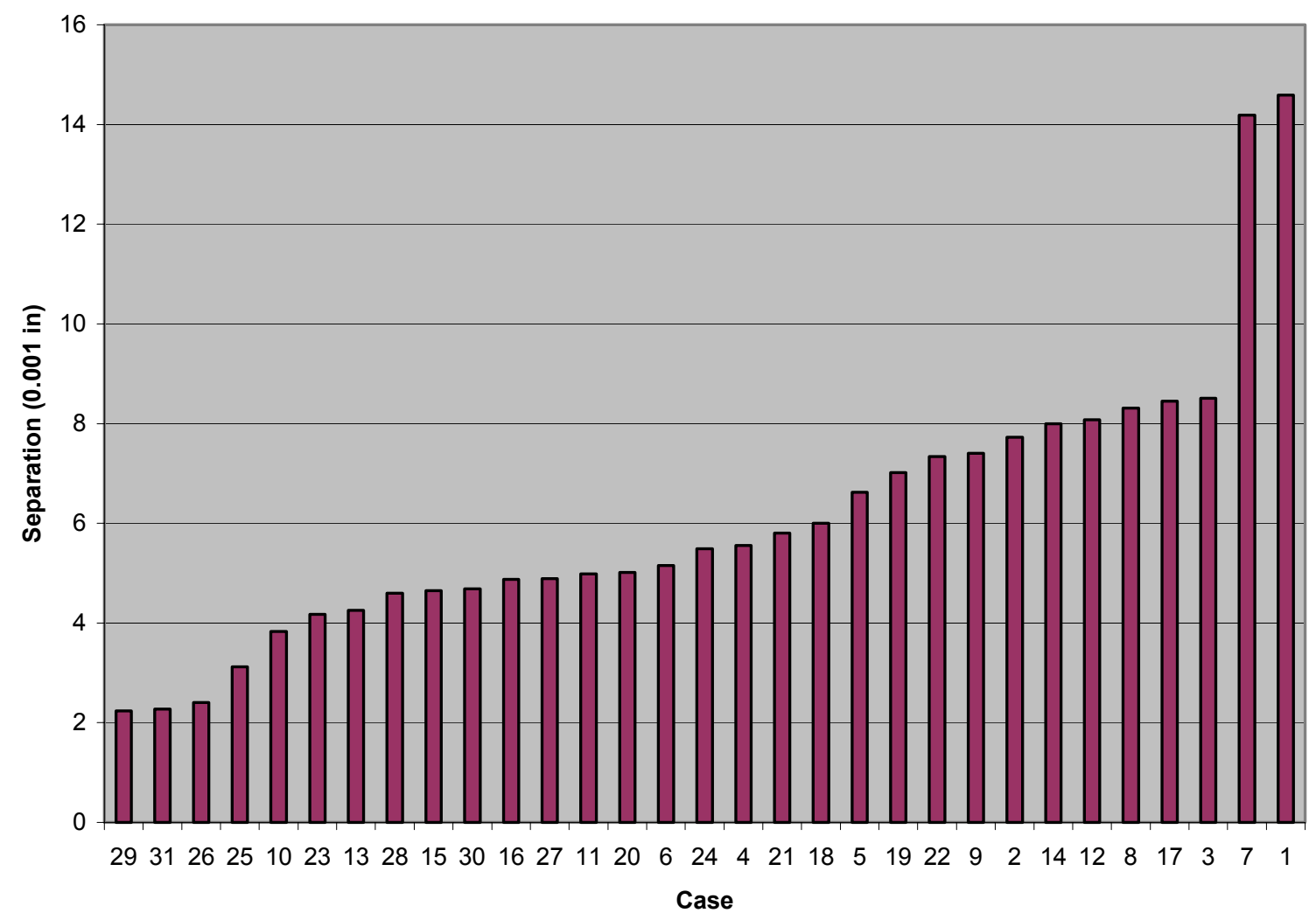

Figure 3.2 Cover Separation 
Ejector Separation

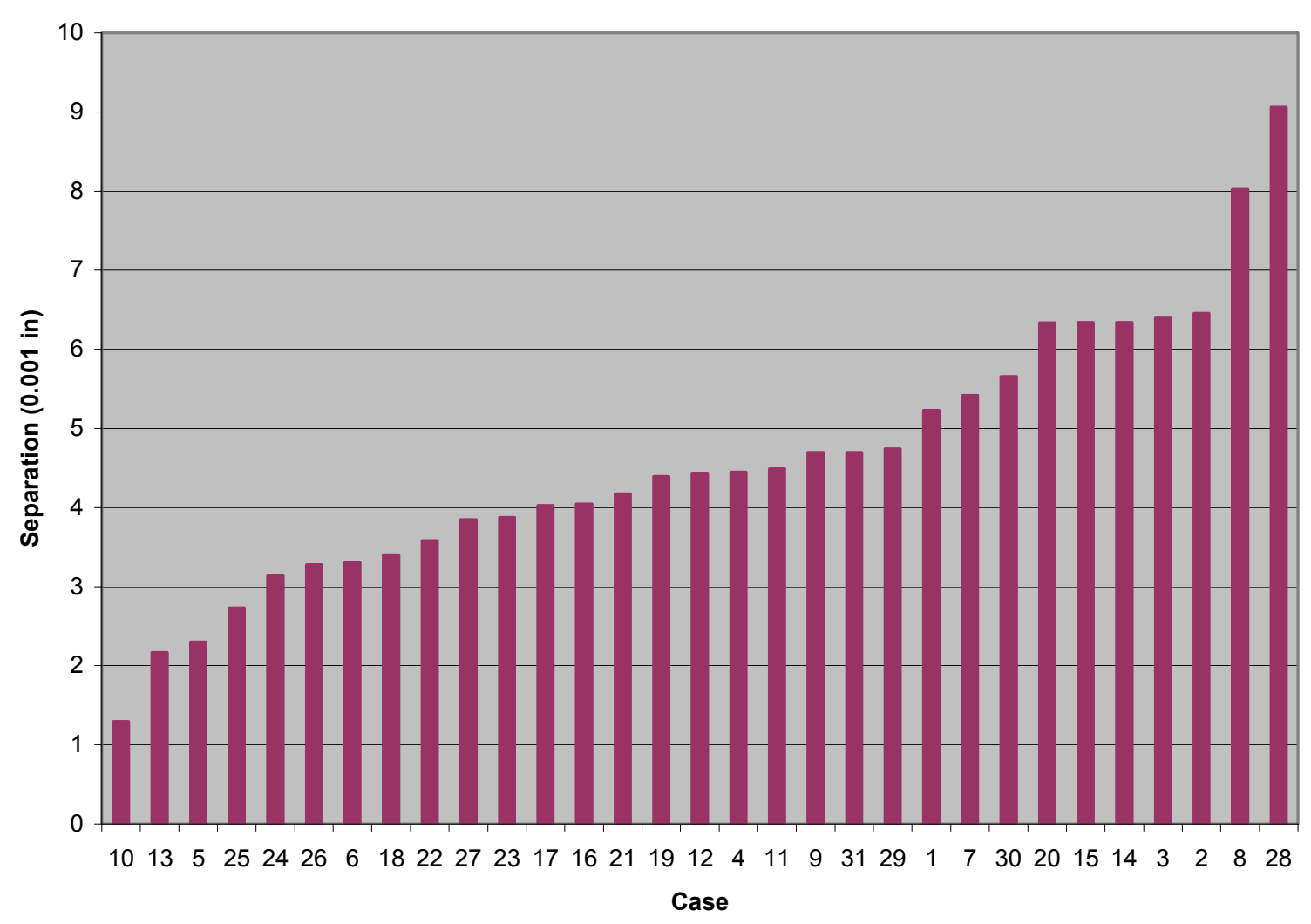

Figure 3.3 Ejector Separation 


\subsection{Regression analysis for the cover and ejector side.}

Response surfaces for the cover and ejector side were constructed and edited following the procedures described earlier. The cover side results are summarized in Table 3.1 .

\begin{tabular}{|c|c|c|c|c|}
\hline Coefficients & Value & Std.Error & $t$ & $p$ \\
\hline Constant & 6.8393 & 0.2123 & 32.2081 & 0.0000 \\
\hline A & 1.1178 & 0.2656 & 4.2088 & 0.0004 \\
\hline $\mathrm{C}$ & -1.5519 & 0.3032 & -5.1180 & 0.0000 \\
\hline $\mathrm{D}$ & -0.5170 & 0.2558 & \begin{tabular}{|l|}
-2.0209 \\
\end{tabular} & 0.0556 \\
\hline$A^{*} B$ & -1.3994 & 0.2793 & -5.0109 & 0.0001 \\
\hline$A^{*} C$ & -1.1763 & 0.3064 & -3.8394 & 0.0009 \\
\hline $\mathrm{B}^{*} \mathrm{C}$ & 0.9077 & 0.2971 & 3.0547 & 0.0058 \\
\hline$C^{*} E$ & -0.8029 & 0.3264 & -2.4596 & 0.0222 \\
\hline$D^{*} E$ & 0.7809 & 0.3299 & 2.3669 & 0.0272 \\
\hline
\end{tabular}

Table 3.1 Estimated Model for Cover Contribution to Separation: Edited Model

The quality of the response surface fit is not quite as good as for total separation, but the results are still quite acceptable. The standard error is about 0.001 " as it was for total separation.

For comparison, the coefficients for total separation and for the cover contribution are shown side by side below in Table 3.2. The only term that contributes to the cover and not to the total is a small $\mathrm{D}^{*} \mathrm{E}$ interaction. With this exception, there are no location terms (E) contribution to the cover model. Similarly, die thickness (B) participates in fewer combinations. Clearly, the dominate factors on the cover side are die size (smaller is better), platen thickness (thicker is better).

\begin{tabular}{|l|l|l|}
\hline & Max Sep & Cover \\
\hline Constant & 10.3545 & 6.8393 \\
\hline$A$ & 0.9883 & 1.1178 \\
\hline$B$ & 1.1719 & 0 \\
\hline$C$ & -1.7490 & -1.5519 \\
\hline$D$ & -0.7422 & 0 \\
\hline$D^{*} D$ & 1.6327 & 0 \\
\hline$A^{*} B$ & -1.9343 & -1.3994 \\
\hline$A^{*} C$ & -1.2429 & -1.1763 \\
\hline$A^{*} E$ & 1.4315 & 0 \\
\hline$B^{*} C$ & 0.8825 & 0.9077 \\
\hline$B^{*} E$ & -0.6891 & 0 \\
\hline$C^{*} D$ & -0.6266 & 0 \\
\hline$D^{*} E$ & 0 & 0.7809 \\
\hline
\end{tabular}

Table 3.2 Comparison of Response Surface for Max Separation and Cover Contribution to Max 
The ejector side fits are not as good as the total or the cover. The results for the edited model are summarized in Table 3.3. Very few terms are significant and the adjusted $\mathrm{R}^{2}$ is much lower than the other analyses. Basically this means that the response surface does not explain what is going on in this case. The response surfaces do a good job of characterizing the cover or the total, but they do not explain the ejector side. Judging from the other analyses that have been described in chapter 2, we know that pillar locations and the location of the ejector rails are very important. These factors are not controlled as factors in the experiment and lead to additional noise in the results. Additional runs are needed to understand the ejector side of the die. It is also possible, that inaccuracies are introduced by the estimation procedure used to extract the cover and ejector data.

\begin{tabular}{|c|c|c|c|c|}
\hline Coefficients: & Value & Std.Error & $\mathbf{t}$ & $\mathbf{p}$ \\
\hline Constant & 5.1170 & 0.2407 & 21.2613 & 0.0000 \\
\hline B & 0.7999 & 0.2649 & 3.0192 & 0.0056 \\
\hline E & -0.5975 & 0.2848 & -2.0980 & 0.0458 \\
\hline A:B & -0.8736 & 0.3011 & -2.9014 & 0.0075 \\
\hline C:D & -0.7018 & 0.2916 & -2.4069 & 0.0235 \\
\hline \multicolumn{4}{|l}{} \\
\hline
\end{tabular}

Table 3.3 Estimated Model for Cover Contribution to Separation: Edited Model

\subsection{Distortion of the dies along dimensions parallel to parting plane:}

The results discussed previously show that a small thin die on a thick platen performs better than might be expected with respect to parting plane separation. The distortion plots, however provide some hints that the small die might distort more along the $\mathrm{x}$ and $\mathrm{y}$ axes than larger dies. To analyze this, at least approximately, the mean square error along each dimension, computed from the residuals after the rigid body motion is removed from the data, was used. The values for all the three components are given in Table 3.4.

The Figure 3.4 and 3.5 show the deviations of $\mathrm{x}$ and $\mathrm{y}$ plotted against die size and die thickness respectively. Clearly the small, thin dies show greater deviation in $\mathrm{x}$ and $\mathrm{y}$ as compared to large thick dies. The small die is squeezed shut along $\mathrm{z}$, but this results in distortion along the other axes. Some of this may be due to inaccuracies in the models, for example leader pins that prevent surfaces from shifting are not modeled. 


\begin{tabular}{|c|c|c|c|c|c|c|c|c|}
\hline Case & A & $\mathrm{B}$ & C & $D$ & $E$ & $\mathrm{MSE}_{\mathrm{x}}$ & $\mathrm{MSE}_{\mathrm{y}}$ & $\mathrm{MSE}_{\mathrm{z}}$ \\
\hline 1 & 1 & -1 & -1 & 1.0000 & 1 & 0.5280 & 2.4433 & 2.1093 \\
\hline 2 & 1 & 1 & -1 & 1.0000 & 0.302326 & 0.0782 & 0.4642 & 0.6144 \\
\hline 3 & -1 & 1 & 1 & 1.0000 & -1 & 0.8766 & 0.6610 & 0.5621 \\
\hline 4 & -1 & -1 & 1 & -1.0000 & -1 & 1.1871 & 4.0040 & 0.8780 \\
\hline 5 & -1 & -1 & -1 & -1.0000 & 1 & 0.8426 & 1.2824 & 0.3588 \\
\hline 6 & 1 & -1 & 1 & 1.0000 & 0.302326 & 0.3669 & 1.1658 & 1.3745 \\
\hline 7 & 1 & -1 & -1 & -1.0000 & 0.302326 & 0.5719 & 1.3869 & 1.9296 \\
\hline 8 & -1 & 1 & -1 & -1.0000 & -1 & 0.7031 & 0.5995 & 0.6978 \\
\hline 9 & -1 & 1 & -1 & 1.0000 & 1 & 0.5092 & 1.0945 & 0.3188 \\
\hline 10 & -1 & -1 & 1 & 1.0000 & 1 & 1.3125 & 3.4879 & 0.9350 \\
\hline 11 & 0 & 0 & 0 & 1.0000 & -0.39535 & 0.3280 & 0.9556 & 0.7149 \\
\hline 12 & 0 & 0 & -1 & 0.0000 & 0.767442 & 0.3035 & 1.6116 & 0.6735 \\
\hline 13 & -1 & -1 & 0 & 0.0000 & 0.767442 & 1.1092 & 3.8986 & 0.5392 \\
\hline 14 & 0 & 1 & 0 & -1.0000 & 0.186047 & 0.2567 & 1.6453 & 0.3640 \\
\hline 15 & 1 & 0 & 1 & 0.0000 & 1 & 0.2252 & 1.0284 & 0.9174 \\
\hline 16 & -0.49333 & 0.5 & 0.490909 & -0.4971 & 0.883721 & 0.7249 & 2.6306 & 3.6845 \\
\hline 17 & 1 & 0.5 & -0.49091 & -0.4000 & 0.883721 & 0.3420 & 1.4904 & 18.3013 \\
\hline 18 & 0.506667 & 0 & 0.490909 & 0.0000 & -0.04186 & 0.4692 & 2.2987 & 9.1976 \\
\hline 19 & 0 & 1 & 0.018182 & 0.0000 & 0.767442 & 0.5143 & 0.8227 & 7.0209 \\
\hline 20 & 0.506667 & 1 & 1 & -0.4000 & \begin{tabular}{|l|}
0.883721 \\
\end{tabular} & 0.2408 & 1.3675 & 1.4533 \\
\hline 21 & 0.506667 & -1 & 0.490909 & -0.4000 & 0.883721 & 0.8087 & 2.0050 & 13.1683 \\
\hline 22 & 0.506667 & 0.5 & 0.490909 & 1.0000 & 0.767442 & 0.6138 & 0.9982 & 13.0374 \\
\hline 23 & 0 & -1 & 1 & 1.0000 & 0.767442 & 1.3707 & 3.3365 & 9.6483 \\
\hline 24 & -1 & -1 & -1 & -1.0000 & -1 & 1.0490 & 7.0526 & 4.9402 \\
\hline 25 & -1 & -1 & 1 & -1.0000 & 1 & 1.3143 & 6.5610 & 2.8156 \\
\hline 26 & -1 & -1 & 1 & 1.0000 & -1 & 2.7470 & 3.8504 & 5.1955 \\
\hline 27 & -1 & -1 & -1 & 1.0000 & 0 & 3.3733 & 7.0809 & 9.5933 \\
\hline 28 & -1 & 1 & 1 & -1.0000 & 1 & 1.1369 & 1.6444 & 10.7954 \\
\hline 29 & 0 & -1 & 1 & 0.0000 & 1 & 3.0644 & 6.9281 & 5.1155 \\
\hline 30 & -1 & -1 & -1 & 1.0000 & -1 & 3.6467 & 3.3287 & 16.0481 \\
\hline 31 & -1 & -1 & 0 & 1.0000 & 1 & 0.9510 & 10.1695 & 5.4200 \\
\hline
\end{tabular}

Table 3.4 : Values for deviation in $\mathrm{X}, \mathrm{Y}$ and $\mathrm{Z}$ directions 

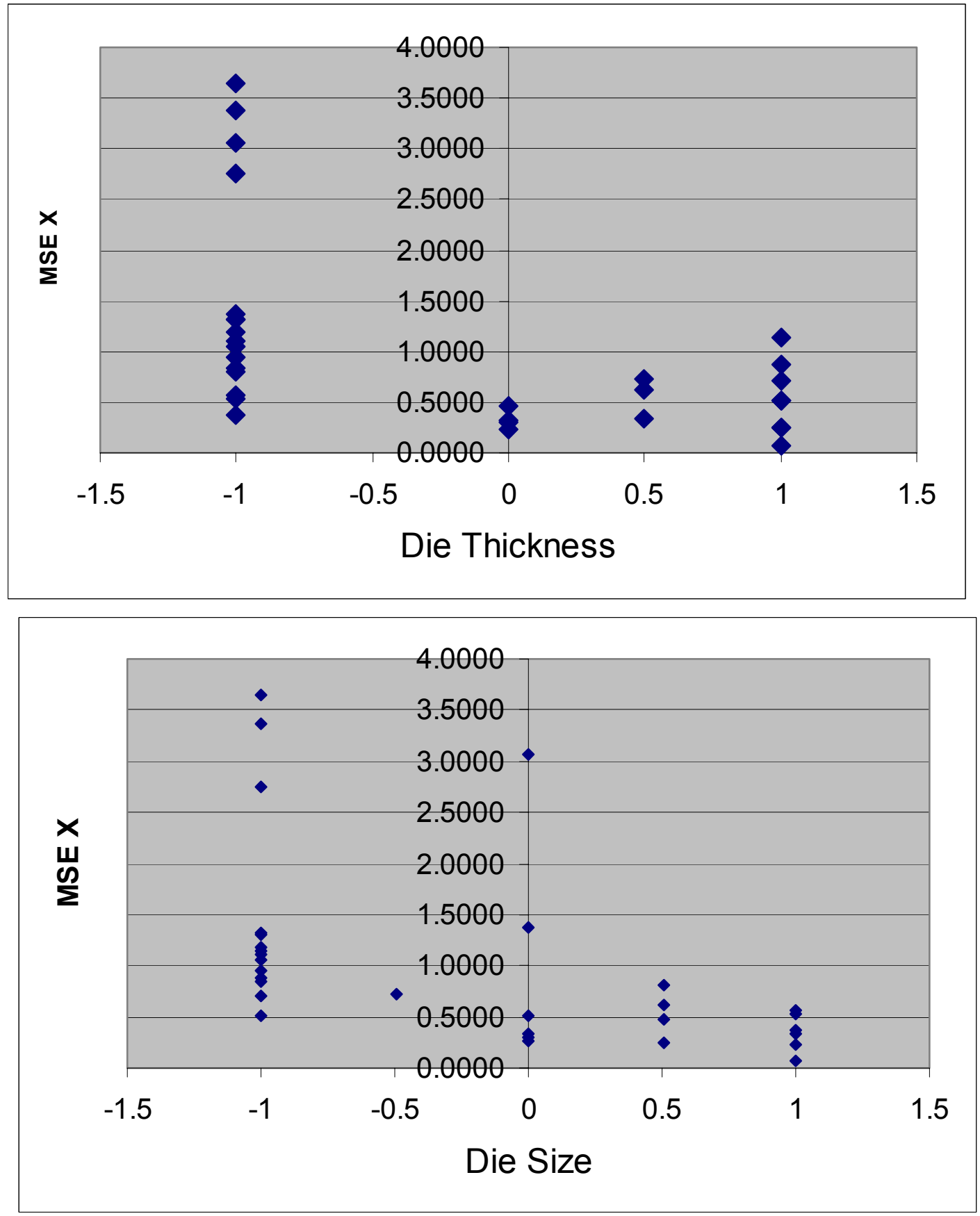

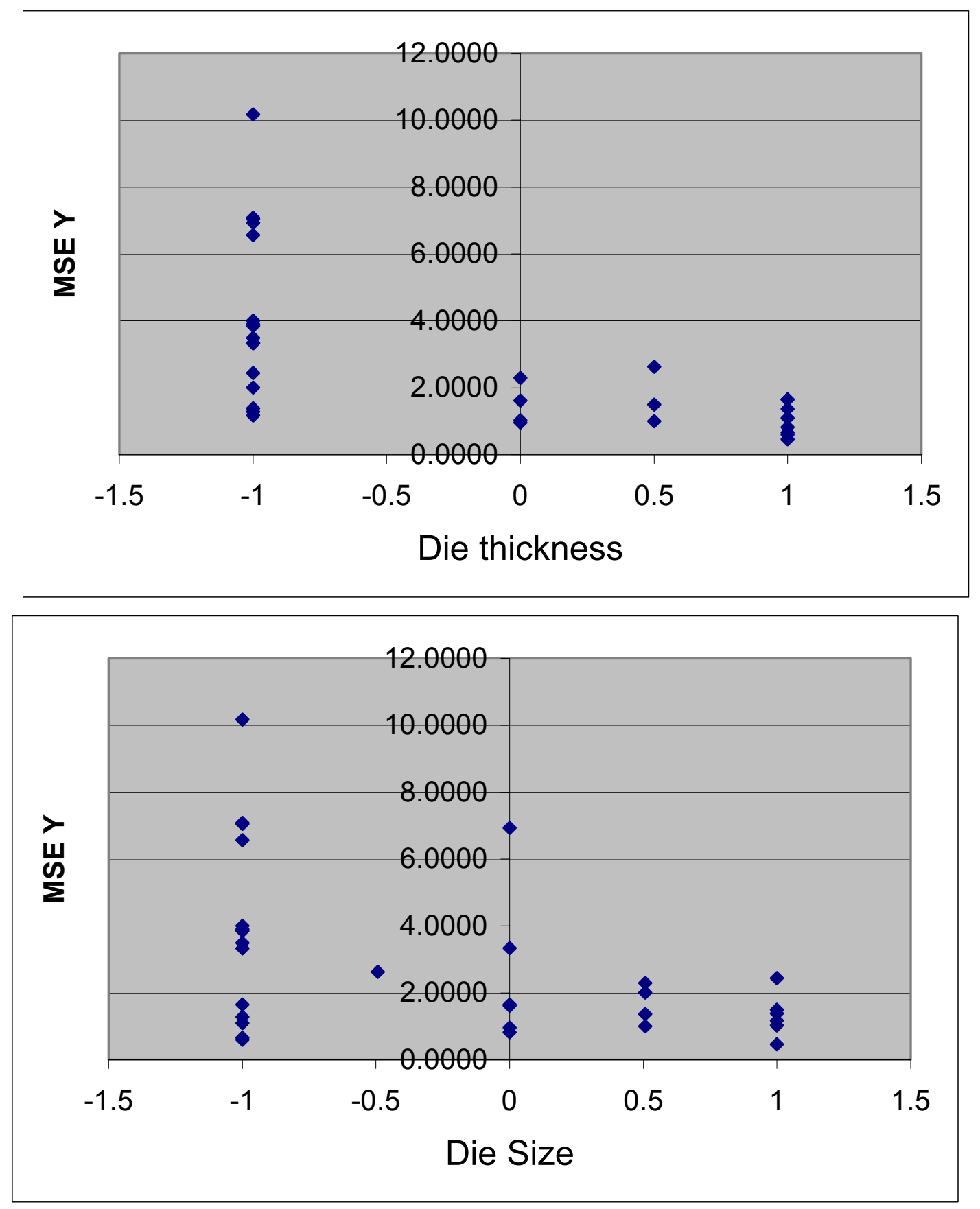

Figure 3.5: Deviation in $\mathrm{Y}$ with respect die size and die thickness

\subsection{Center of pressure}

As seen from response surface analysis dies mounted high seem to perform better. For the dies mounted high the center of pressure is above the geometric center of the platen for the part we have considered. But, due to the thermal growth of the die, the center of pressure after the die has reached the steady state does not coincide with the cold center of 
pressure. An analysis was done to determine the center of pressure after the die had reached a steady state.

The contact pressure at the cover platen- cover die interface was used for this calculation. The contact pressure values for nodes on the contact surface are written in the data file $(*$.DAT). These values were used to determine the center of the pressure at the end of the tenth cycle. The method to find the center was as follows:

- Find the nodes on the contact surface of the cover die and the corresponding values from the data file.

- Find the elements that constitute the contact surface.

- Find the nodes that constitute the element.

- Sort out the nodes that lie on the contact surface.

- Sort out the nodes that lie at vertices of the triangular face.

- Calculate the area of the triangular face and the centroid for the triangle.

- Calculate the average pressure at the centroid of the triangle.

- Calculate the center of pressure using the formula:

$$
Y=\frac{P_{1} A_{1} Y_{2}+P_{1} A_{2} Y_{2}+\ldots+P_{n} A_{n} Y_{n}}{P_{1} A_{12}+P_{1} A_{2}+\ldots+P_{n} A_{n}}
$$

Where,

$P_{n} \quad$ Average contact pressure acting at the $n^{\text {th }}$ element face.

$\mathrm{A}_{\mathrm{n}} \quad$ Area of the $\mathrm{n}^{\text {th }}$ element face.

$Y_{n} \quad$ Distance of centroid of the $n^{\text {th }}$ element face from the datum.

Table 3.5 shows the values for hot and cold center of pressure for a sampling of cases. Figure 3.6 shows the values for cold and hot center of pressure. The hot center of pressure after the die has reached a steady state is located below the cold center of pressure in each case and often the difference is substantial. This results into better alignment of the center of pressure with the geometric center of the platen if the die is mounted a little above center in most instances. 


\begin{tabular}{|c|c|c|}
\hline Case & $\begin{array}{c}\text { Cold center of } \\
\text { pressure }\end{array}$ & $\begin{array}{c}\text { Hot center of } \\
\text { pressure }\end{array}$ \\
\hline 10 & 3.6334 & 1.80905 \\
\hline 17 & 3.0084 & 1.598617 \\
\hline 19 & 2.3834 & 0.206259 \\
\hline 21 & 3.0084 & 0.259172 \\
\hline 22 & 2.3834 & -0.04291 \\
\hline 25 & 3.6334 & 3.473533 \\
\hline 28 & 3.6334 & 3.525916 \\
\hline 29 & 3.6334 & 3.506042 \\
\hline 31 & 3.6334 & 3.542535 \\
\hline
\end{tabular}

Table 5.5: Values hot and cold center of pressure

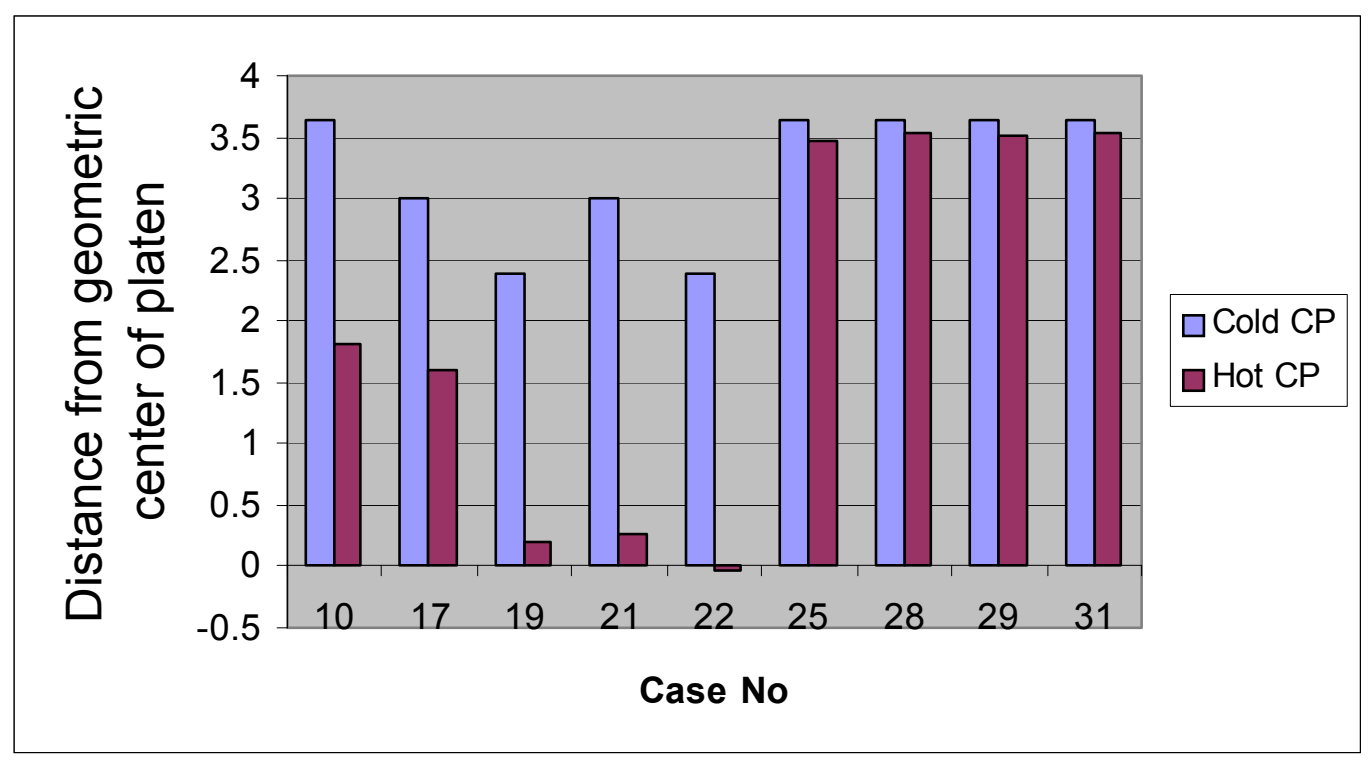

Figure 3.6: Plot for hot center pressure vs cold center of pressure 


\subsection{Summary}

The results obtained form the simulations and the regression analysis suggests that the cover side and the ejector side behave differently. It can be concluded that a die that has better support gives best results. However, good support on the ejector side and the cover side has a different meaning.

The separation on the cover side is mainly due to bowing of the cover platen and shoving on the insert into the die pocket. Hence, a thicker platen helps in providing better support on the cover side. Small, thin dies mounted with center of pressure above the geometric center of platen perform well. Small dies are subjected to higher loads and hence, provide good seal around the cavity. The model suggests that thicker the amount steel behind the insert, better is support provided to the cavity and hence lower values of separation.

On the ejector side, providing better support translates into designing a small die. For a small die, the ejector box is closer to the cavity than for a large die. Hence, the support provided by the ejector box helps in reducing the parting plane separation. A slightly thin compliant platen provides a better support on the ejector side. Thus, on the ejector side a small, thin die mounted on nominal platen with center of pressure above the geometric center of platen performs best. 



\section{STRESSES IN THE PLATENS}

\subsection{Introduction}

The conclusion that a small footprint die actually performs better than a large die with respect to parting plane separation runs counter to standard practice. It also breeds a concern that there is danger of coining (plastically deforming) the platens. Machine manufacturers recommend that die should be made as big as possible, so as to reduce chances of coining of platens. It is assumed that a large die spreads the forces over a larger area, and thus reduces the stresses on the platen.

The following study focuses on analyzing the compressive stresses in the platens as a function of the design parameters studied.

\subsection{Contact pressure between the die and the platen}

Before addressing the details of looking at the compressive stresses in the platens and its effect on plastic deformation of the platens, let us first revisit the contact pressure between the dies and the platens that was considered in chapter 2. For studying and comparing the contact pressure and compressive stress, we have picked 3 cases from our array. The 3 cases are, case 7 , with a die size $80 \%$ platen area covered (large die), die thickness 5 " and platen thickness of 9"; case 14, with die size 50\% platen area covered (medium die), die thickness 10 " and platen thickness of 11.75"; and case 10 (our best case in terms of parting plane separation), with die size 30\% platen area covered (small die), die thickness 5 " and platen thickness of 14.5". Cases 10 and 7 were used in chapter 2. Case 14 is based on parameters that are close to standard practice. 
and Figure 4.1 show the contact pressure plots of the cover die with cover platen and ejector die with ejector platen respectively. It can be observed from the contact pressure plots of the cases shown in the Figures 4.1 and 4.2 that although the footprint of the die in case of a large die is large, the contact between the die and platen is restricted to a much smaller portion of the total die footprint as compared to the case of a medium die or a small die. As the footprint of the die gets smaller the distribution of contact pressure becomes more and more uniform across the footprint, i.e. a medium die has more uniform support on the back of the die as compared to the large die and the small die has even better and more uniform support on the back of the die as compared to the medium die.

As observed earlier, in case of a large die, the pressure is in fact concentrated on a small fraction of the contact surface between the die and the platen, so that the contact pressure might be higher in the regions of contact. So, the idea that bigger dies result in reduction of pressure on the platens is incorrect and is based on the assumption that the contact pressure is distributed over the total area, which is also not true given the distortion of the die. 


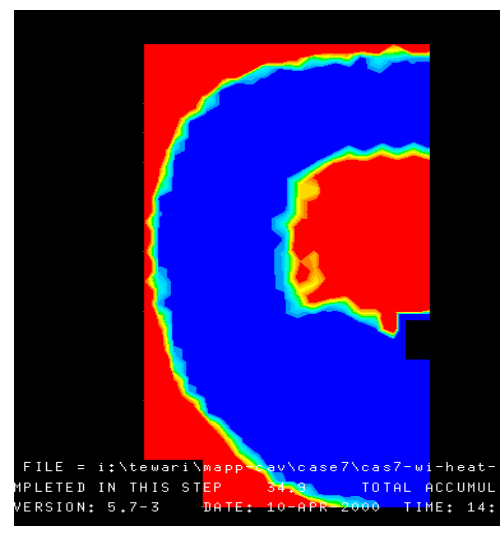

Case 7

Die size: 39" (78\%)

Die Thickness: 5"

Platen Thickness: 9"

Insert Thickness: 3"

Shoulder Thickness: 2"

Die located at bottom

Max. Separation: 0.0196"

(Large die)

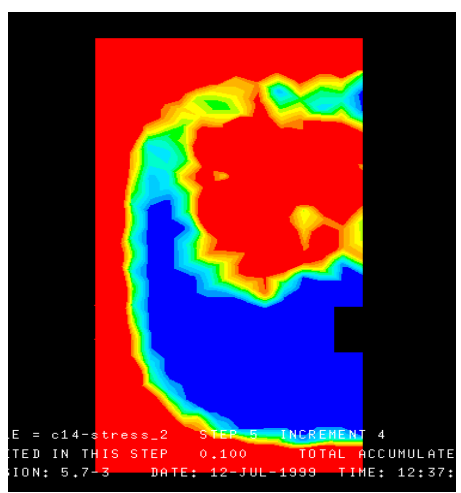

Case 14

Die size: $31.5 "(50 \%)$

Die Thickness: 10"

Platen Thickness: 11.75"

Insert Thickness: 6"

Shoulder Thickness: 4"

Die located close to geometric center of platens

Max. Separation: 0.0143"

(Medium die)

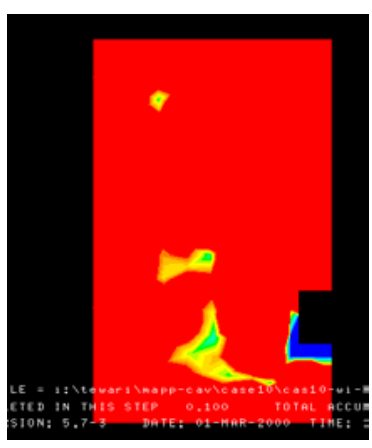

Case 10

Die size: 24" (30\%)

Die Thickness: 5"

Platen Thickness: 14.5"

Insert Thickness: 2.5 "

Shoulder Thickness: 2.5"

Die located at top

Max. Separation: 0.0051"

(Small die)

Figure $4.1^{5}$ Contact pressure at the back of the cover die i.e. the contact surface between the cover die and cover platen

\footnotetext{
${ }^{5}$ Red denotes maximum contact pressure, blue no pressure.
} 


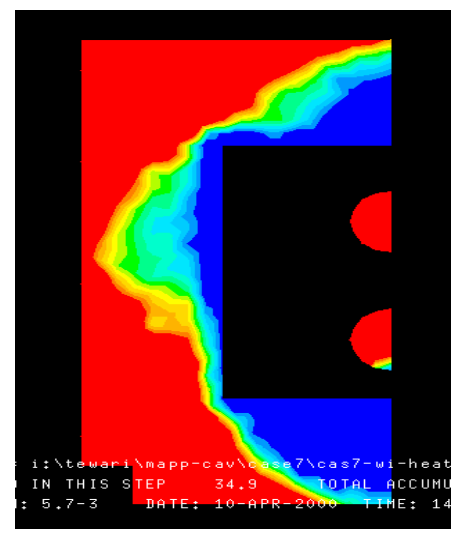

Case 7

Die size: $39 "(78 \%)$

Die Thickness: 5"

Platen Thickness: 9"

Insert Thickness: 3"

Shoulder Thickness: 2"

Die located at bottom

Max Separation: 0.0196"

(Large die)

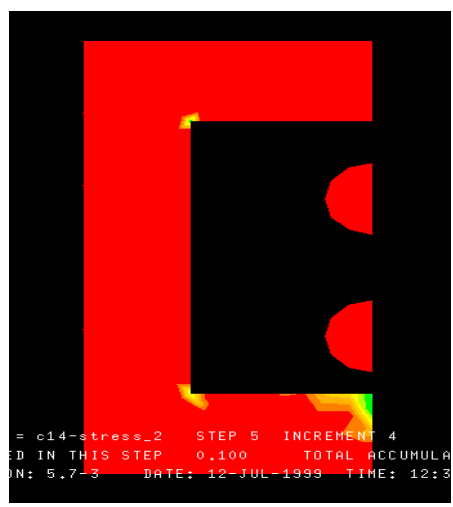

Case 14

Die size: $31.5 "(50 \%)$

Die Thickness: 10"

Platen Thickness: 11.75"

Insert Thickness: 6"

Shoulder Thickness: 4"'”

Die located close to

geometric center of

platens

Max Separation: 0.0143

(Medium die)

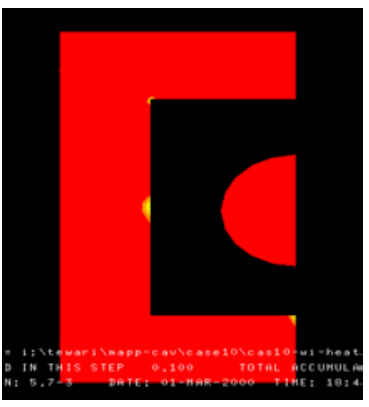

Case 10

Die size: 24" (30\%)

Die Thickness: 5"

Platen Thickness: 14.5"

Insert Thickness: 2.5 "

Shoulder Thickness: 2.5"

Die located at top

Max Separation: 0.0051

(Small die)

Figure $4.1^{6}$ Contact pressure plots at the back of the ejector die i.e. the contact surface between the ejector die and ejector platen

\subsection{Compressive stresses in the platens}

The contact pressure at the contact surface between dies and platens is the boundary force that loads the platens. This force will result in displacements, strains and stresses. The stresses, if high enough, will result in damage to the platen. Figure $4.3 \mathrm{a}, \mathrm{b}$ and $\mathrm{c}$ (the two subfigures are different angles for viewing the same plot) show the smallest principle stresses (generally compressive) in the platens. The maximum compressive stress plots for the platens for several cases can be found in Appendix A.1 through AppendixA.23.

For the large die on a thin platen, Figure 4.3a shows that the maximum compressive stresses are about $117 \mathrm{Mpa}$ with the max occurring on behind one of the pillars on the ejector side. The maximum on the cover side is about $80 \mathrm{Mpa}$ with smaller compressive stresses at the corners of the die. The largest stresses are tensile and located on the back the cover platen and in the region of the tie bar holes. The stresses at the tie bar hole edge are the result of platen bending and suggest that bushing wear is possible. It must be noted that the analysis is elastic only and can be used only as a rough guide for the actual stresses.

\footnotetext{
${ }^{6}$ Red denotes maximum contact pressure, blue denotes no pressure.
} 

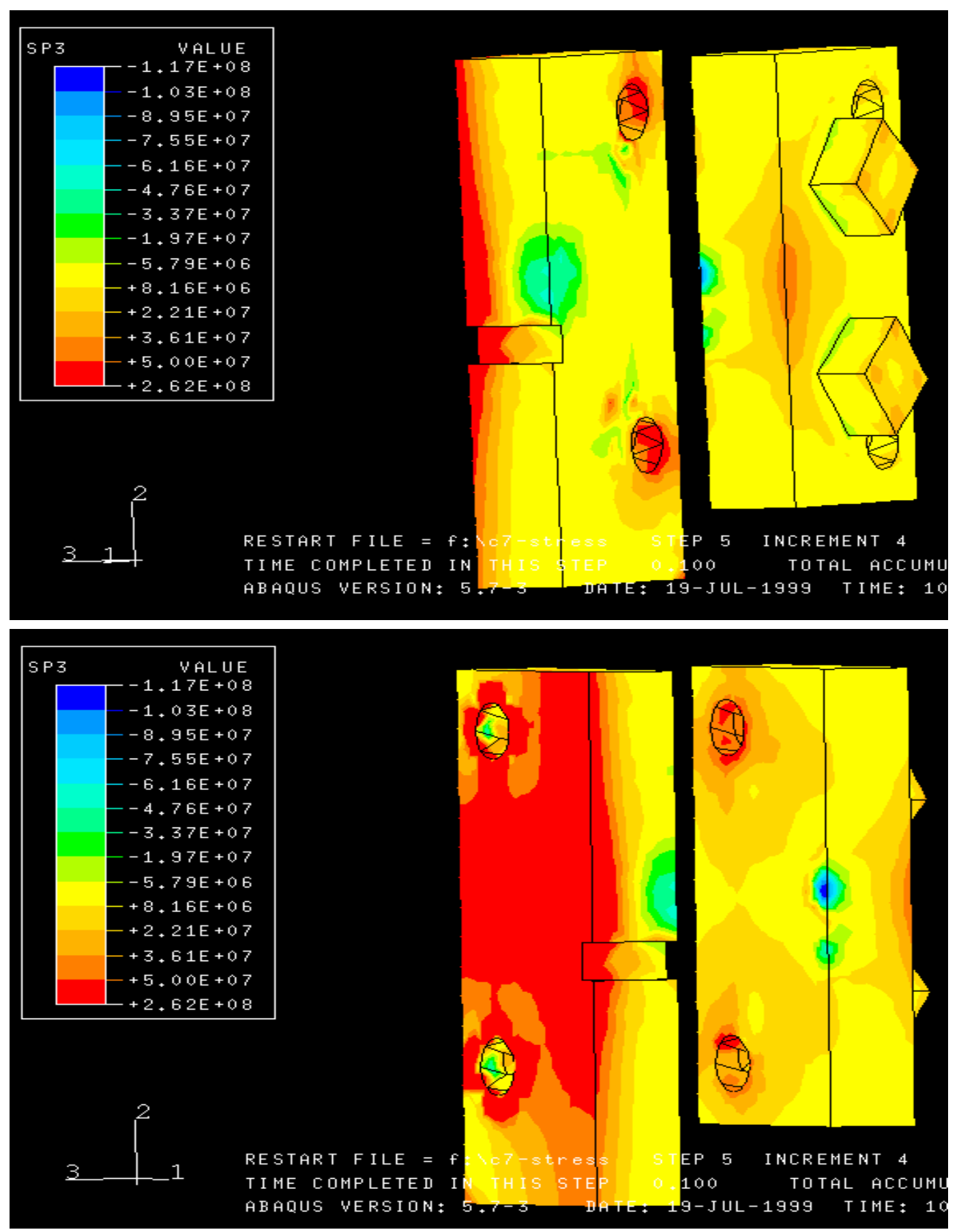

Figure4.3a, Case 7

Die size: 39" Pl Area Covered: $78 \%$

Die Thickness: 5" Platen Thickness: 9"

Max. Stress: 117Mpa

(Large die) 

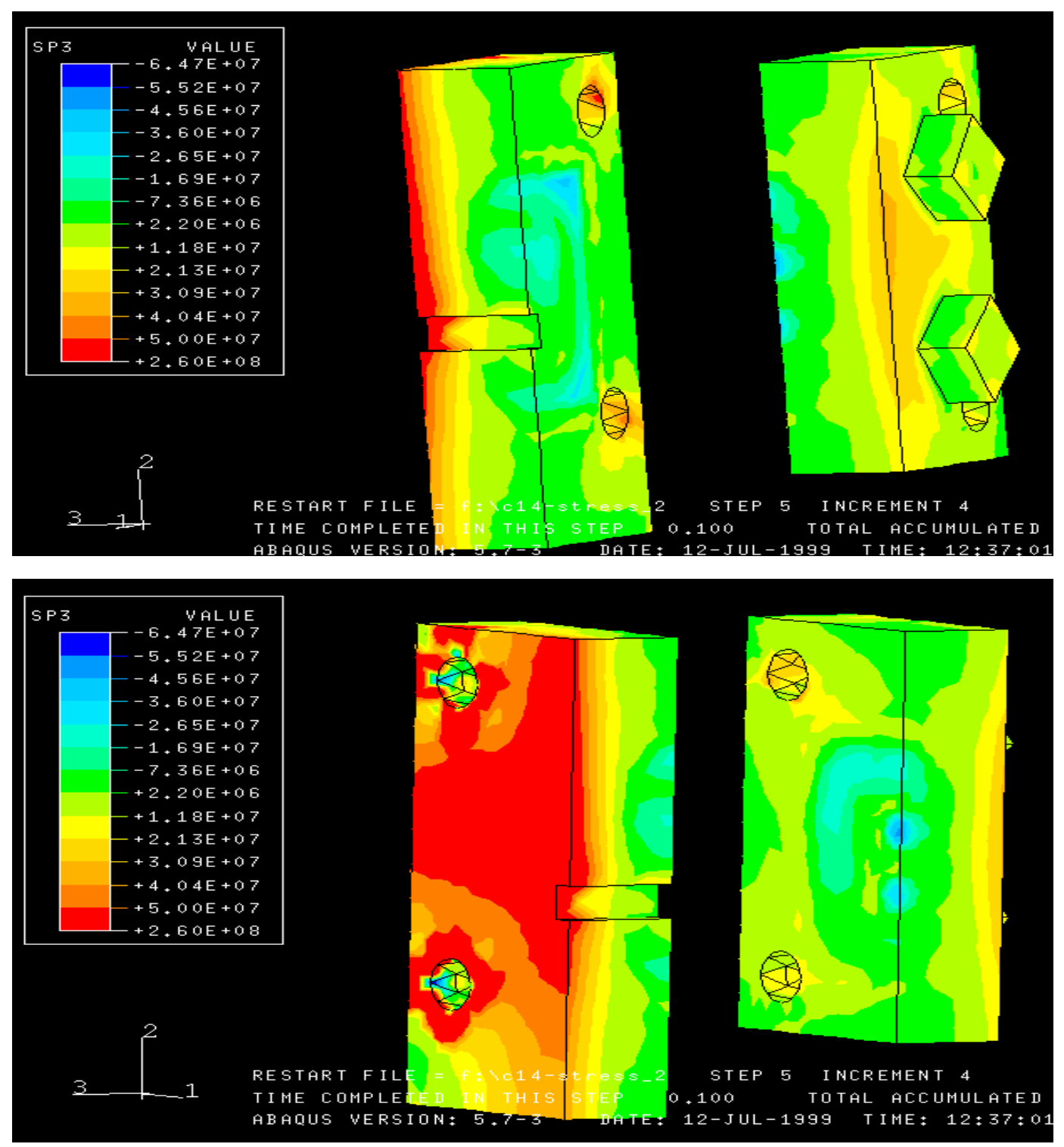

Figure 4.3 b, Case 14

Die size: $31.5 "$

P1 Area Covered: 50\%

Die Thickness: 5" Platen Thickness: 11.75"

Max. Stress: 65Mpa

(Medium die)

For the medium die case shown in Figure 4.3b, the maximum value of compressive stress is $65 \mathrm{Mpa}$ and again it is located behind the top pillar on the ejector side. The stresses at the corner of the die on the cover side are about 50-55 Mpa and are located at the corners. The tensile stress pattern is similar to the large die case. 

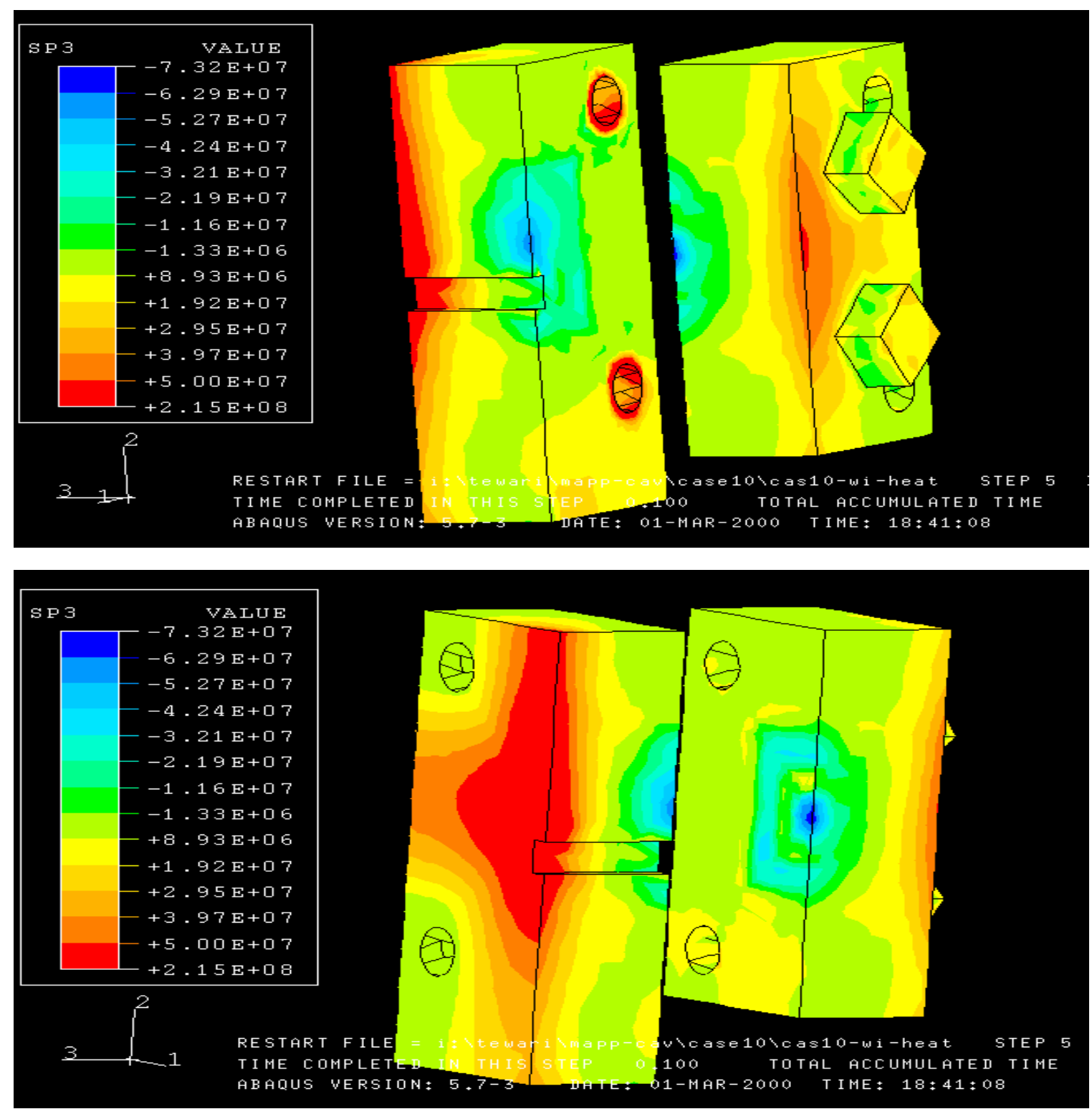

Figure 4.3c, Case 10

Die size: 24” Pl Area Covered: $30 \%$

Die Thickness: 5" Platen Thickness: 14.5"

Max. Stress: 73 Mpa

(Small die)

For the small die, the maximum compressive stresses of $73 \mathrm{Mpa}$ are still behind the pillar on the ejector side. The stresses behind the cavity on the cover side are about $55-60$ Mpa and the corners are a bit less. 


\subsection{Analysis and Discussion}

The largest compressive stress was about 117Mpa for the large die. For this case and all of the others considered, the maximum compressive stresses for always occur on the ejector side behind one of the pillars. The stress is higher for the large die in large part due to the fact that the die is also thin and the platens are also thin. The thin die means that the load is passed through to the pillars and is not distributed as well as in some other cases. As we saw with the response surfaces, it is not so much the fact that the die is large, but the combination of factors (interactions) that determines the result.

Stresses on the cover side are similar for all of the cases considered no matter what the die size. The stresses on the ejector side vary primarily due to geometric differences in the size and location of pillar supports relative to the cavity, differences that were not controlled in the design of the computational experiment.

The fact that the cover side stresses are very similar in all cases, although the patterns vary slightly, confirms the statement made early with respect to the contact pressure pattern. Increasing the die footprint does not distribute the load and decrease the local pressure. The pressures, and hence the stresses, tend to be very similar in all of the cases.

The yield stress for 4140 steel is about 500-600Mpa in compression. Out of the three cases studied here, we observe that the magnitude of maximum compressive stresses present in the case of a large die is the highest with a magnitude of $117 \mathrm{Mpa}$, where as they are $73 \mathrm{Mpa}$ and $65 \mathrm{Mpa}$ for a small and medium die respectively. Accounting for the effects of dynamic loads, which haven't been considered in our model, if compressive stresses are assumed to be about 4-5 times the magnitude of what has been predicted, the larger die is more likely to plastically deform the platen rather than the small die. It must be noted that these calculations are approximate at best since plasticity has not been considered in the stress calculations.

A graph shown in Figure 4.4 plots the maximum compressive stresses for various cases against the respective die sizes. From the plot it can be observed that the average compressive stress for die size 24 " (30\% platen area covered) is less than that of both the medium and large dies. The key point is that the stresses in the platen are not determined by the die size alone but by interactions with the other factors.

A response surface analysis of the available maximum compressive stress data (cases $1-23$ only) was performed. The coefficients of the edited model are displayed in table 4.1. For the most part, the results are intuitive. As might be expected, maximum stress goes down as the die thickness increases. This is the largest effect. Maximum stress also goes down as the platen thickness increases. Counter intuitively, the maximum stress goes up as the die size increases. However there are interaction terms between die size and die thickness, and die size and platen thickness that make it more difficult to interpret the net result. The unexpected part of the result is that there is no dependency on location in the edited model at all. The optimum conditions for stress based on this response surface are a middle sized, fixed die with a thick platen. Essentially, stresses are improved with more material to distribute the load. The nominal or middle size may be a result of the pillar effects discussed earlier and might change is the ejector side is designed more carefully. 
The bottom line is that die size is not the controlling factor in platen coining. The thickness of the die and the thickness of the platen play significant roles in the stress magnitude.

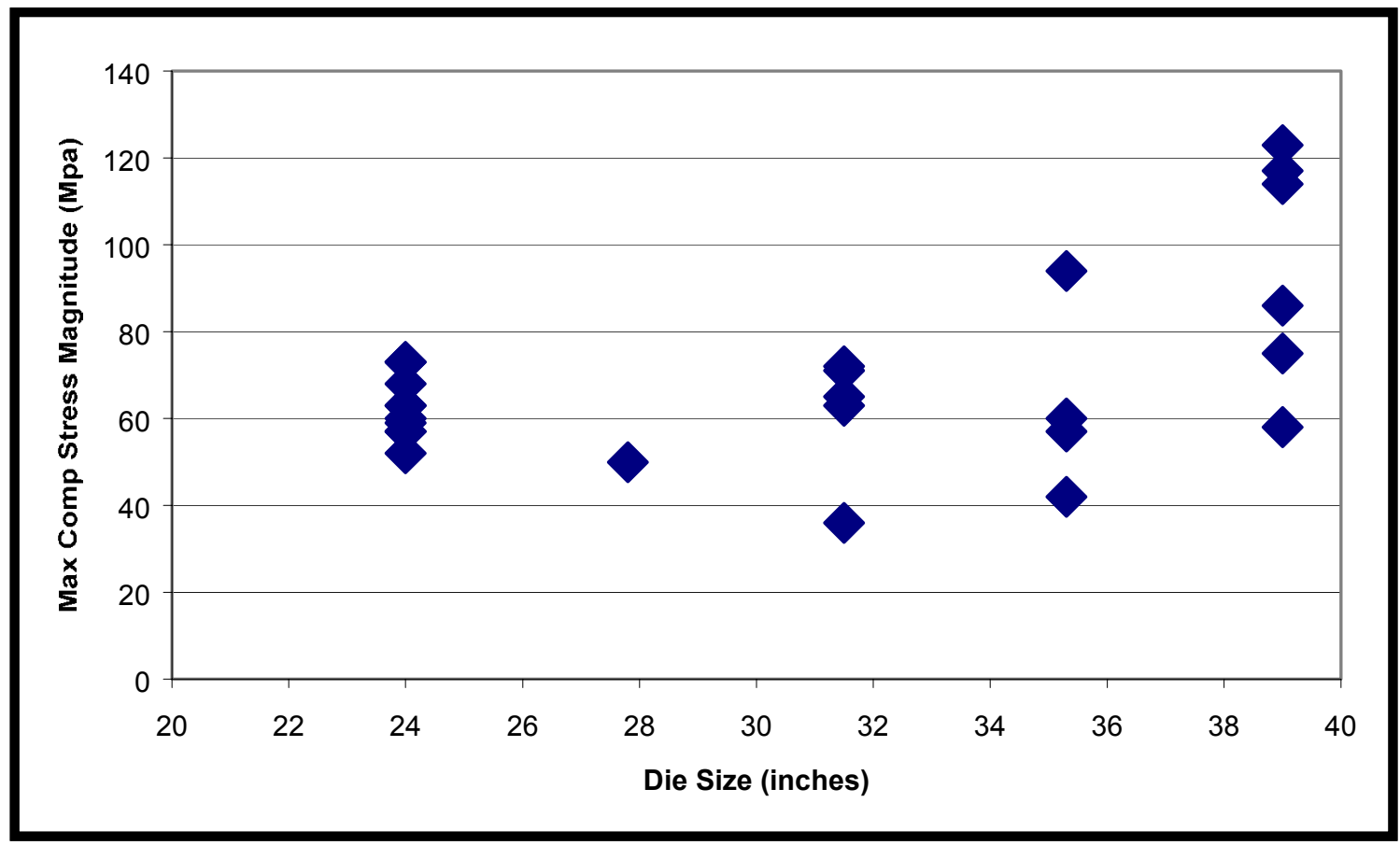

Figure 4.2: Maximum compressive stress versus die size

\begin{tabular}{|l|l|l|l|l|}
\hline Coefficients: & Value & Std.Error & $\mathbf{t}$ & $\mathbf{p}$ \\
\hline (Intercept) & 57.1734 & 3.5764 & 15.9862 & 0.0000 \\
\hline $\mathrm{A}$ & 13.6048 & 2.1824 & 6.2338 & 0.0000 \\
\hline$B$ & -15.0691 & 2.0093 & -7.4998 & 0.0000 \\
\hline $\mathrm{I}$ & -5.2887 & 2.0945 & -2.5250 & 0.0233 \\
\hline $\mathrm{I}\left(\mathrm{A}^{\wedge} 2\right)$ & 7.6676 & 4.0324 & 1.9015 & 0.0766 \\
\hline $\mathrm{I}\left(\mathrm{D}^{\wedge} 2\right)$ & 12.8022 & 4.0409 & 3.1682 & 0.0064 \\
\hline $\mathrm{A}: \mathrm{B}$ & -7.1200 & 2.4454 & -2.9116 & 0.0107 \\
\hline $\mathrm{A}: \mathrm{C}$ & -5.4895 & 2.3953 & -2.2918 & 0.0368 \\
\hline
\end{tabular}

Residual standard error: 7.723 on 15 degrees of freedom. $\mathrm{R}^{2}: 0.9213$

Figure 4.1 Edited response surface for Max Compressive Stress (coded units) 



\section{EFFECTS OF BACKPLATE AND PROUD INSERTS ON SEPARATION}

\subsection{Introduction}

Die casting dies are designed to maintain dimensional integrity of the cavity during the casting cycle. It is common practice to compensate at the fabrication stage for thermal growth of the cavity during operation. Structural features are added in the die in order to minimize parting plane separations. One such feature is proud inserts, intended to guarantee a seal-off area around the periphery of the cavity. Proud insert might be helpful in offsetting the effects of pressure that pushes the inserts into the die pocket.

The results discussed so far suggest that parting plane separation is reduced with uniform support. There is not much that can be done to have a better-supported cover die except having better platens. But, for the ejector die, one practice that is currently used in the die casting industry is to place a backplate behind it. The backplate is intended to distribute the load over the platen surface and prevent damage to the platen and to stiffen the structure.

The two main objectives of this chapter are:

- To study the effects of adding a backplate, on the parting plane separation.

- To study the effect of proud inserts that proud by a small amount, on the order of 2-6 thousandths of an inch

\subsection{Effect of adding the backplate to the ejector die}

The main objective of this analysis was to gauge the effects of adding a backplate behind the ejector die connected to the ejector box and support pillars and compare it with a corresponding case that doesn't have a backplate.

There were a few modeling changes that had to be made for this case. The backplate was modeled as being rigidly attached to the support pillars and the ejector box. In this case, there was only one contact surface pair, the backplate with the ejector platen. The rest of the model was identical to the earlier cases.

Two cases were simulated with the backplate attached behind the die to find whether the backplate helps in reducing maximum parting plane separation. The result of one of the cases that was run is shown here. The case described here is based on case 7, our worst case, with a die size of 39", die thickness 5", platen thickness 9", die ratio 0.4 and the die mounted as high as it can be mounted (limited by the shot hole window). We have compared the case with the backplate with the one without the backplate, with the rest of the variables being identical.

Figure 5.1a shows the deformed structure of the case with the backplate and Figure $5.1 \mathrm{~b}$ shows the deformed structure for a corresponding case without a backplate. Figure 5.1a, shows how the backplate was attached to the ejector die via the ejector box and support pillars. 


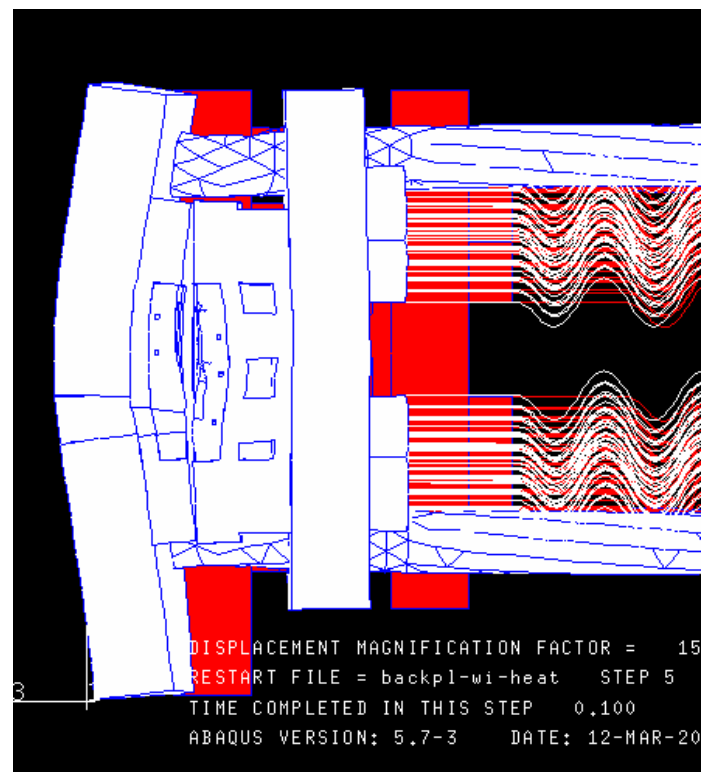

Figure: 5.1a(with backplate)

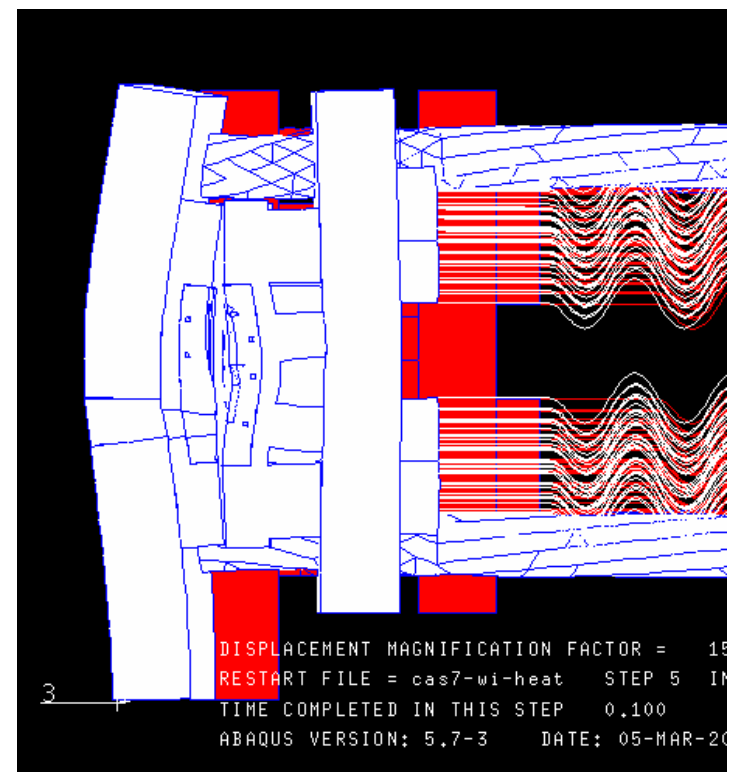

Figure: $5.1 \mathrm{~b}$ (without backplate)

Figure 5. 1 $\mathrm{a}$ and $\mathrm{b}$ show the deformed structures for both the cases

The contact pressure plots for both cases are shown in Figure 5.2. The contact pressure plots are nearly identical with the obvious exception that the plate itself is between the pillars and the platen and spreads the pressure somewhat. This figure indicates that even if you have a backplate behind the ejector die for uniform support, only the portions right behind the ejector box and support pillars carry loads between the die and the platen.

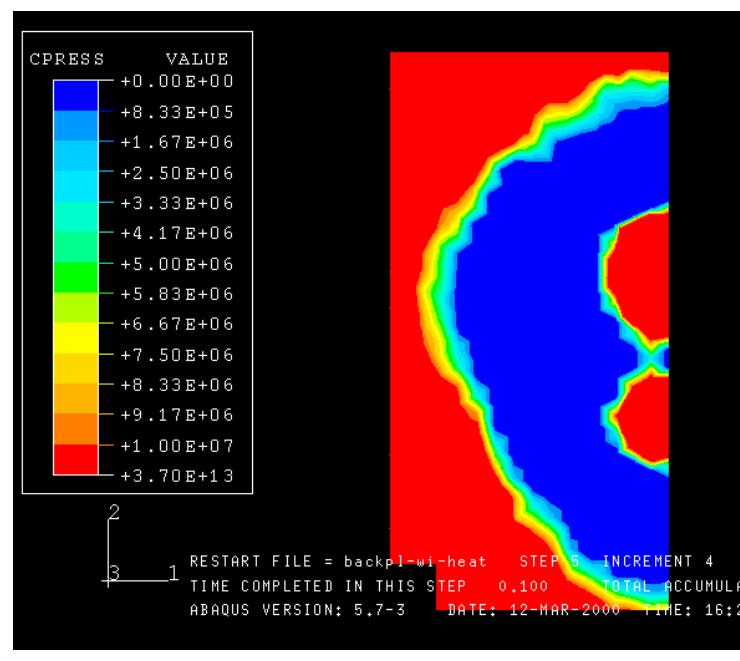

Figure: 5.2a(with backplate)

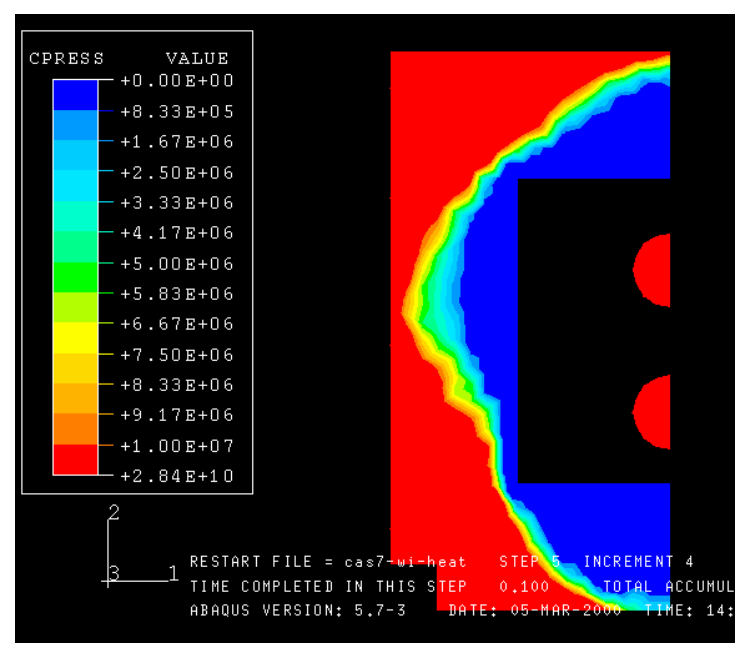

Figure: $5.2 \mathrm{~b}$ (without backplate)

Figure $5.2^{7}$ Contact pressure between the ejector die and ejector platen

\footnotetext{
7 Red represents maximum contact pressure and dark blue means 0 pressure.
} 


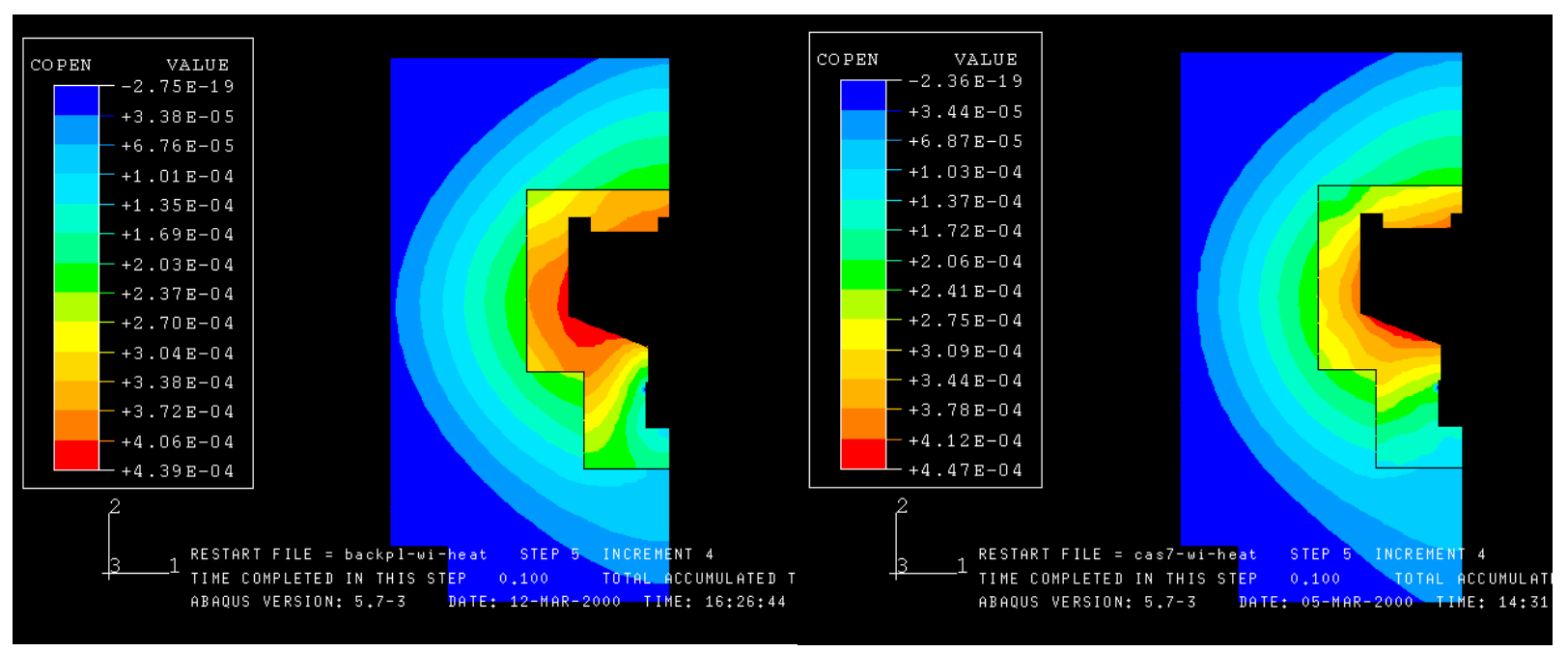

Figure: $5.3 \mathrm{a}$ (with backplate)

Figure: $5.3 b$ (without backplate)

Figure $5.3^{8}$ Parting Plane Separation

The parting plane separation patterns are shown in Figure 5.3. The scales are not the same in the two plots so the magnitudes cannot be directly compared. The magnitudes, however are summarized in table 5.1. There is very little difference in the magnitudes or the pattern with or without the backplate.

\begin{tabular}{|c|c|c|}
\hline Case & with backplate & w/o backplate \\
\hline 7 & 17.3 & 17.6 \\
\hline 18 & 8.43 & 8.7 \\
\hline
\end{tabular}

Table 5.1: showing the maximum separation for cases with and without the backplate

In summary, the backplate does distribute the load from the pillars to the platen and protect the platen. However, it does not significantly stiffen the structure and therefore does not impact the parting plane separation. Note that the model the plate is rigidly attached to the rails and pillars which means that the model would over estimate stiffness effects. Since we see little effect in the model, we can expect little effect in practice.

\subsection{Proud inserts}

Setting an insert proud, or above the surface of the die shoe, is intended to guarantee a seal-off area around the periphery of the cavity. The objective of this analysis was to gauge the effect of proud inserts on reducing the parting plane separation and the trade offs involved in having the insert proud on the compressive stresses on the platens and in the dies

\footnotetext{
8 Red represents maximum separation and dark blue represents perfect contact.
} 
(in the die pockets). The main concern is that the proud insert will change the load path and as a consequence both stress and separation values would differ from expectations.

Modeling of the proud insert cases was very similar to the modeling for the normal cases with flush inserts. In case of the proud inserts both the inserts were simply made proud by 0.004 ". The other boundary conditions and assumptions remained the same as for other cases.

To determine the effect of proud inserts on the parting plane separation, three cases out of our array were simulated. The cases that were analyzed and compared with flush inserts were case 10 (best case) with die size 24" (30\% platen area covered), die thickness 5", platen thickness 14.5 ", ratio 0.5 and the die located all the way to the top. The second case was case16 with die size 27.8 " (40\% platen area covered), die thickness 8.75 ", platen thickness 13.1 , ratio 0.43 and die mounted slightly above the center of platen. The third case that was analyzed was case 19 with die size 31.5 " (55\% platen area covered), die thickness 10 ", platen thickness 11.8 ", ratio 0.45 and die mounted above the center of platen.

The results of these cases are shown in Figures 5.4 thru 5.22 (for case 10, Figure 5.55.10; for case 16 Figure 5.11-5.16 and for case19, Figure 5.17-5.22).

The values for maximum parting plane separation for the proud insert cases are given in Table 5.2. Proud inserts result in reduction of parting plane separation in all cases.

\begin{tabular}{|c|c|c|c|c|}
\hline & \multicolumn{2}{|c|}{$\begin{array}{c}\text { Max. Parting Plane Sep. for } \\
\text { Inserts }\end{array}$} & \multicolumn{2}{c|}{$\begin{array}{c}\text { Maximum Parting Plane } \\
\text { Sep. Overall }\end{array}$} \\
\hline Case & Proud & Flush & Proud & Flush \\
\hline 10 & 3.1 & 5.1 & 8.6 & 5.1 \\
\hline 16 & 4.5 & 8.8 & 7.3 & 8.8 \\
\hline 19 & 5.7 & 10.6 & 5.7 & 10.6 \\
\hline
\end{tabular}

Table 5.2 Comparison of maximum parting plane separations for proud and flush insert cases. (units: 0.001”)

The proud insert might cause higher compressive stresses in the die pockets, as the inserts bear most of the loads when the insert is proud rather than the insert and holder blocks in case of flush inserts. This in turn might cause higher compressive stresses in the platens. But, it can be observed from the plots for compressive stresses in the platens and in the die pockets (given at the end of this chapter Figures 5.5 thru 5.22) that the proud inserts do not significantly affect the compressive stresses although the patterns are affected to a small degree. 


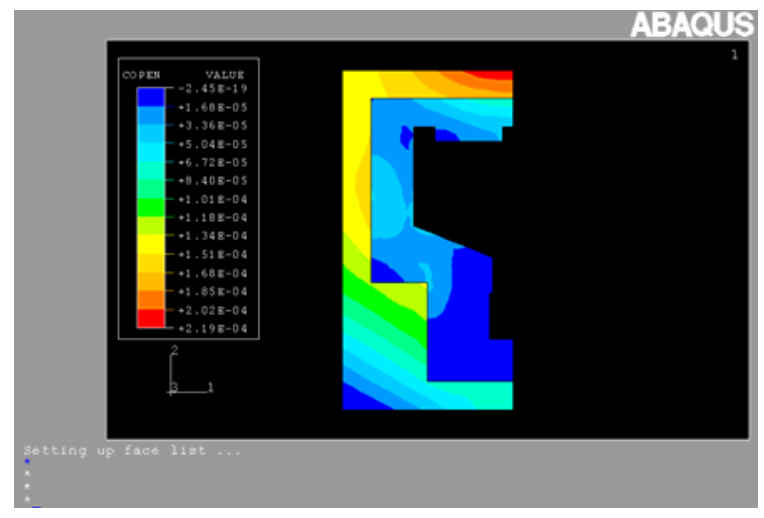

Figure 5.5a (proud insert)

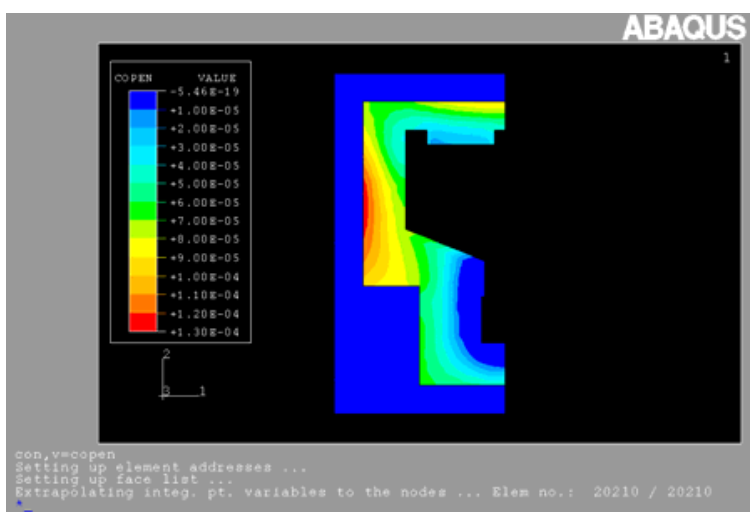

Figure 5.5b (Flush insert)

Figure 5.5 parting plane separation

case 10. Die size24", die thickness 5", platen thickness 14.5", ratio 0.5 and die mounted all the way to the top

Note that the die shoe is in contact only at the lower left corner for the proud insert case. This means that the die shoe is not carrying load from direct contact as it does in the flush insert case. One consequence is some bending of the shoe as indicated by the large separation (red region) at the top of the proud insert case. The parting surface of the insert is ironed nearly flat with little indication of the crowning that appears in the flush case. 


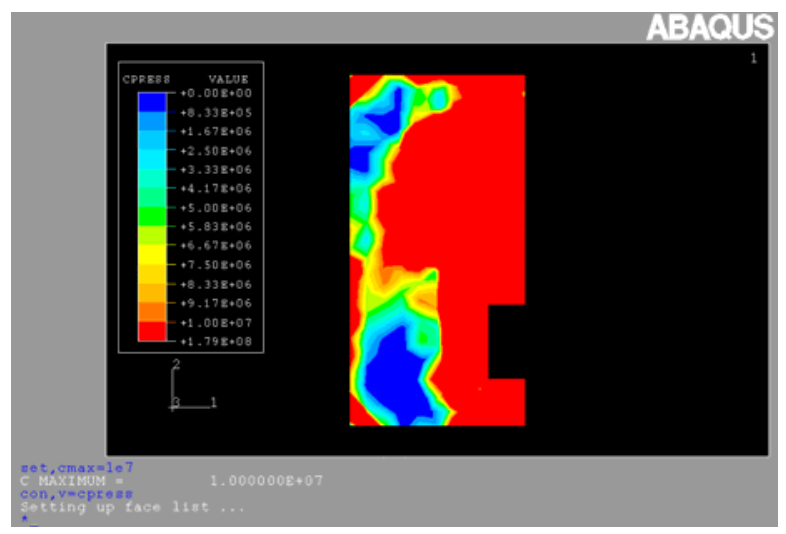

Figure 5.6a (proud insert)

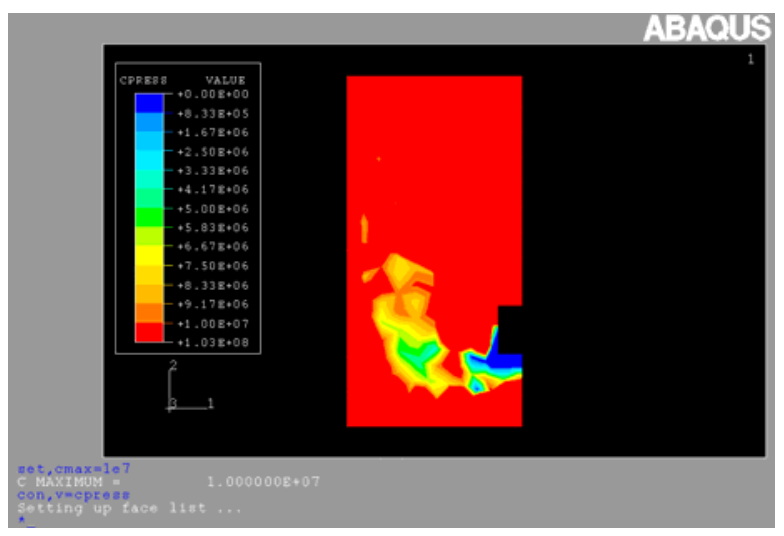

Figure 5.6b (Flush insert)

Figure 5.6 contact pressure between the cover die and the cover platen case 10. Die size24", die thickness 5", platen thickness 14.5", ratio 0.5 and die mounted high

The contact pressure is concentrated a little more directly behind the platen in the proud case. This is a consequence of the load path. However there is relatively uniform support behind the cavity.

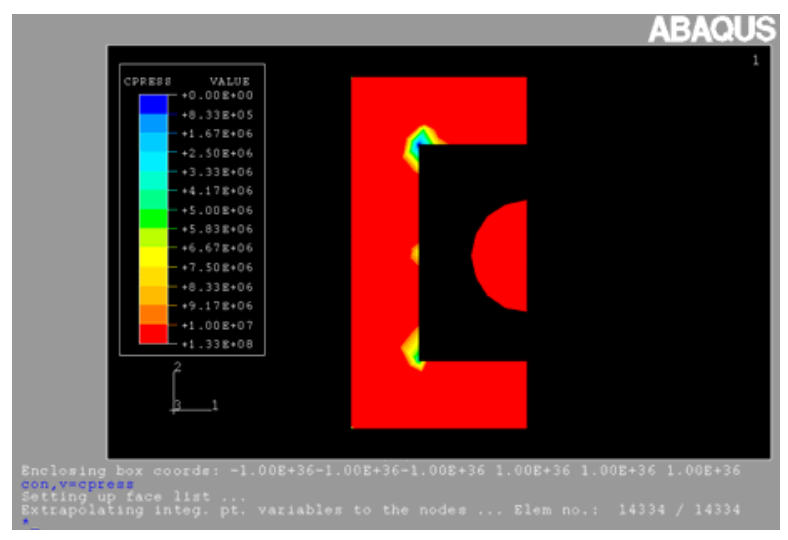

Figure 5.7a (proud insert)

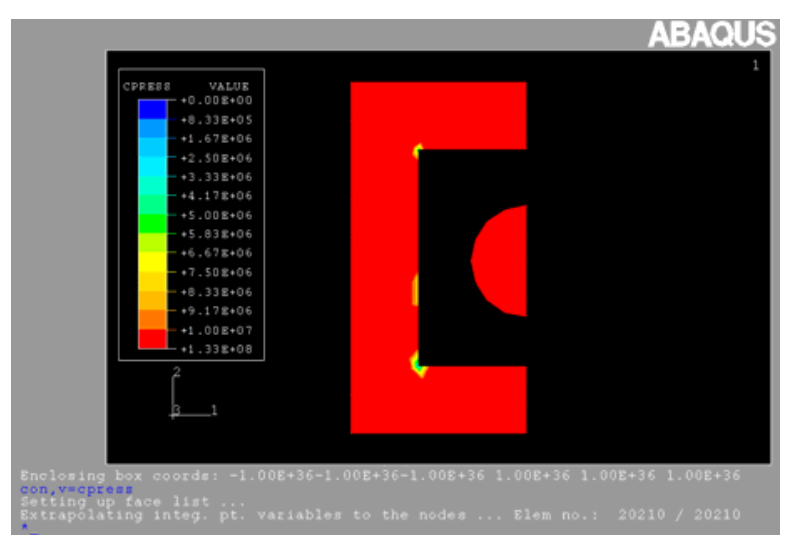

Figure 5.7b (Flush insert)

Figure 5.7 contact pressure between the ejector die and the ejector platen case 10. Die size24", die thickness 5", platen thickness 14.5 ", ratio 0.5 and die mounted high 


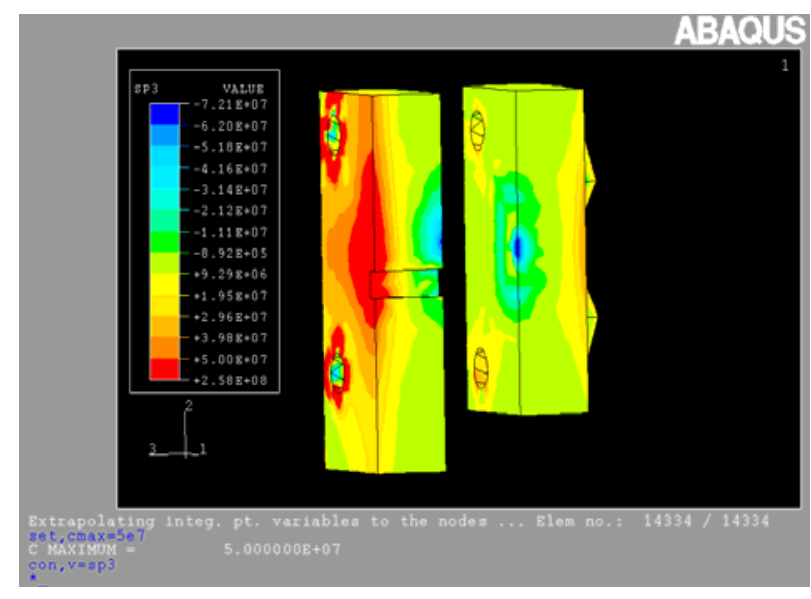

Figure 5.8a (proud insert)

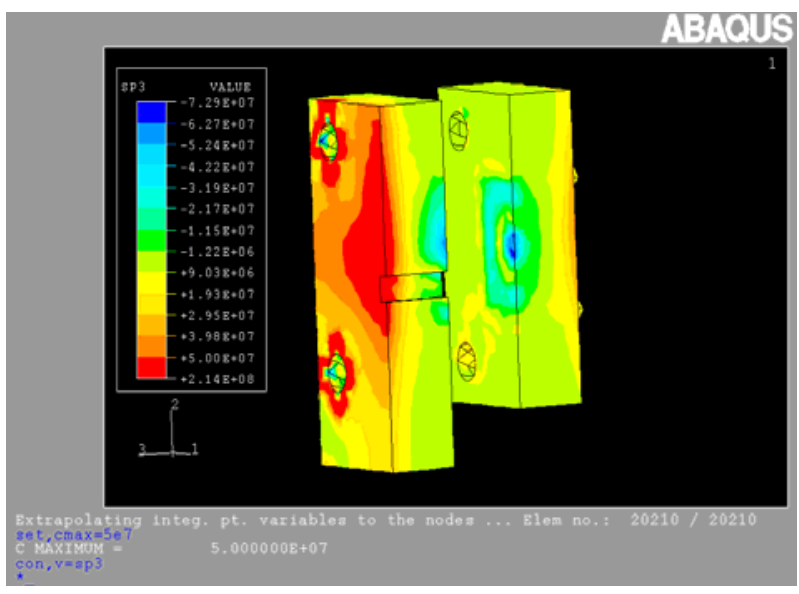

Figure $5.8 \mathrm{~b}$ (Flush insert)

Figure 5.8 compressive stresses in the platens

case 10. Die size24", die thickness 5", platen thickness 14.5 ", ratio 0.5 and die mounted all the way to the top

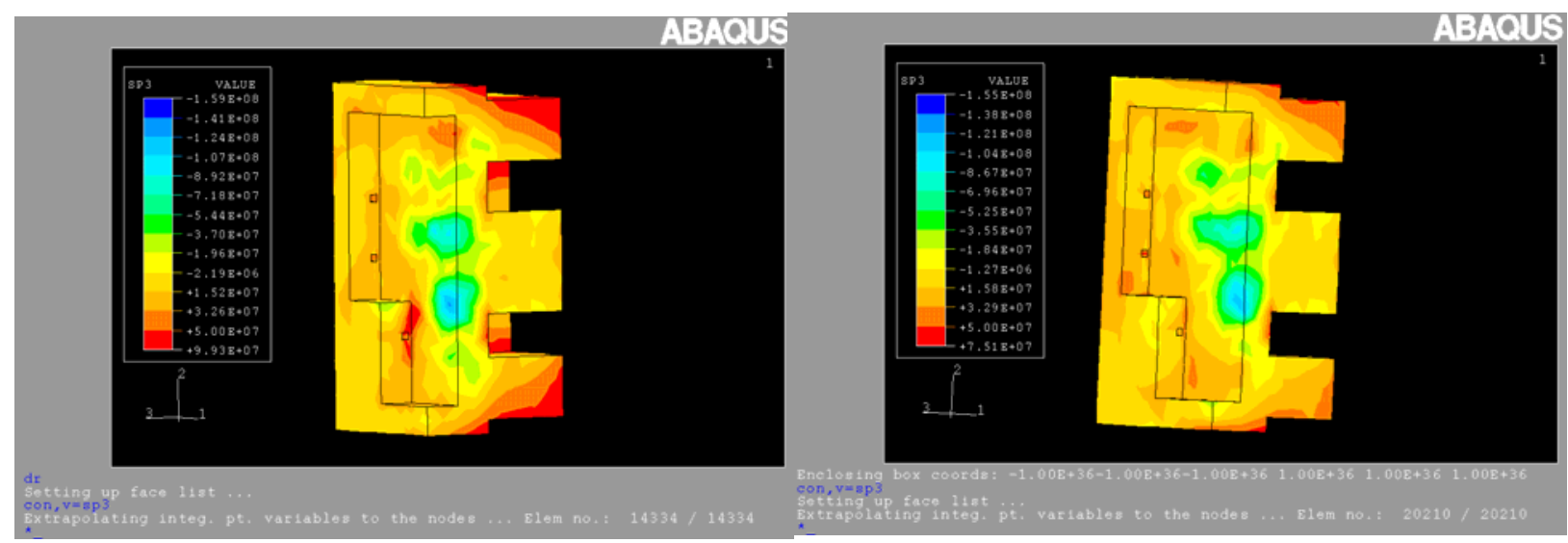

Figure 5.9a (proud insert)

Figure 5.9b (Flush insert)

Figure 5.9 compressive stress plot in the ejector die pocket

case 10. Die size24", die thickness 5", platen thickness 14.5", ratio 0.5 and die mounted all the way to the top

The stress patterns in the platen are not effected very much, but there are some increases in the ejector shoe because of the changes in the load path. Some of the difference could be modeling artifacts since die clamping is modeled via tied nodes in which the corners of the shoe are tied to the platen. This would increases stresses in general and more in the proud insert case since the there is tendency to pull the die in from the concentrated load as shown in the figure. 


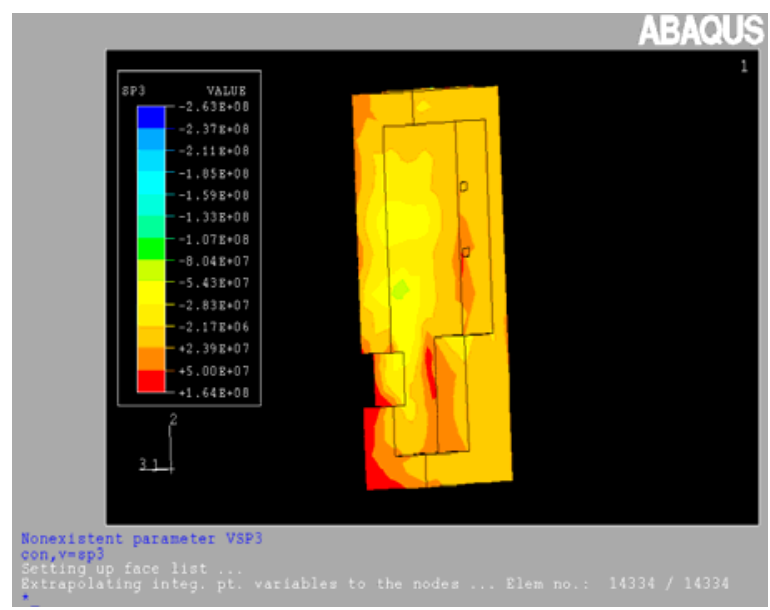

Figure 5.10a (proud insert)

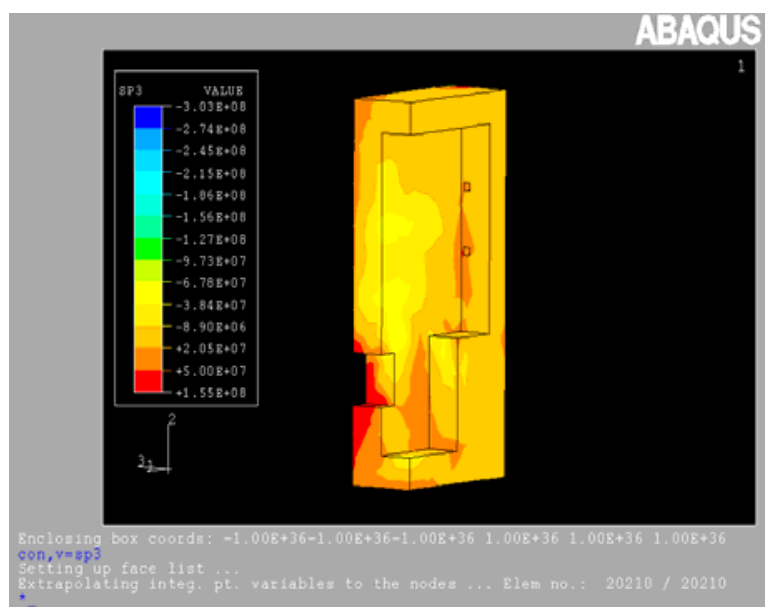

Figure 5.10b (Flush insert)

Figure 5.10 compressive stress in the cover die pocket case 10. Die size24", die thickness 5", platen thickness 14.5", ratio 0.5 and die mounted all the way to the top

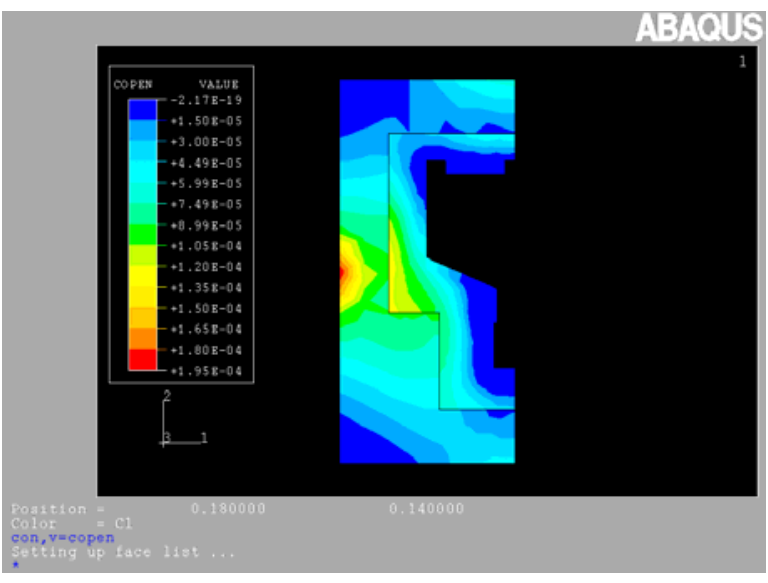

Figure 5.11a (proud insert)

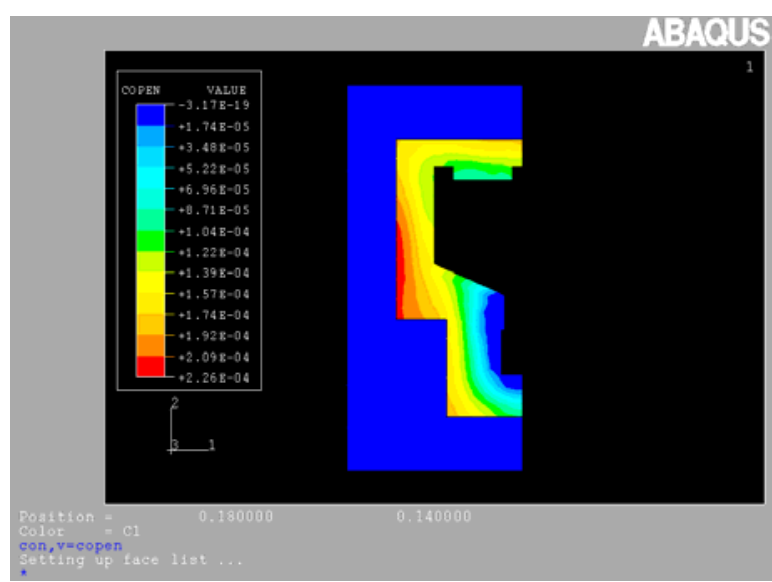

Figure 5.11b (Flush insert)

Figure 5.11 parting plane separation

case 16. Die size 27.8", die thickness 8.75 ", platen thickness 13.1 ”, ratio 0.43 and die mounted slightly above center

Compared to case 10, the bending of the shoe with proud inserts follows a slightly different pattern and the insert does not remain in full contact. 


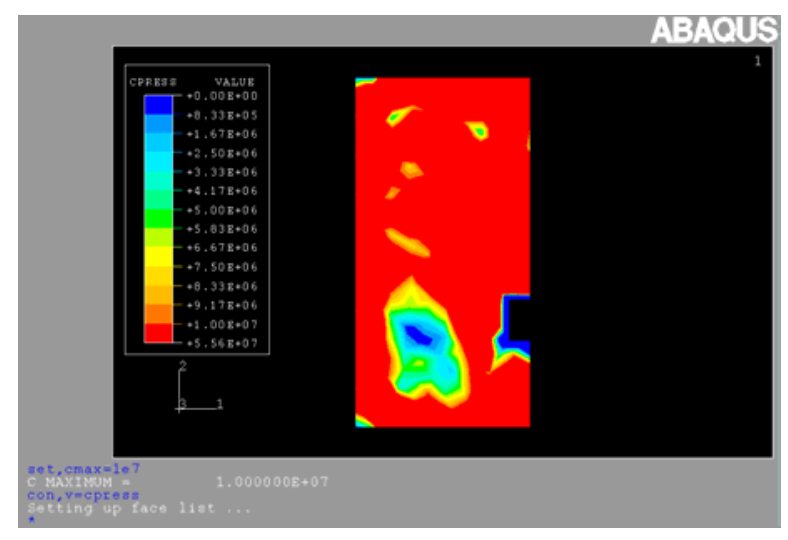

Figure 5.12a (proud insert)

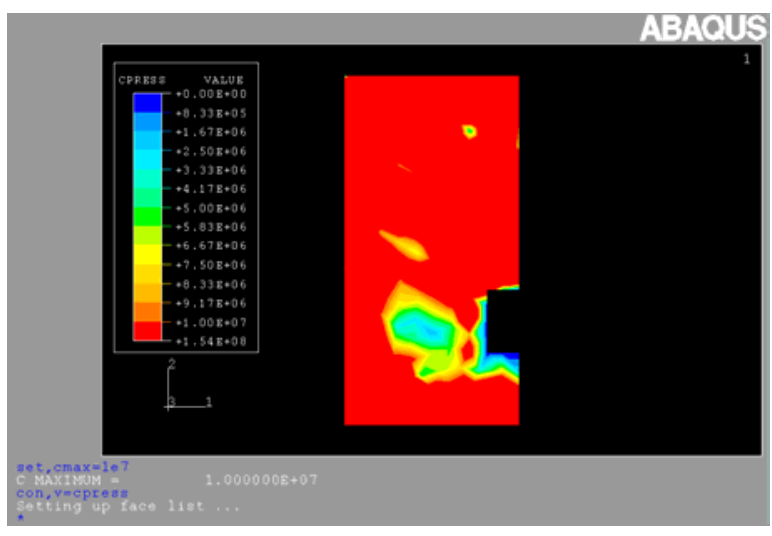

Figure 5.12b (Flush insert)

Figure 5.12 contact pressure between the cover die and the cover platen case 16. Die size 27.8”, die thickness 8.75 ", platen thickness 13.1", ratio 0.43 and die mounted slightly above center
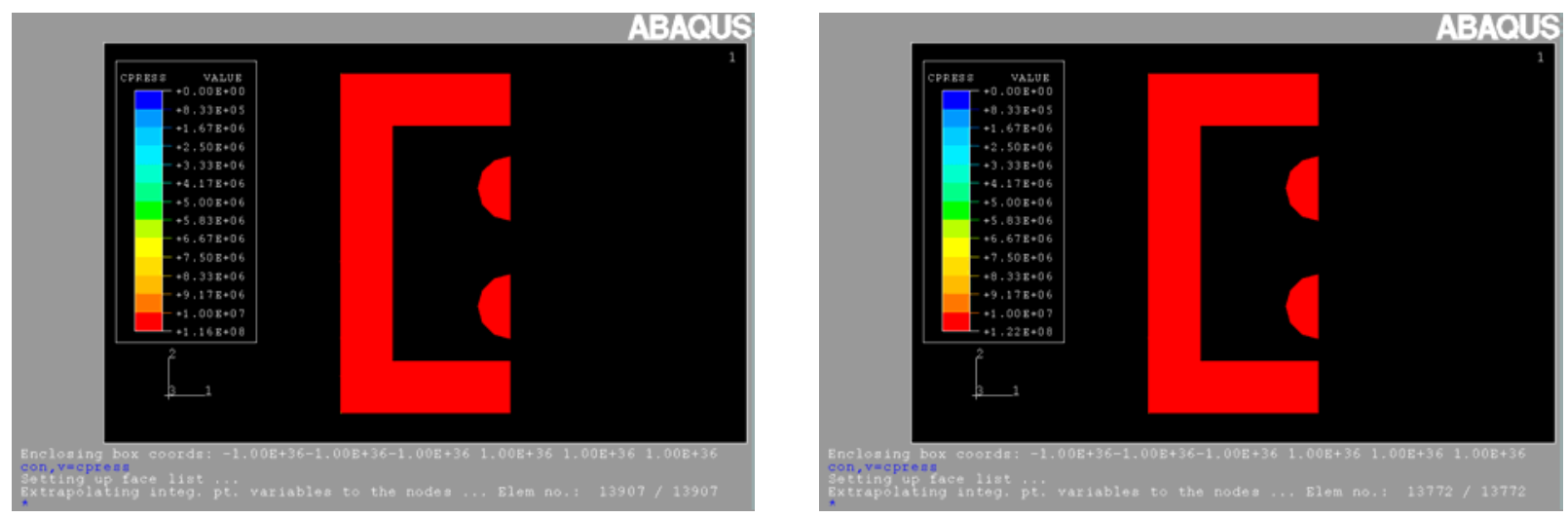

Figure 5.13a (proud insert)

Figure 5.13 contact pressure between the ejector die and the ejector platen case 16. Die size 27.8", die thickness 8.75", platen thickness 13.1", ratio 0.43 and die mounted slightly above center 


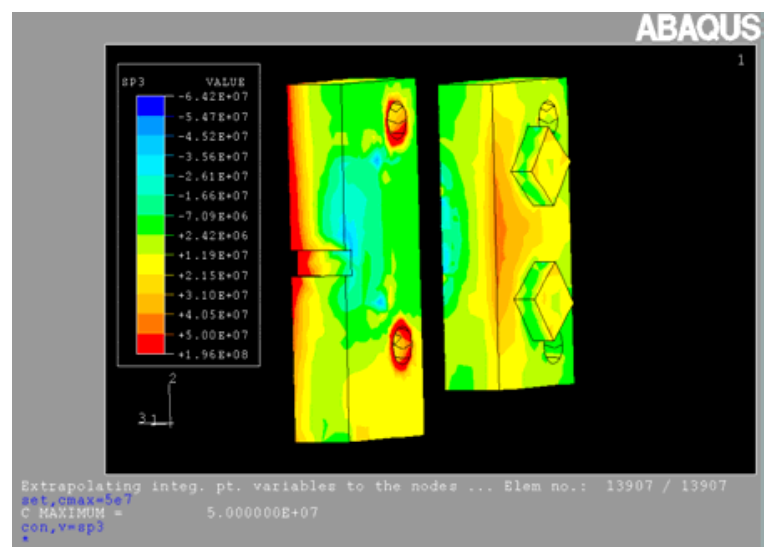

Figure 5.14a (proud insert)

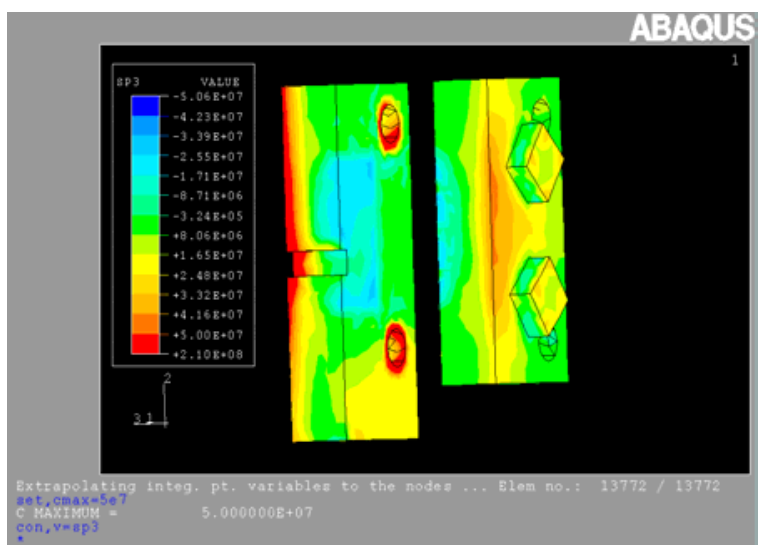

Figure 5.14b (Flush insert)

Figure 5.14 compressive stresses in the platens

case 16. Die size 27.8", die thickness 8.75 ", platen thickness 13.1", ratio 0.43 and die mounted slightly above center

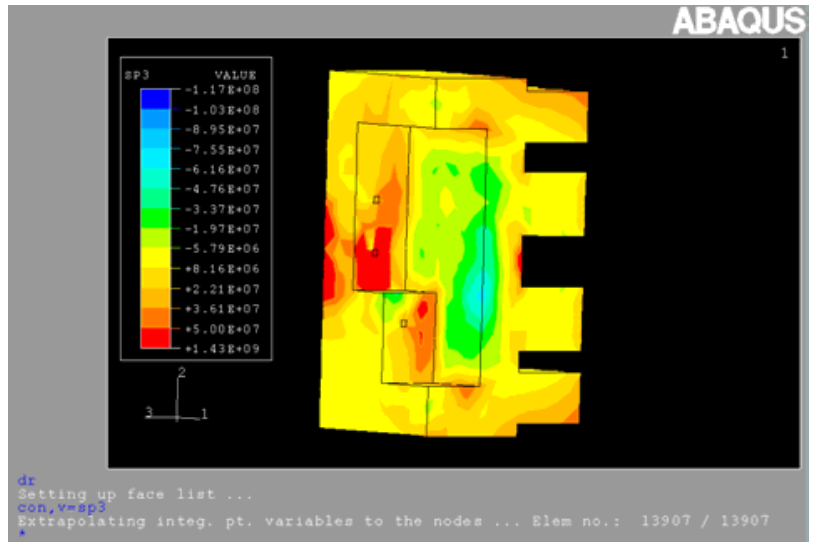

Figure 5.15a (proud insert)

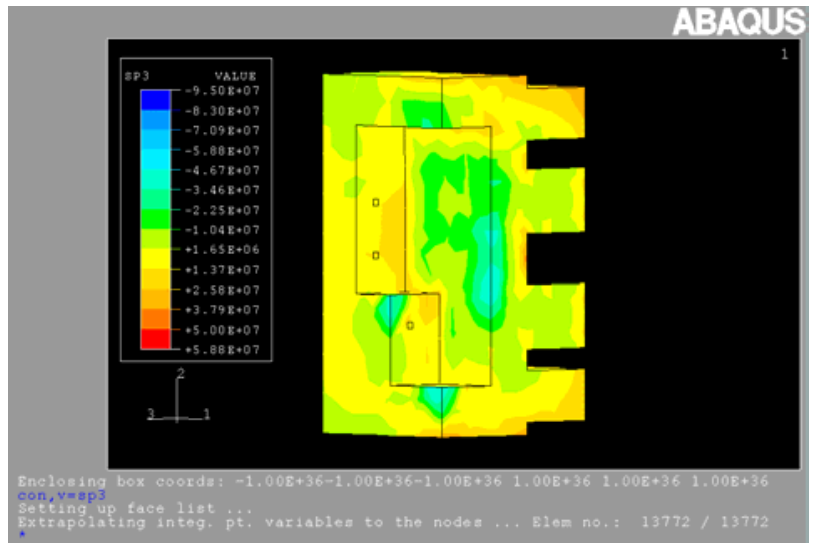

Figure 5.15b (Flush insert)

Figure 5.15 compressive stress in the ejector die pocket

case 16. Die size 27.8", die thickness $8.75^{\prime \prime}$, platen thickness 13.1", ratio 0.43 and die mounted slightly above center 


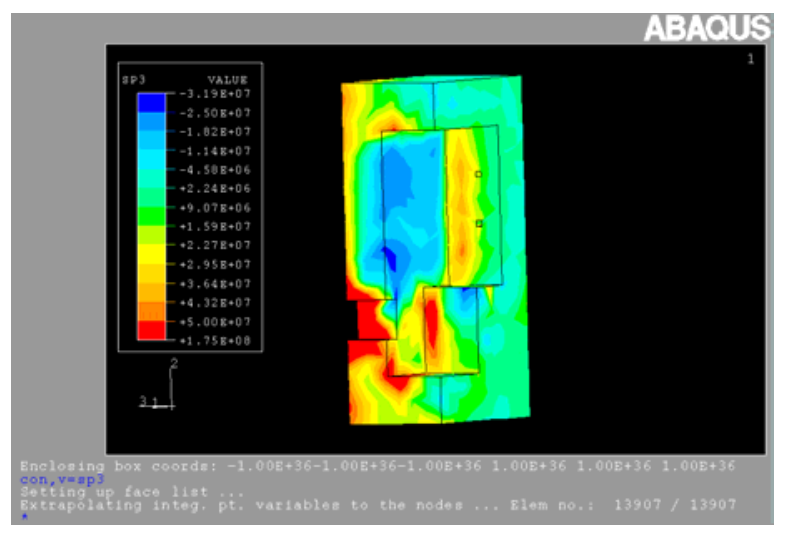

Figure 5.16a (proud insert)

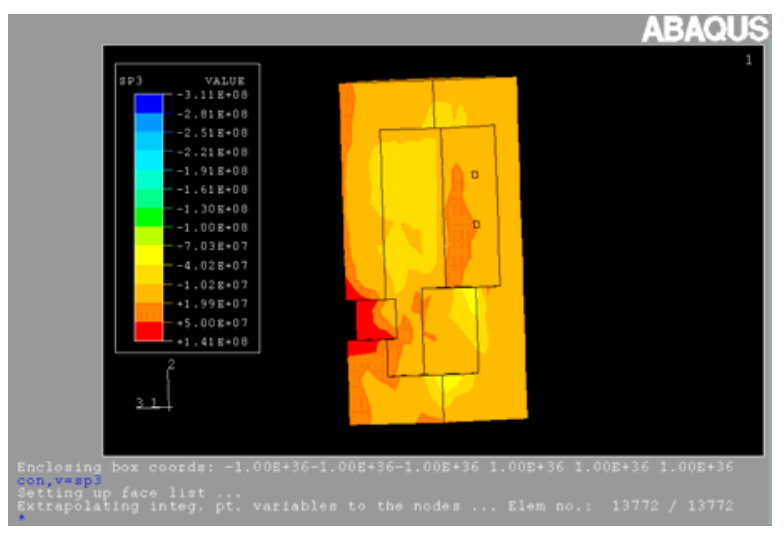

Figure 5.16b (Flush insert)

Figure 5.16 compressive stress in the cover die pocket

case 16. Die size 27.8", die thickness 8.75", platen thickness 13.1", ratio 0.43 and die mounted slightly above center

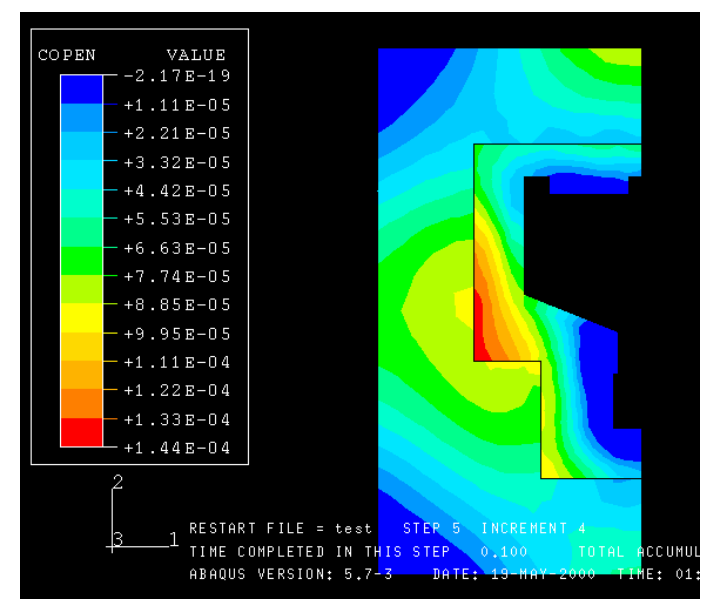

Figure 5.17a (proud insert)

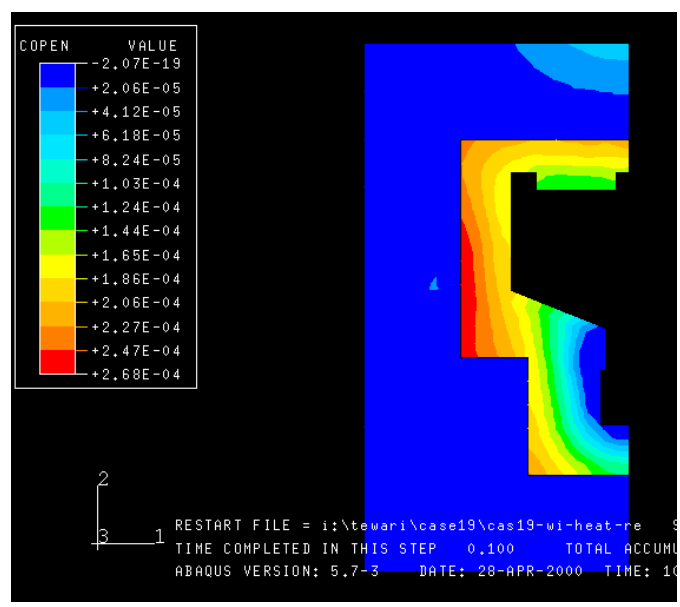

Figure 5.17b (Flush insert)

Figure 5.17 parting plane separation

case 19. Die size31.5", die thickness 10", platen thickness 11.8 ", ratio 0.45 and die mounted above the center of the platen 


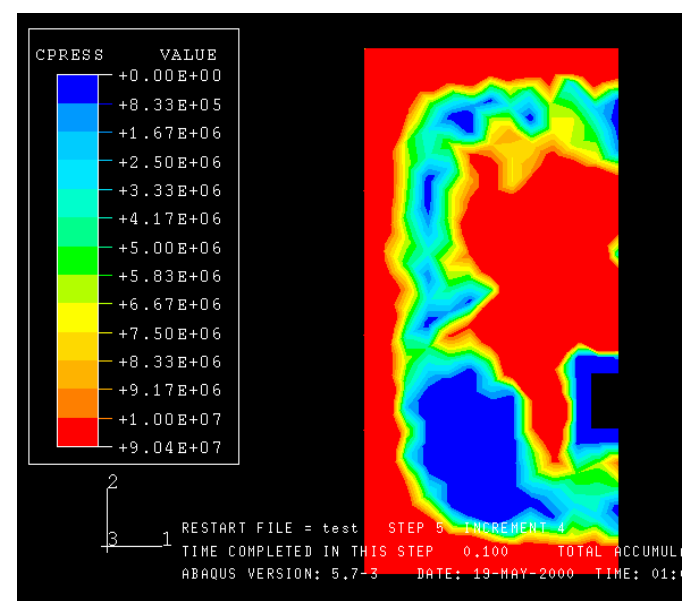

Figure 5.18a (proud insert)

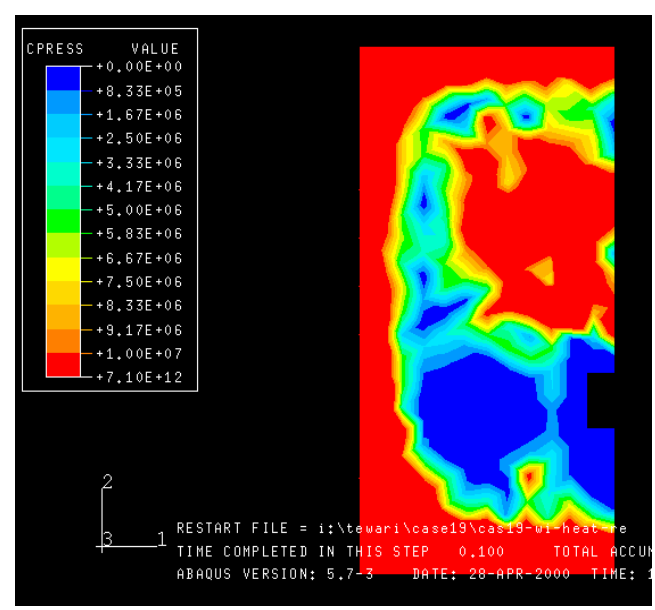

Figure 5.18b (Flush insert)

Figure 5.18 contact pressure plots between the cover die and the cover platen case 19. Die size 31.5", die thickness 10 ", platen thickness 11.8 ", ratio 0.45 and die mo

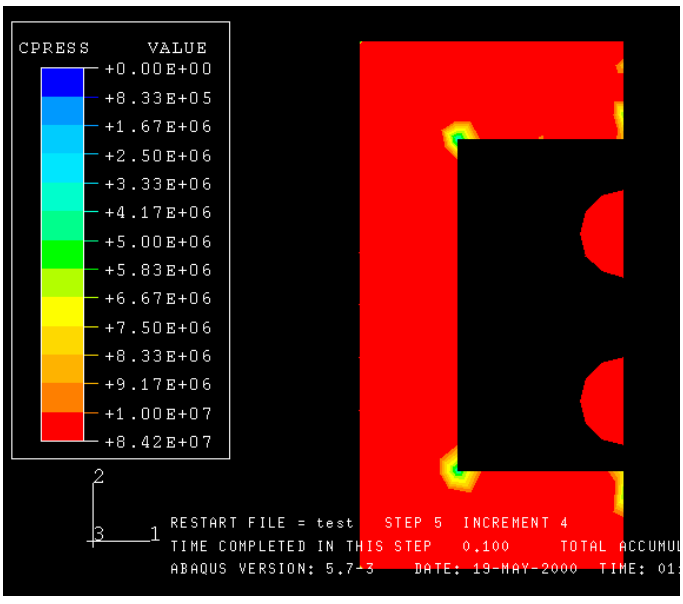

Figure 5.19a (proud insert)

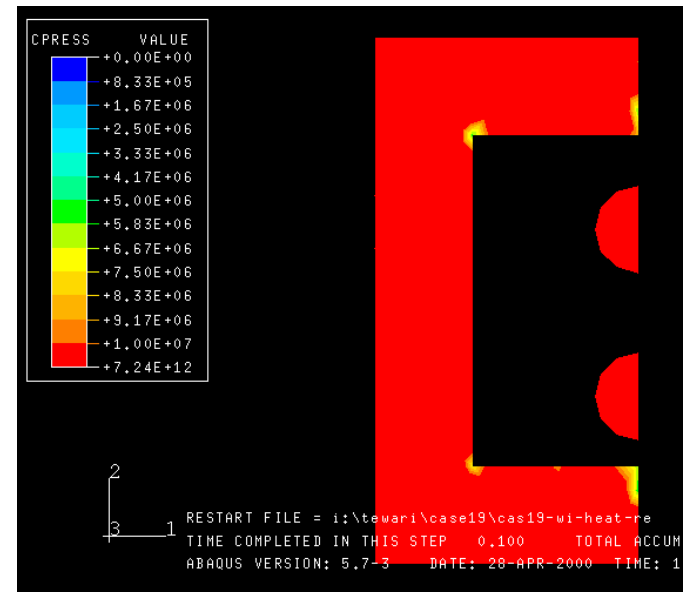

Figure $5.19 \mathrm{~b}$ (Flush insert)

Figure 5.19 contact pressure between the ejector die and the ejector platen

case 19. Die size 31.5", die thickness 10", platen thickness 11.8 ", ratio 0.45 and die mounted high. 


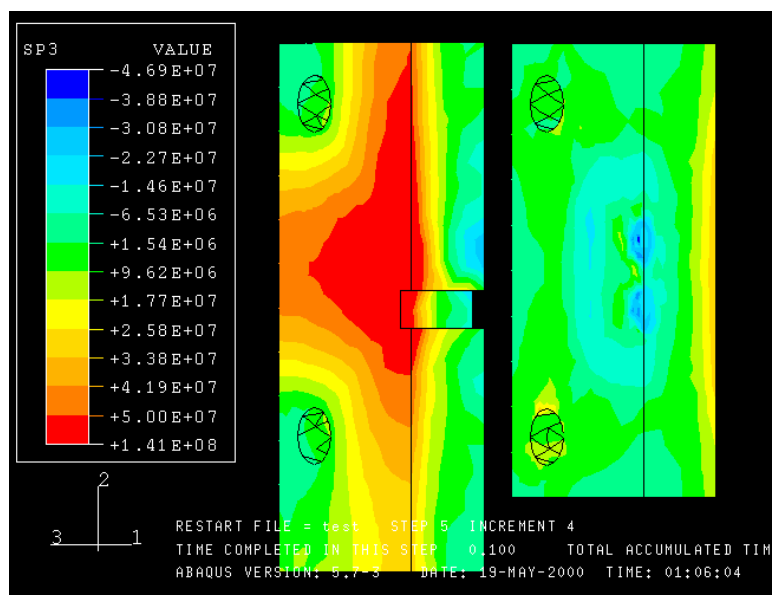

Figure 5.20a (proud insert)

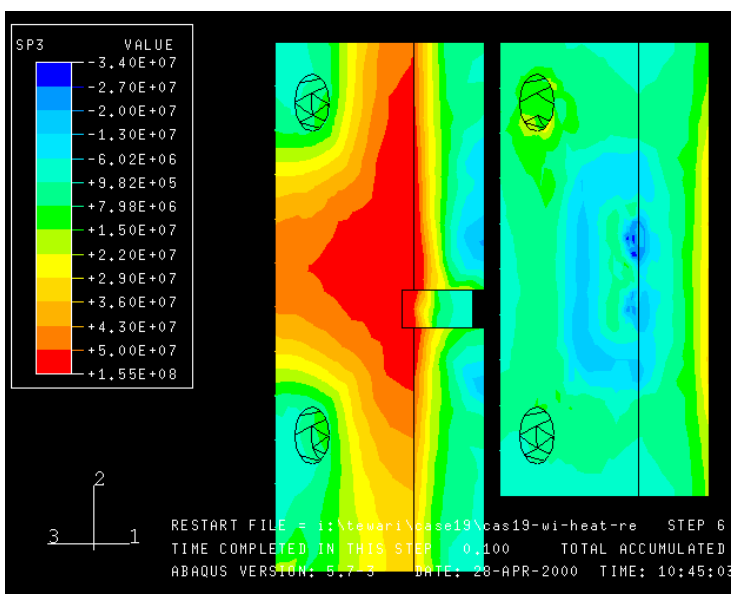

Figure 5.20b (Flush insert)

Figure 5.20 compressive stresses in the platens

case 19. Die size31.5", die thickness 10", platen thickness 11.8 ", ratio 0.45 and die mounted above the center of the platen

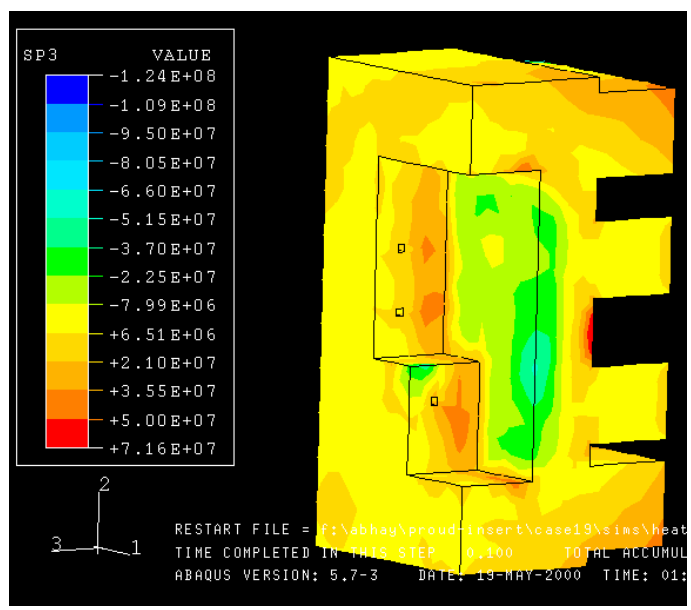

Figure 5.21a (proud insert)

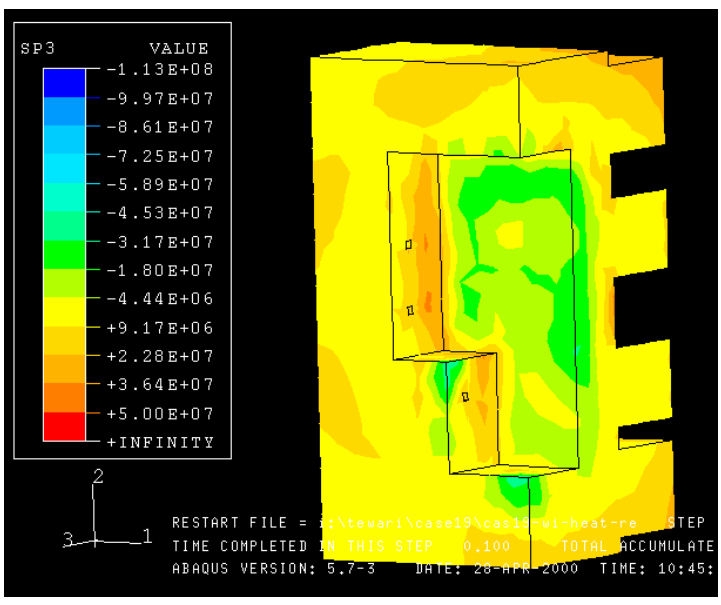

Figure $5.21 \mathrm{~b}$ (Flush insert)

Figure 5.21 compressive stress in the ejector die pocket

case 19. Die size31.5", die thickness 10", platen thickness 11.8 ", ratio 0.45 and die mounted above the center of the platen 


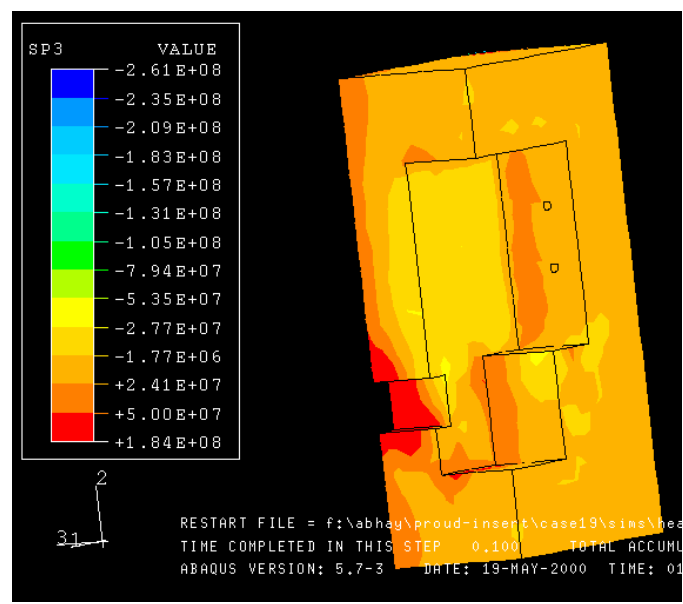

Figure 5.22a (proud insert)

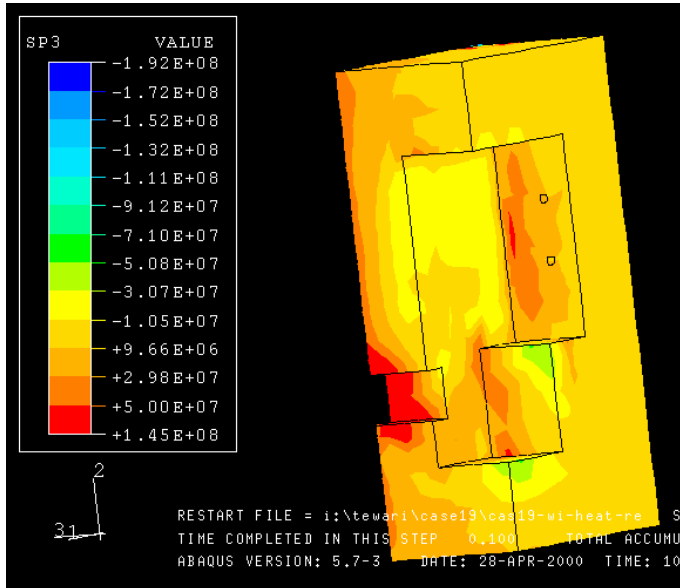

Figure 5.22b (Flush insert)

Figure 5.22 compressive stress in the cover die pocket

case 19. Die size31.5", die thickness 10", platen thickness 11.8", ratio 0.45 and die mounted above the center of the platen

Since the point of maximum parting plane separation could be away from the cavity edge, a set of points on the periphery was selected to evaluate more directly the chances of flash occurring. Several nodes at the edges of the cavity were chosen and their separations for both proud and flush insert cases were compared. The Figure 5.23 shows the cavity (half model) and the locations of the nodes chosen for the comparison. Table 5.3 shows the location of those nodes with respect to the $(0,0)$ location as shown in figure.5.23 and separation data for the flush and proud cases. Figure 5.24 shows the comparison of separations at the 9 chosen points for all the three cases (10, 16 and 19). Table 5.4, 5.5 and 5.6 show the comparison for cases 10, 16 and 19 respectively. These tables show the comparison of the separations at the chosen locations.

\begin{tabular}{|c|c|}
\hline Point & Location \\
\hline 1 & $(0,15)$ \\
\hline 2 & $(0.75,15)$ \\
\hline 3 & $(0.75,14)$ \\
\hline 4 & $(5.5,14)$ \\
\hline 5 & $(5.5,15)$ \\
\hline 6 & $(7,15)$ \\
\hline 7 & $(7,8)$ \\
\hline 8 & $(1.4,5.75)$ \\
\hline 9 & $(1.625,0)$ \\
\hline
\end{tabular}

Table 5.3 Location of the chosen points for comparison and results 


\begin{tabular}{|c|c|c|}
\hline Point & Flush (separation, in) & Proud (separation, in) \\
\hline 1 & $1.86 \mathrm{E}-03$ & $1.80 \mathrm{E}-03$ \\
\hline 2 & $1.73 \mathrm{E}-03$ & $1.69 \mathrm{E}-03$ \\
\hline 3 & $1.36 \mathrm{E}-03$ & $1.45 \mathrm{E}-03$ \\
\hline 4 & $8.62 \mathrm{E}-04$ & $5.94 \mathrm{E}-04$ \\
\hline 5 & $1.32 \mathrm{E}-03$ & $8.32 \mathrm{E}-04$ \\
\hline 6 & $1.65 \mathrm{E}-03$ & $7.50 \mathrm{E}-04$ \\
\hline 7 & $2.96 \mathrm{E}-03$ & $1.37 \mathrm{E}-03$ \\
\hline 8 & $9.57 \mathrm{E}-21$ & $8.59 \mathrm{E}-19$ \\
\hline 9 & $2.60 \mathrm{E}-18$ & $0.00 \mathrm{E}+00$ \\
\hline
\end{tabular}

Table 5.4 Comparison of separations for the chosen points for flush and proud insert for case 10

\begin{tabular}{|c|c|c|}
\hline Point & Flush (separation, in) & Proud (separation, in) \\
\hline 1 & $4.92 \mathrm{E}-03$ & $1.07 \mathrm{E}-04$ \\
\hline 2 & $4.83 \mathrm{E}-03$ & $4.74 \mathrm{E}-05$ \\
\hline 3 & $4.00 \mathrm{E}-03$ & $8.90 \mathrm{E}-21$ \\
\hline 4 & $3.86 \mathrm{E}-03$ & $1.97 \mathrm{E}-19$ \\
\hline 5 & $4.47 \mathrm{E}-03$ & $0.00 \mathrm{E}+00$ \\
\hline 6 & $5.00 \mathrm{E}-03$ & $1.10 \mathrm{E}-17$ \\
\hline 7 & $6.17 \mathrm{E}-03$ & $2.22 \mathrm{E}-03$ \\
\hline 8 & $4.08 \mathrm{E}-05$ & $4.71 \mathrm{E}-19$ \\
\hline 9 & $2.56 \mathrm{E}-04$ & $1.72 \mathrm{E}-19$ \\
\hline
\end{tabular}

Table 5.5 Comparison of separations for the chosen points for flush and proud insert for case 16

\begin{tabular}{|c|c|c|}
\hline Point & Flush (separation, in) & Proud (separation, in) \\
\hline 1 & $6.31 \mathrm{E}-03$ & $6.80 \mathrm{E}-04$ \\
\hline 2 & $6.22 \mathrm{E}-03$ & $6.61 \mathrm{E}-04$ \\
\hline 3 & $5.53 \mathrm{E}-03$ & $1.55 \mathrm{E}-04$ \\
\hline 4 & $5.49 \mathrm{E}-03$ & $4.67 \mathrm{E}-18$ \\
\hline 5 & $6.16 \mathrm{E}-03$ & $3.60 \mathrm{E}-04$ \\
\hline 6 & $6.90 \mathrm{E}-03$ & $1.02 \mathrm{E}-03$ \\
\hline 7 & $7.58 \mathrm{E}-03$ & $3.08 \mathrm{E}-03$ \\
\hline 8 & $3.43 \mathrm{E}-04$ & $2.62 \mathrm{E}-18$ \\
\hline 9 & $6.85 \mathrm{E}-04$ & $8.50 \mathrm{E}-18$ \\
\hline
\end{tabular}

Table 5.6 Comparison of separations for the chosen points for flush and proud insert for case 19 


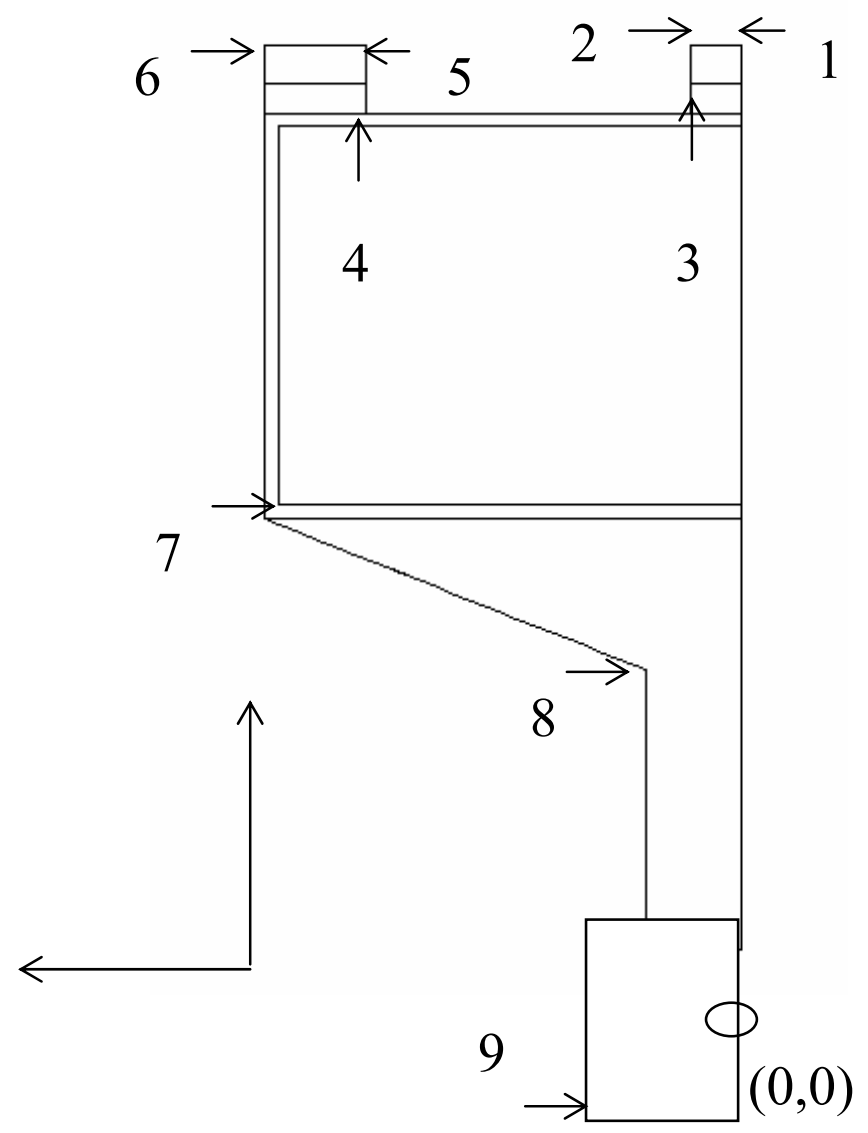

Figure 5.23: Figure showing the location of the points chosen for the comparison of displacements

The proud inserts result in lower parting plane separation as compared to the case of flush inserts. The compressive stresses on the platens and the pockets change by within the range of $0-20 \%$ because of the proud inserts. Even, the contact pressures at the back of the die remain more or less the same. Making the inserts proud helps in reducing the parting plane separation caused by movement of the insert into the die pockets due to pressure. 


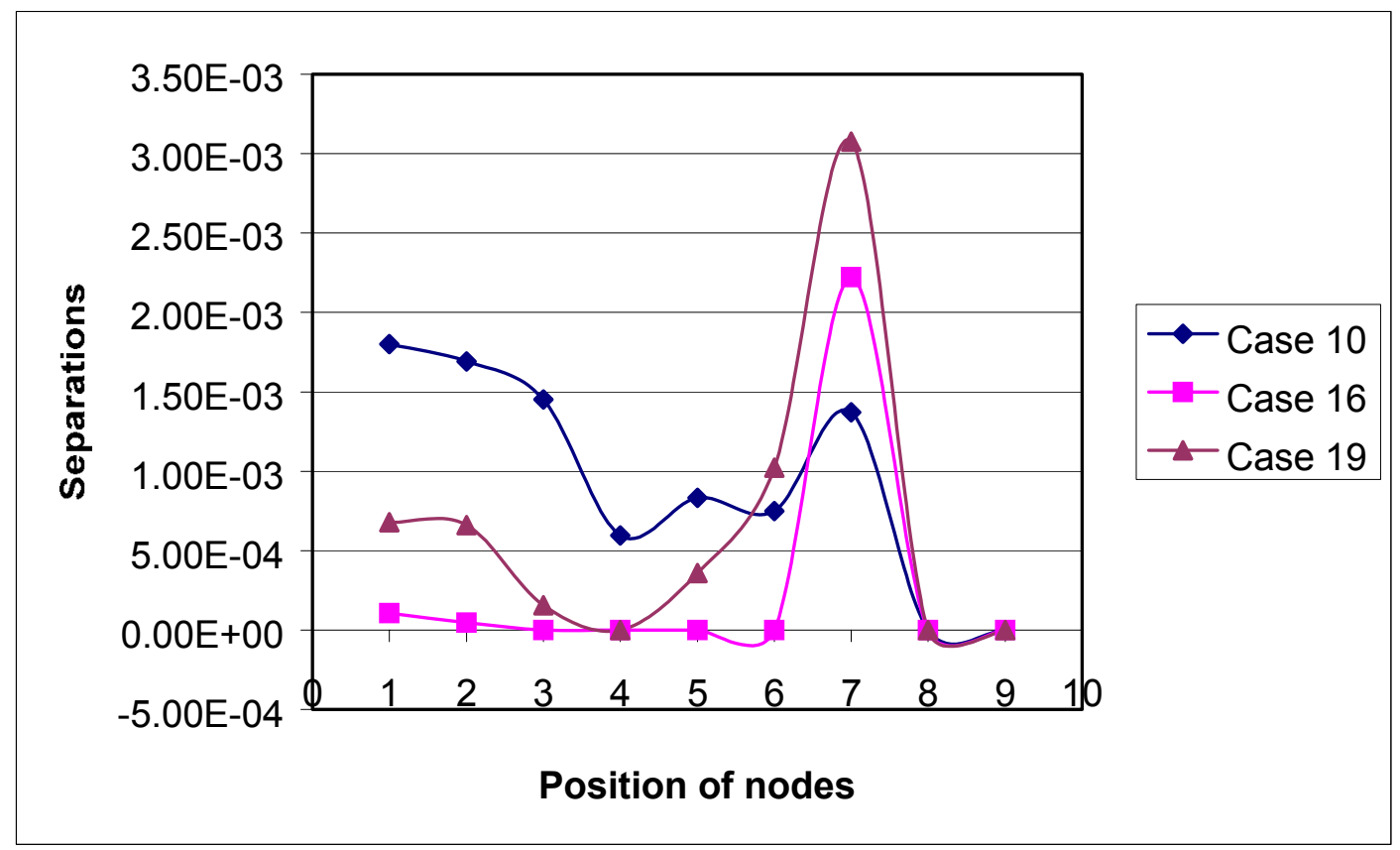

Figure 5.24: The comparison of separations at the 9 chosen points for all the three cases (10, 16 and 19 ). Proud inserts

With the exception of case 10, the peak occurs at the lower left corner of the cavity and in all cases the cavity is sealed at the biscuit and runner. The data for case 16 suggest that very good performance could be obtained with proud inserts if the bending of the shoe could be reduced.

\subsection{Summary}

The analyses show that bolster plates are not effective at increasing stiffness and therefore do not reduce parting plane separation. Proud inserts however can be effective in reducing separation. In all cases analyzed, proud inserts reduced parting plane separation. However, caution is needed because the load paths are modified by the proud insert and additional distortion of the die shoe takes place. It is very difficult to predict by intuition exactly what the impact will be since cavity geometry, cooling line placement, and the die design itself will combine to determine the overall effect. At present, modeling is the only way to obtain answers. 



\section{TWO CAVITY DIE}

\subsection{Introduction and Model Setup}

The Box part used for a single cavity was modified so as to have approximately the same projected area and total volume as that of a single cavity die. The part is shown in Figure 6.1. An 800-ton Prince machine was selected for simulation purposes. The surface area and volume for single cavity and double cavity die are presented in Table 6.1

\begin{tabular}{|c|c|c|}
\hline & Single cavity die & Double cavity die \\
\hline Surface Area $\left(\mathrm{in}^{2}\right)$ & 62.48 & 64.02 \\
\hline Volume $\left(\mathrm{in}^{3}\right)$ & 27.84 & 27.66 \\
\hline
\end{tabular}

Table 6.1: Comparison of single cavity and Double cavity die

A few trial simulations were carried out to find the proper placement of the ejector pillars. From these simulations it was concluded that proper, even distribution of the ejector pillar behind the ejector die helps in reducing the deflection.

A solidification analysis was carried out to find the cycle time and the placement of cooling lines for the double cavity part. A cycle time of 55 seconds was found appropriate. The solidification obtained using this cycle time was $94 \%$. Details of the die casting cycle for the cavity die are presented in Table 6.2.

\begin{tabular}{|c|c|}
\hline Time (sec) & Step \\
\hline $0-1$ & Dies are clamped \\
\hline $1-36$ & Heat and pressure loads applied to the cavity \\
\hline $36-47$ & Die halves open and let to cool; part is ejected \\
\hline $47-50$ & Lubricant spray on cavity \\
\hline $50-55$ & Dies are clamped \\
\hline
\end{tabular}

Table 6.2: Die casting cycle for double cavity die

The loads and boundary conditions were identical to those used for the single cavity studies with the exception that the heat loads were recomputed based on the two cavity geometry. 

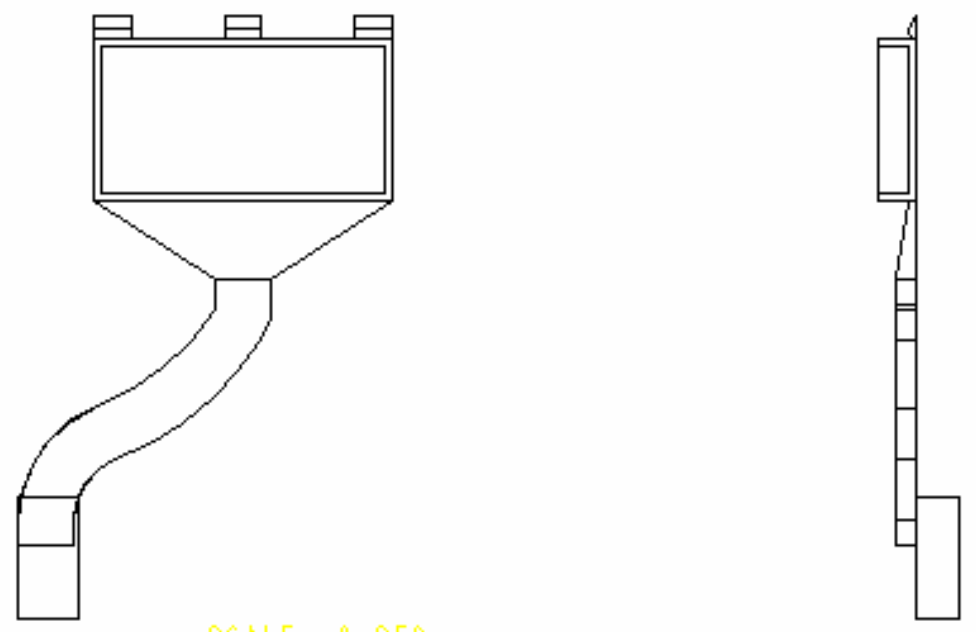

Figure 6.1: Double cavity part

Three cases were selected for analysis based on the results from the single cavity die. These are the smallest die possible on a thick platen, a nominal case close to one that might be used in industry, and a large thin die on a thin platen. The smallest die that was designed for a double cavity die was 30 inches. The details of the three cases are given in Table 6.3.

\begin{tabular}{|c|c|c|c|c|c|}
\hline Case & Die Size & $\begin{array}{c}\text { Die } \\
\text { Thickness }\end{array}$ & $\begin{array}{c}\text { Platen } \\
\text { Thickness }\end{array}$ & Ratio & Location \\
\hline 1 & 30 & 5 & 14.5 & 0.5 & Center \\
\hline 2 & 33 & 8.75 & 11.75 & 0.5 & Center \\
\hline 3 & 39 & 10 & 9 & 0.4 & Low \\
\hline
\end{tabular}

Table 6.3: De ails for cases chosen iur double cavity die. 


\subsection{Results and Analysis}

Figures $6.2-6.5$ show the parting plane separation plots for each case, for cycles 1 and 10. Cycle 1 is the initial cold condition, cycle 10 is a hot die. Clearly, the thermal growth of the die over the ten cycles affects the parting plane separation. As the die grows it is observed that the portion near the cavity is sealed and the inserts open at the edges. The patterns are not the same as with a single cavity and represent the differences that result from different heat growth and cooling with the additional cavity. The smaller die still shows the smallest separation.

As discussed earlier, the deflection on the cover side is caused mainly due to movement of the insert into the die-holder block and the bowing of the platen. Thus, a thick platen on the cover side means less bowing and consequently better support to the dies. On the ejector side, a small die means that the ejector box is closer to the cavity as compared to the big dies. Thus, in small dies the ejector box and the pillars provide better support as opposed to big dies in which, the ejector pillars provide the support predominantly.

A thin die is more compliant than a thick die. Thus, support provided by the platen is much better on the cover side for a small, thin die. This can observed from the plots contact pressure plots between cover die and platen (Figure $6.4 \mathrm{a}, \mathrm{b}, \mathrm{c}$ ), which indicate more contact for small, thin, die as compared to other two. Figure $6.5 \mathrm{a}, \mathrm{b}, \mathrm{c}$ show contact pressure between the platen and the die for the ejector side. 

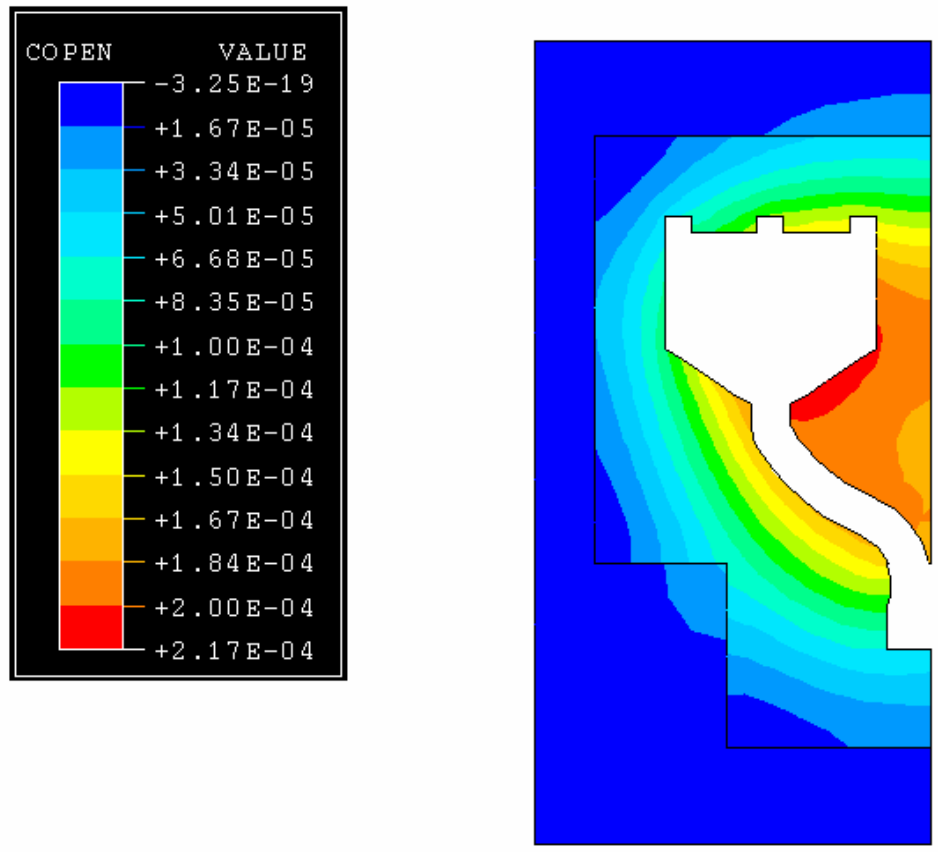

Figure 6.2a: Parting plane separation at cycle 1 for case 1
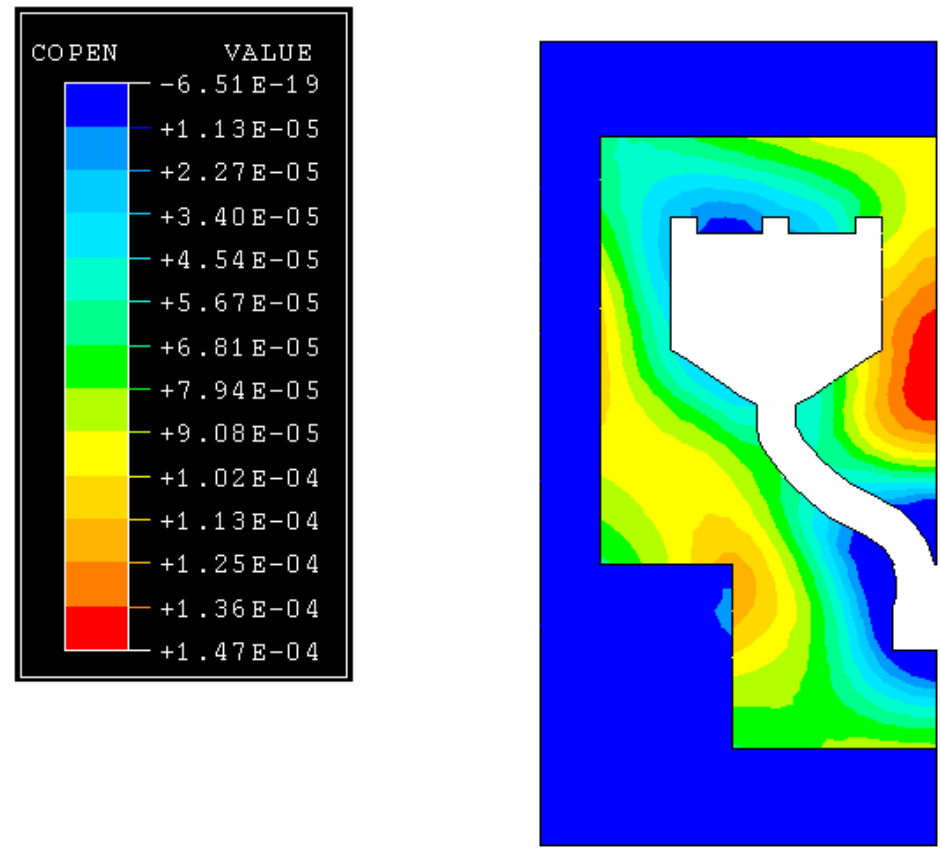

Figure 6.2b: Parting plane separation at cycle 10 for case 1 

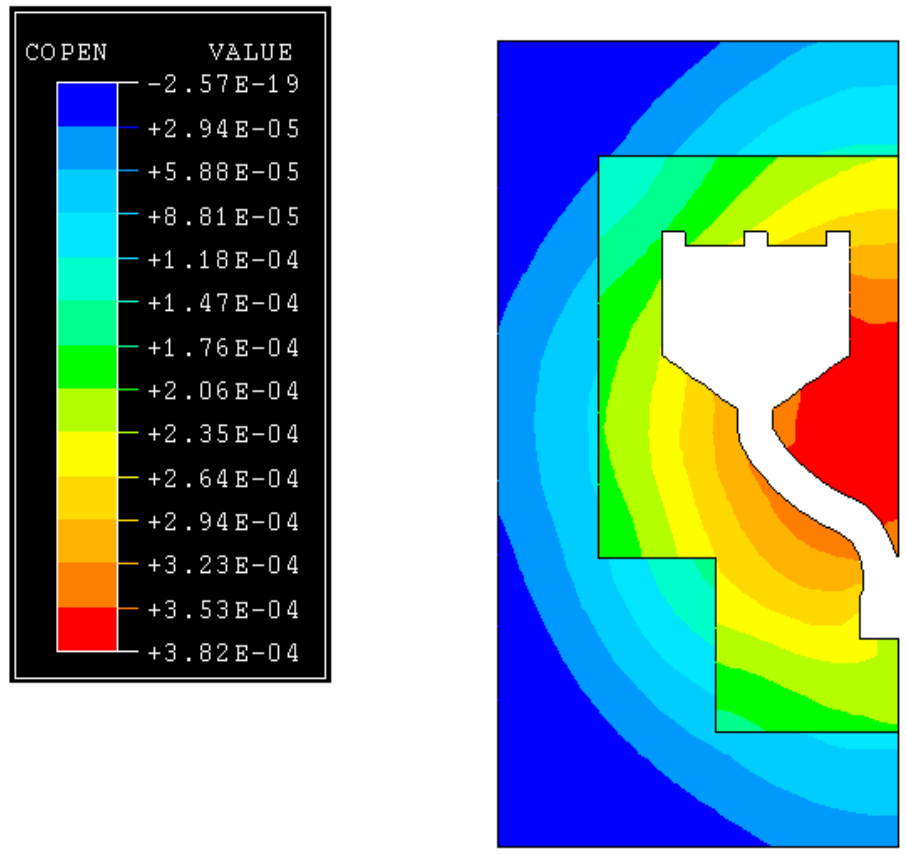

Figure 6.3a: Parting plane separation at cycle 1 for case2
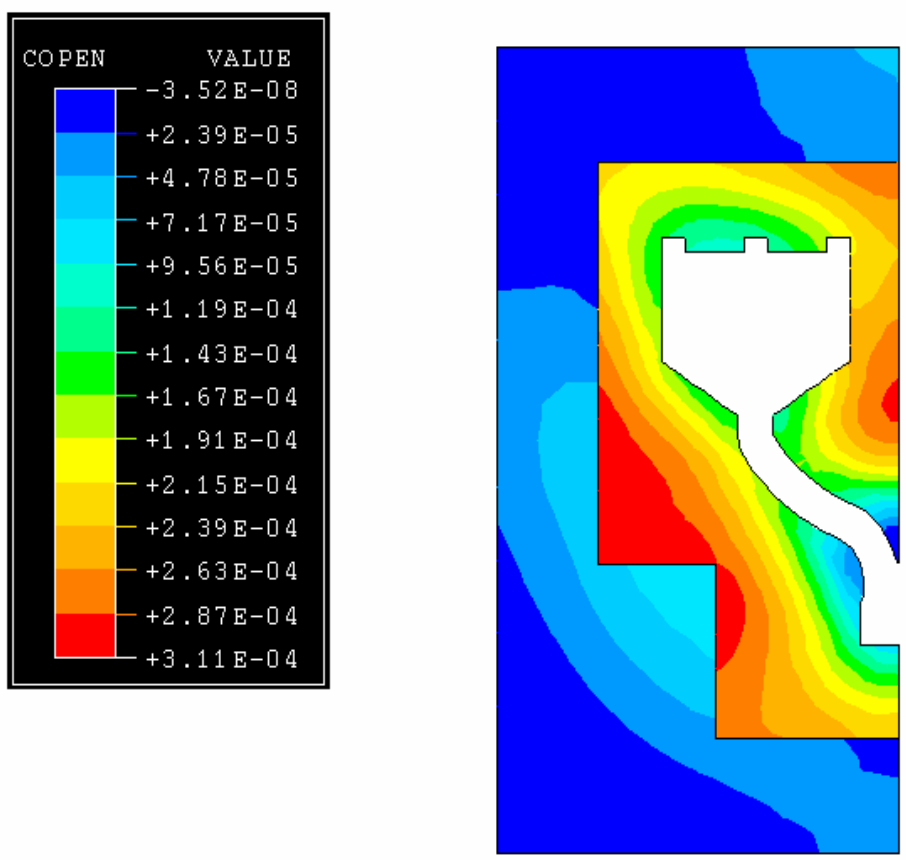

Figure 6.3b: Parting plane separation at cycle 10 for case2 

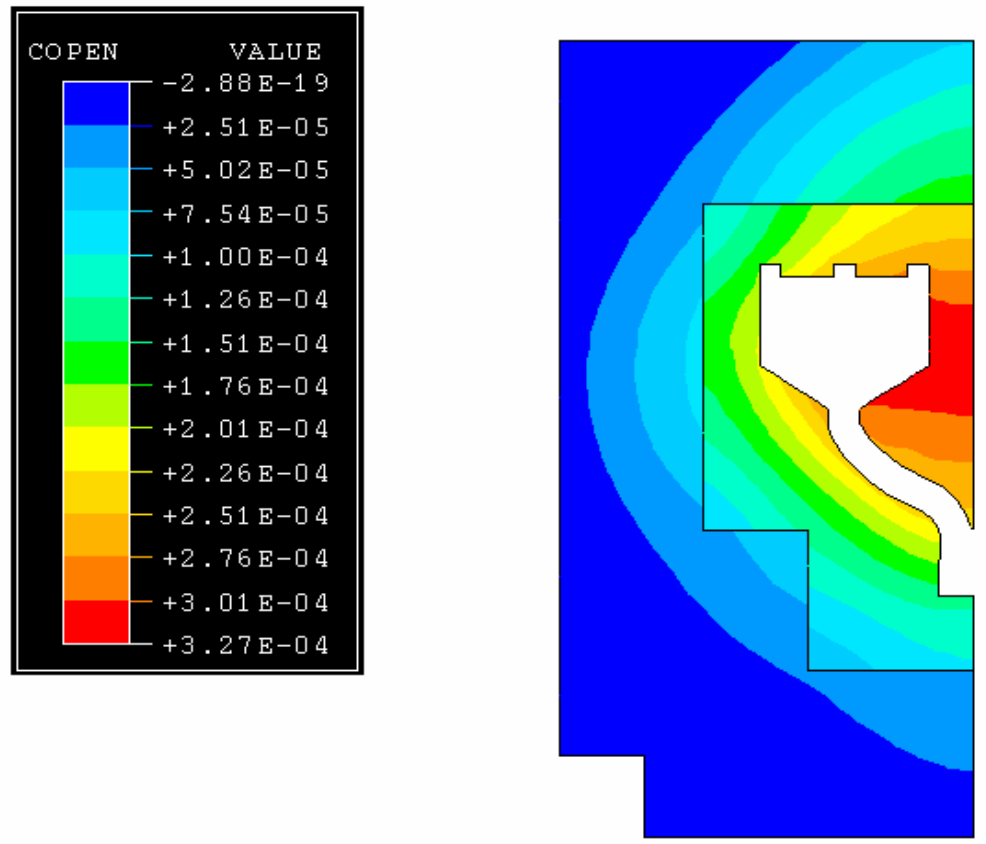

Figure 6.4a: Parting plane separation at cycle 1 for case 3
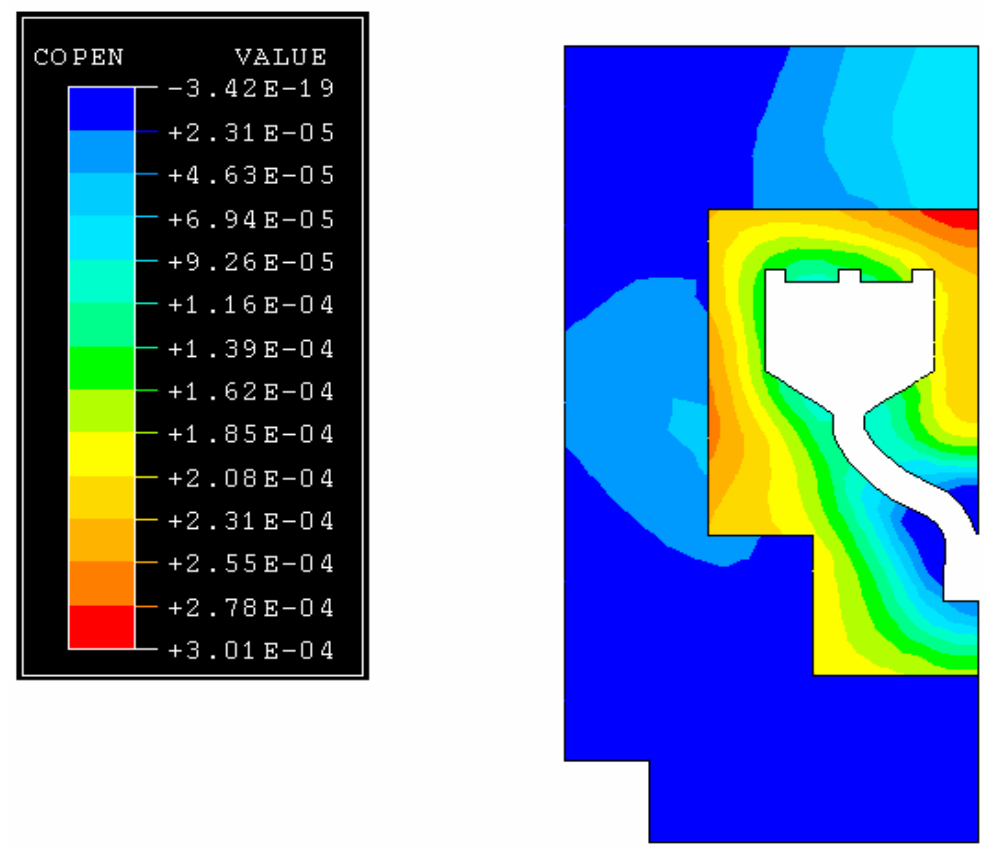

Figure 6.4b: Parting plane separation at cycle 1 for case 3 

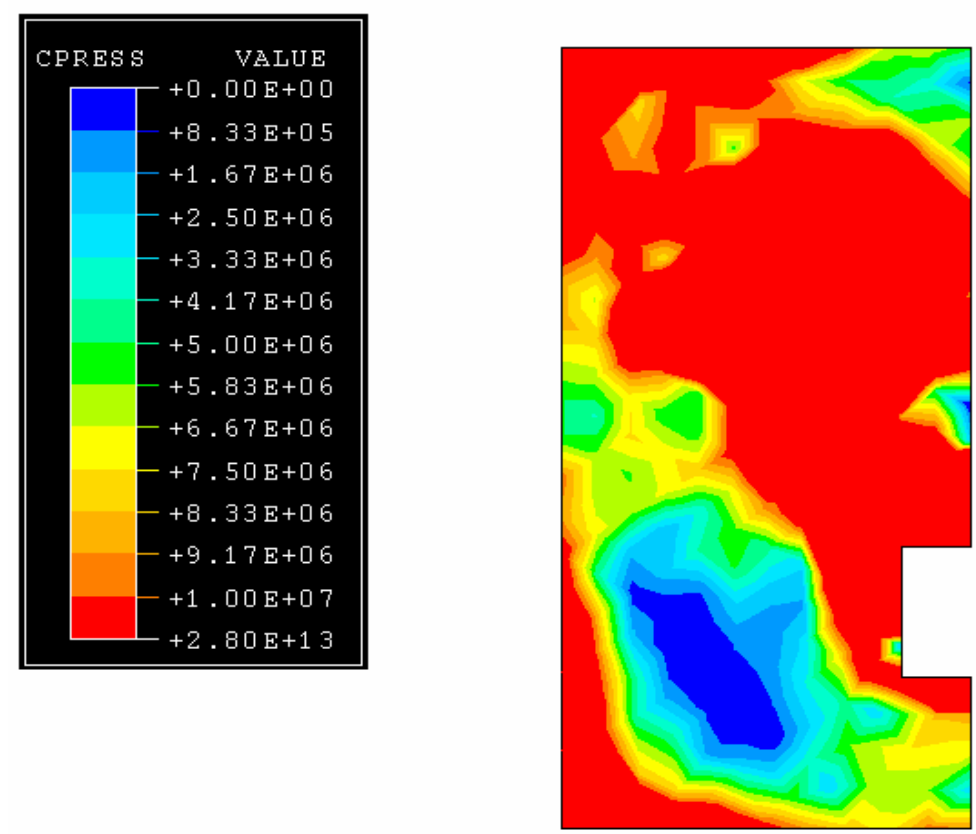

Figure 6.5a: Contact pressure plots at cycle 10 for case 1
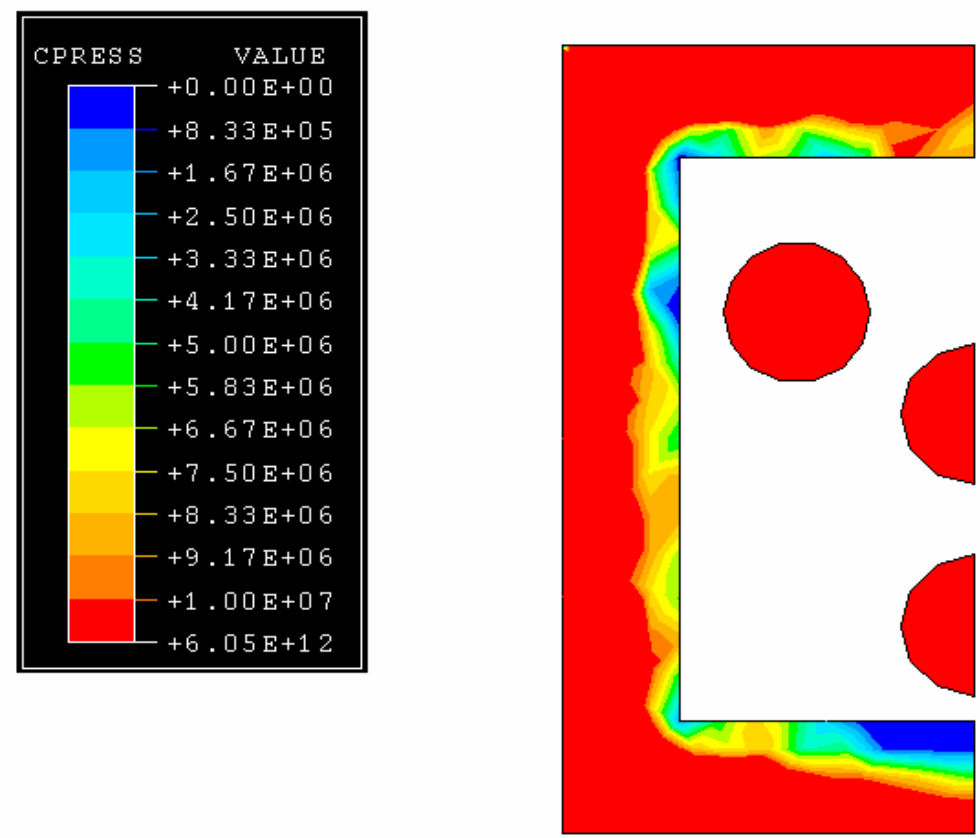

Figure 6.5b: Contact pressure plots at cycle 10 for case 1 

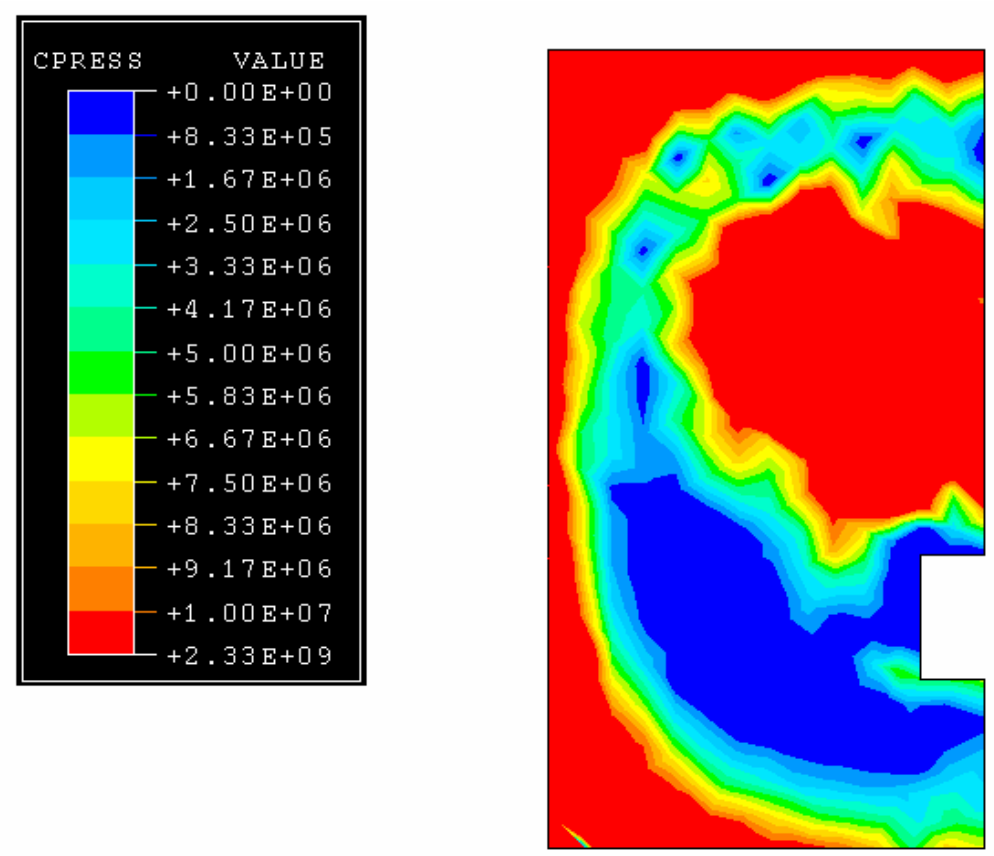

Figure 6.6a: Contact pressure plots at cycle 10 for case2
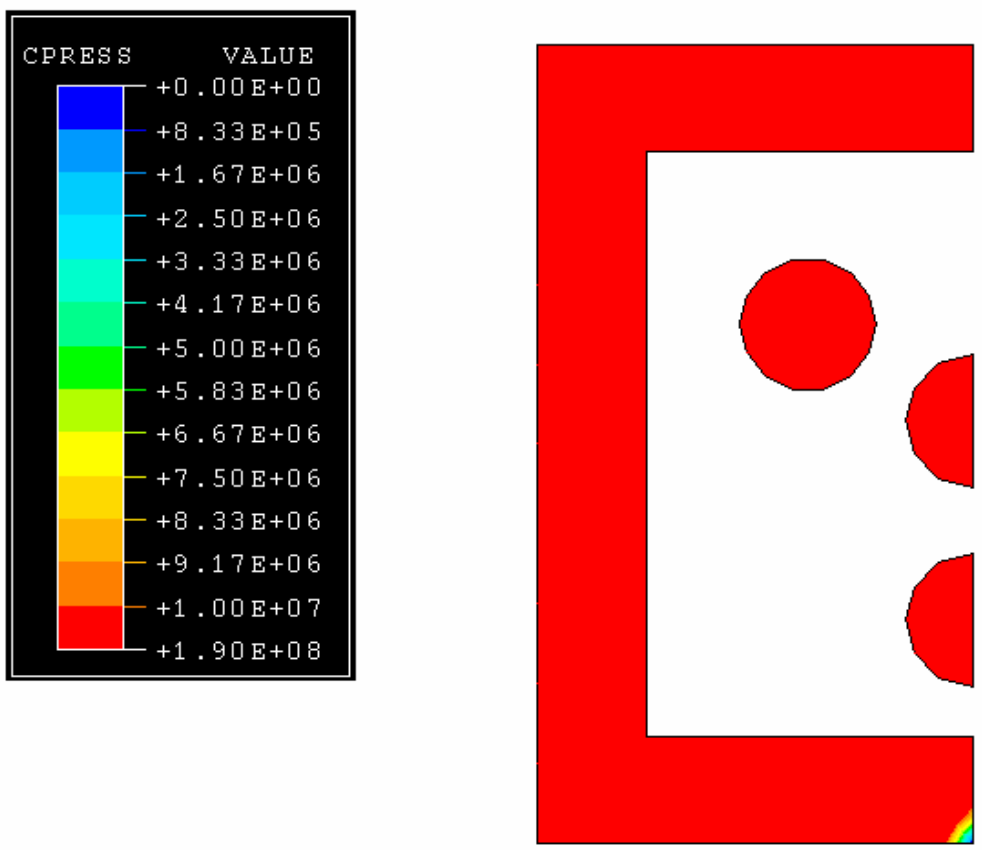

Figure 6.6b: Contact pressure plots at cycle 10 for case 2 

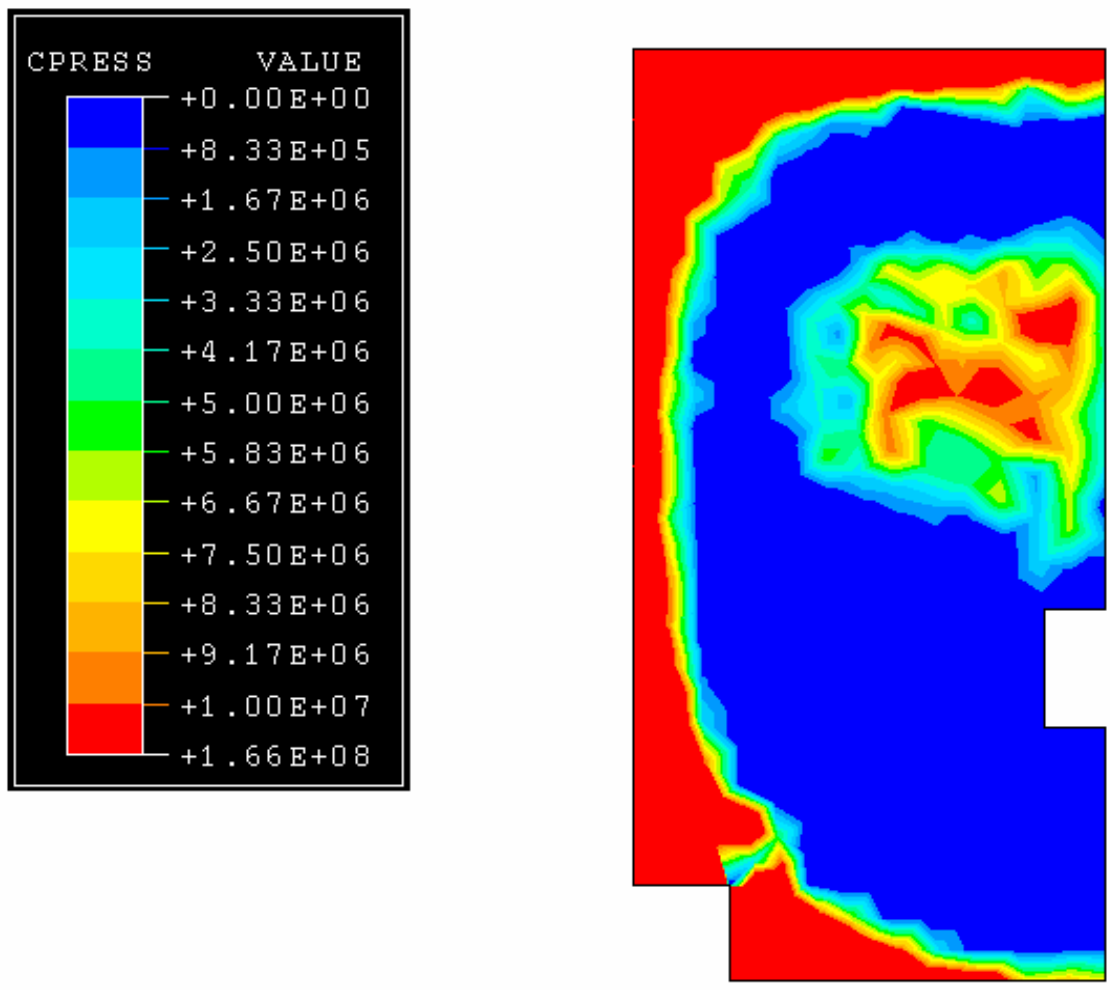

Figure 6.7a: Contact pressure plots at cycle 10 for case 3
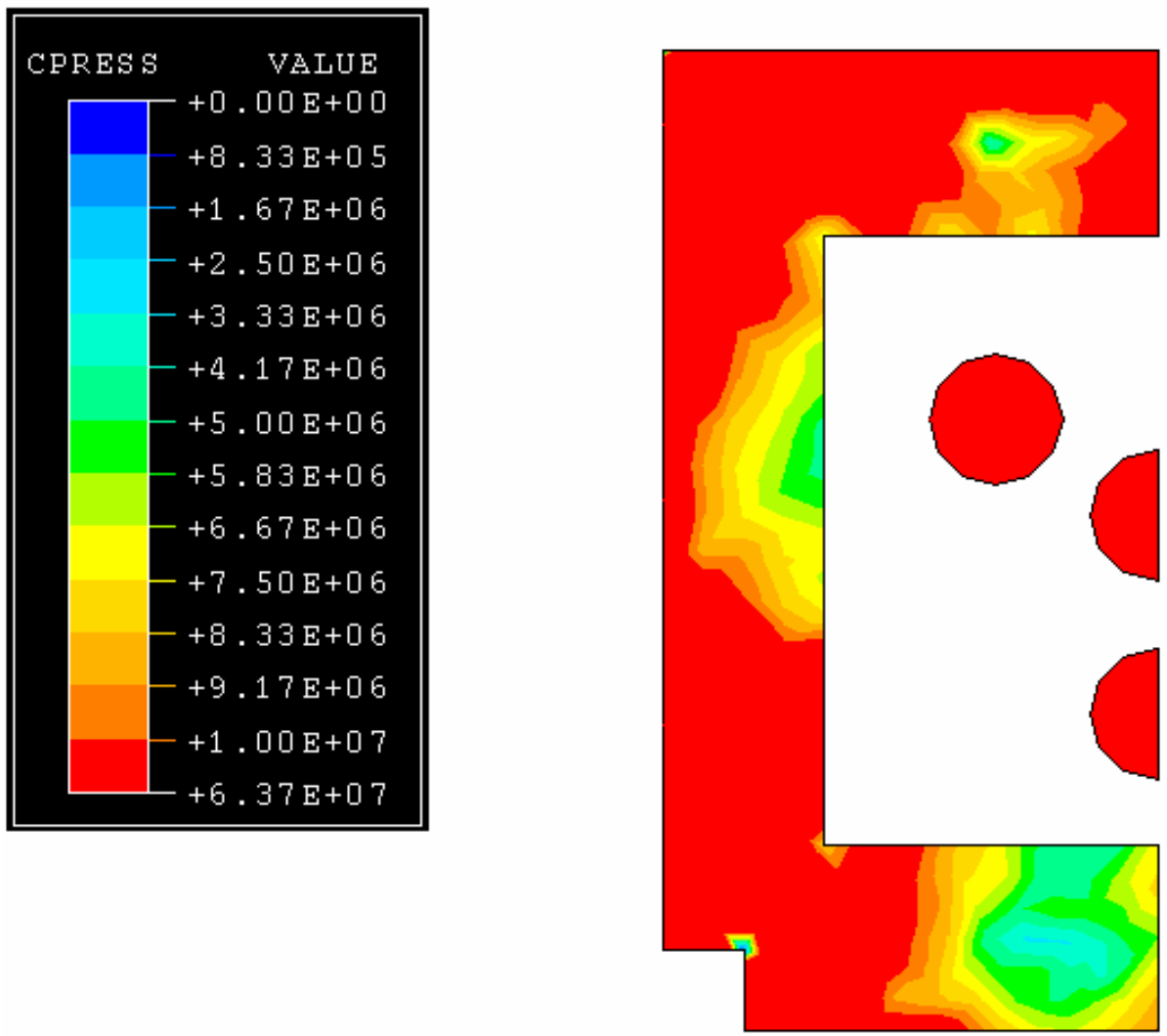

Figure 6.7b: Contact pressure plots at cycle 10 for case 3 


\subsection{Summary}

From the three cases analyzed it can be observed that the trends shown by the single cavity die hold true for an open-close multicavity die. The pattern at parting plane is quite different than the single cavity die due to different distribution of mechanical and thermal loads, but overall sensitivity of the separation to the die and machine variables is not different. 


\section{CONCLUSIONS}

This research aimed at identifying the die casting die and the machine variables that contribute to separation of the die at the parting plane. Changing these variables alters the rigidity of the structure and thus, the parting plane behavior.

This study estimates the effects of the thermal and the mechanical loads on the parting plane separation. It identifies the important die-casting die and the machine variables and interactions between them. The simulations performed and the regression analysis done has helped to formulate initial guidelines to correlate the behavior of the die to certain design parameters. These guidelines are specific to open close dies.

In this research, basic die designs used in industry were used for the deflection analysis. As mentioned earlier, some initial guidelines have been developed as far as the structural design of the die and the machine is concerned. The results of the work so far indicate:

\section{On the cover side:}

- The main factors that cause the separation are deflection of the cover platen and the compression of the insert into the die pocket.

- The rigidity of the machine is dominant factor on the cover side. Hence a thicker platen always results in lower separation.

- Small to medium size dies seem to be optimal setting as far as die size is concerned. Small dies are subjected to more uniform loads and provide good seal around cavity.

- Thin dies perform better than thick dies. Thin dies are more compliant than thick ones and result in lower separation at the parting plane.

- The center of pressure shifts (downwards in the cases studied) as the die reaches steady state. Hence mounting the die with center of pressure above the geometric center of platen seems to be an optimal setting. In general, the die should be mounted with the hot center of pressure in line with the platen center line.

- The results suggest that an insert slightly thicker than the shoulder tends to be better.

\section{On the ejector side}

- The main factors that cause the separation are: Lack of support for the cavity behind the insert, buckling of the support pillars and compression of the insert in the die pocket.

- The results obtained to date are not able to fully explain the performance on the ejector side. Pillar size and location was not controlled in the experiments which means that there is considerable noise in the ejector side data. Explaining ejector side performance is still an open question.

The single most important factor is the platen stiffness. A stiffer machine will reduce die separation. The analysis suggests that parting plane separation is directly related to the uniformity of the support provided by the platen and the degree to which the clamping load is uniformly applied to the die parting surface. Larger dies result in platen bending and bending 
affects the degree to which the platen supports the die. Essentially, the smaller footprint means that the die mates with the platen a bit better.

Analysis of stresses showed that a small footprint is not a major contributor to the stresses on the platen, in fact in the cases studied, a smaller footprint reduced stresses Our intuition about die footprint is based on assuming the structure is rigid which it clearly is not. Given the die and platens deflect, the contact areas are a function of the machine stiffness, the die construction, and the geometry.

There are a number of open questions about the contributions of the ejector side design to parting plane separation. These questions remain a subject for future research. 


\section{APPENDIX A SEPARATION S, CONTACT PRESSURE AND COMPRESSIVE STRESS PLOTS FOR ALL CASES.}

\section{APPENDIX A.1 Plots for Case 1}

\section{Specifications for case 1:}

- $\quad \operatorname{Die} \operatorname{size}(\mathrm{A})$ : 39"

- Die thickness (B): 5"

- Platen thickness (C): 9"

- Thickness ratio (D): 0.5 (Insert thickness: 2.5", Shoulder thickness: 2.5")

- Die Location (E): Mid-high

\begin{tabular}{|c|r|}
\hline \multicolumn{1}{|c|}{ COPEN } & VALUE \\
\hline & $-3.96 \mathrm{E}-19$ \\
$+3.86 \mathrm{E}-05$ \\
$+7.73 \mathrm{E}-05$ \\
$+1.16 \mathrm{E}-04$ \\
$-+1.55 \mathrm{E}-04$ \\
$-+1.93 \mathrm{E}-04$ \\
$-+2.32 \mathrm{E}-04$ \\
$-+2.70 \mathrm{E}-04$ \\
$-+3.09 \mathrm{E}-04$ \\
$-+3.48 \mathrm{E}-04$ \\
$-+3.86 \mathrm{E}-04$ \\
$-+4.25 \mathrm{E}-04$ \\
$-+4.64 \mathrm{E}-04$ \\
$+5.02 \mathrm{E}-04$ \\
\hline
\end{tabular}

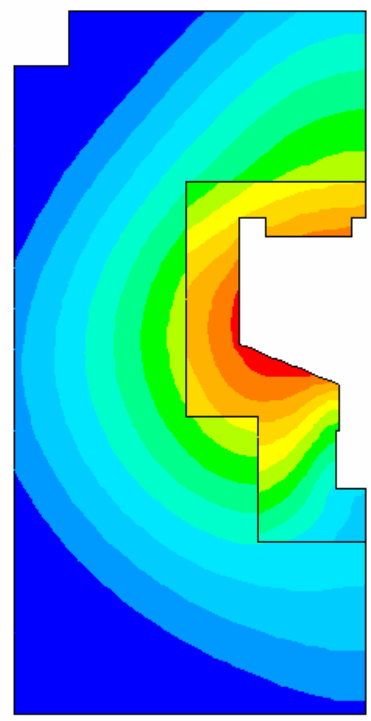

Figure A.1.1: showing parting plane separation for case 1 

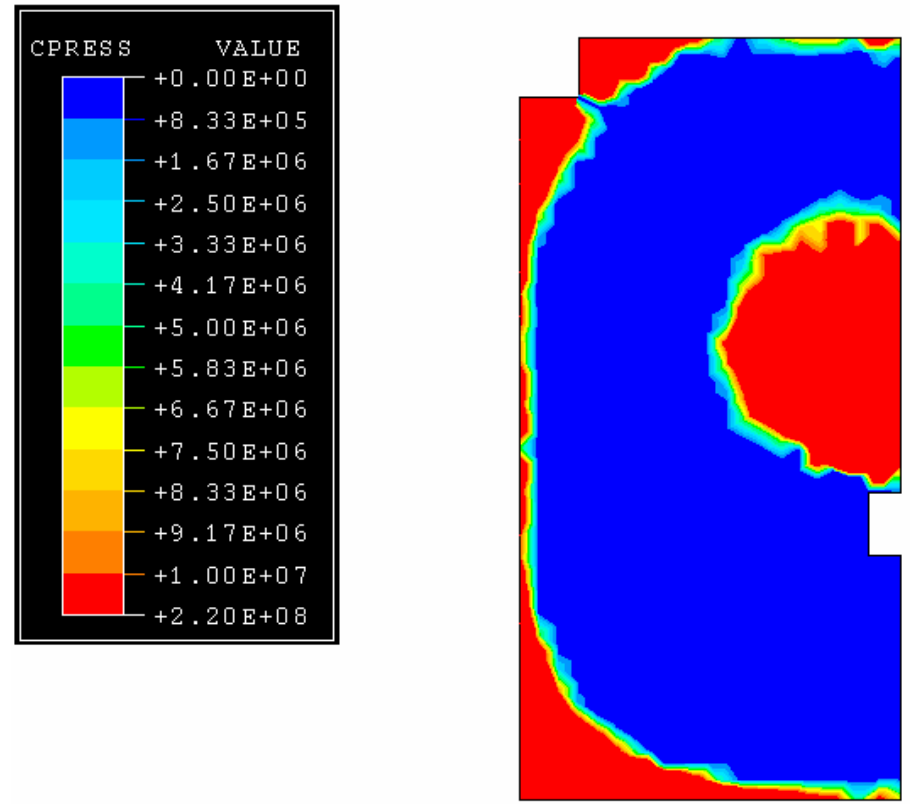

Figure A.1.2: showing contact pressure at the back of the cover die for case 1

\begin{tabular}{|c|c|}
\hline \multirow[t]{15}{*}{ CPRESS } & VALUE \\
\hline & $+0.00 \mathrm{E}+00$ \\
\hline & $+8.33 E+05$ \\
\hline & $+1.67 \mathrm{E}+06$ \\
\hline & $-+2.50 E+06$ \\
\hline & $-+3.33 \mathrm{E}+06$ \\
\hline & $-+4.17 \mathrm{E}+06$ \\
\hline & $-+5.00 \mathrm{E}+06$ \\
\hline & $-+5.83 E+06$ \\
\hline & $-+6.678+06$ \\
\hline & $-+7.50 \mathrm{E}+06$ \\
\hline & $-+8.33 \mathrm{E}+06$ \\
\hline & $-+9.17 \mathrm{E}+06$ \\
\hline & $-+1.00 \mathrm{E}+07$ \\
\hline & $-+2.12 \mathrm{E}+08$ \\
\hline
\end{tabular}

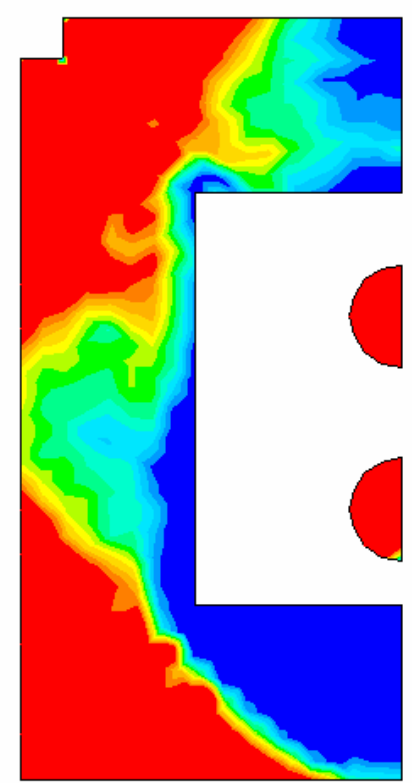

Figure A.1.3: showing contact pressure at the back of the ejector die for case 1 

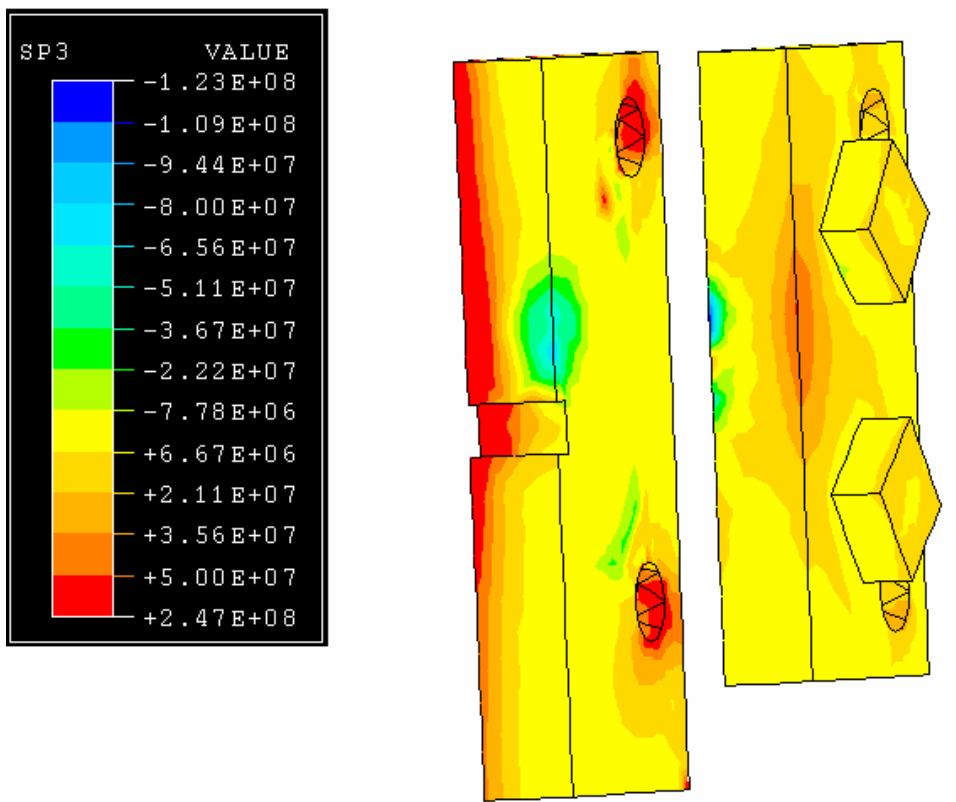

Figure A.1.4: showing compressive stresses in the platens for case 1

\begin{tabular}{|r|r|}
\hline \multicolumn{1}{|l|}{ SP3 } & VALUE \\
\hline & $-1.23 E+08$ \\
$-1.09 E+08$ \\
$-9.44 E+07$ \\
$-8.00 E+07$ \\
$-6.56 E+07$ \\
$-5.11 E+07$ \\
$-3.67 E+07$ \\
$-2.22 E+07$ \\
$-7.78 E+06$ \\
$-+6.67 E+06$ \\
$-+2.11 E+07$ \\
$-3.56 E+07$ \\
$-5.00 E+07$ \\
$+2.47 E+08$ \\
\hline
\end{tabular}

Figure A.1.5: s

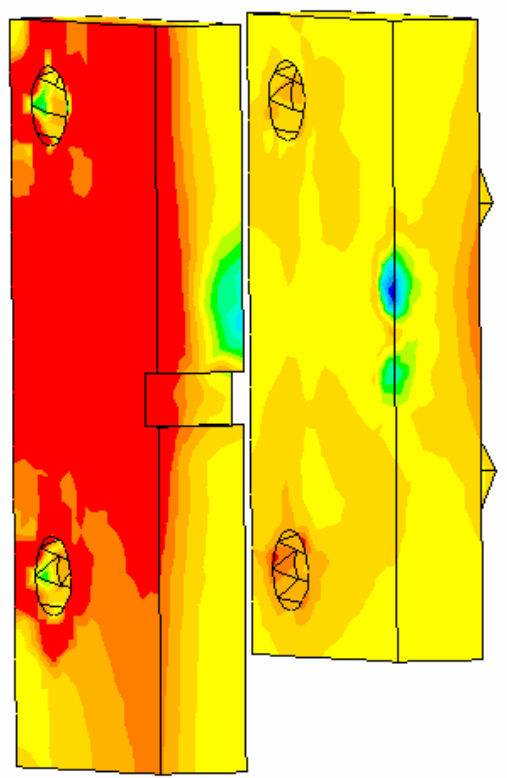

se 1 
APPENDIX A.2 Plots for Case 2

\section{Specifications for case 2:}

- Die size (A): 39"

- Die thickness (B):10"

- Platen thickness (C): 9"

- Thickness ratio (D): 0.5 (Insert thickness: 5", Shoulder thickness: 5")

- Die Location (E): Low

\begin{tabular}{|r|r|}
\hline COPEN & VALUE \\
\hline & $-4.86 E-19$ \\
$+2.77 E-05$ \\
$-5.54 E-05$ \\
$-+8.31 E-05$ \\
$-+1.11 E-04$ \\
$-+1.38 E-04$ \\
$-+1.66 E-04$ \\
$-1.94 E-04$ \\
$-+2.22 E-04$ \\
$-+2.49 E-04$ \\
$-+2.77 E-04$ \\
$-+3.05 E-04$ \\
$+3.32 E-04$ \\
$+3.60 E-04$ \\
\hline
\end{tabular}

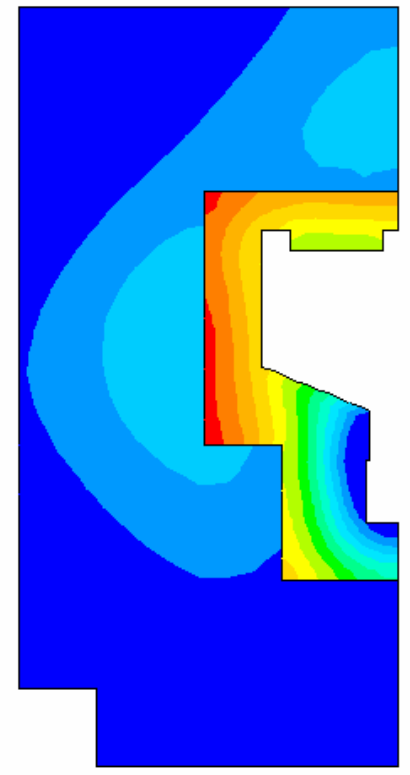

Figure A.2.1: showing parting plane separation for case 2 


\begin{tabular}{|c|c|}
\hline \multirow{15}{*}{ CPRESS } & VALUE \\
\hline & \\
\hline & $+8.33 E+05$ \\
\hline & $-+1.67 \mathrm{E}+06$ \\
\hline & $-+2.50 \mathrm{E}+06$ \\
\hline & $-+3.33 E+06$ \\
\hline & $-+4.17 \mathrm{E}+06$ \\
\hline & $-+5.00 E+06$ \\
\hline & $-+5.83 E+06$ \\
\hline & $-+6.67 \mathrm{E}+06$ \\
\hline & $-+7.50 \mathrm{E}+06$ \\
\hline & $-+8.33 E+06$ \\
\hline & $-+9.17 \mathrm{E}+06$ \\
\hline & $-+1.00 E+07$ \\
\hline & $-+1.91 \mathrm{E}+08$ \\
\hline
\end{tabular}

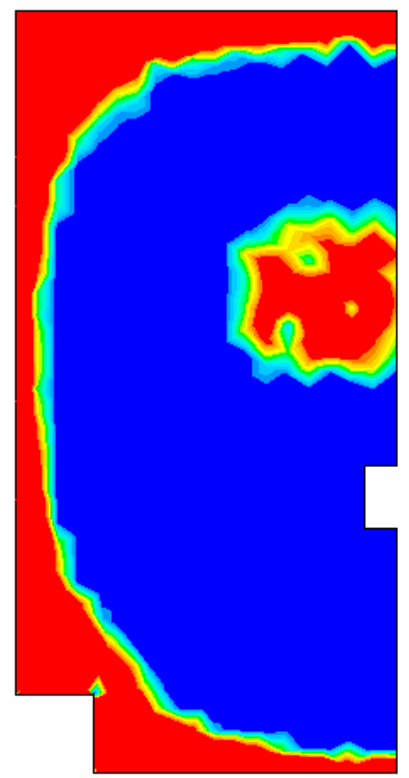

Figure A.2.2: showing contact pressure at the back of the cover die for case 2
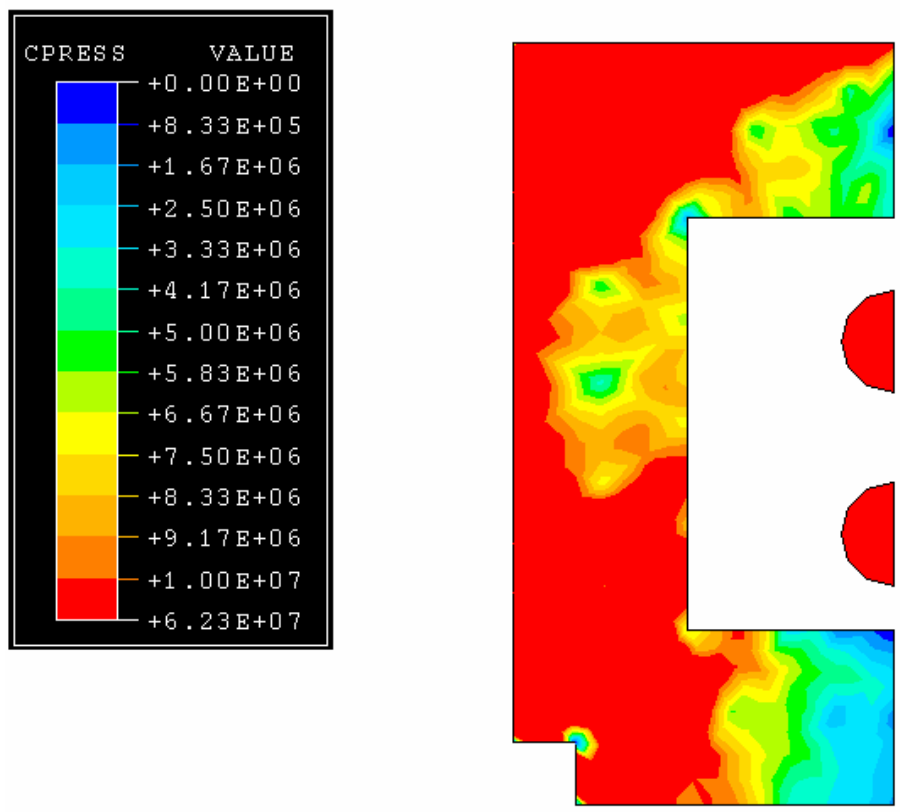

Figure A.2.3: showing contact pressure at the back of the ejector die for case 2 

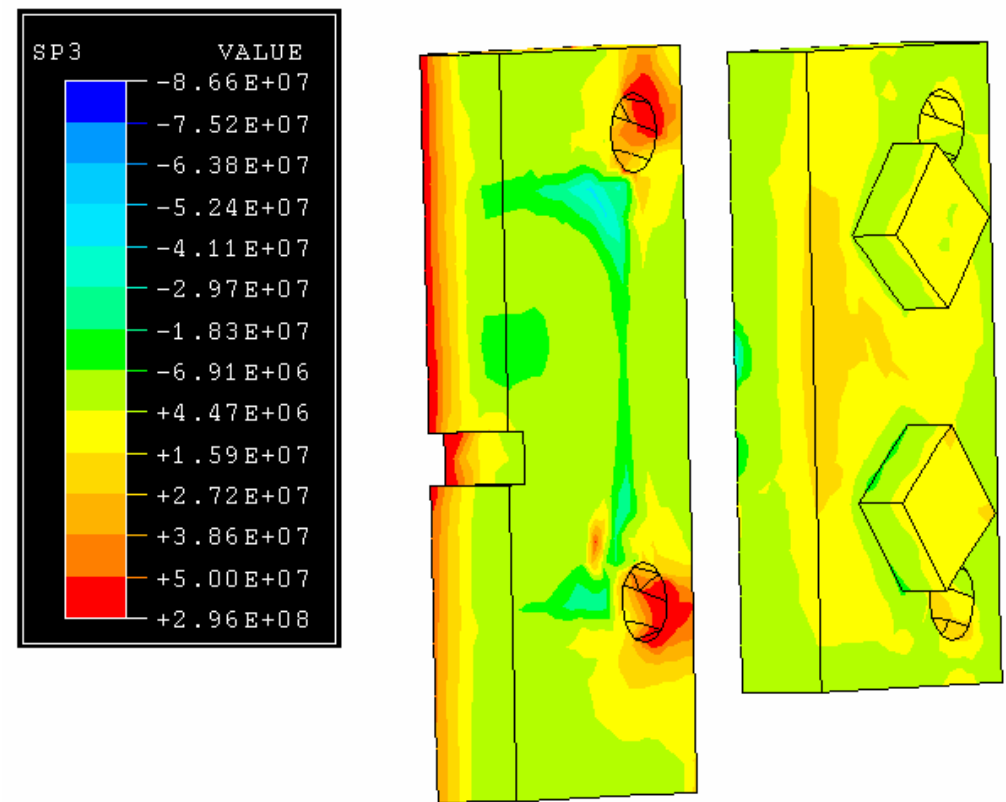

Figure A.2.4: showing compressive stresses in the platens for case 2
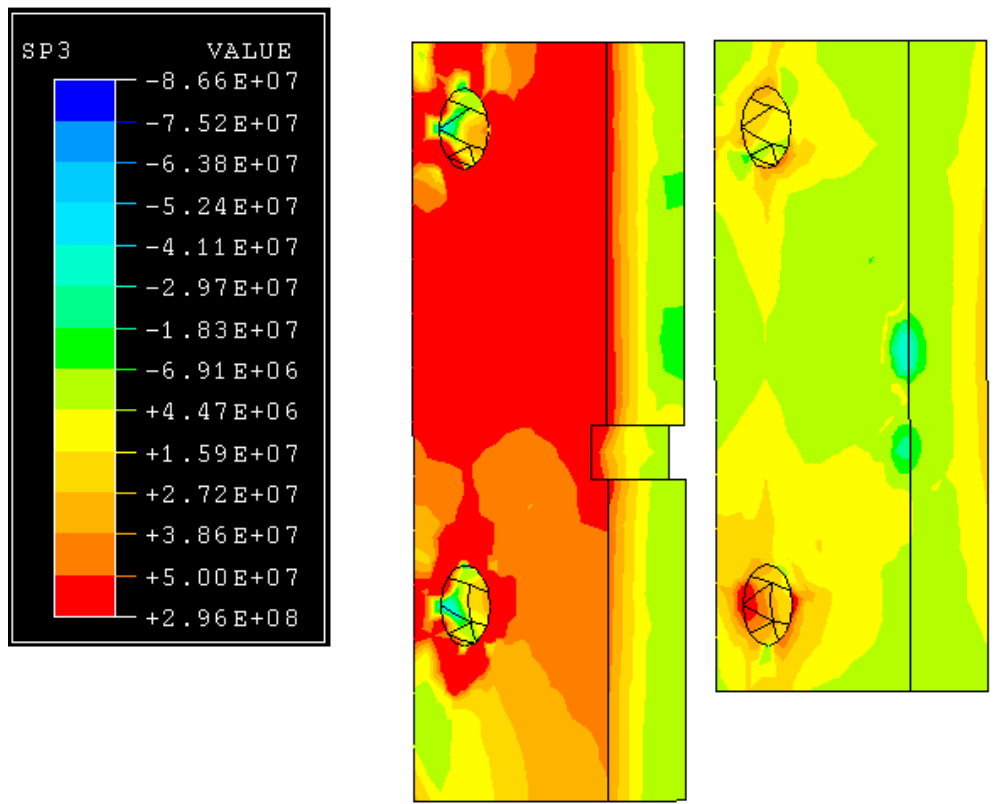

Figure A.2.5: showing compressive stresses in the platens (another view) for case 2 


\section{APPENDIX A.3 Plots for Case 3}

\section{Specifications for case 3:}

- $\quad \operatorname{Die} \operatorname{size}(\mathrm{A}): 24 "$

- Die thickness (B): 10"

- Platen thickness (C): 14.5 "

- Thickness ratio (D): 0.5 (Insert thickness: 5", Shoulder thickness: 5")

- Die Location (E): Low

\begin{tabular}{|c|c|}
\hline \multicolumn{1}{|c|}{ COPEN } & VALUE \\
\hline & $-1.71 \mathrm{E}-19$ \\
& $+2.91 \mathrm{E}-05$ \\
& $+5.82 \mathrm{E}-05$ \\
- & $+8.73 \mathrm{E}-05$ \\
- & $.16 \mathrm{E}-04$ \\
- & $+1.45 \mathrm{E}-04$ \\
$-+1.75 \mathrm{E}-04$ \\
$-+2.04 \mathrm{E}-04$ \\
$-+2.33 \mathrm{E}-04$ \\
$+2.62 \mathrm{E}-04$ \\
$+2.91 \mathrm{E}-04$ \\
$+3.20 \mathrm{E}-04$ \\
$+3.49 \mathrm{E}-04$ \\
$+3.78 \mathrm{E}-04$ \\
\hline
\end{tabular}

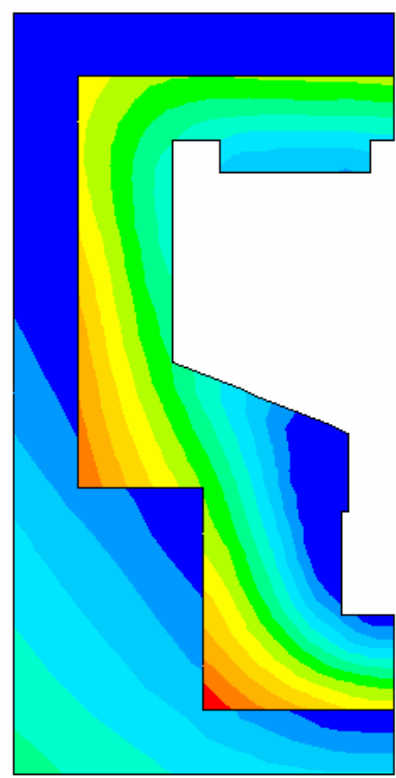

Figure A.3.1: showing parting plane separation for case 3 

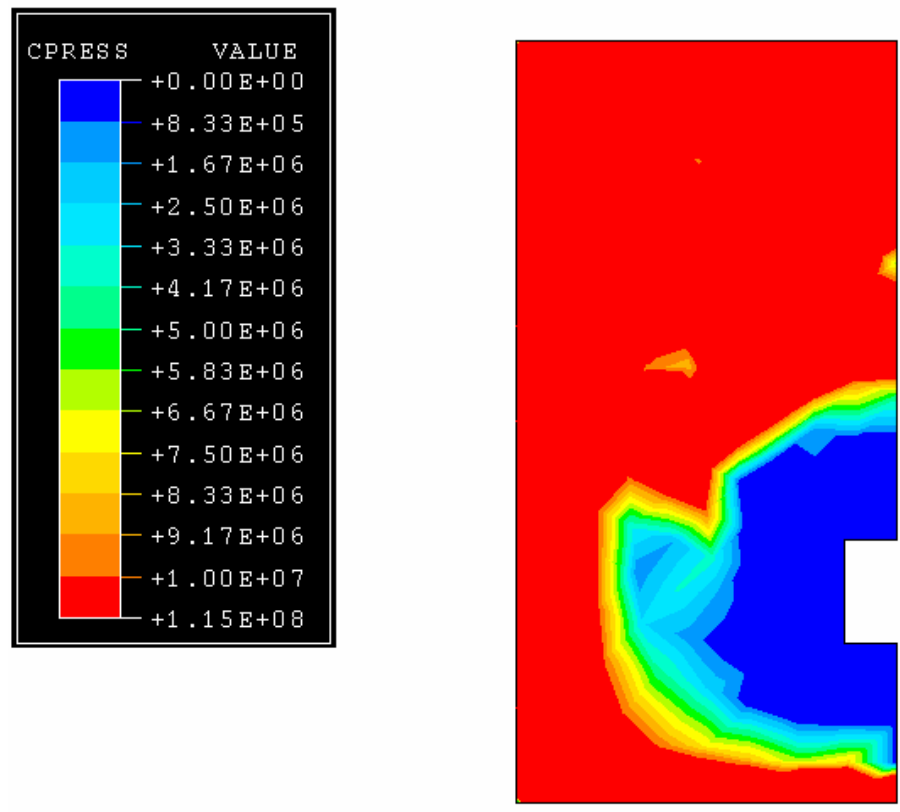

Figure A.3.2: showing contact pressure at the back of the cover die for case 3
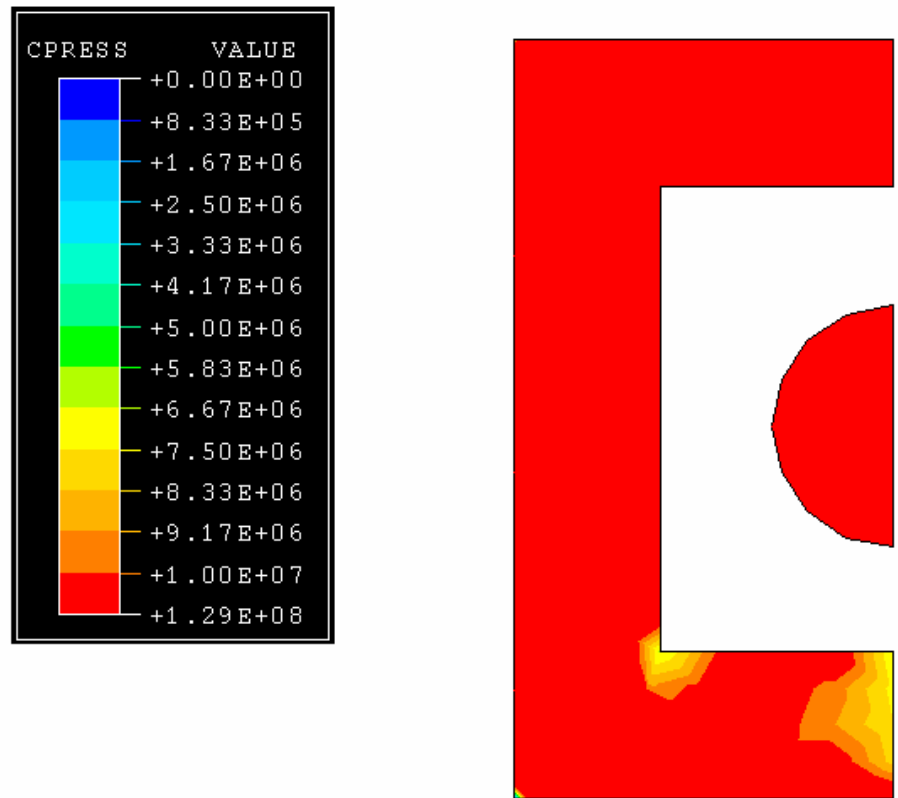

Figure A.3.3: showing contact pressure at the back of the ejector die for case 3 

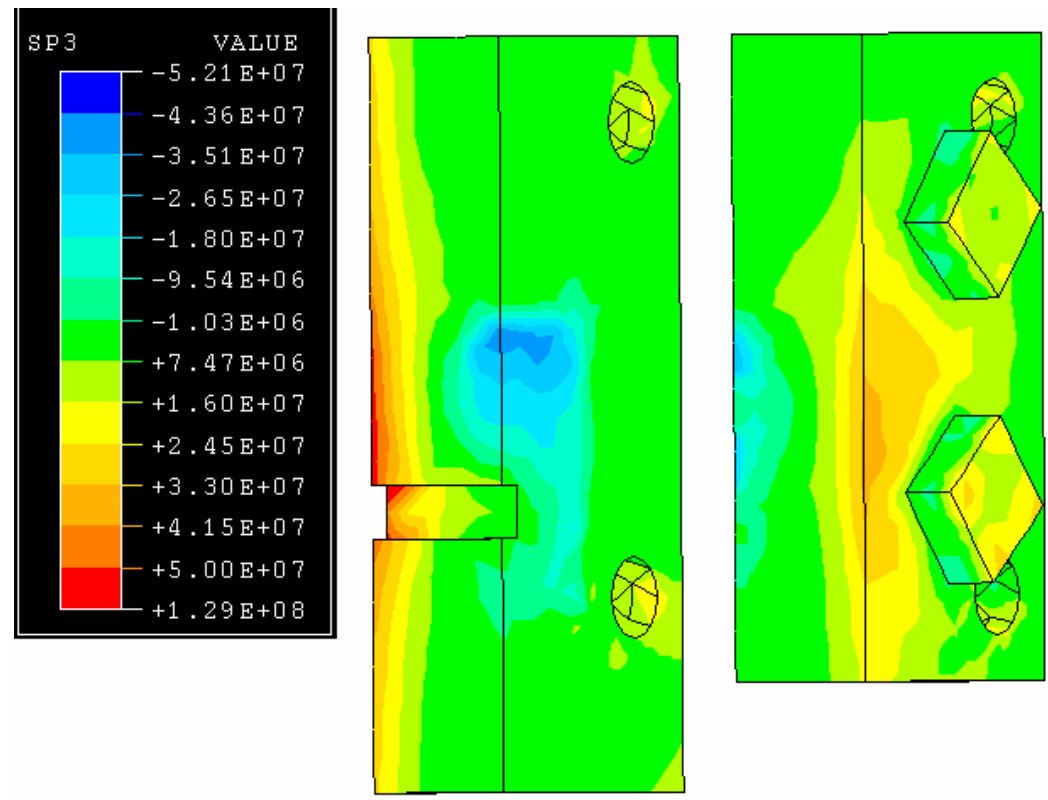

Figure A.3.4: showing compressive stresses in the platens for case 3
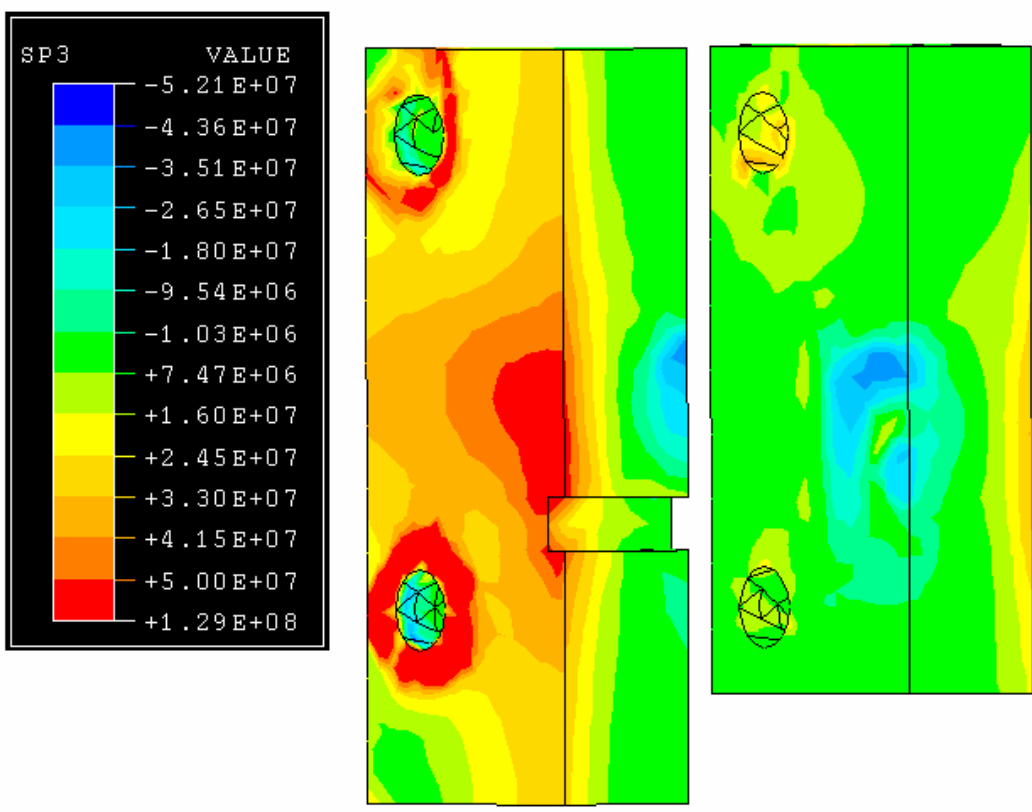

Figure A.3.5: showing compressive stresses in the platens (another view) for case 3 


\section{APPENDIX A.4 Plots for Case 4}

\section{Specifications for case 4:}

- Die size (A): 24"

- Die thickness (B): 5"

- Platen thickness (C): 14.5"

- Thickness ratio (D): 0.4 (Insert thickness: 3", Shoulder thickness: 2")

- Die Location (E): Low

\begin{tabular}{|c|c|}
\hline \multirow{14}{*}{ COPEN } & $\begin{array}{r}\text { VALUE } \\
-2.29 E-19\end{array}$ \\
\hline & $+1.95 E-05$ \\
\hline & $-+3.91 \mathrm{E}-05$ \\
\hline & $-+5.86 \mathrm{E}-05$ \\
\hline & $-+7.81 \mathrm{E}-05$ \\
\hline & $-+9.76 \mathrm{E}-05$ \\
\hline & $-+1.17 \mathrm{E}-04$ \\
\hline & $-+1.37 \mathrm{E}-04$ \\
\hline & $-+1.56 \mathrm{E}-04$ \\
\hline & $-+1.76 \mathrm{E}-04$ \\
\hline & $-+1.95 \mathrm{E}-04$ \\
\hline & $-+2.15 \mathrm{E}-04$ \\
\hline & $-+2.34 \mathrm{E}-04$ \\
\hline & $-+2.54 \mathrm{E}-04$ \\
\hline
\end{tabular}

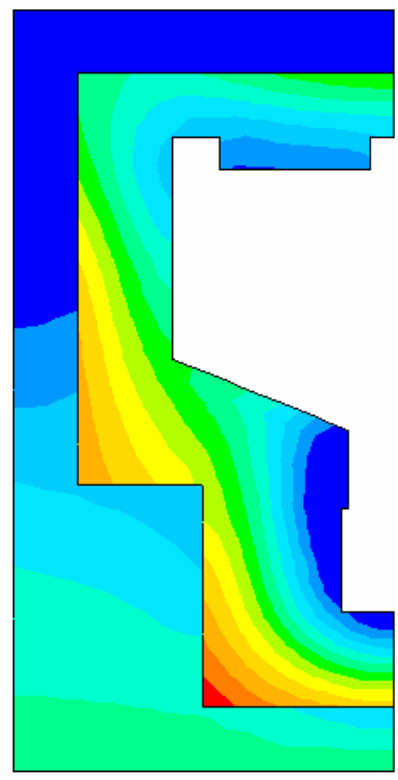

Figure A.4.1: showing parting plane separation for case 4 

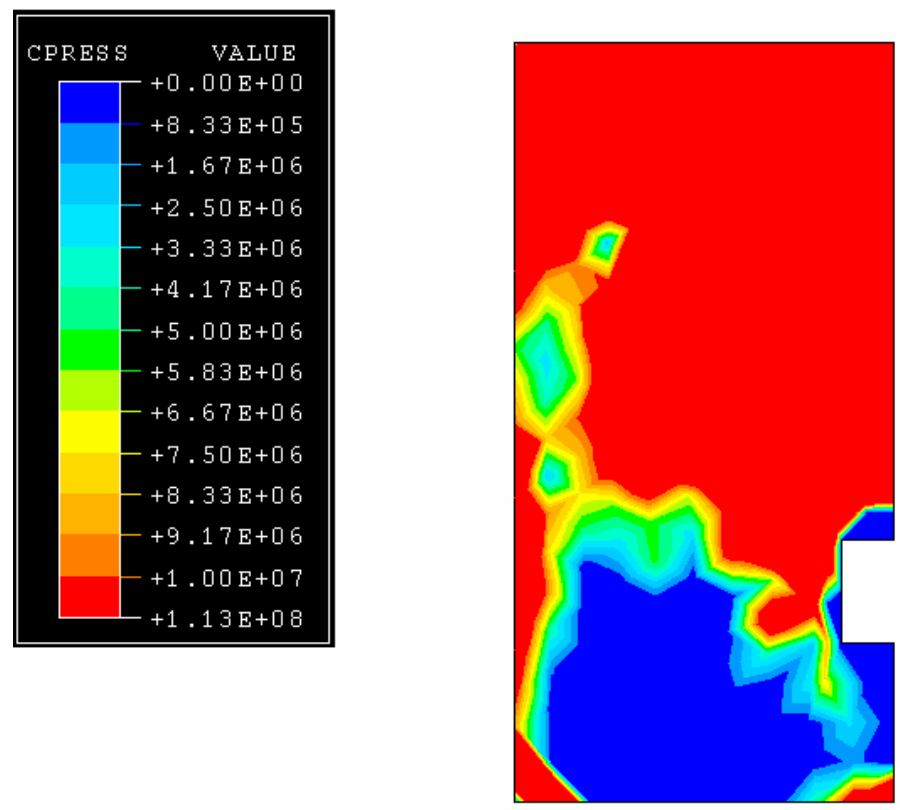

Figure A.4.2: showing contact pressure at the back of the cover die for case 4
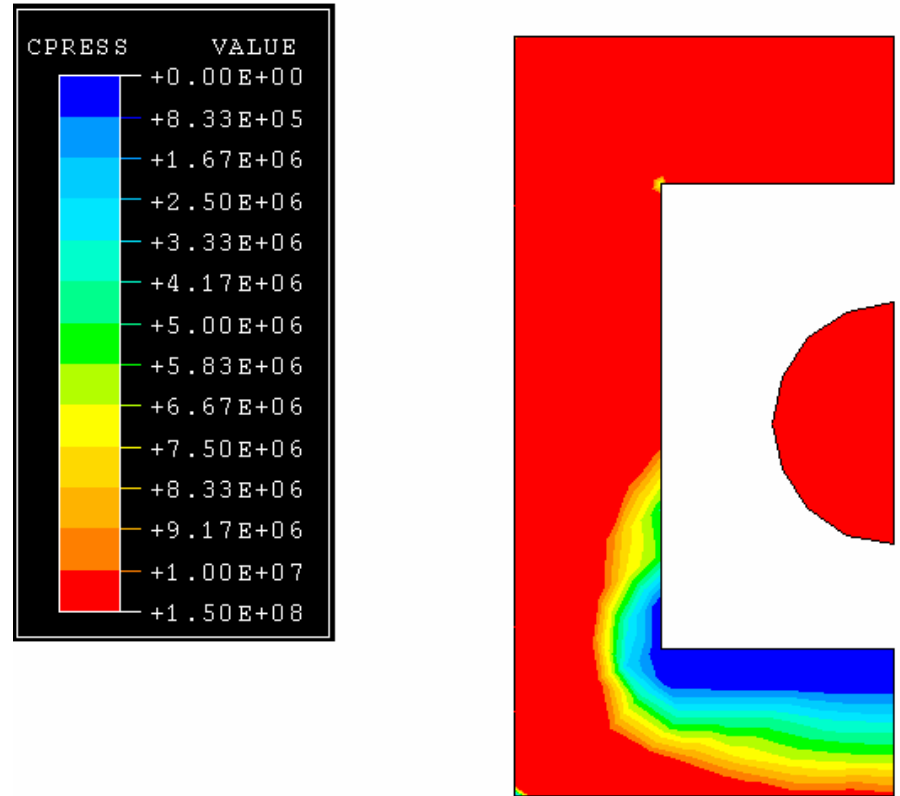

Figure A.4.3: showing contact pressure at the back of the ejector die for case 4 

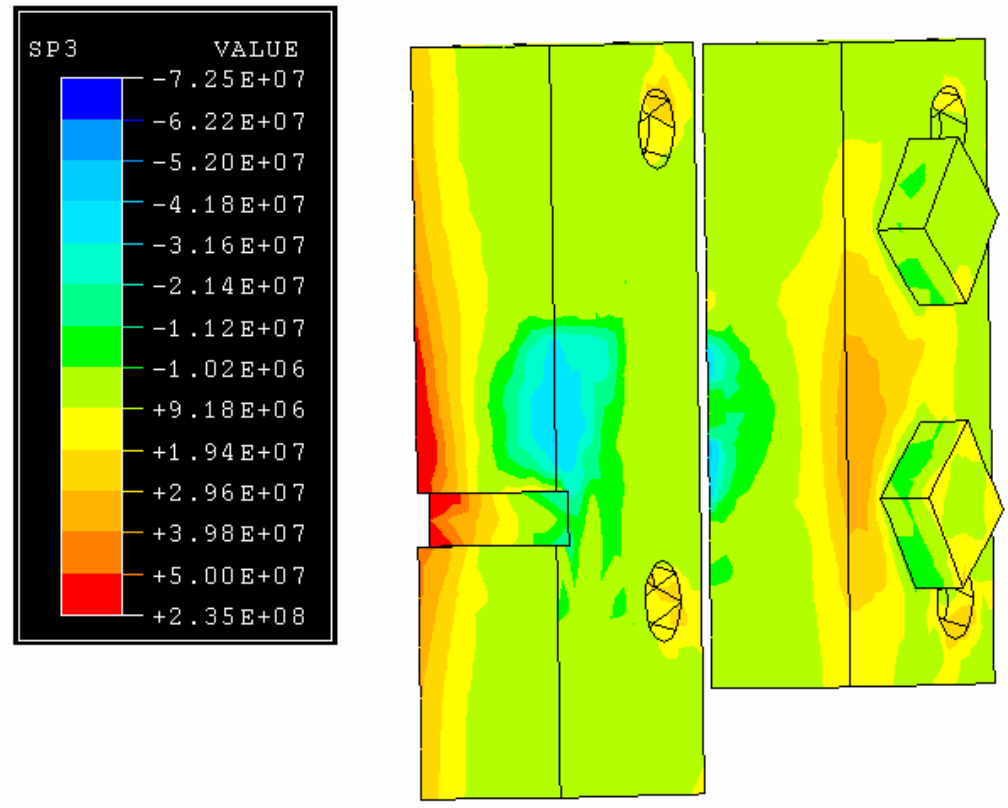

Figure A.4.4: showing compressive stresses in the platens for case 4
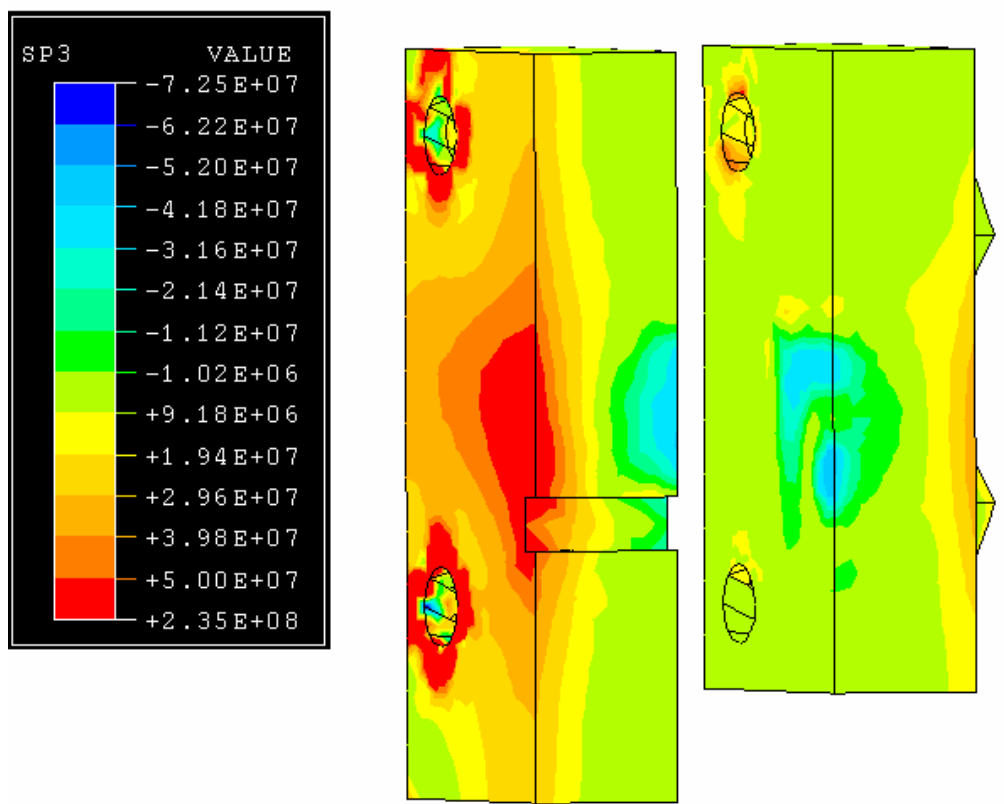

Figure A.4.5: showing compressive stresses in the platens (another view) for case 4 


\section{APPENDIX A.5 Plots for Case 5}

\section{Specifications for case 5:}

- Die size (A): 24”

- Die thickness (B): 5"

- Platen thickness (C): 9"

- Thickness ratio (D): 0.4 (Insert thickness: 3", Shoulder thickness: 2")

- Die Location (E): High

\begin{tabular}{|c|r|}
\hline \multicolumn{1}{|l|}{ COPEN } & VALUE \\
\hline & $-4.02 E-19$ \\
$+1.74 E-05$ \\
$+3.48 E-05$ \\
$-+5.23 E-05$ \\
$-+6.97 E-05$ \\
$-+8.71 E-05$ \\
$-+1.05 E-04$ \\
$+1.22 E-04$ \\
$-+1.39 E-04$ \\
$-+1.57 E-04$ \\
$-+1.74 E-04$ \\
$-1.92 E-04$ \\
$+2.09 E-04$ \\
$+2.26 E-04$ \\
\hline
\end{tabular}

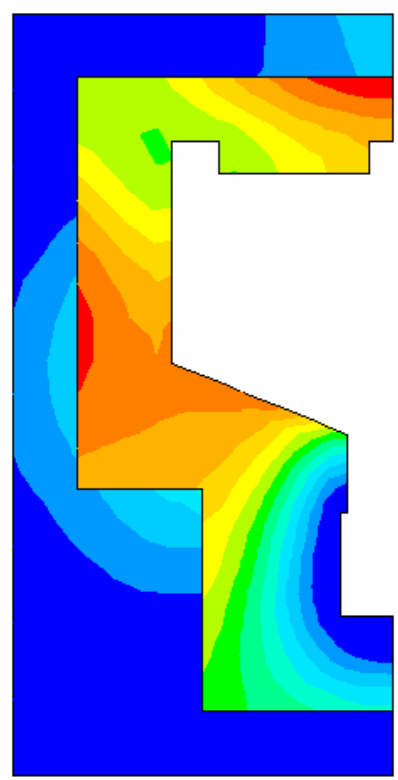

Figure A.5.1: showing parting plane separation for case 5 

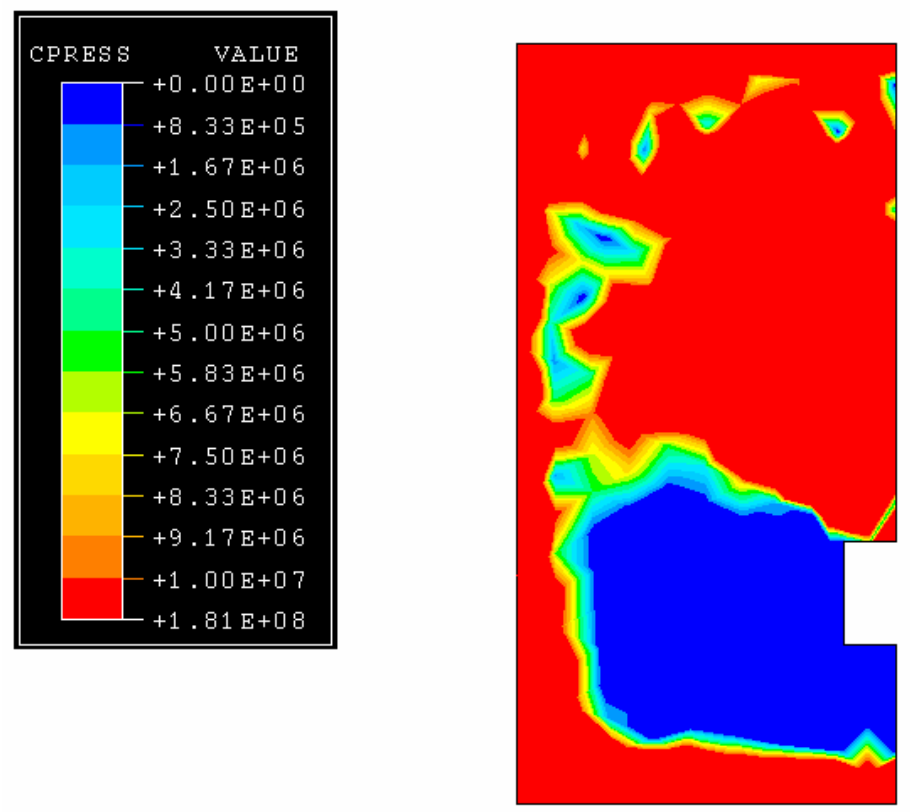

Figure A.5.2: showing contact pressure at the back of the cover die for case 5
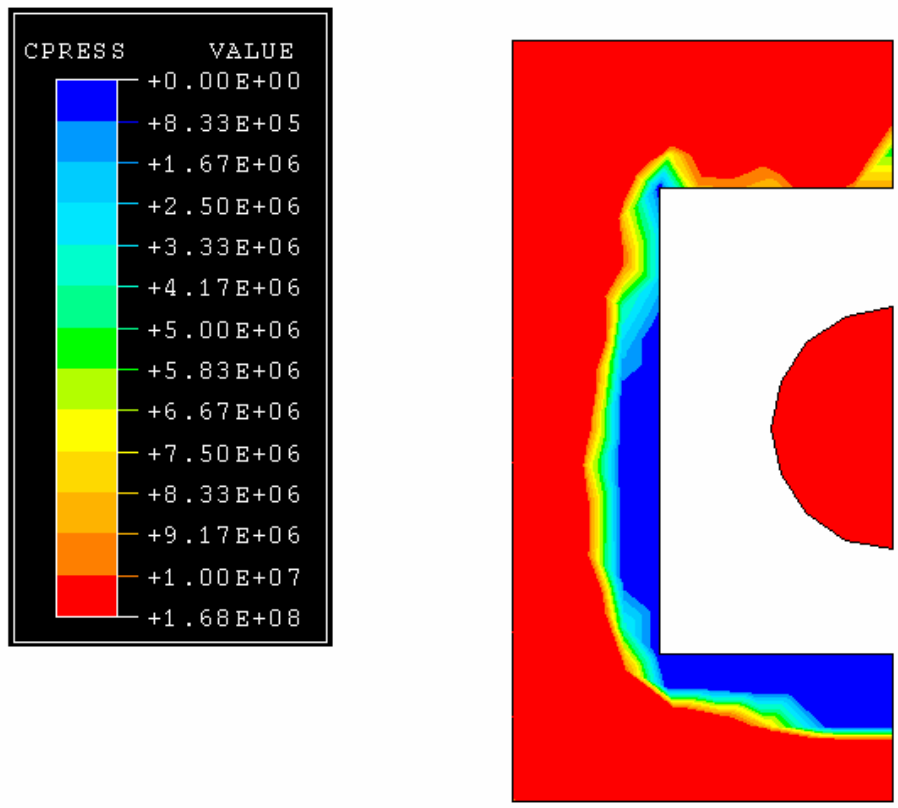

Figure A.5.3: showing contact pressure at the back of the ejector die for case 5 

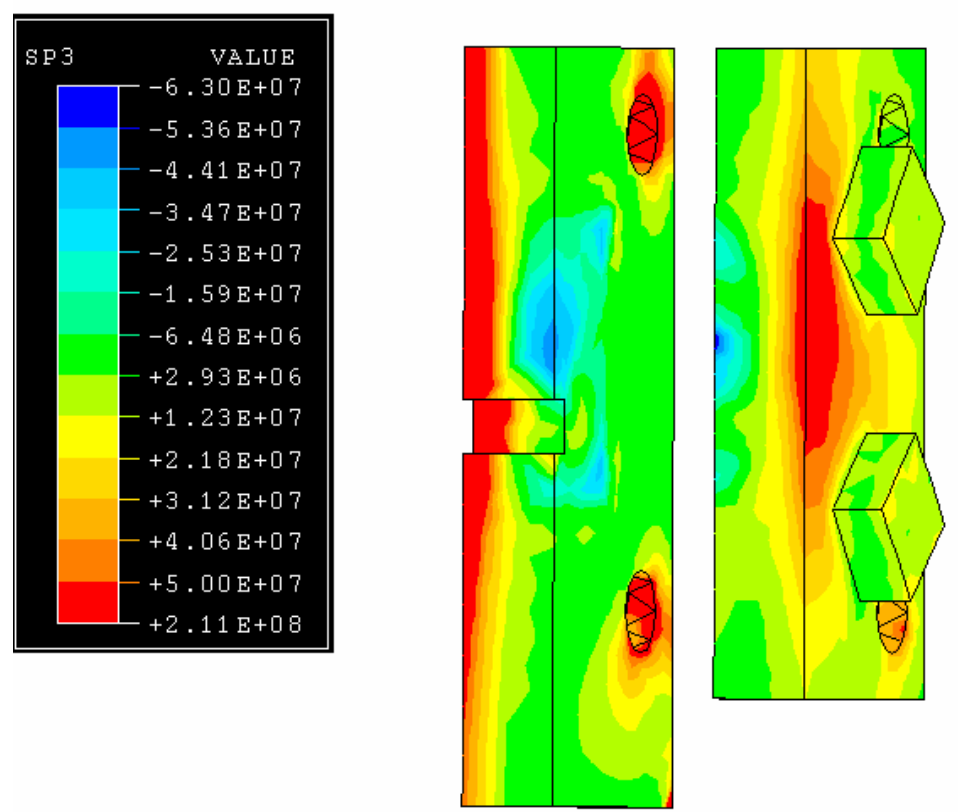

Figure A.5.4: showing compressive stresses in the platens for case 5

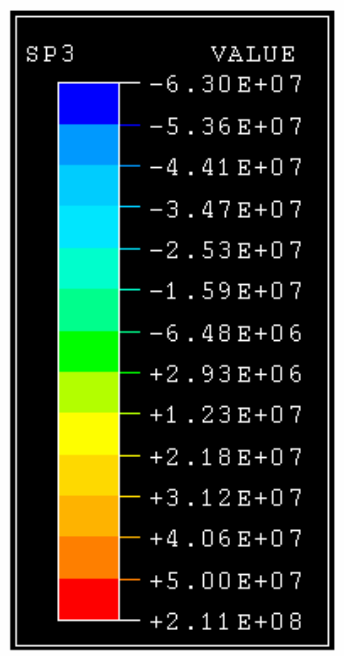
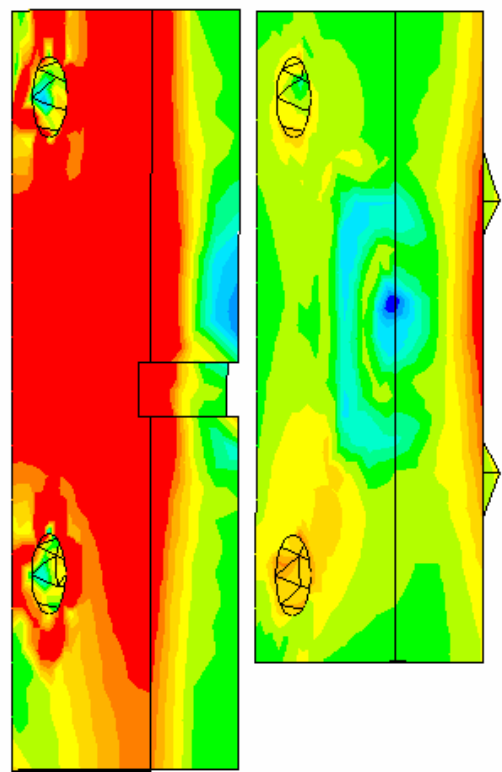

Figure A.5.5: showing compressive stresses in the platens (another view) for case 5 


\section{APPENDIX A.6 Plots for Case 6}

\section{Specifications for case 6:}

- Die size (A): 39"

- Die thickness (B): 5"

- Platen thickness (C): 14.5"

- Thickness ratio (D): 0.5 (Insert thickness: 2.5", Shoulder thickness: 2.5")

- Die Location (E): Low

\begin{tabular}{|c|r|}
\hline COPEN & VALUE \\
\hline & $-3.28 E-19$ \\
$+1.65 E-05$ \\
$-3.30 E-05$ \\
$-+4.96 E-05$ \\
$-+6.61 E-05$ \\
$-+8.26 E-05$ \\
$-+9.91 E-05$ \\
$-+1.16 E-04$ \\
$-+1.32 E-04$ \\
$-+1.49 E-04$ \\
$-+1.65 E-04$ \\
$-+1.82 E-04$ \\
$-+1.98 E-04$ \\
$+2.15 E-04$ \\
\hline
\end{tabular}

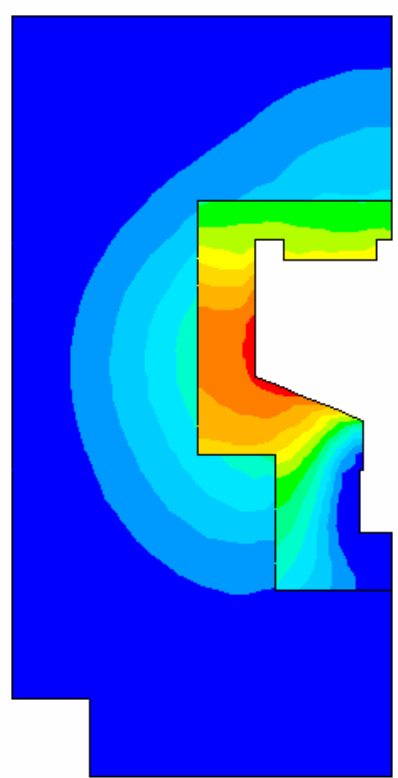

FigureA.6.1: showing parting plane separation for case 6 

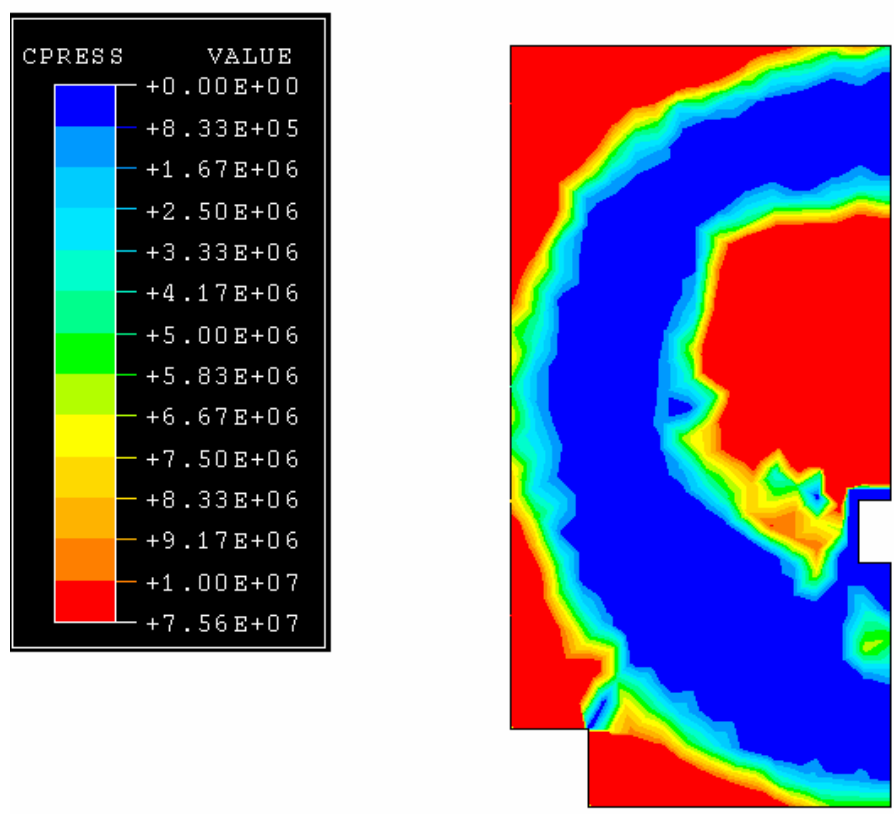

FigureA.6.2: showing contact pressure at the back of the cover die for case 6

\begin{tabular}{|c|c|}
\hline \multirow[t]{15}{*}{ CPRESS } & VALUE \\
\hline & +U. $00 \mathrm{E}+00$ \\
\hline & $+8.33 E+05$ \\
\hline & $-+1.67 \mathrm{E}+06$ \\
\hline & $-+2.50 E+06$ \\
\hline & $-+3.33 E+06$ \\
\hline & $-+4.17 \mathrm{E}+06$ \\
\hline & $-+5.00 E+06$ \\
\hline & $-+5.83 E+06$ \\
\hline & $-+6.67 \mathrm{E}+06$ \\
\hline & $-+7.50 \mathrm{E}+06$ \\
\hline & $-+8.33 E+06$ \\
\hline & $-+9.17 \mathrm{E}+06$ \\
\hline & $-+1.00 \mathrm{E}+07$ \\
\hline & $-+2.14 \mathrm{E}+08$ \\
\hline
\end{tabular}

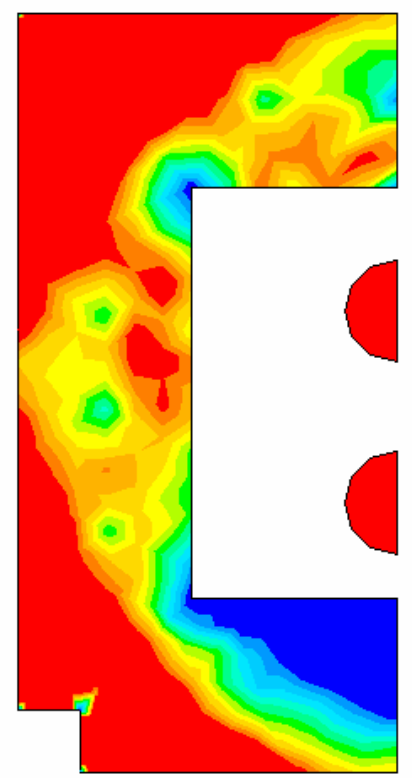

FigureA.6.3: showing contact pressure at the back of the ejector die for case 6 

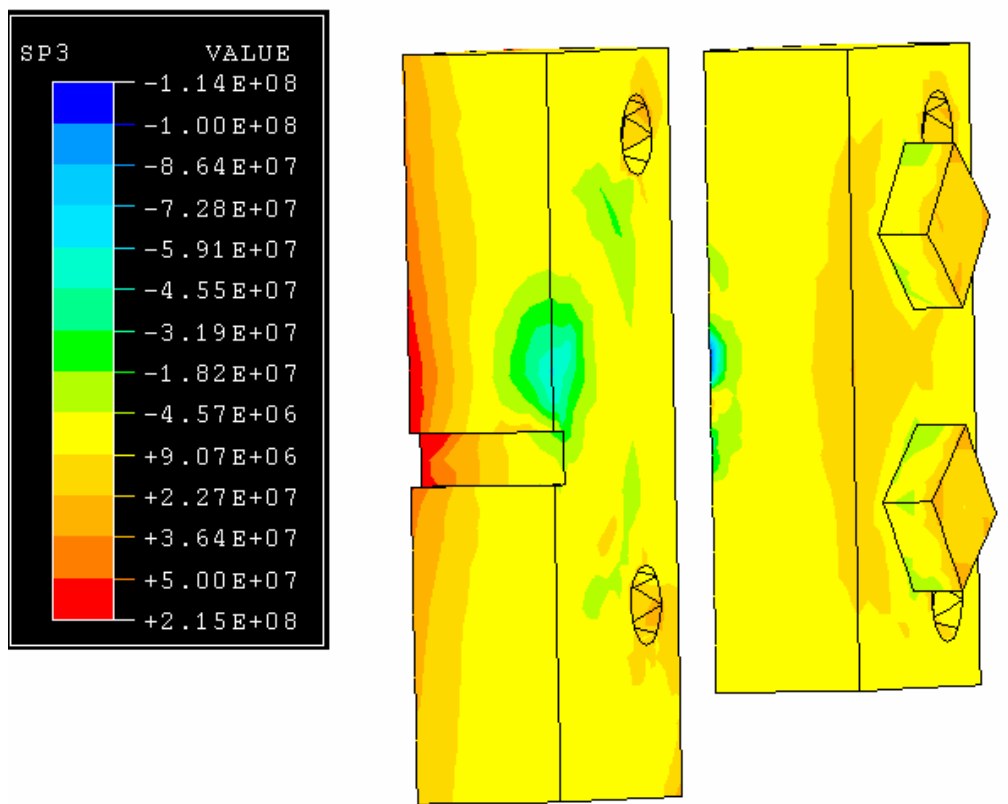

Figure A.6.4: showing compressive stresses in the platens for case 6
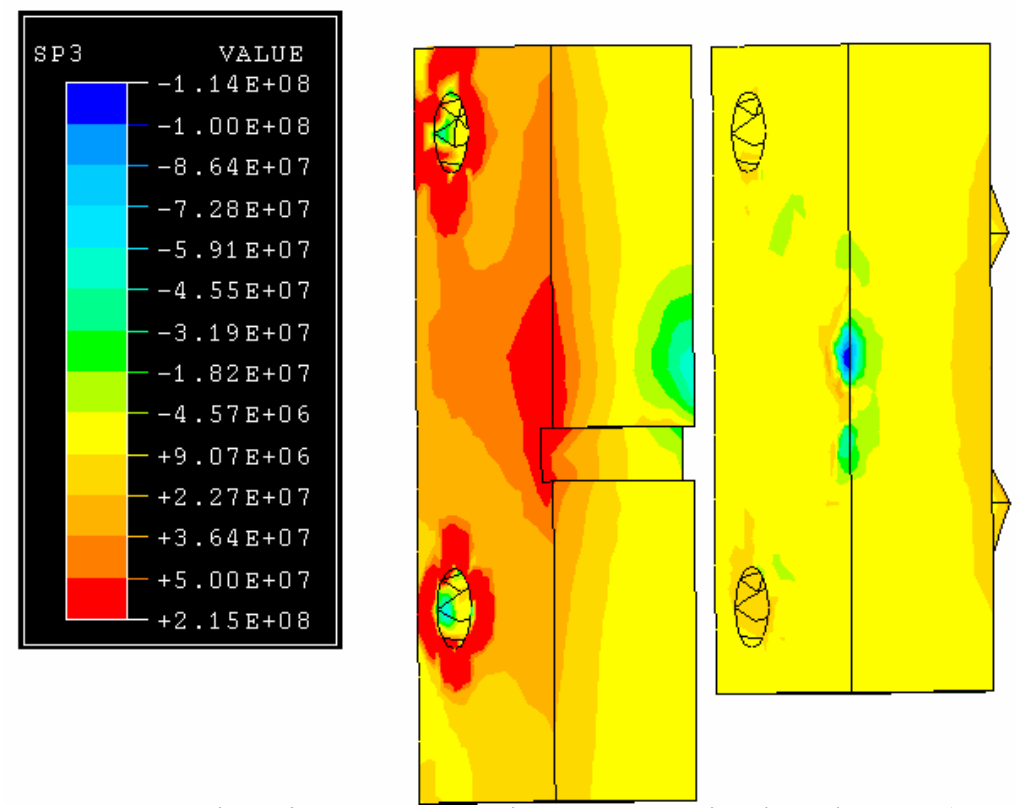

Figure A.6.5: showing compressive stresses in the platens (another view) for case 6 


\section{APPENDIX A.7 Plots for Case 7}

\section{Specifications for case 7:}

- $\operatorname{Die} \operatorname{size}(\mathrm{A}): 39$ "

- Die thickness (B): 5"

- Platen thickness (C): 9"

- Thickness ratio (D): 0.4 (Insert thickness: 3", Shoulder thickness: 2")

- Die Location (E): Low

\begin{tabular}{|l|r|}
\hline COPEN & VALUE \\
\hline & $-3.88 E-19$ \\
$+3.83 E-05$ \\
$+7.65 E-05$ \\
$-+1.15 E-04$ \\
$-+1.53 E-04$ \\
$-+1.91 E-04$ \\
$-+2.30 E-04$ \\
$-+2.68 E-04$ \\
$-+3.06 E-04$ \\
$-+3.44 E-04$ \\
$-+3.83 E-04$ \\
$-+4.21 E-04$ \\
$-+4.59 E-04$ \\
$+4.97 E-04$ \\
\hline
\end{tabular}

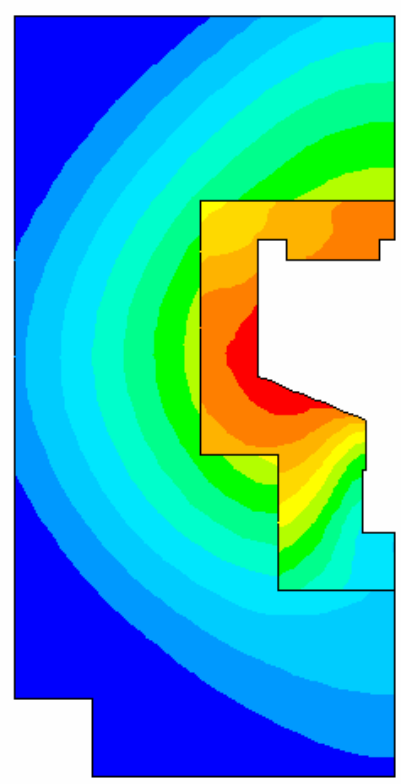

FigureA.7.1: showing parting plane separation for case 7 

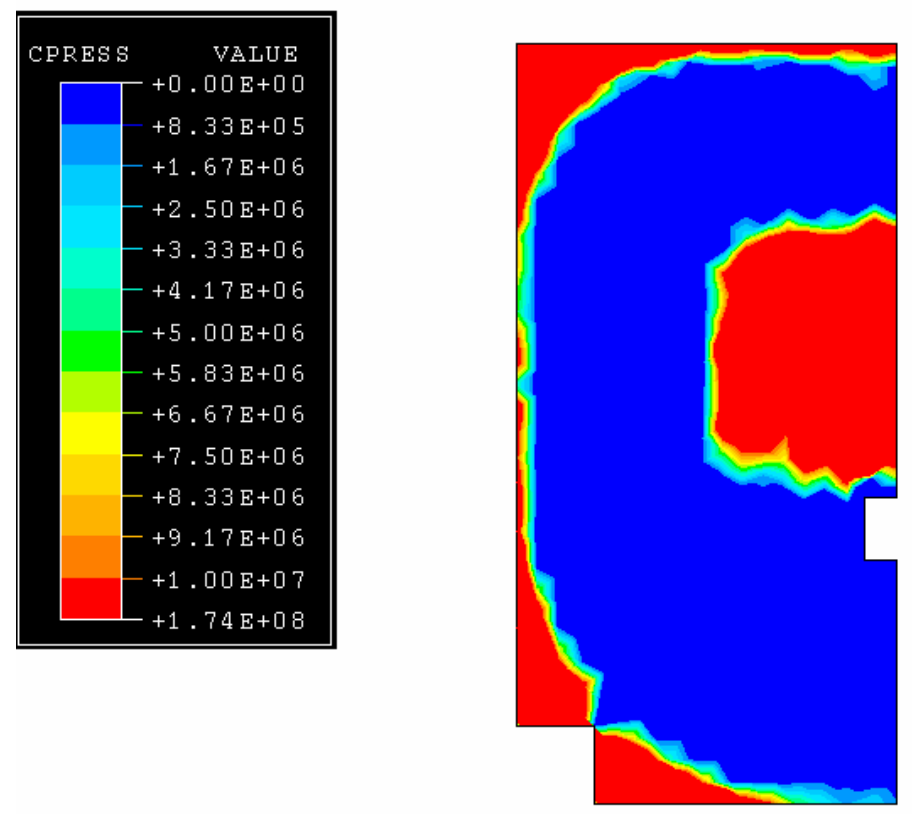

FigureA.7.2: showing contact pressure at the back of the cover die for case 7
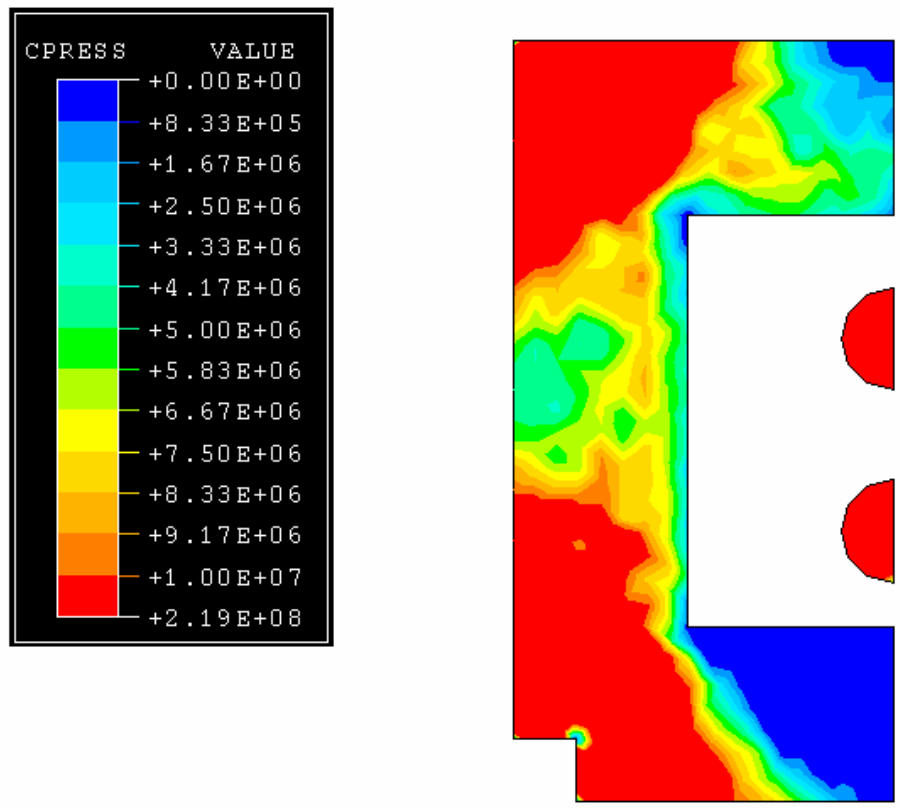

FigureA.7.3: showing contact pressure at the back of the ejector die for case 7 

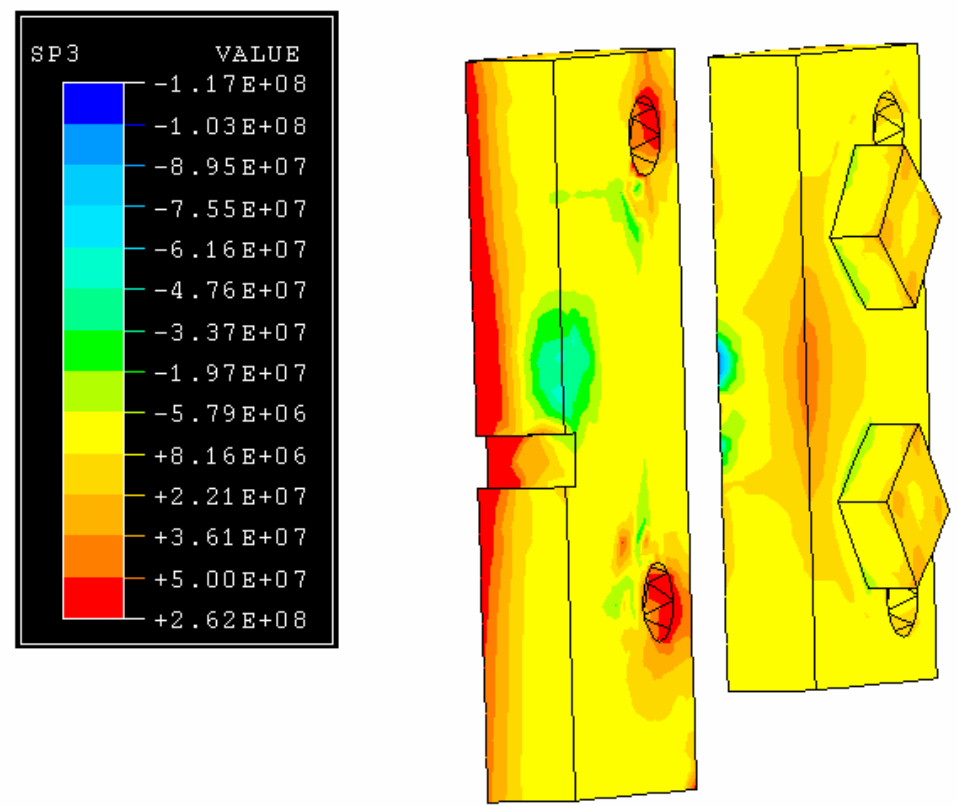

Figure A.7.4: showing compressive stresses in the platens for case 7
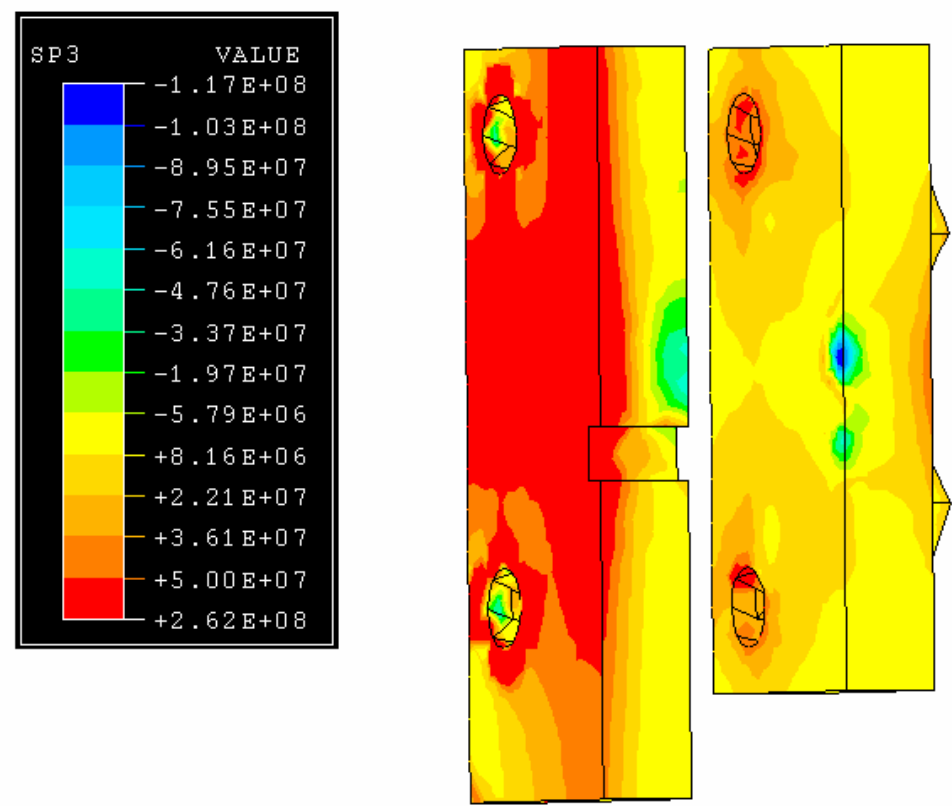

Figure A.7.5: showing compressive stresses in the platens (another view) for case 7 


\section{APPENDIX A.8 Plots for Case 8}

\section{Specifications for case 8:}

- Die size (A): 24”

- Die thickness (B): 10"

- Platen thickness (C): 9"

- Thickness ratio (D): 0.4 (Insert thickness: 6", Shoulder thickness: 4")

- Die Location (E): Low

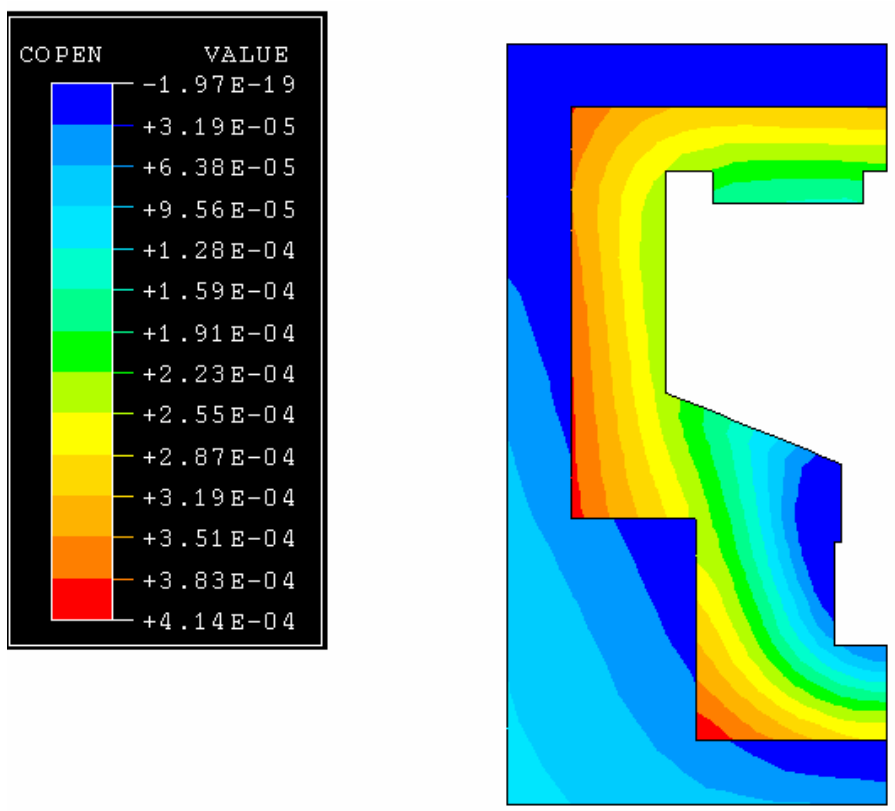

FigureA.8.1: showing parting plane separation for case 8 

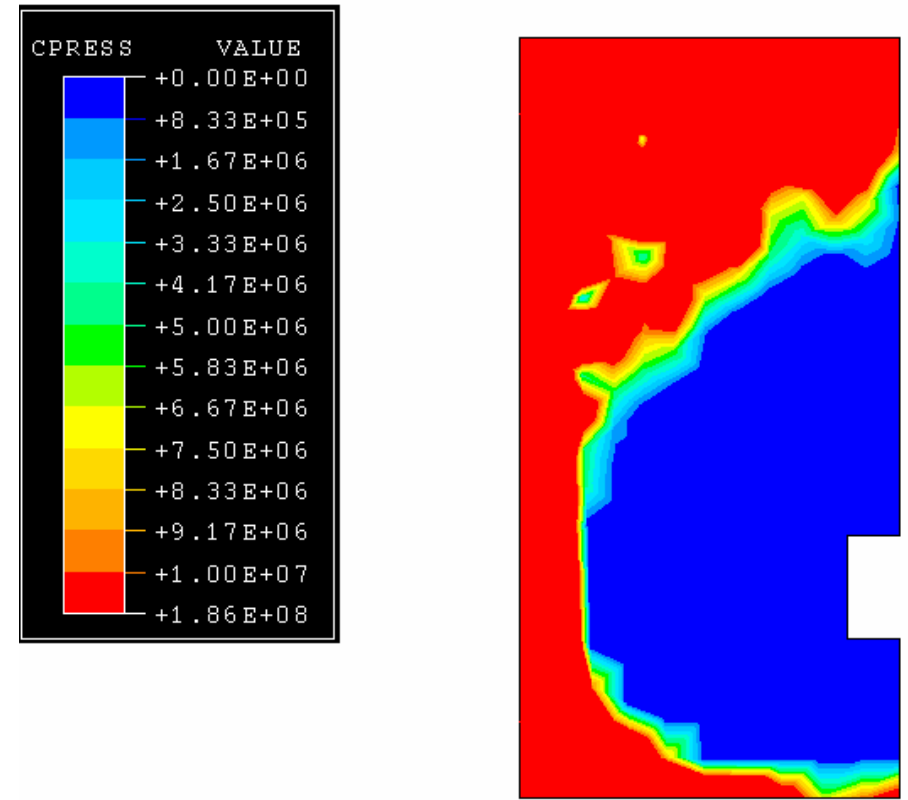

FigureA.ð.L: snowing contact pressure at the back or the cover die for case 8
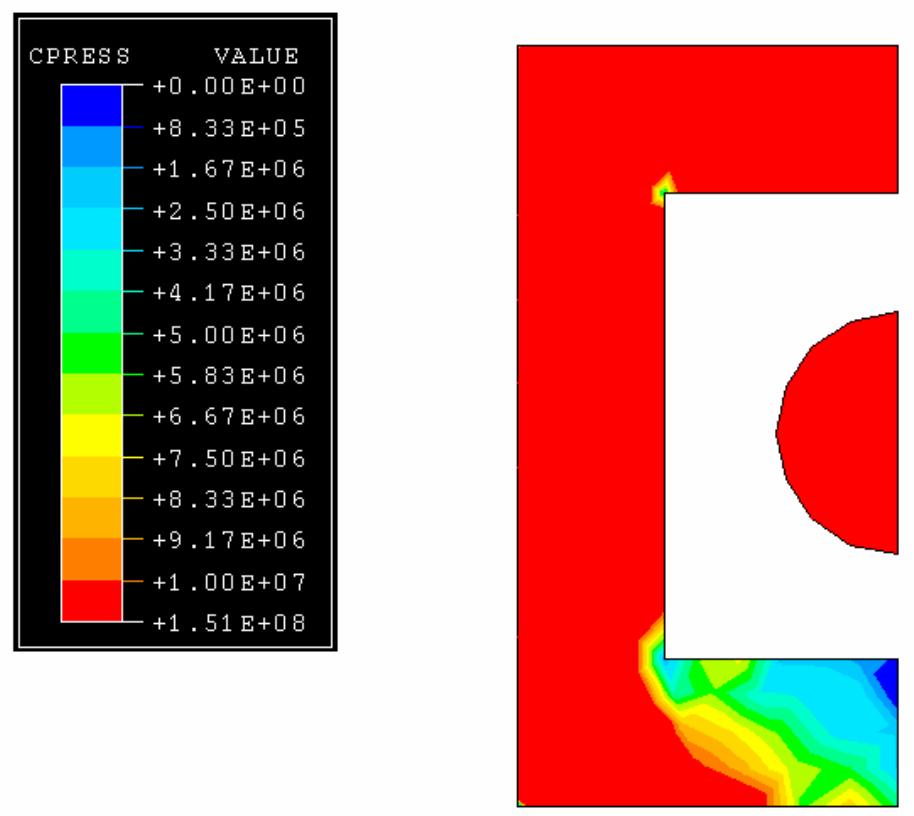

FigureA.8.3: showing contact pressure at the back of the ejector die for case 8 

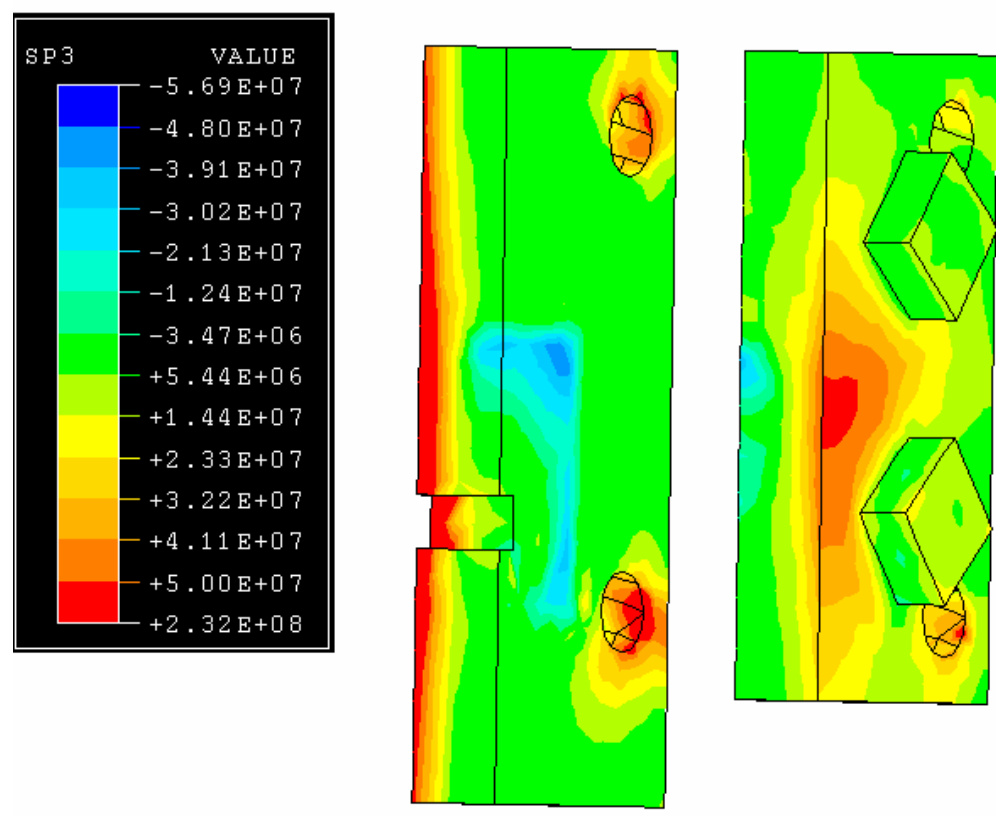

Figure A.8.4: showing compressive stresses in the platens for case 8
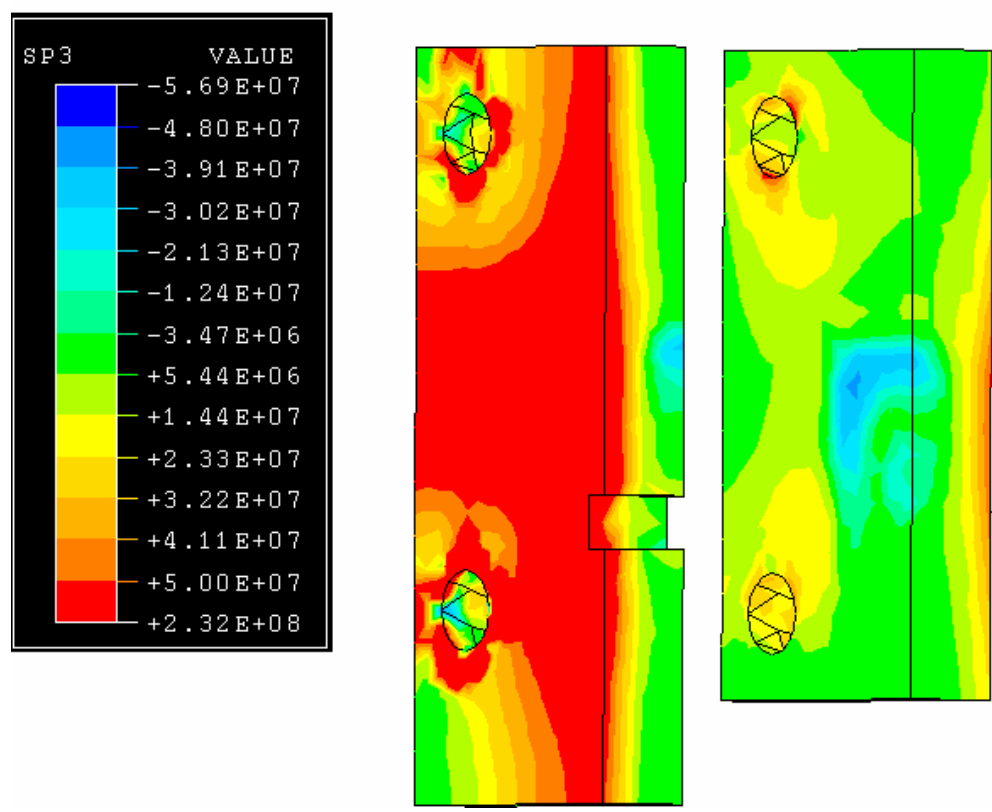

Figure A.8.5: showing compressive stresses in the platens (another view) for case 8 


\section{APPENDIX A.9 Plots for Case 9}

\section{Specifications for case 9:}

- Die size (A): 24”

- Die thickness (B): 10"

- Platen thickness (C): 9"

- Thickness ratio (D): 0.5 (Insert thickness: 5", Shoulder thickness: 5")

- Die Location (E): High

\begin{tabular}{|c|r|}
\hline \multicolumn{1}{|l|}{ COPEN } & VALUE \\
\hline & $-6.98 \mathrm{E}-19$ \\
$+2.36 \mathrm{E}-05$ \\
$+4.72 \mathrm{E}-05$ \\
$-7.09 \mathrm{E}-05$ \\
$-+9.45 \mathrm{E}-05$ \\
$-+1.18 \mathrm{E}-04$ \\
$-+1.42 \mathrm{E}-04$ \\
$-1.65 \mathrm{E}-04$ \\
$-+1.89 \mathrm{E}-04$ \\
$-+2.13 \mathrm{E}-04$ \\
$-+2.36 \mathrm{E}-04$ \\
$-+2.60 \mathrm{E}-04$ \\
$-+2.83 \mathrm{E}-04$ \\
$+3.07 \mathrm{E}-04$ \\
\hline
\end{tabular}

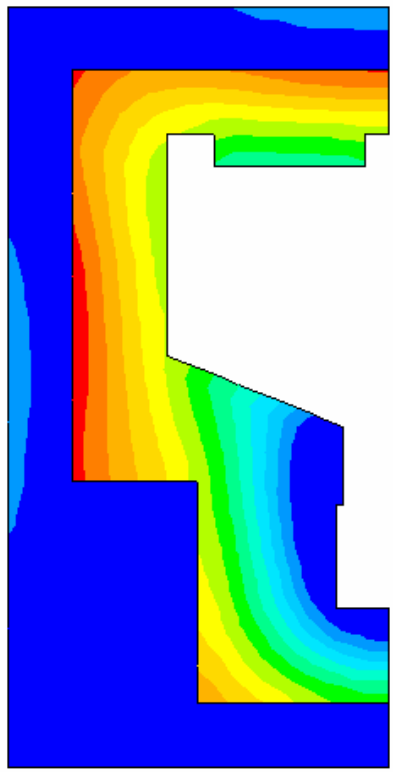

FigureA.9.1: showing parting plane separation for case 9 

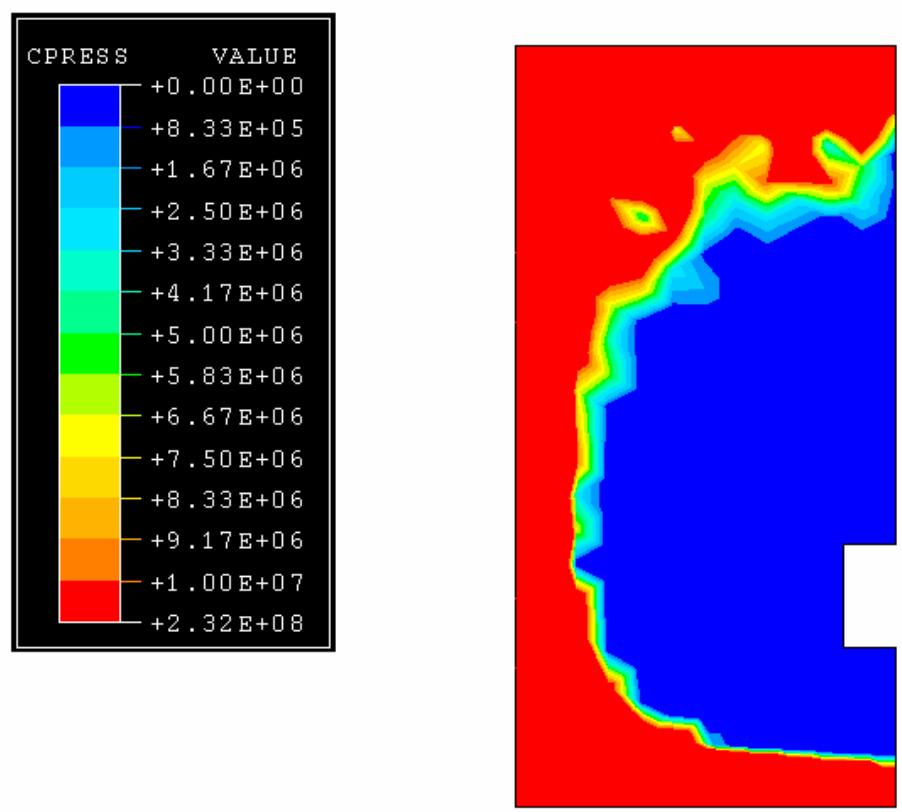

FigureA.9.2: showing contact pressure at the back of the cover die for case 9
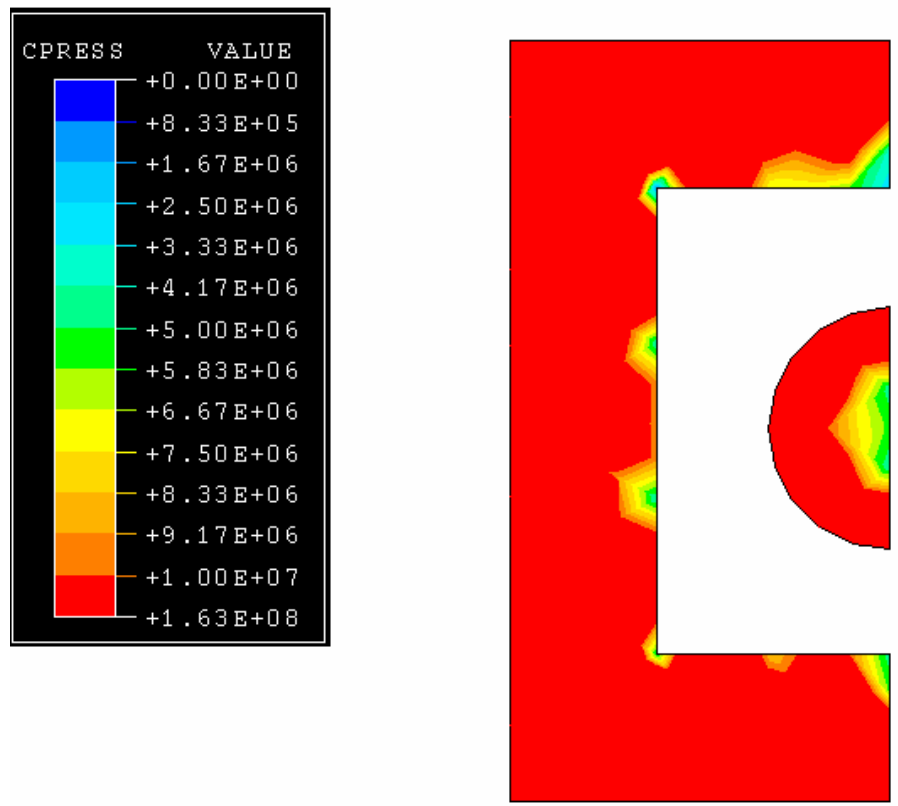

FigureA.9.3: showing contact pressure at the back of the ejector die for case 9 


\begin{tabular}{|r|r|}
\hline \hline \multicolumn{1}{|l|}{ SP3 } & VALUE \\
\hline & $-5.74 E+07$ \\
$-4.84 E+07$ \\
$-3.95 E+07$ \\
$-3.05 E+07$ \\
$-2.16 E+07$ \\
$-1.26 E+07$ \\
$-3.68 E+06$ \\
$-+5.26 E+06$ \\
$-+1.42 E+07$ \\
$-+2.32 E+07$ \\
$+3.21 E+07$ \\
$+4.11 E+07$ \\
$+5.00 E+07$ \\
$+1.92 E+08$ \\
\hline
\end{tabular}
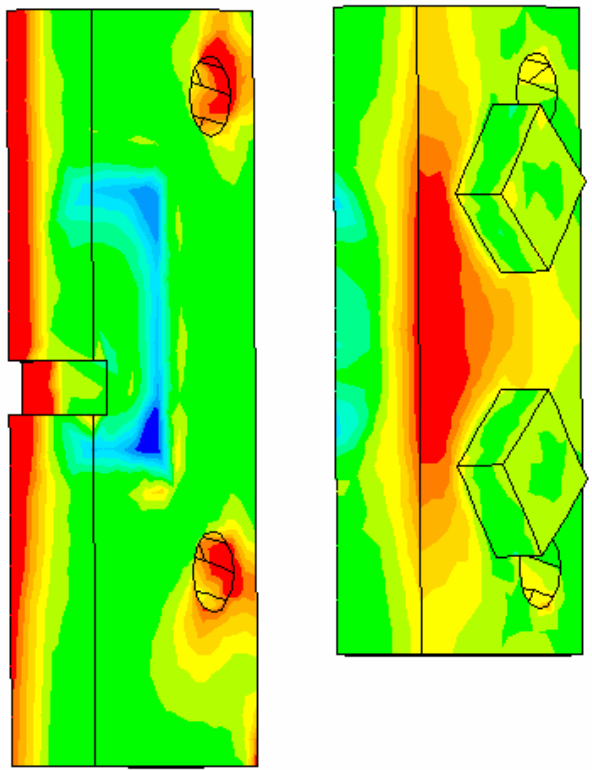

Figure A.9.4: showing compressive stresses in the platens for case 9
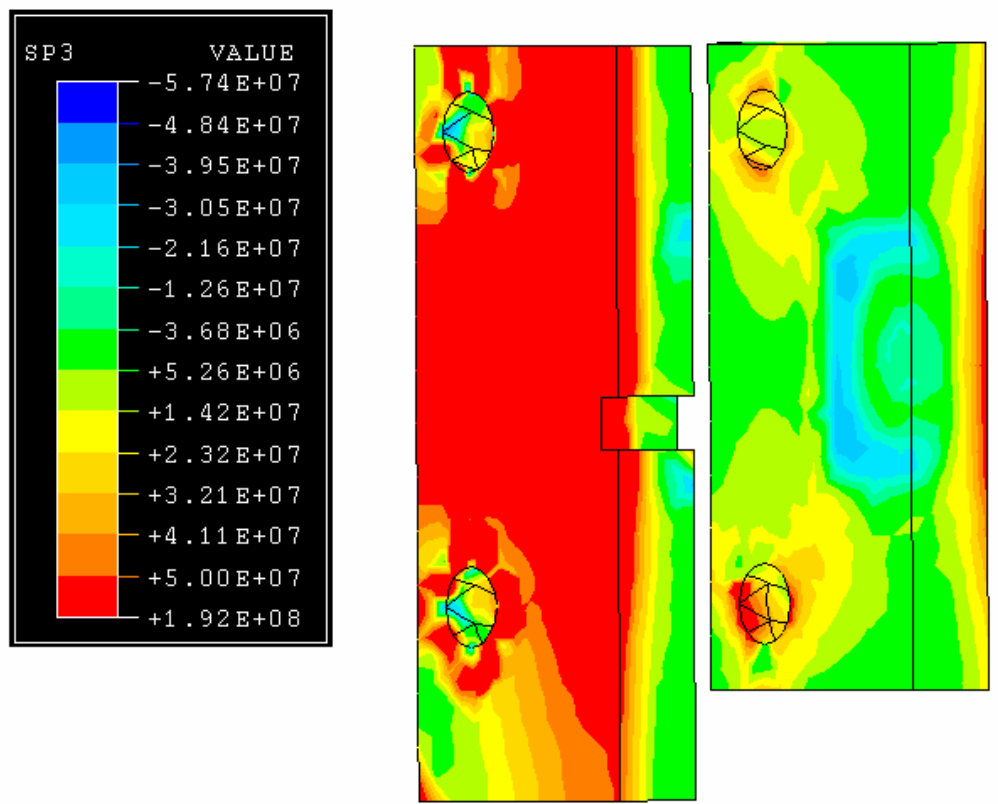

Figure A.9.5: showing compressive stresses in the platens (another view) for case 9 
APPENDIX A.10 Plots for Case 10

\section{Specifications for case 10:}

- $\operatorname{Die} \operatorname{size}(\mathrm{A}): 24$ "

- Die thickness (B): 5"

- Platen thickness (C): 14.5"

- Thickness ratio (D): 0.5 (Insert thickness: 2.5", Shoulder thickness: 2.5")

- Die Location (E): High

\begin{tabular}{|c|r|}
\hline COPEN & VALUE \\
\hline & $-5.44 \mathrm{E}-19$ \\
$+1.00 \mathrm{E}-05$ \\
$+2.00 \mathrm{E}-05$ \\
$-+3.00 \mathrm{E}-05$ \\
$-+4.00 \mathrm{E}-05$ \\
$-+5.00 \mathrm{E}-05$ \\
$-+6.00 \mathrm{E}-05$ \\
$-7.00 \mathrm{E}-05$ \\
$-+8.00 \mathrm{E}-05$ \\
$-+9.00 \mathrm{E}-05$ \\
$-1.00 \mathrm{E}-04$ \\
$-1.10 \mathrm{E}-04$ \\
$-1.20 \mathrm{E}-04$ \\
$+1.30 \mathrm{E}-04$
\end{tabular}

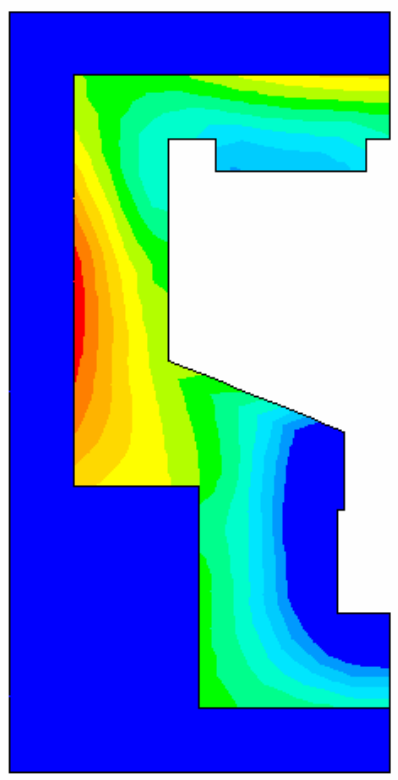

FigureA.10.1: showing parting plane separation for case 10 


\begin{tabular}{|c|c|}
\hline \multirow{14}{*}{ CPRESS } & VALUE \\
\hline & $+8.33 E+05$ \\
\hline & $-+1.67 \mathrm{E}+06$ \\
\hline & $-+2.50 \mathrm{E}+06$ \\
\hline & $-+3.33 \mathrm{E}+06$ \\
\hline & $-+4.17 \mathrm{E}+06$ \\
\hline & $-+5.00 \mathrm{E}+06$ \\
\hline & $-+5.83 E+06$ \\
\hline & $-+6.67 \mathrm{E}+06$ \\
\hline & $-+7.50 \mathrm{E}+06$ \\
\hline & $-+8.33 E+06$ \\
\hline & $-+9.17 \mathrm{E}+06$ \\
\hline & $-+1.00 \mathrm{E}+07$ \\
\hline & $-+1.03 E+08$ \\
\hline
\end{tabular}

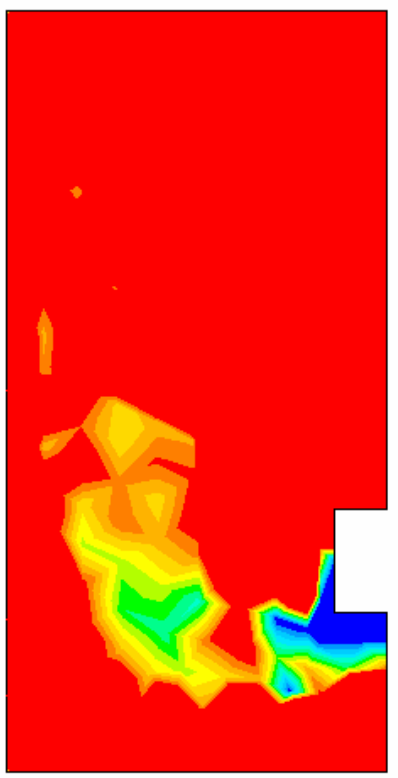

FigureA.10.2: showing contact pressure at the back of the cover die for case 10

\begin{tabular}{|c|c|}
\hline \multirow[t]{15}{*}{ CPRESS } & VALUE \\
\hline & $+0.00 \mathrm{E}+00$ \\
\hline & $+8.33 E+05$ \\
\hline & $-+1.67 \mathrm{E}+06$ \\
\hline & $-+2.50 \mathrm{E}+06$ \\
\hline & $-+3.33 E+06$ \\
\hline & $-+4.17 \mathrm{E}+06$ \\
\hline & $-+5.00 E+06$ \\
\hline & $-+5.83 E+06$ \\
\hline & $-+6.67 \mathrm{E}+06$ \\
\hline & $-+7.50 \mathrm{E}+06$ \\
\hline & $-+8.33 \mathrm{E}+06$ \\
\hline & $-+9.17 \mathrm{E}+06$ \\
\hline & $-+1.000+07$ \\
\hline & $-+1.33 \mathrm{E}+08$ \\
\hline
\end{tabular}

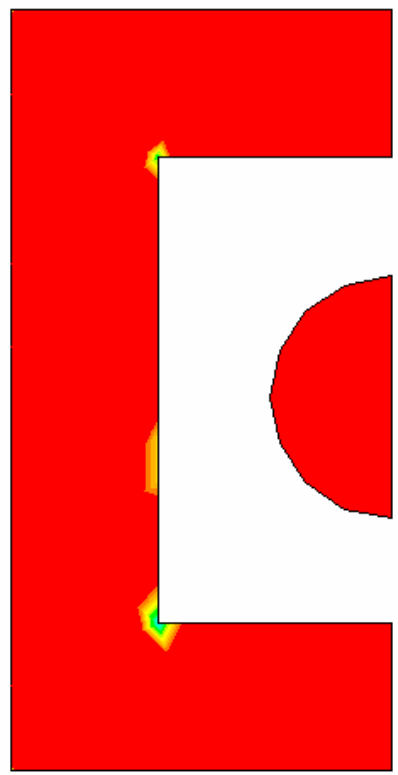

FigureA.10.3: showing contact pressure at the back of the ejector die for case 10 

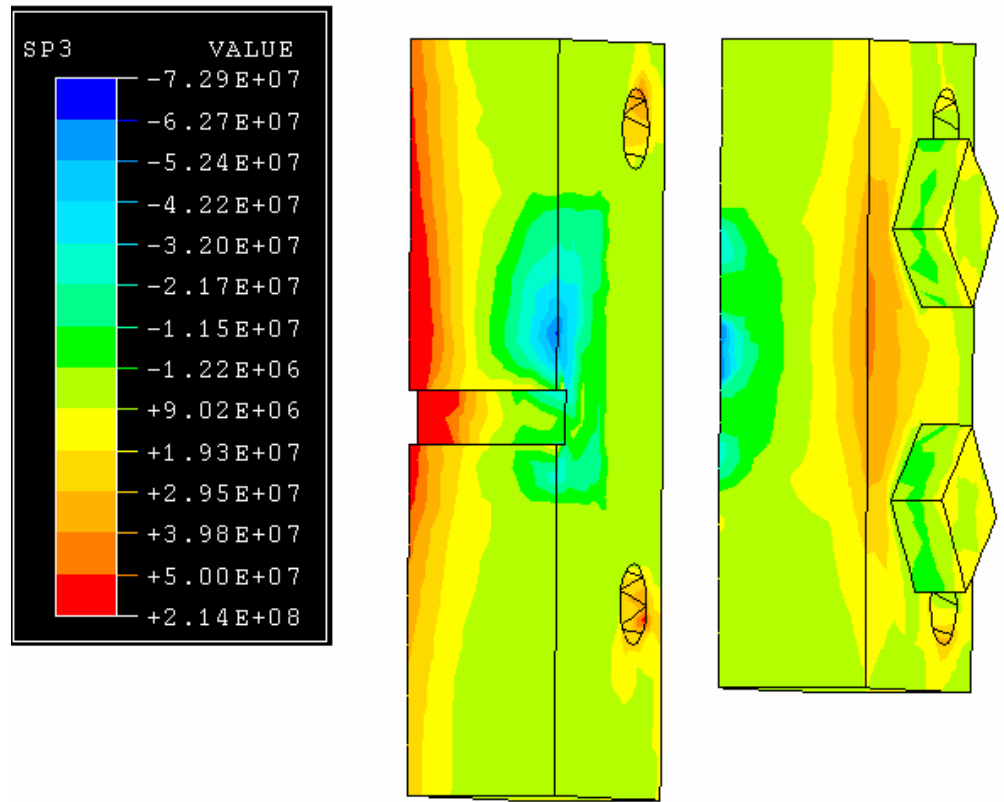

Figure A.10.4: showing compressive stresses in the platens for case 10
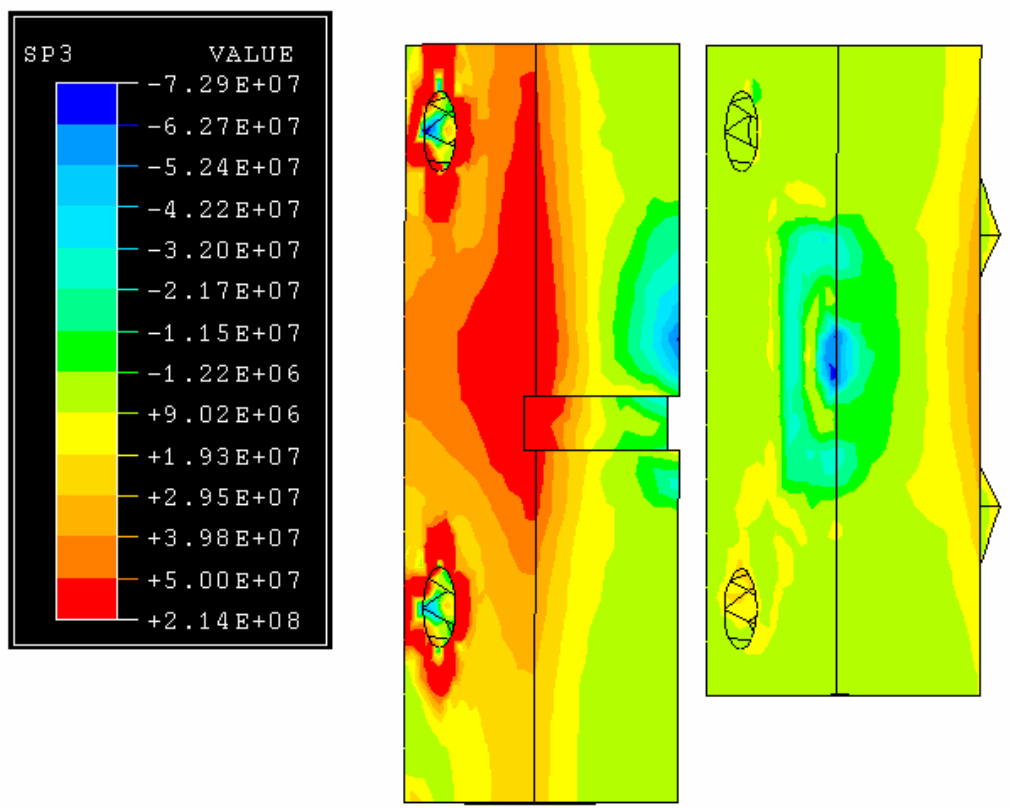

Figure A.10.5: showing compressive stresses in the platens (another view) for case 10 


\section{APPENDIX A.11 Plots for Case 11}

\section{Specifications for case 11:}

- $\operatorname{Die} \operatorname{size}(\mathrm{A}): 31.5$ "

- Die thickness (B): 7.5"

- Platen thickness (C): 11.75"

- Thickness ratio (D): 0.5 (Insert thickness: 3.75", Shoulder thickness: 3.75”)

- Die Location (E): Low

\begin{tabular}{|c|r|}
\hline \multicolumn{1}{|c|}{ COPEN } & VALUE \\
\hline & $-6.42 \mathrm{E}-19$ \\
$+1.85 \mathrm{E}-05$ \\
$-3.70 \mathrm{E}-05$ \\
$-+5.55 \mathrm{E}-05$ \\
$-+7.40 \mathrm{E}-05$ \\
$-+9.25 \mathrm{E}-05$ \\
$-+1.11 \mathrm{E}-04$ \\
$-1.30 \mathrm{E}-04$ \\
$-1.48 \mathrm{E}-04$ \\
$-+1.67 \mathrm{E}-04$ \\
$-1.85 \mathrm{E}-04$ \\
$-+2.04 \mathrm{E}-04$ \\
$-+2.22 \mathrm{E}-04$ \\
$+2.41 \mathrm{E}-04$ \\
\hline
\end{tabular}

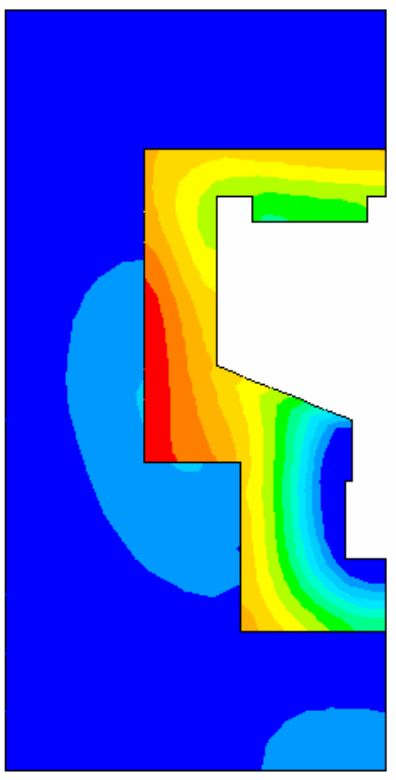

Figure A.11.1: showing parting plane separation for case 11 

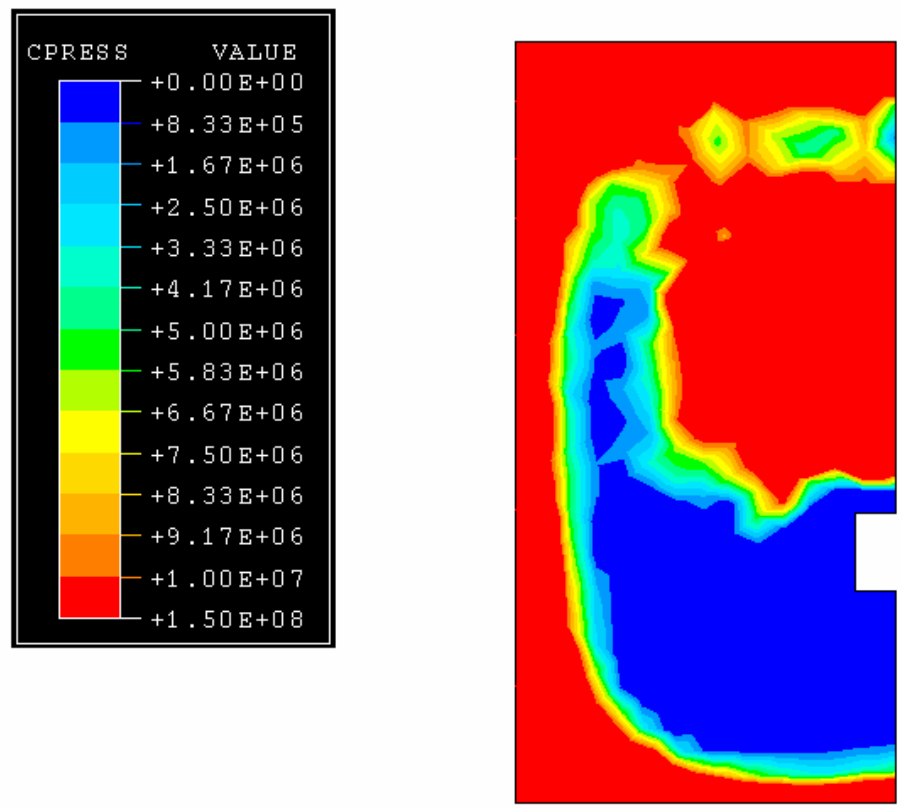

FigureA.11.2: showing contact pressure at the back of the cover die for case 11
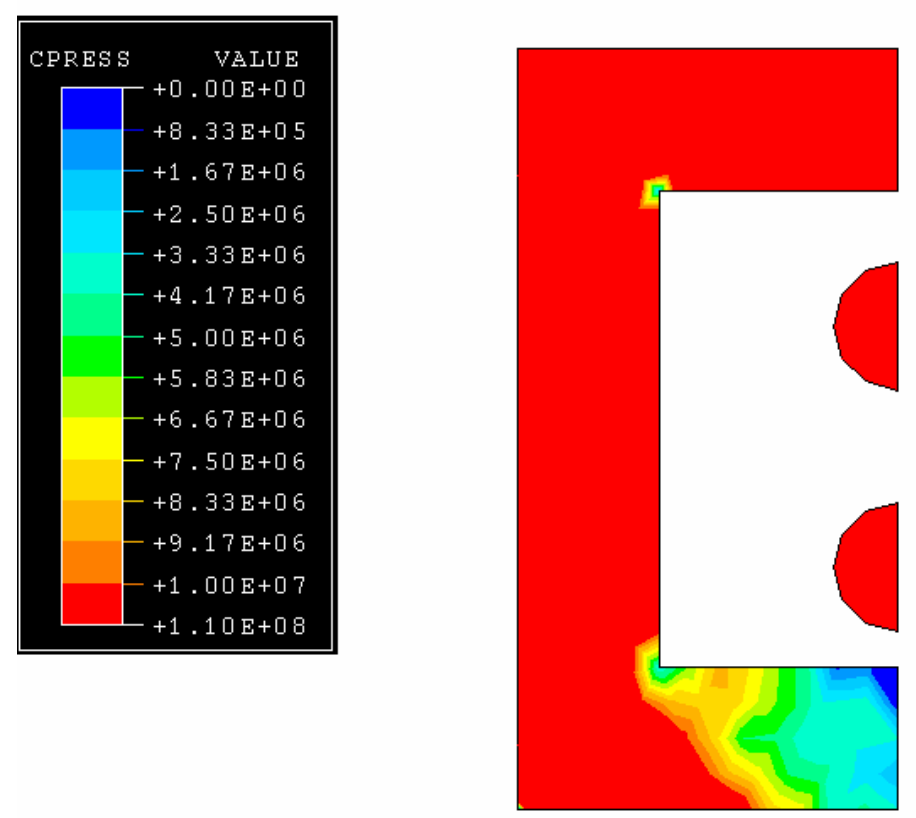

FigureA.11.3: showing contact pressure at the back of the ejector die for case 11 

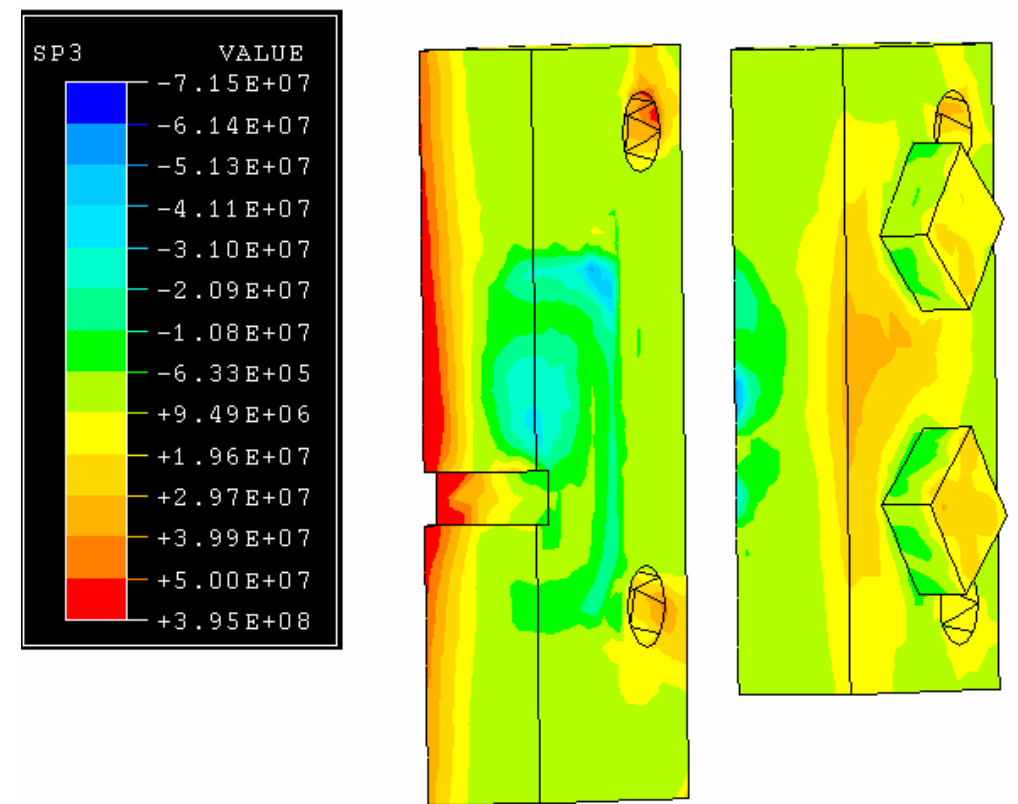

Figure A.11.4: showing compressive stresses in the platens for case 11
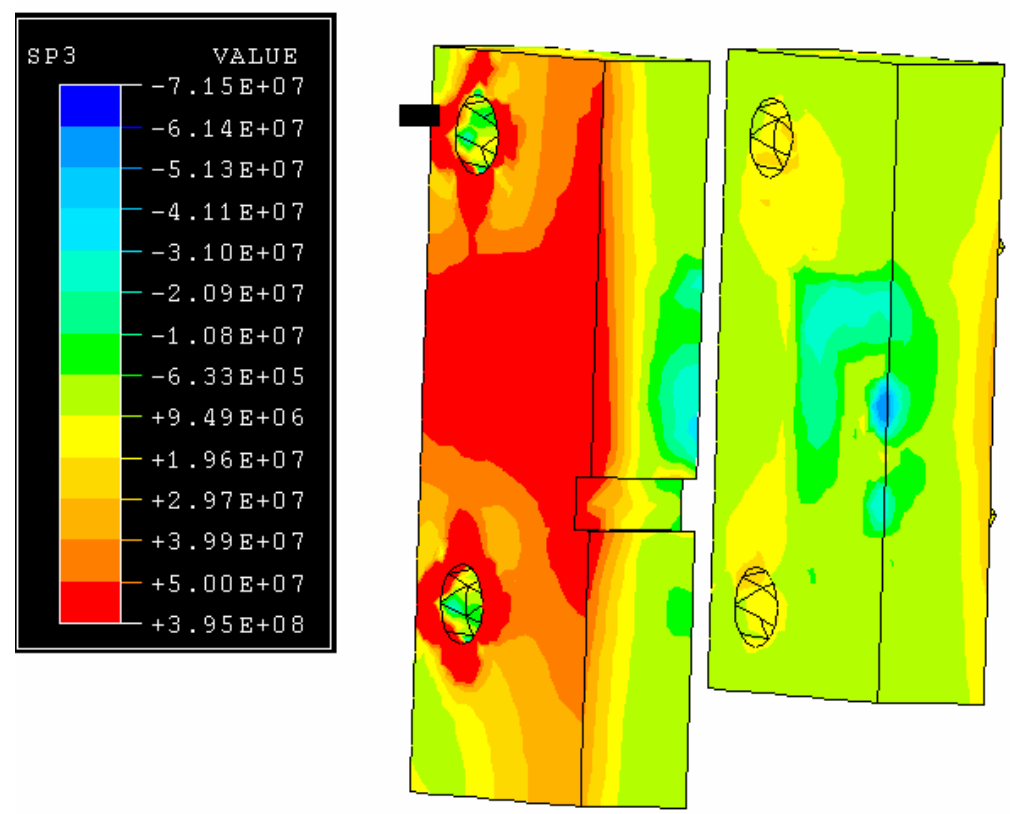

Figure A.11.5: showing compressive stresses in the platens (another view) for case 11 
APPENDIX A.12 Plots for Case 12

\section{Specifications for case 12:}

- $\operatorname{Die} \operatorname{size}(\mathrm{A}): 31.5$ "

- Die thickness (B): 7.5"

- Platen thickness (C): 9"

- Thickness ratio (D): 0.45 (Insert thickness: 4.125", Shoulder thickness: 3.375 ")

- Die Location (E): Centered

\begin{tabular}{|r|r|}
\hline \multicolumn{1}{|c|}{ COPEN } & VALUE \\
\hline & $-5.97 \mathrm{E}-19$ \\
$+2.44 \mathrm{E}-05$ \\
$+4.88 \mathrm{E}-05$ \\
$-+7.32 \mathrm{E}-05$ \\
$-+9.76 \mathrm{E}-05$ \\
$-+1.22 \mathrm{E}-04$ \\
$-+1.46 \mathrm{E}-04$ \\
$+1.71 \mathrm{E}-04$ \\
$-+1.95 \mathrm{E}-04$ \\
$-+2.20 \mathrm{E}-04$ \\
$-+2.44 \mathrm{E}-04$ \\
$+2.68 \mathrm{E}-04$ \\
$+2.93 \mathrm{E}-04$ \\
$+3.17 \mathrm{E}-04$ \\
\hline
\end{tabular}

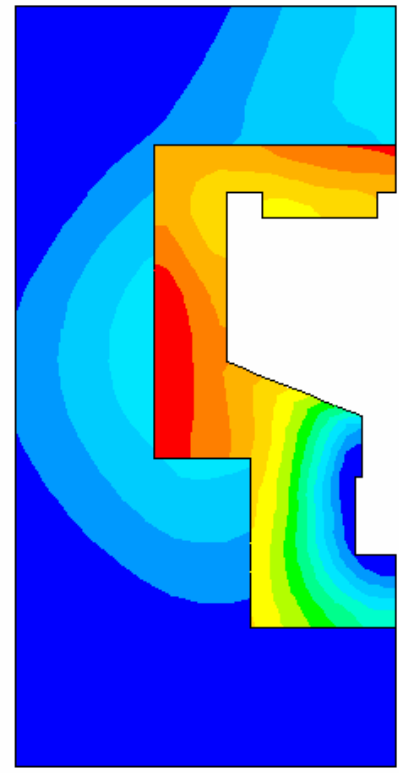

FigureA.12.1: showing parting plane separation for case 12 


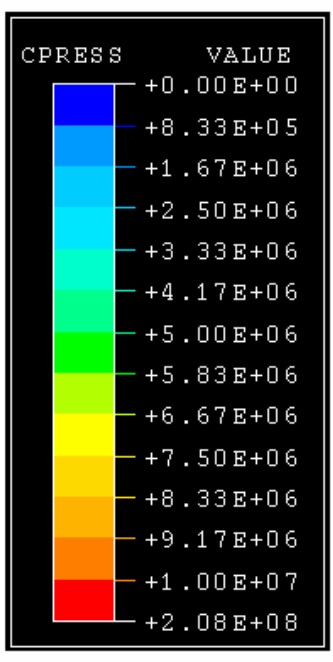

FigureA

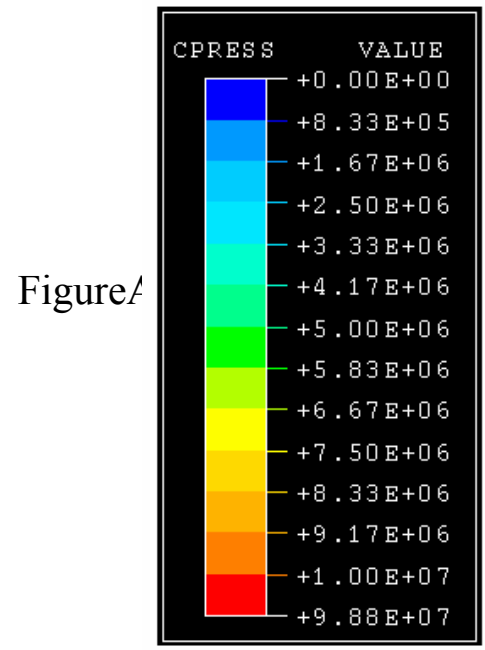

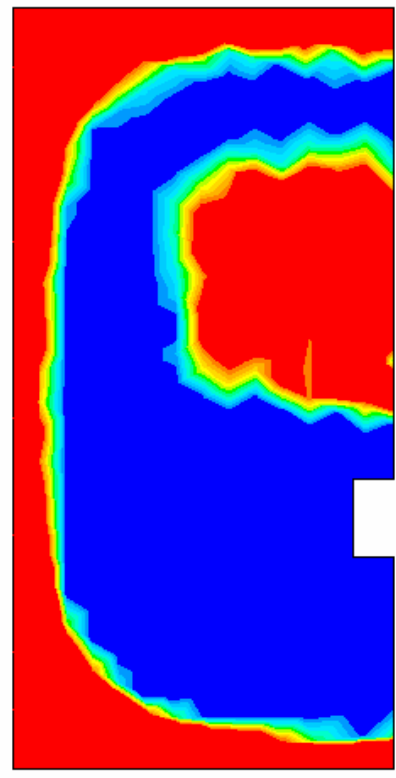

die for case 12

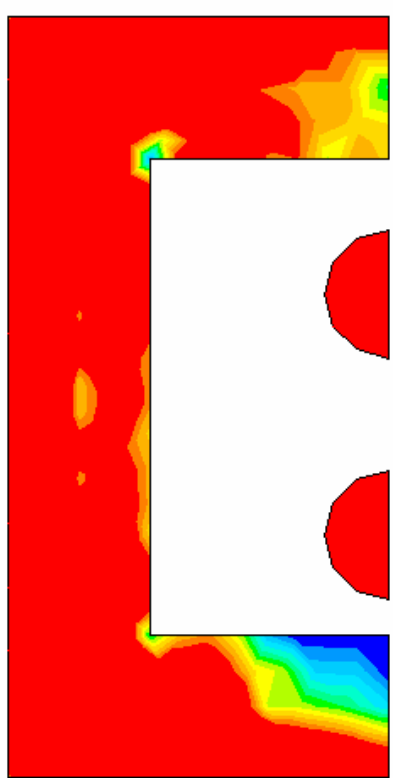

$r$ die for case 12 


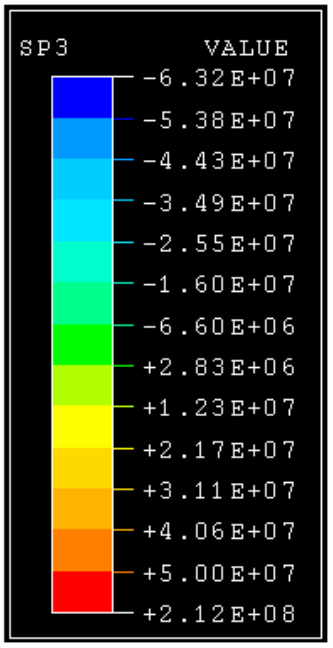

Figu

\begin{tabular}{|r|r|}
\hline \multicolumn{1}{|l|}{ SP3 } & VALUE \\
\hline & $-6.32 \mathrm{E}+07$ \\
$-5.38 \mathrm{E}+07$ \\
$-4.43 \mathrm{E}+07$ \\
$-3.49 \mathrm{E}+07$ \\
$-2.55 \mathrm{E}+07$ \\
$-1.60 \mathrm{E}+07$ \\
$-6.60 \mathrm{E}+06$ \\
$-+2.83 \mathrm{E}+06$ \\
$-+1.23 \mathrm{E}+07$ \\
$-2.17 \mathrm{E}+07$ \\
$-3.11 \mathrm{E}+07$ \\
$+4.06 \mathrm{E}+07$ \\
$+5.00 \mathrm{E}+07$ \\
$+2.12 \mathrm{E}+08$ \\
\hline
\end{tabular}

12
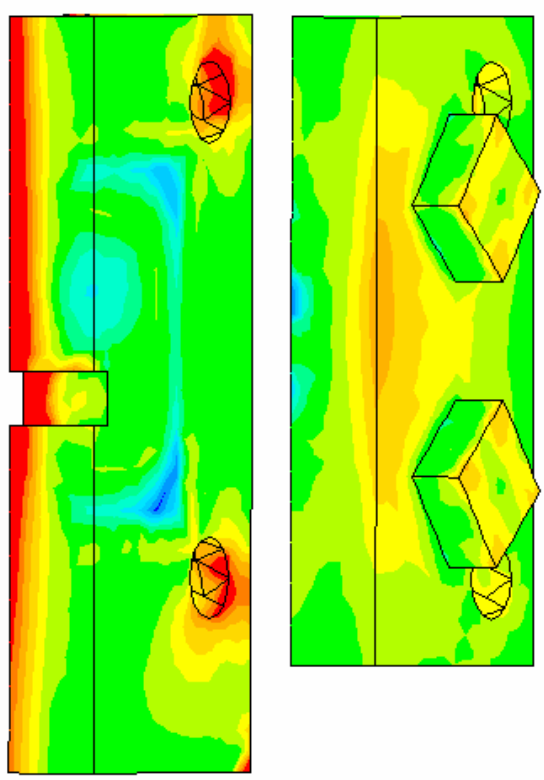

se 12

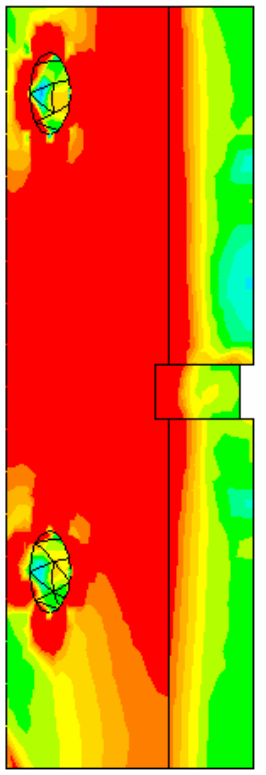

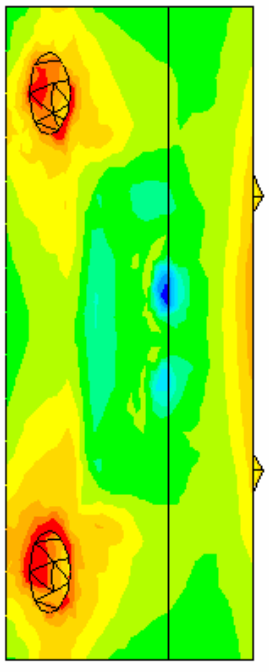

$r$ view) for case 


\section{APPENDIX A.13 Plots for Case 13}

\section{Specifications for case 13:}

- $\quad \operatorname{Die} \operatorname{size}(\mathrm{A}): 24 "$

- Die thickness (B): 5"

- Platen thickness (C): 11.75"

- Thickness ratio (D): 0.4 (Insert thickness: 2.75", Shoulder thickness: 2.25")

- Die Location (E): Centered

\begin{tabular}{|c|c|}
\hline \multirow[t]{13}{*}{ COPEN } & $\begin{array}{r}\text { VALUE } \\
-2.93 E-19\end{array}$ \\
\hline & $+1.25 \mathrm{E}-05$ \\
\hline & $-+2.50 \mathrm{E}-05$ \\
\hline & $-+3.76 \mathrm{E}-05$ \\
\hline & $-+5.01 \mathrm{E}-05$ \\
\hline & $-+6.26 \mathrm{E}-05$ \\
\hline & $-+7.51 \mathrm{E}-05$ \\
\hline & $-+8.76 \mathrm{E}-05$ \\
\hline & $-+1.00 \mathrm{E}-04$ \\
\hline & $-+1.13 \mathrm{E}-04$ \\
\hline & $-+1.25 \mathrm{E}-04$ \\
\hline & $-+1.38 \mathrm{E}-04$ \\
\hline & $-+1.50 E-04$ \\
\hline & $+1.63 E-04$ \\
\hline
\end{tabular}

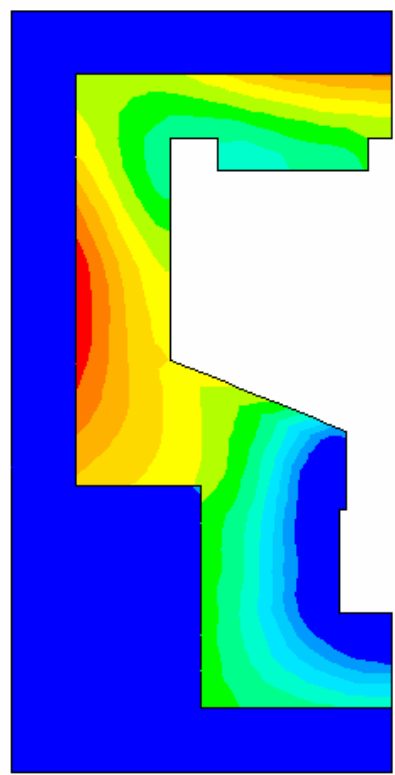

FigureA.13.1: showing parting plane separation for case 13 

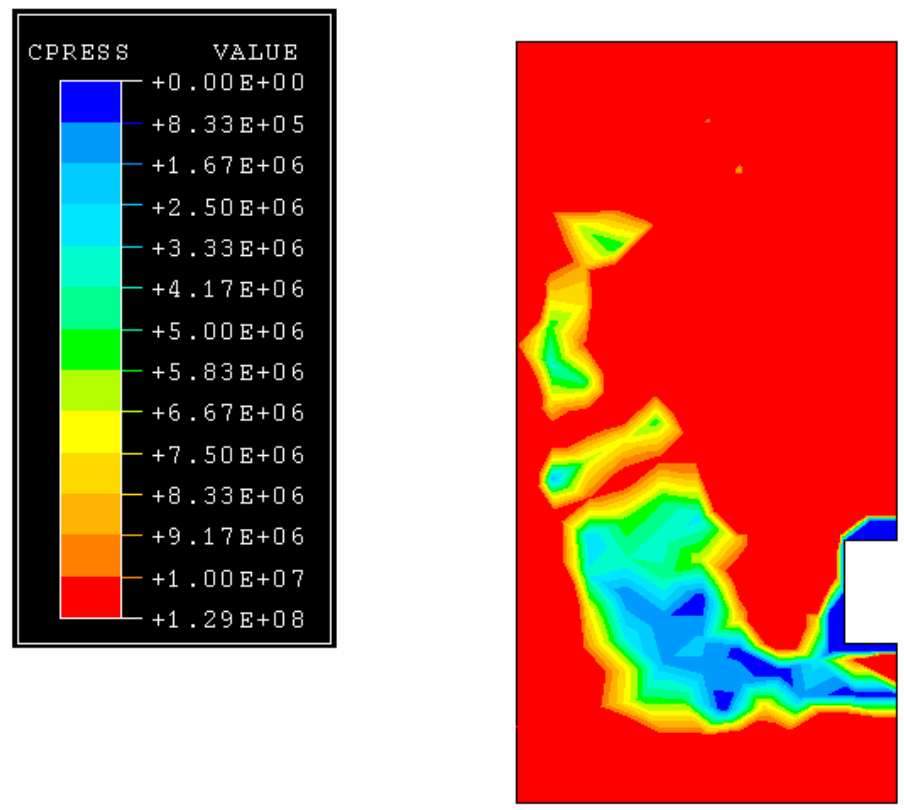

FigureA.13.2: showing contact pressure at the back of the cover die for case 13
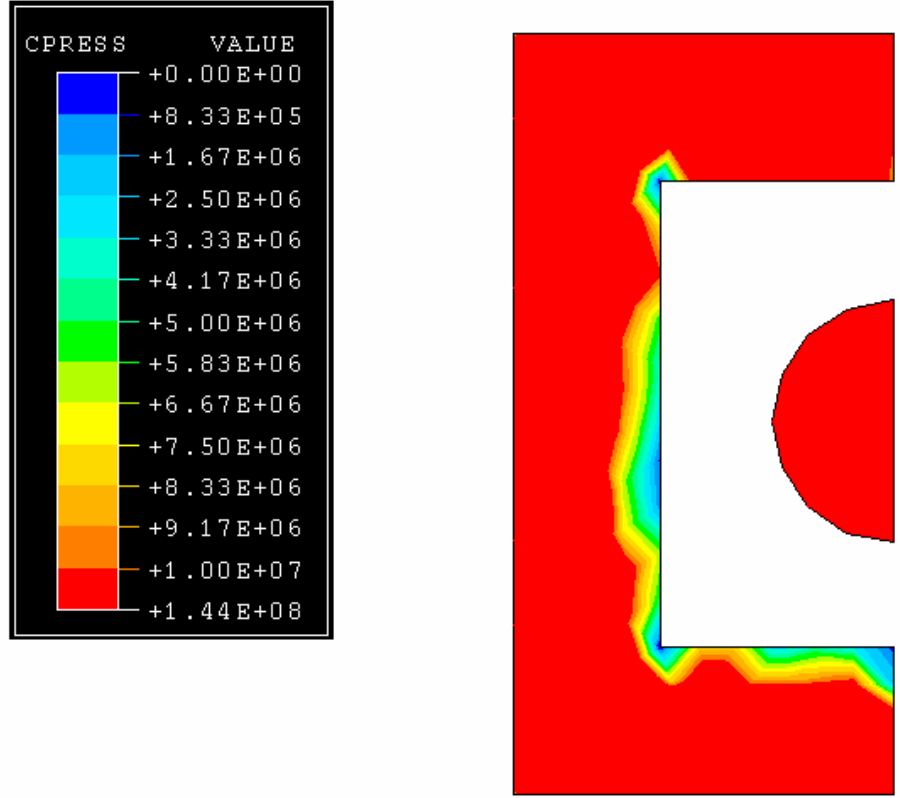

FigureA.13.3: showing contact pressure at the back of the ejector die for case 13 

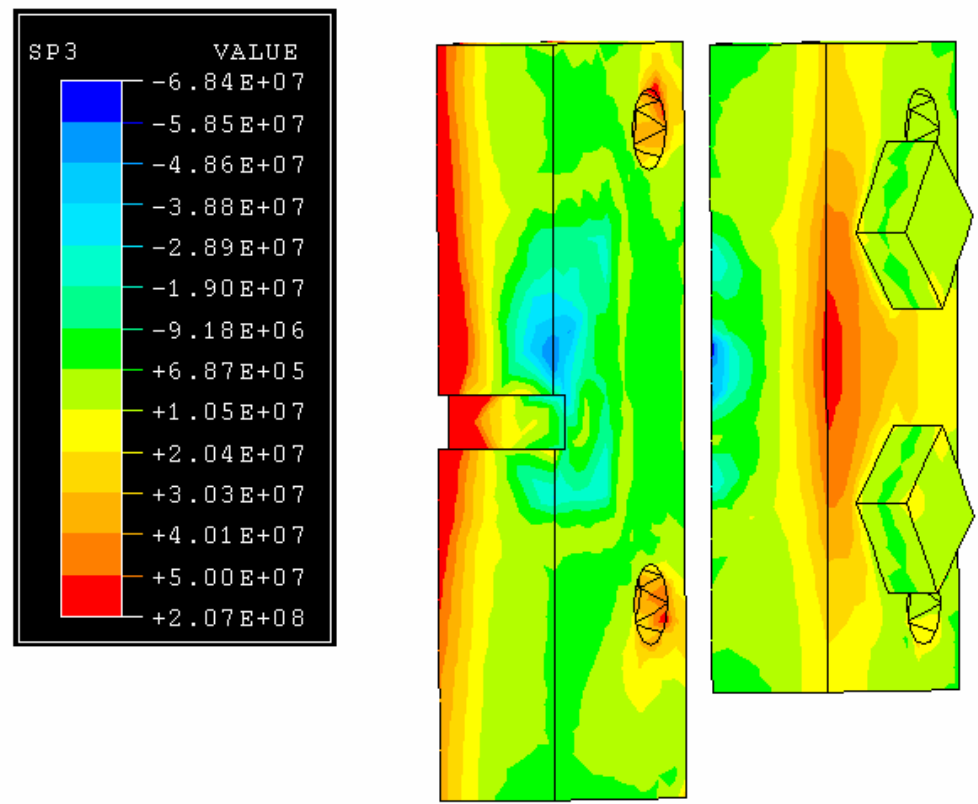

Figure A.13.4: showing compressive stresses in the platens for case 13
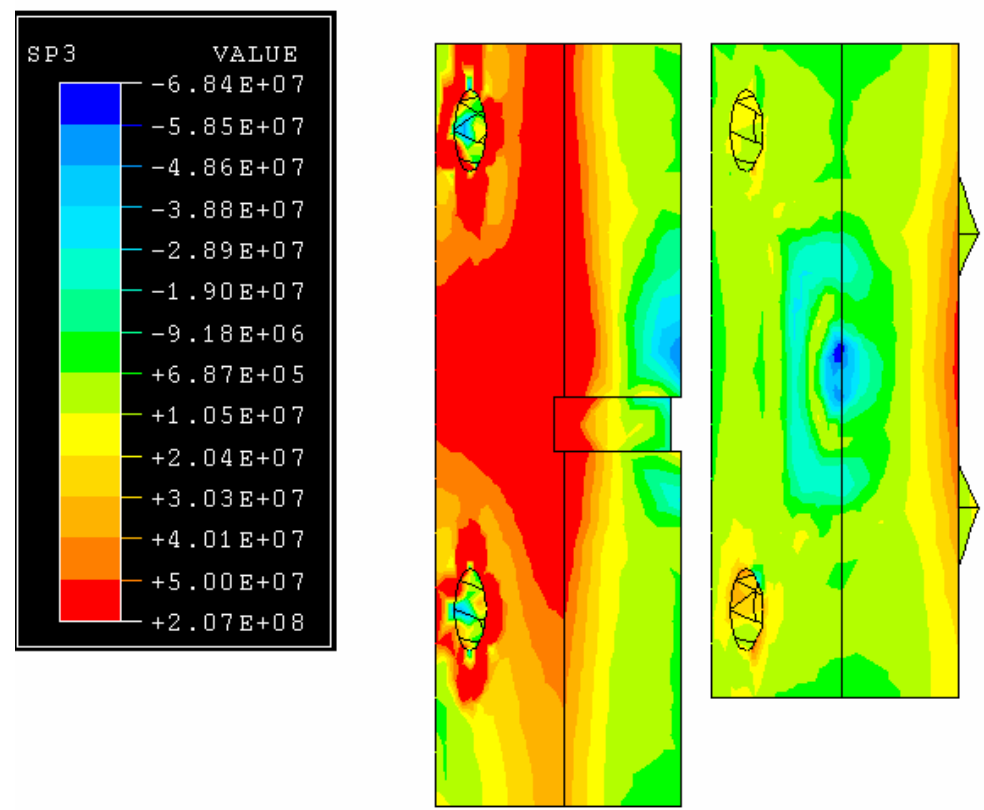

Figure A.13.5: showing compressive stresses in the platens (another view) for case 13 
APPENDIX A.14 Plots for Case 14

\section{Specifications for case 14:}

- $\operatorname{Die}$ size (A): 31.5 "

- Die thickness (B): 10"

- Platen thickness (C): 11.75"

- Thickness ratio (D): 0.4 (Insert thickness: 6", Shoulder thickness: 4")

- Die Location (E): Mid-low
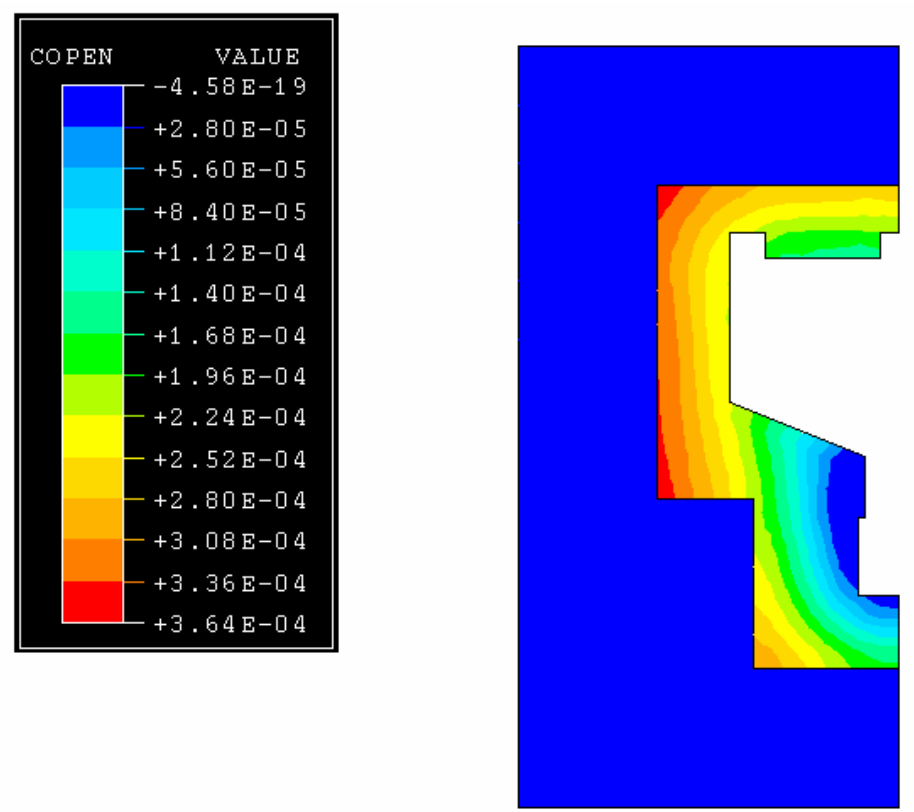

FigureA.14.1: showing parting plane separation for case 14 

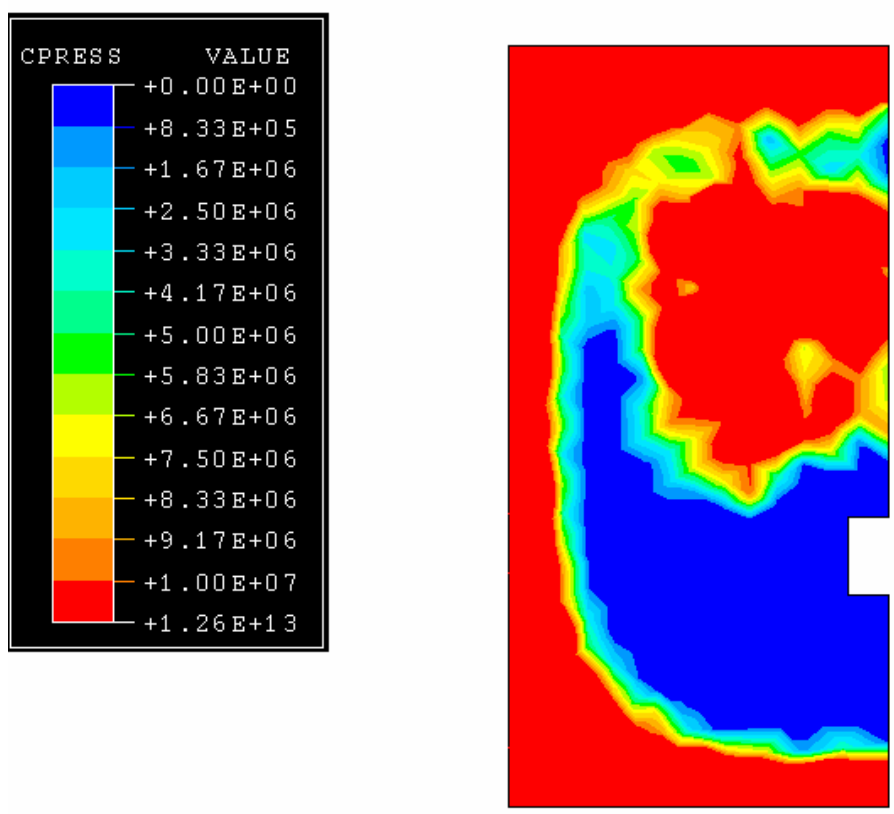

FigureA.14.2: showing contact pressure at the back of the cover die for case 14

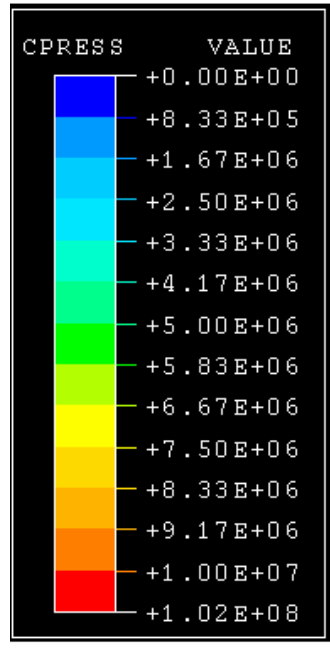

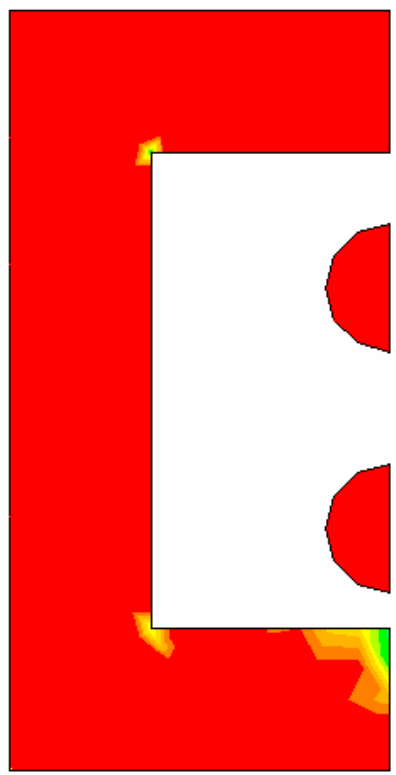

FigureA.14.3: showing contact pressure at the back of the ejector die for case 14 

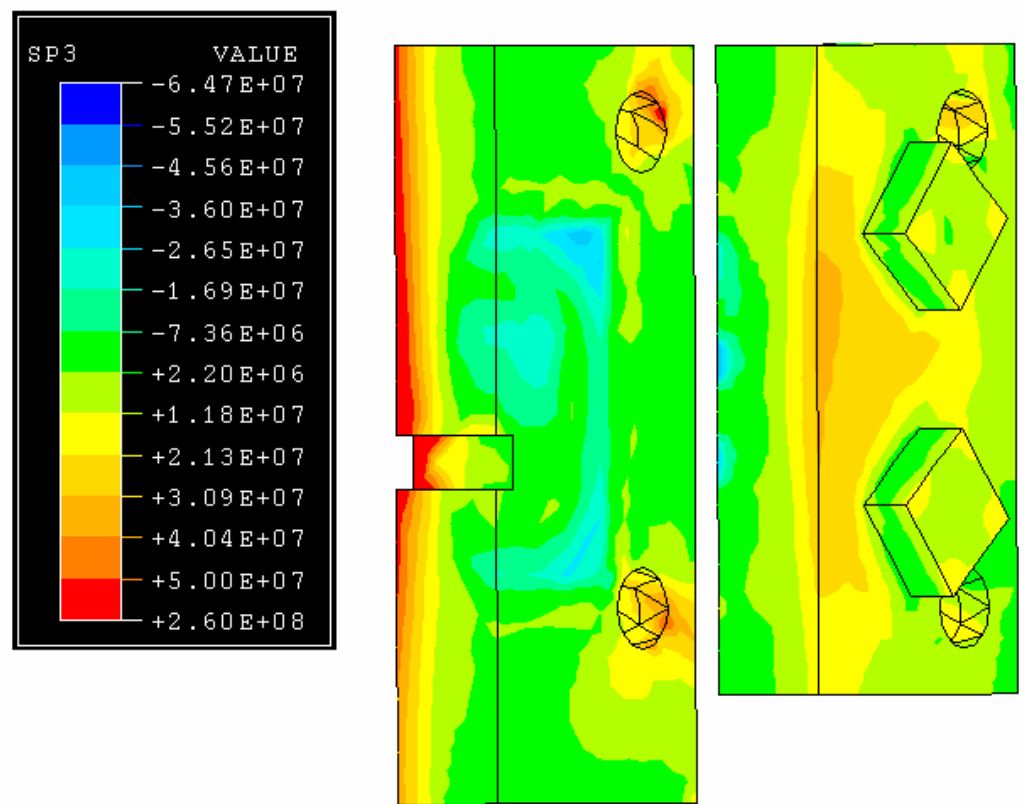

Figure A.14.4: showing compressive stresses in the platens for case 14
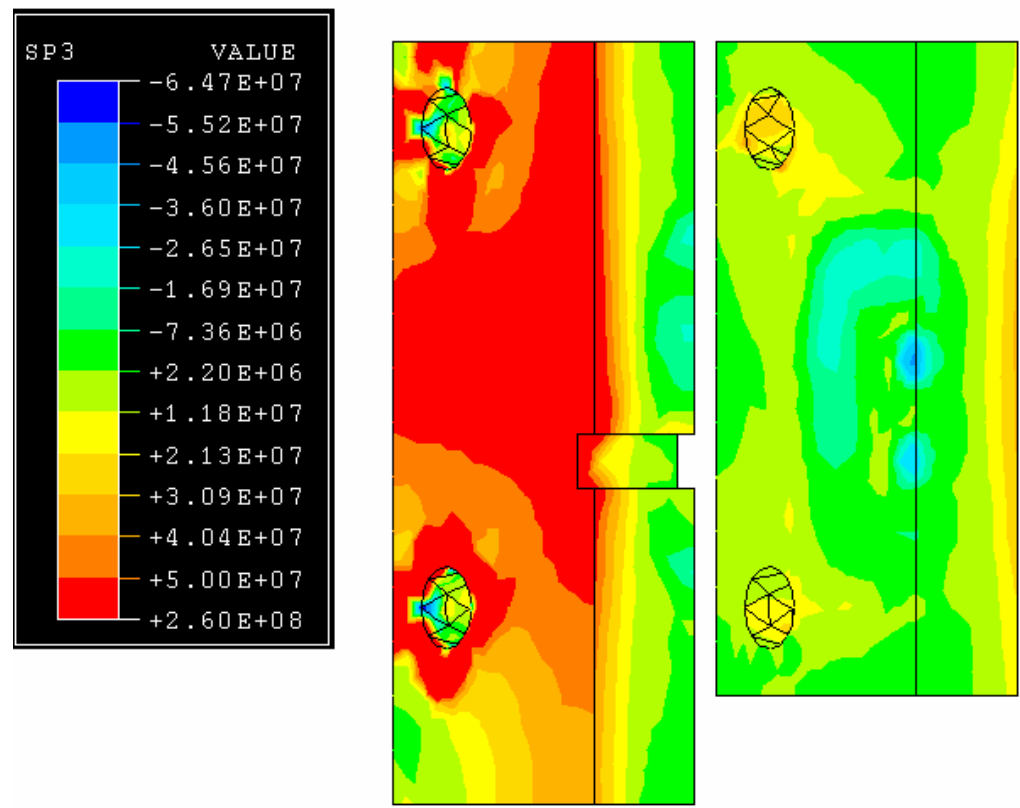

Figure A.14.5: showing compressive stresses in the platens (another view) for case 14 


\section{APPENDIX A.15 Plots for Case 15}

\section{Specifications for case 15:}

- $\operatorname{Die} \operatorname{size}(\mathrm{A}): 39$ ”

- Die thickness (B): 7.5"

- Platen thickness (C): 14.5"

- Thickness ratio (D): 0.45 (Insert thickness: 3.375", Shoulder thickness: 4.125”)

- Die Location (E): High

\begin{tabular}{|c|r|}
\hline COPEN & VALUE \\
\hline & $-2.54 \mathrm{E}-19$ \\
$+2.36 \mathrm{E}-05$ \\
$+4.71 \mathrm{E}-05$ \\
$-7.07 \mathrm{E}-05$ \\
$-9.43 \mathrm{E}-05$ \\
$-1.18 \mathrm{E}-04$ \\
$-1.41 \mathrm{E}-04$ \\
$+1.65 \mathrm{E}-04$ \\
$-1.89 \mathrm{E}-04$ \\
$-+2.12 \mathrm{E}-04$ \\
$-+2.36 \mathrm{E}-04$ \\
$-+2.59 \mathrm{E}-04$ \\
$-+2.83 \mathrm{E}-04$ \\
$+3.06 \mathrm{E}-04$ \\
\hline
\end{tabular}

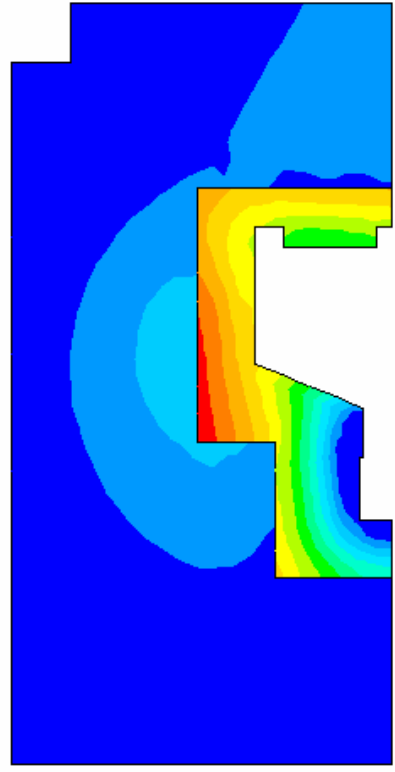

FigureA.15.1: showing parting plane separation for case 15 

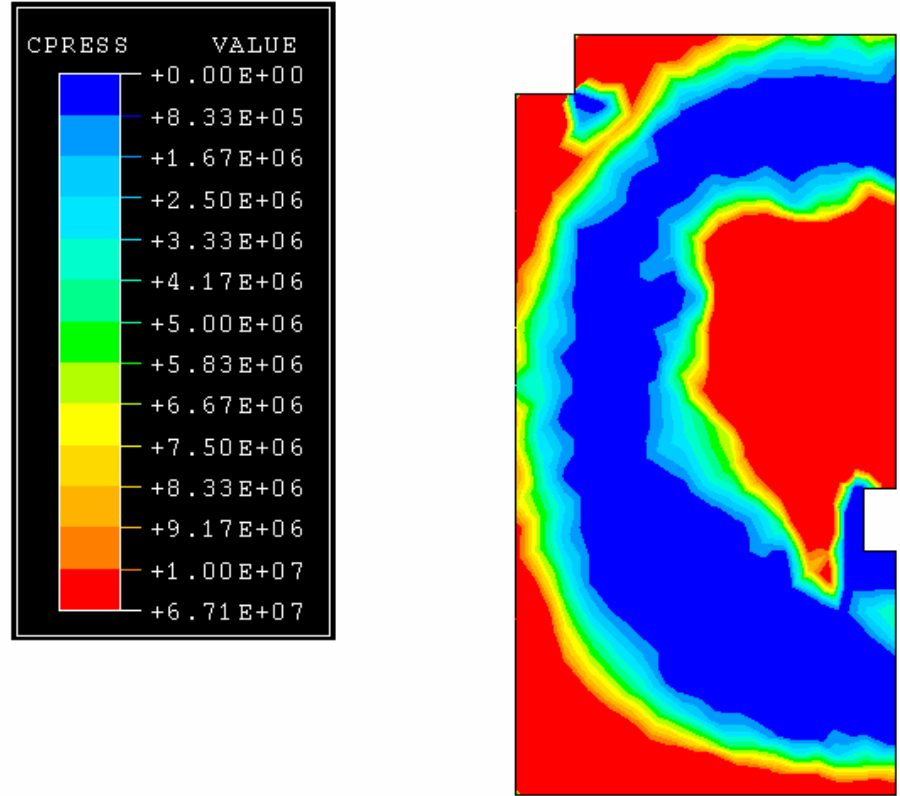

FigureA.1 1.L: snowing contact pressure at the back of the cover die for case 15

\begin{tabular}{|c|c|}
\hline \multirow{15}{*}{ CPRES } & VALUE \\
\hline & $-+0.00 \mathrm{E}+00$ \\
\hline & $+8.33 E+05$ \\
\hline & $-+1.67 \mathrm{E}+06$ \\
\hline & $-+2.50 \mathrm{E}+06$ \\
\hline & $-+3.33 E+06$ \\
\hline & $-+4.17 \mathrm{E}+06$ \\
\hline & $-+5.00 E+06$ \\
\hline & $-+5.83 E+06$ \\
\hline & $-+6.67 \mathrm{E}+06$ \\
\hline & $-+7.50 \mathrm{E}+06$ \\
\hline & $-+8.33 \mathrm{E}+06$ \\
\hline & $-+9.17 \mathrm{E}+06$ \\
\hline & $-+1.00 E+07$ \\
\hline & $-+1.19 \mathrm{E}+08$ \\
\hline
\end{tabular}

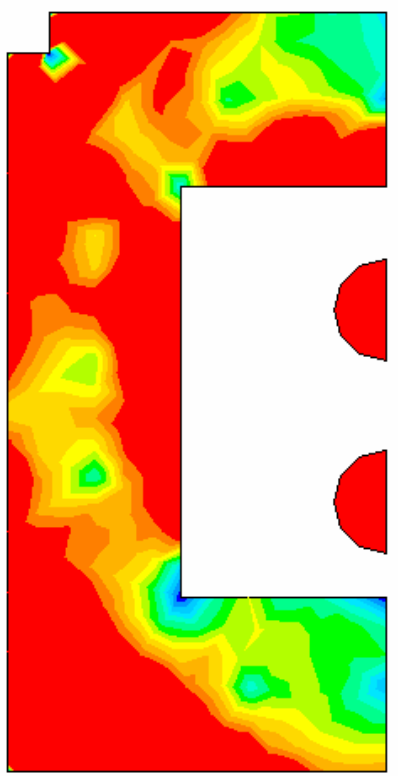

FigureA.15.3: showing contact pressure at the back of the ejector die for case 15 

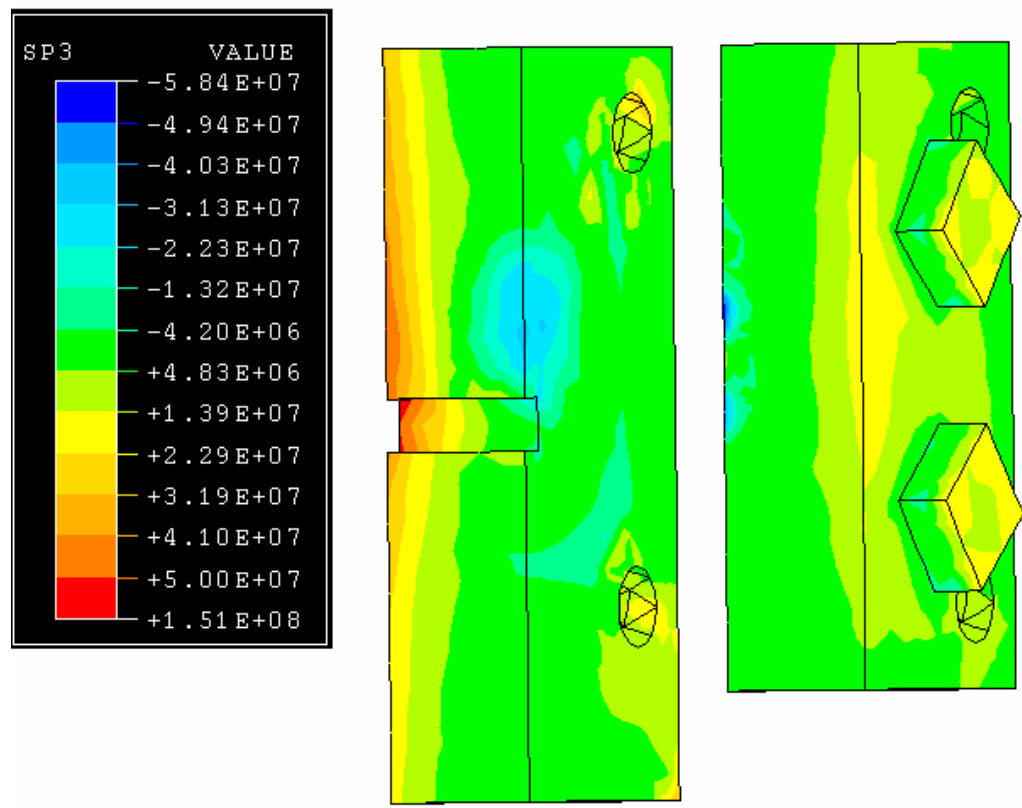

Figure A.15.4: showing compressive stresses in the platens for case 15
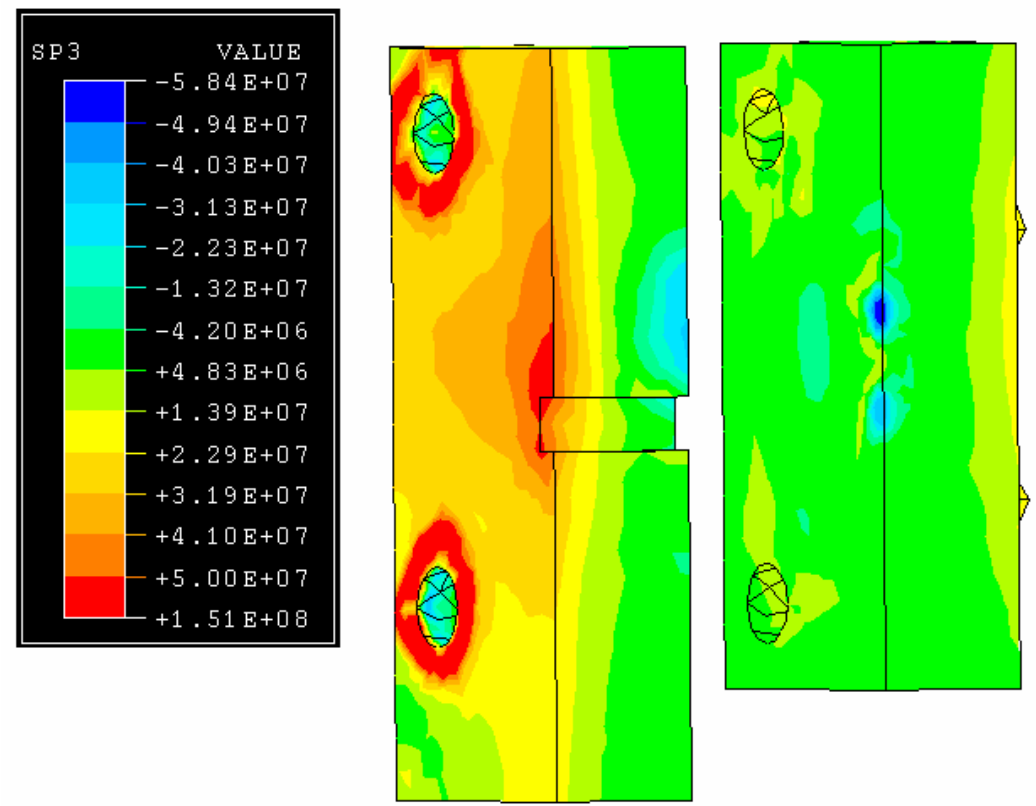

Figure A.15.5: showing compressive stresses in the platens (another view) for case 15 
APPENDIX A.16 Plots for Case 16

\section{Specifications for case 16:}

- $\quad \operatorname{Die} \operatorname{size}(\mathrm{A}): 27.8$ "

- Die thickness (B): 8.75"

- Platen thickness (C): 13.1"

- Thickness ratio (D): 0.425 (Insert thickness: 5.03", Shoulder thickness: 3.72”)

- Die Location (E): Mid-high

\begin{tabular}{|c|r|}
\hline \multicolumn{1}{|c|}{ COPEN } & VALUE \\
\hline & $-3.17 \mathrm{E}-19$ \\
$+1.74 \mathrm{E}-05$ \\
$+3.48 \mathrm{E}-05$ \\
$-+5.22 \mathrm{E}-05$ \\
$-+6.96 \mathrm{E}-05$ \\
$-+8.71 \mathrm{E}-05$ \\
$-+1.04 \mathrm{E}-04$ \\
$-+1.22 \mathrm{E}-04$ \\
$-+1.39 \mathrm{E}-04$ \\
$-+1.57 \mathrm{E}-04$ \\
$-+1.74 \mathrm{E}-04$ \\
$-1.92 \mathrm{E}-04$ \\
$-+2.09 \mathrm{E}-04$ \\
$+2.26 \mathrm{E}-04$ \\
\hline
\end{tabular}

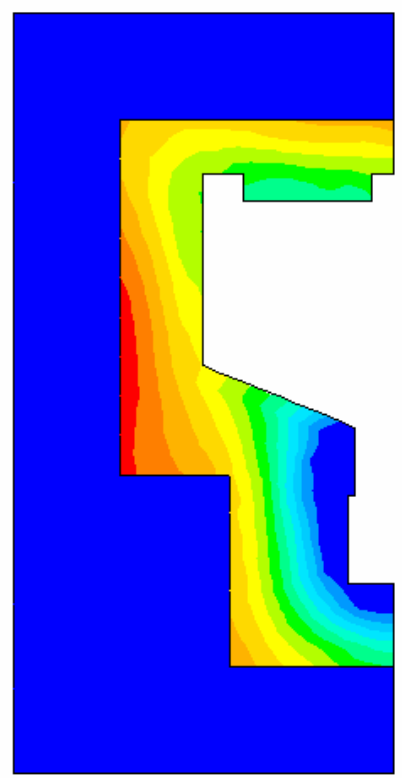

FigureA.16.1: showing parting plane separation for case 16 

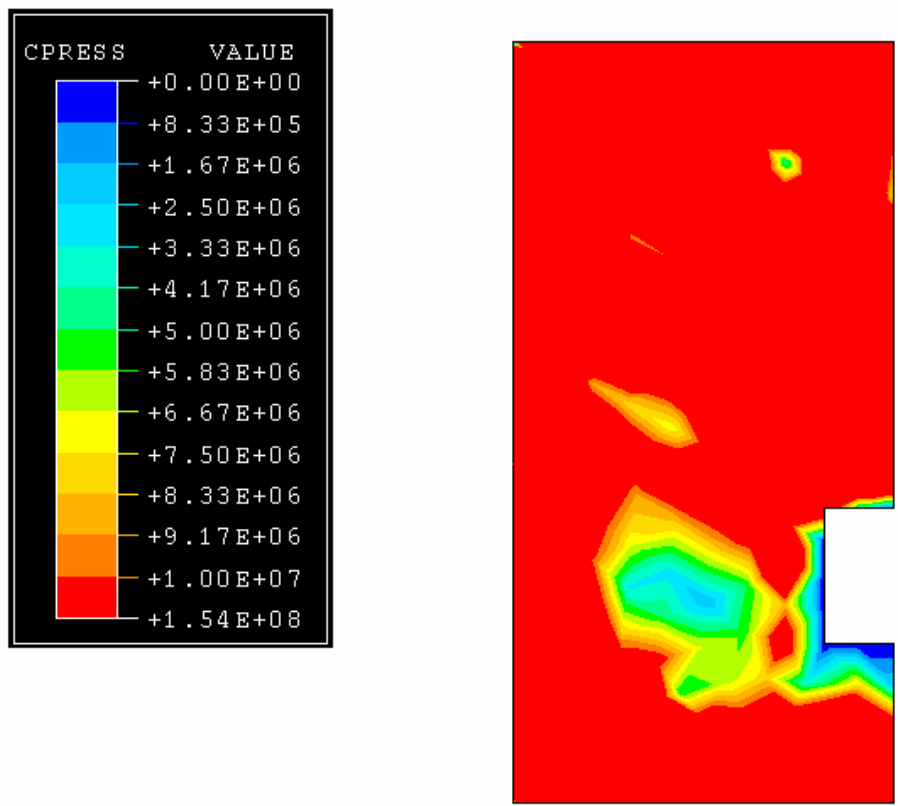

FigureA.16.2: showing contact pressure at the back of the cover die for case 16

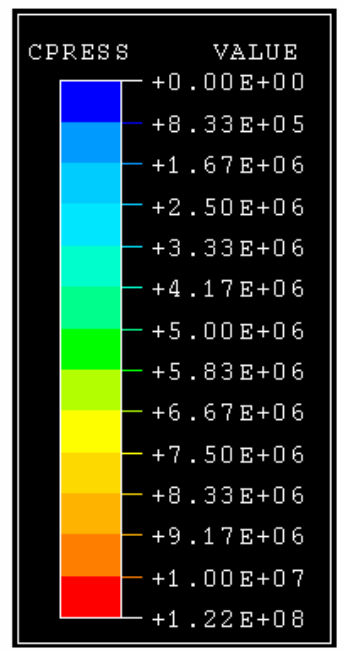

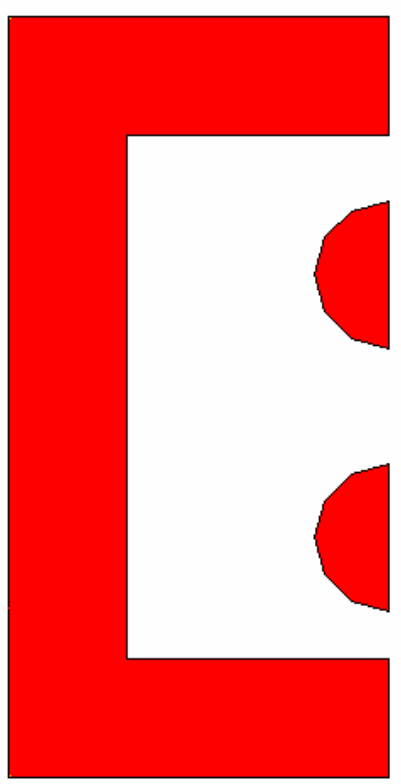

FigureA.16.3: showing contact pressure at the back of the ejector die for case 16 

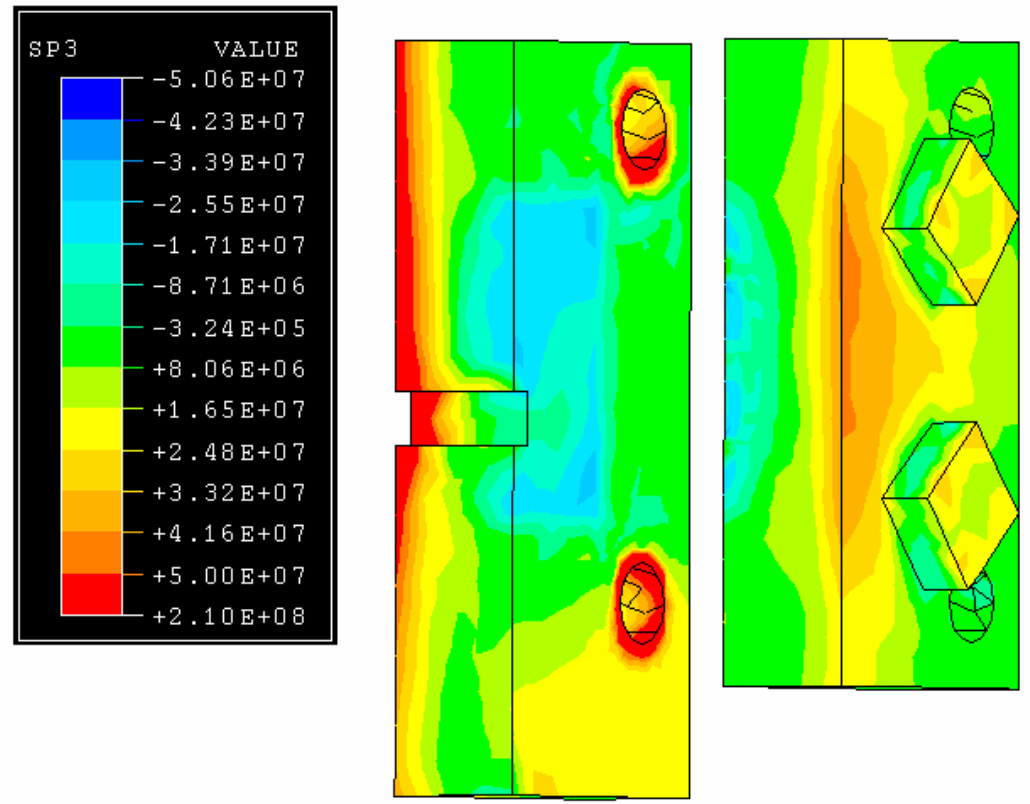

Figure A.16.4: showing compressive stresses in the platens for case 16
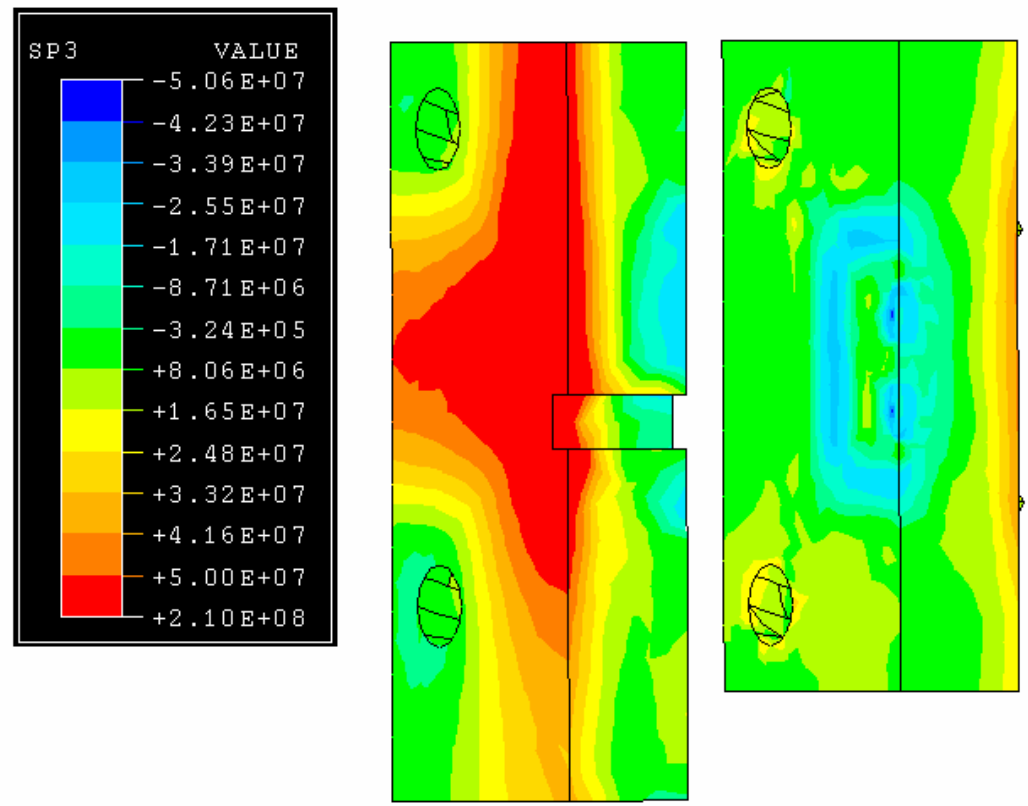

Figure A.16.5: showing compressive stresses in the platens (another view) for case 16 


\section{APPENDIX A.17 Plots for Case 17}

\section{Specifications for case 17:}

- $\quad \operatorname{Die} \operatorname{size}(\mathrm{A})$ : 39"

- Die thickness (B): 8.75"

- Platen thickness (C): 10.4"

- Thickness ratio (D): 0.43 (Insert thickness: 5.03", Shoulder thickness: 3.72”)

- Die Location (E): Mid-high
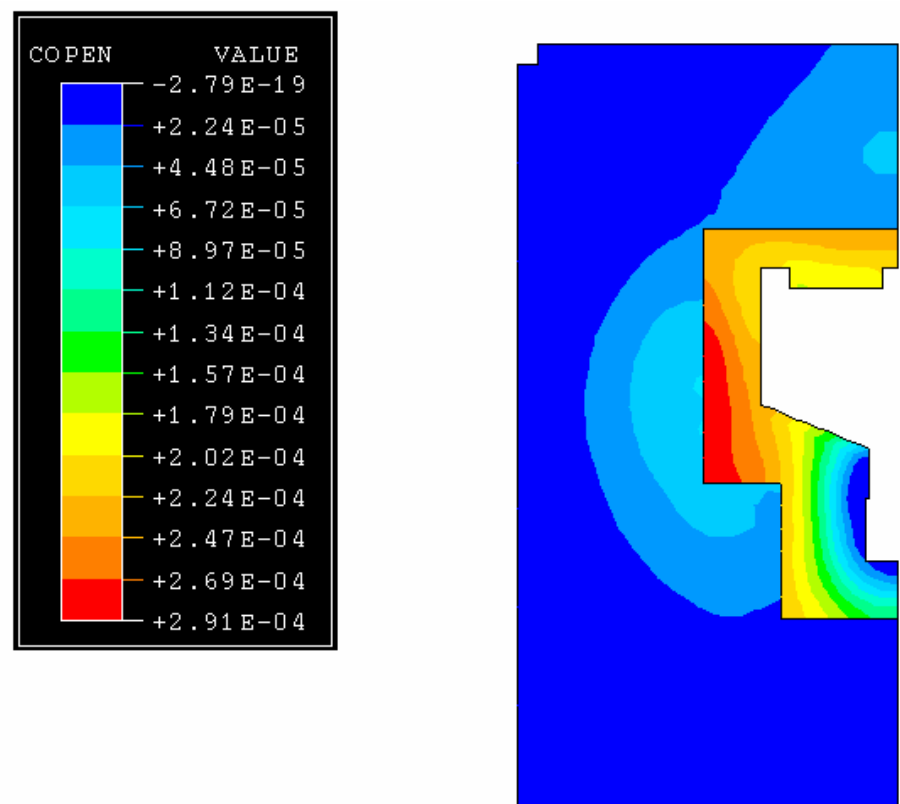

FigureA.17.1: showing parting plane separation for case 17 

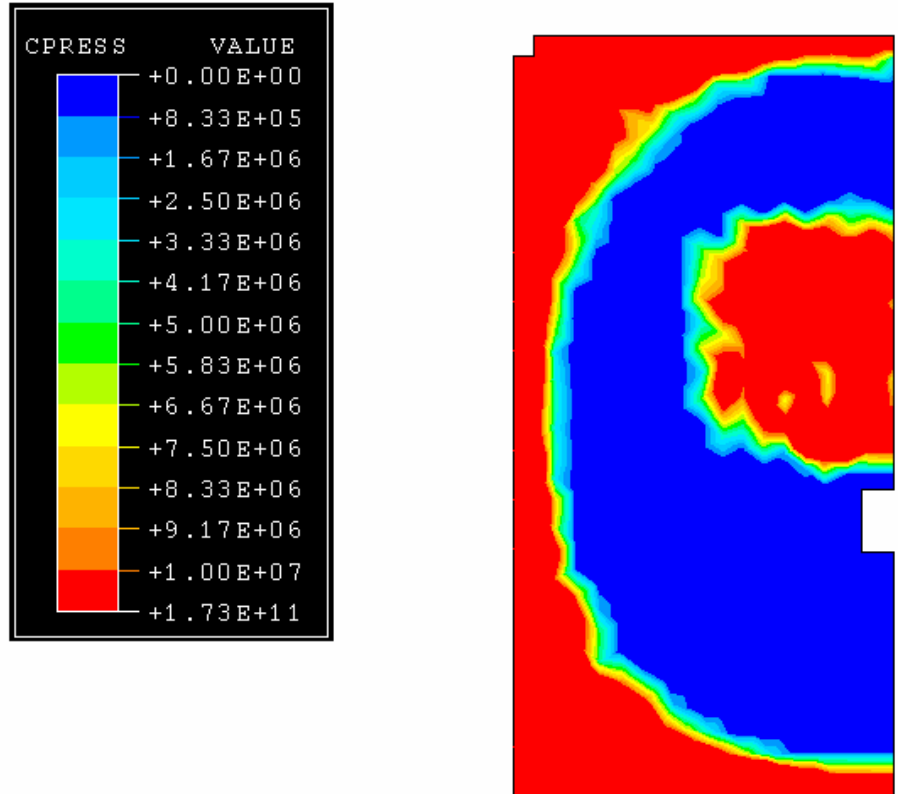

FigureA.1 /.L: snowing contact pressure at the back of the cover die for case 17

\begin{tabular}{|c|r|}
\hline \multicolumn{2}{|l|}{ CPRESS } \\
\hline \\
\hline \\
$+0.00 E+00$ \\
$+8.33 E+05$ \\
$+1.67 E+06$ \\
$+2.50 E+06$ \\
$-+3.33 E+06$ \\
$-+4.17 E+06$ \\
$-+5.00 E+06$ \\
$-5.83 E+06$ \\
$-+6.67 E+06$ \\
$-+7.50 E+06$ \\
$-+8.33 E+06$ \\
$-+9.17 E+06$ \\
$-1.00 E+07$ \\
$+5.29 E+13$ \\
\hline
\end{tabular}

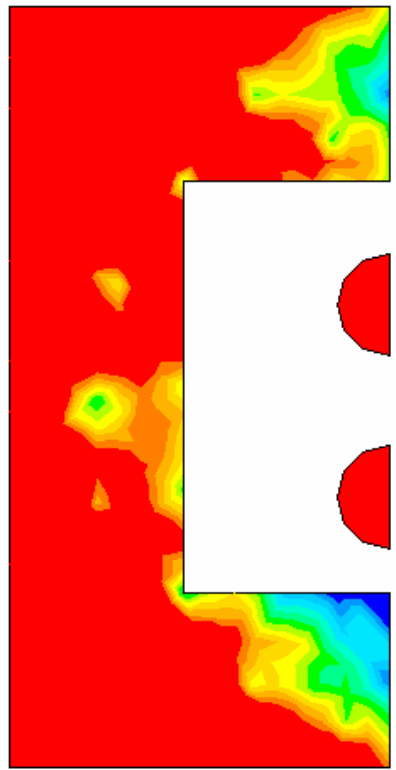

FigureA.17.3: showing contact pressure at the back of the ejector die for case 17 

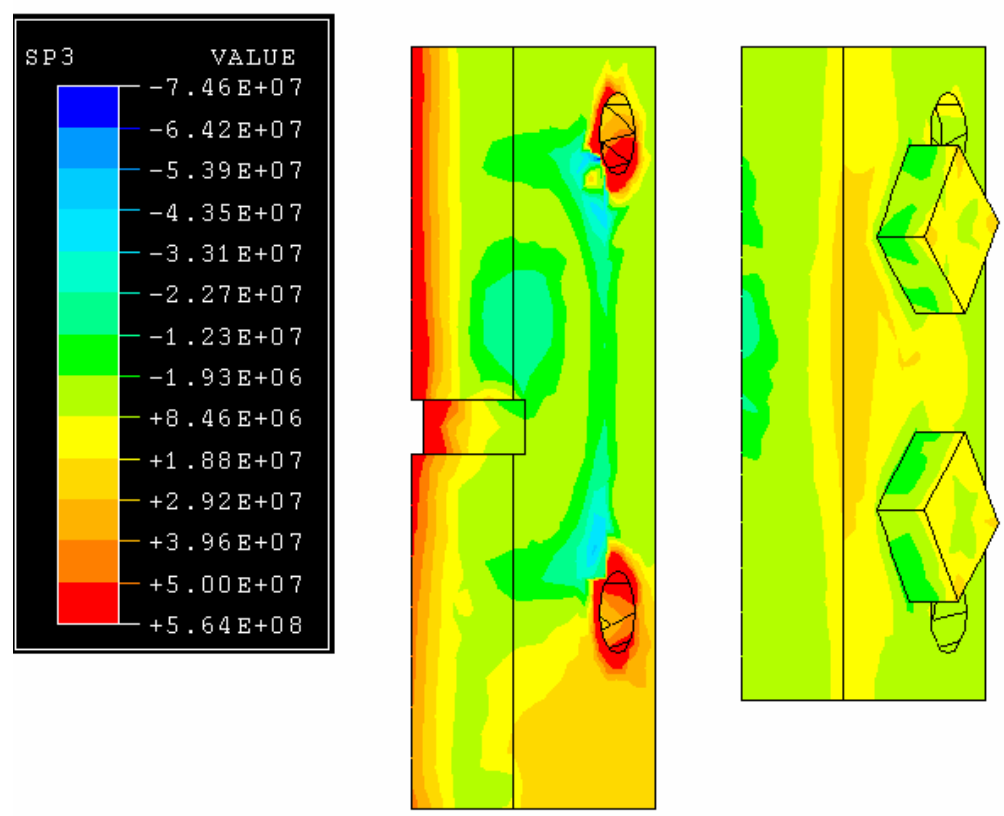

Figure A.17.4: showing compressive stresses in the platens for case 17
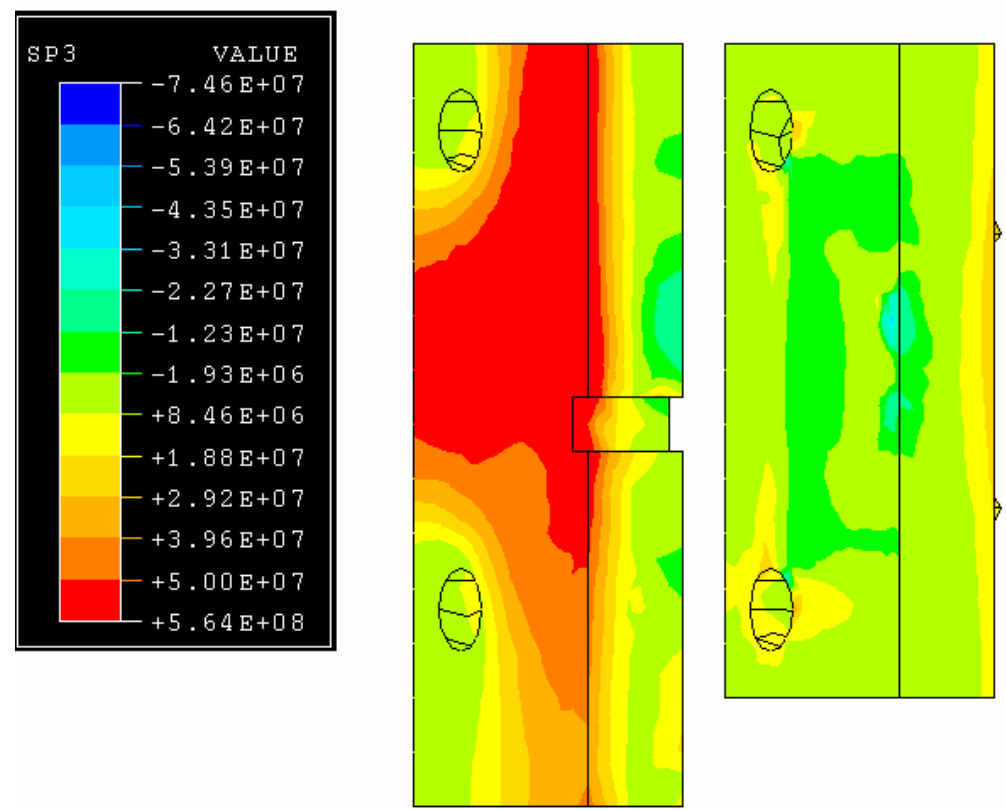

Figure A.17.5: showing compressive stresses in the platens (another view) for case 17 


\section{APPENDIX A.18 Plots for Case 18}

\section{Specifications for case 18:}

- Die size (A): 35.3”

- Die thickness (B): 7.5"

- Platen thickness (C): 13.1"

- Thickness ratio (D): 0.45 (Insert thickness: 4.13", Shoulder thickness: 3.38”)

- Die Location (E): Low

\begin{tabular}{|c|c|}
\hline \multirow[t]{14}{*}{ COPEN } & $\begin{array}{r}\text { VALUE } \\
--3.79 E-19\end{array}$ \\
\hline & $+1.84 \mathrm{E}-05$ \\
\hline & $-+3.67 \mathrm{E}-05$ \\
\hline & $-+5.51 \mathrm{E}-05$ \\
\hline & $-+7.34 \mathrm{E}-05$ \\
\hline & $-+9.18 \mathrm{E}-05$ \\
\hline & $-+1.10 \mathrm{E}-04$ \\
\hline & $-+1.28 \mathrm{E}-04$ \\
\hline & $-+1.47 \mathrm{E}-04$ \\
\hline & $-+1.65 \mathrm{E}-04$ \\
\hline & $-+1.84 \mathrm{E}-04$ \\
\hline & $-+2.02 \mathrm{E}-04$ \\
\hline & $-+2.20 \mathrm{E}-04$ \\
\hline & $+2.39 E-04$ \\
\hline
\end{tabular}

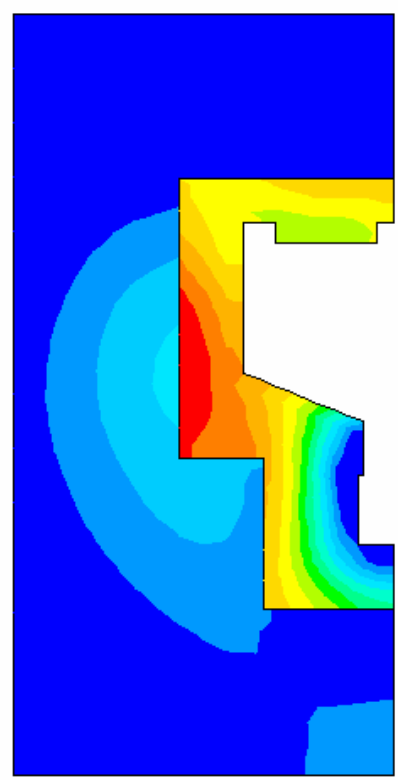

FigureA.18.1: showing parting plane separation for case 18 

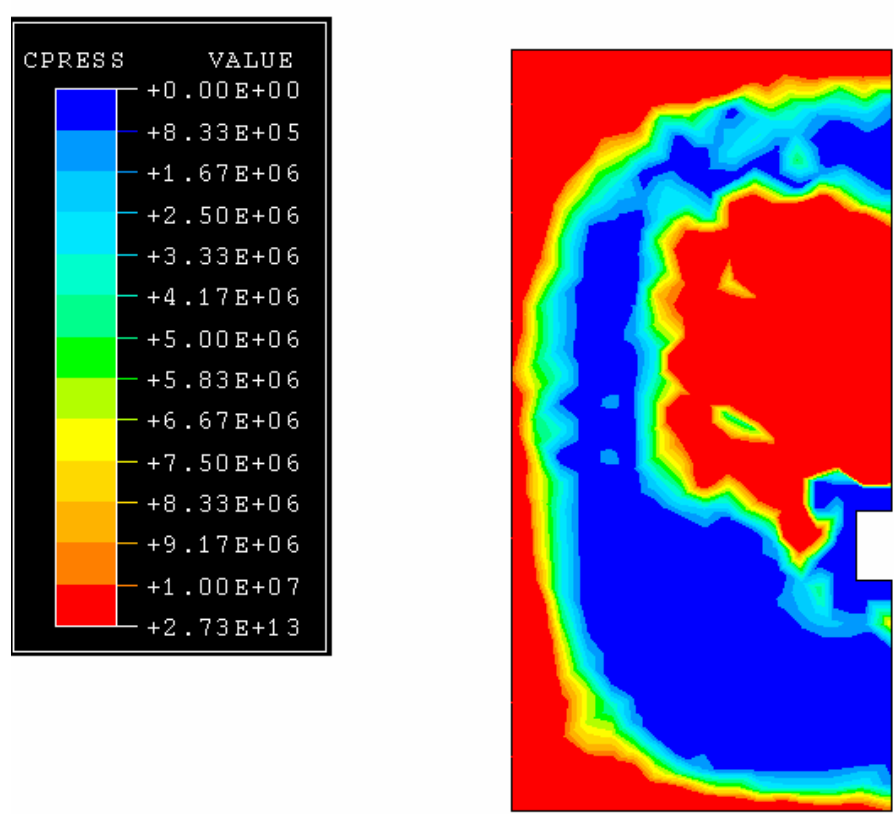

FigureA.18.2: showing contact pressure at the back of the cover die for case 18

\begin{tabular}{|c|c|}
\hline \multirow{15}{*}{ CPRESS } & VALUE \\
\hline & $+1.38 \mathrm{E}+05$ \\
\hline & $+9.59 E+05$ \\
\hline & $-+1.78 \mathrm{E}+06$ \\
\hline & $-+2.60 \mathrm{E}+06$ \\
\hline & $-+3.43 \mathrm{E}+06$ \\
\hline & $-+4.25 E+06$ \\
\hline & $-+5.07 \mathrm{E}+06$ \\
\hline & $-+5.89 E+06$ \\
\hline & $-+6.71 \mathrm{E}+06$ \\
\hline & $-+7.53 \mathrm{E}+06$ \\
\hline & $-+8.36 \mathrm{E}+06$ \\
\hline & $-+9.18 \mathrm{E}+06$ \\
\hline & $-+1.00 \mathrm{E}+07$ \\
\hline & $+2.09 E+12$ \\
\hline
\end{tabular}

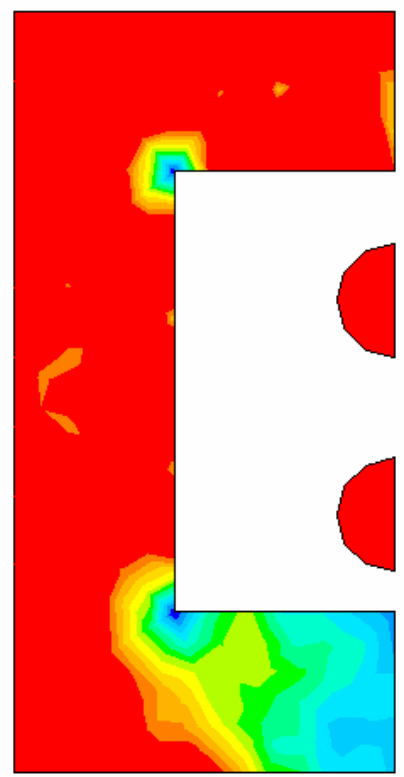

FigureA.18.3: showing contact pressure at the back of the ejector die for case 18 

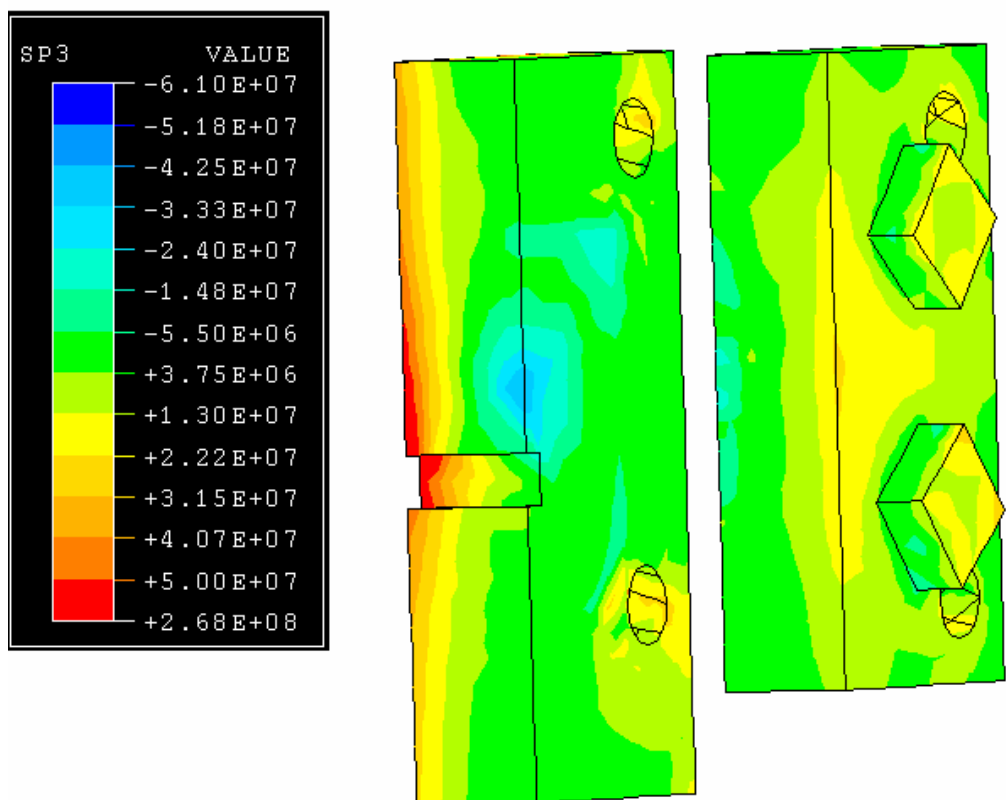

Figure A.18.4: showing compressive stresses in the platens for case 18
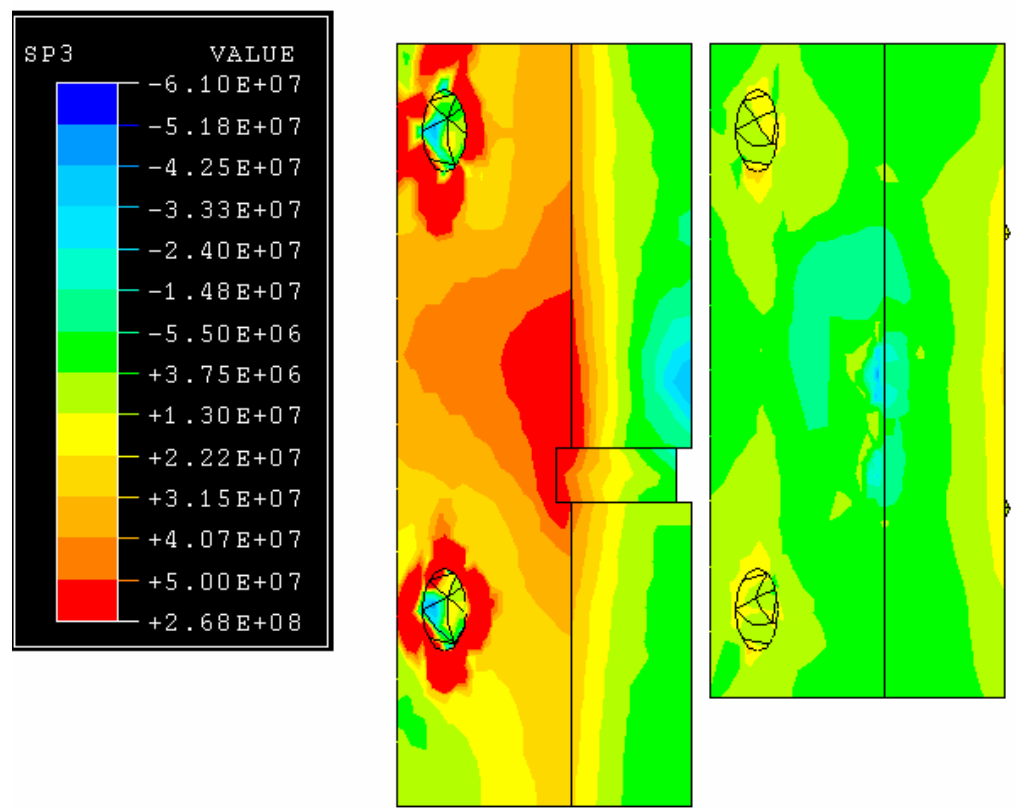

Figure A.18.5: showing compressive stresses in the platens (another view) for case 18 


\section{APPENDIX A.19 Plots for Case 19}

\section{Specifications for case 19:}

- Die size (A): 31.5"

- Die thickness (B): 10"

- Platen thickness (C): 11.8"

- Thickness ratio (D): 0.45 (Insert thickness: 5.5", Shoulder thickness: 4.5")

- Die Location (E): Centered

\begin{tabular}{|c|r|}
\hline \multicolumn{1}{|c|}{ COPEN } & VALUE \\
\hline & $-2.07 \mathrm{E}-19$ \\
& $+2.06 \mathrm{E}-05$ \\
& $+4.12 \mathrm{E}-05$ \\
- & $+6.18 \mathrm{E}-05$ \\
- & $+8.24 \mathrm{E}-05$ \\
- & $+1.03 \mathrm{E}-04$ \\
- & $+2.24 \mathrm{E}-04$ \\
- & $.44 \mathrm{E}-04$ \\
- & $+1.65 \mathrm{E}-04$ \\
- & $+1.86 \mathrm{E}-04$ \\
- & $+2.06 \mathrm{E}-04$ \\
- & $+2.27 \mathrm{E}-04$ \\
- & $+2.47 \mathrm{E}-04$ \\
$+2.68 \mathrm{E}-04$ \\
\hline
\end{tabular}

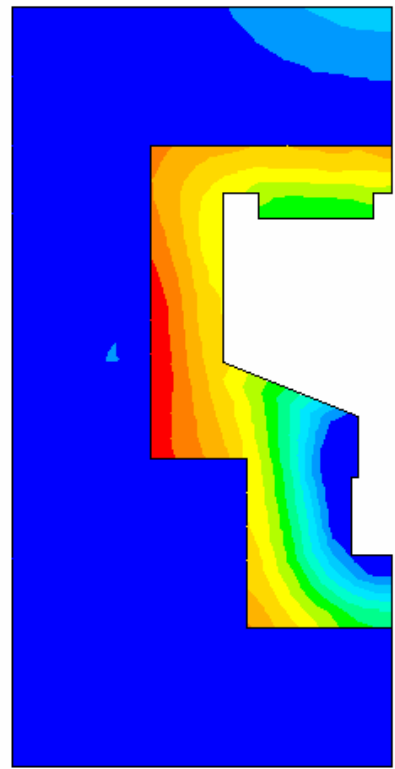

FigureA.19.1: showing parting plane separation for case 19 

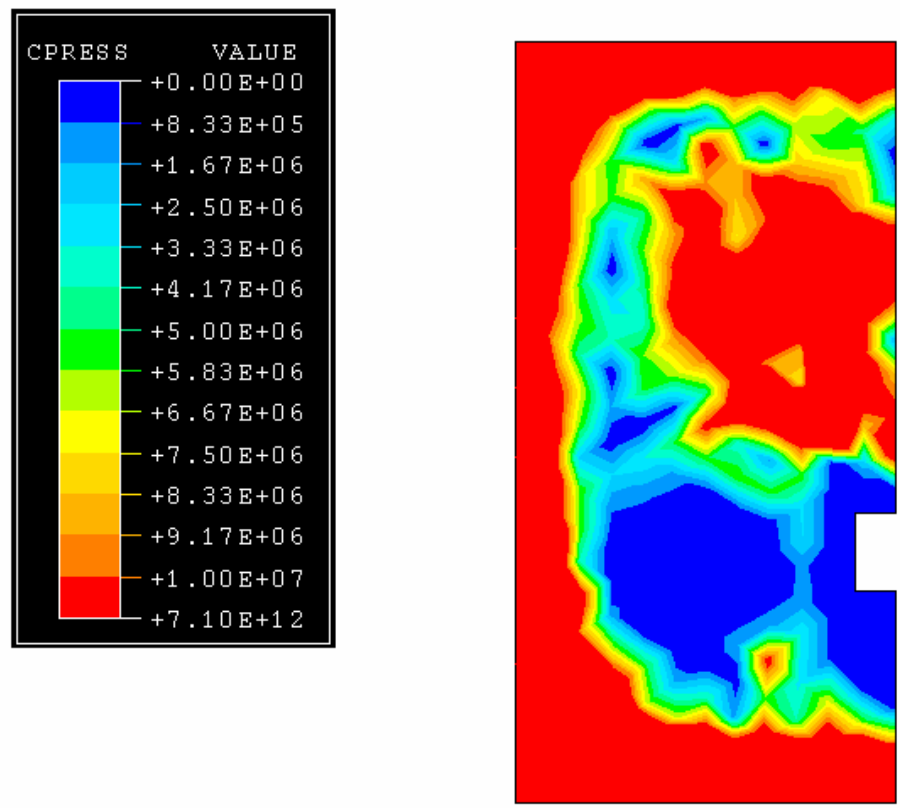

FigureA.19.2: showing contact pressure at the back of the cover die for case 19
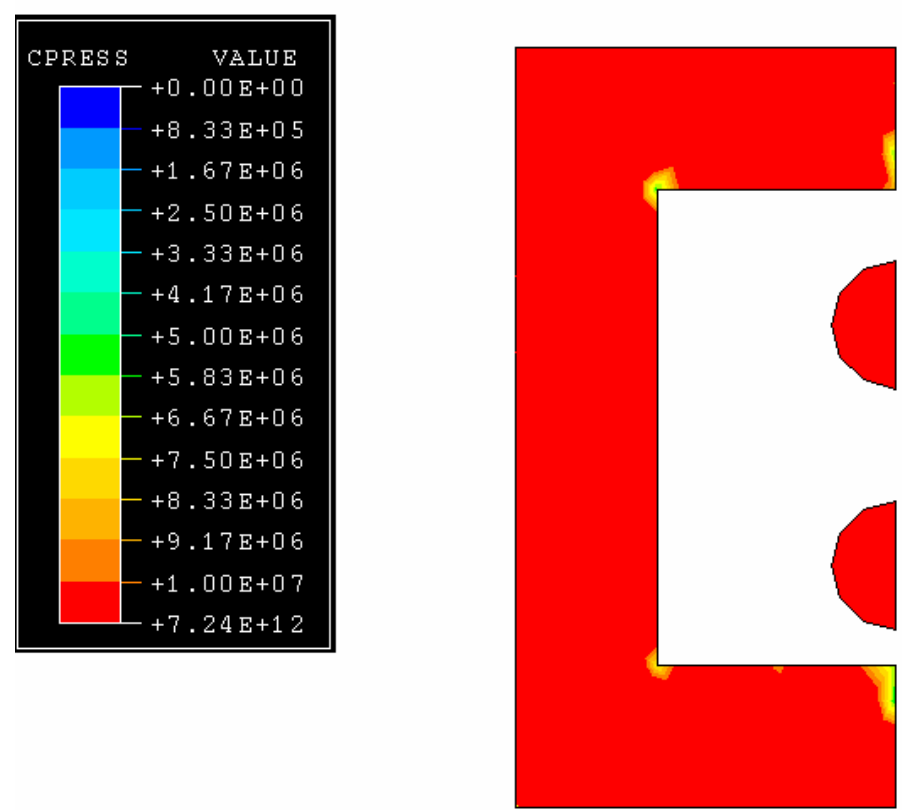

FigureA.19.3: showing contact pressure at the back of the ejector die for case 19 

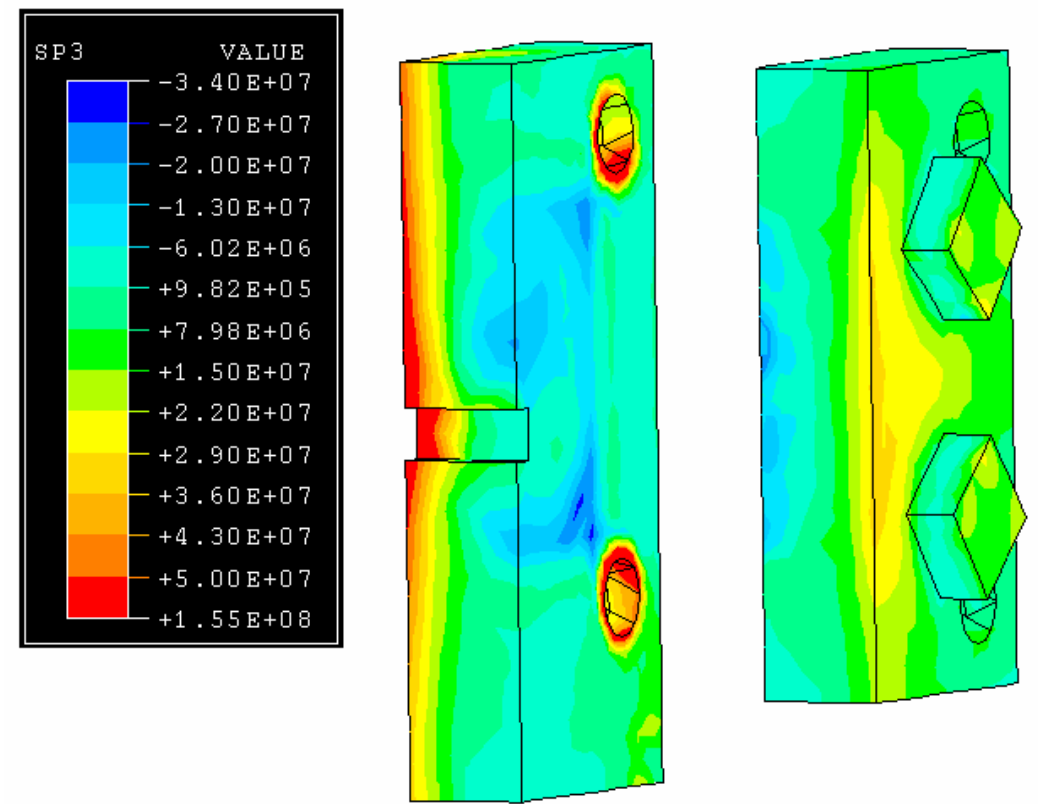

Figure A.19.4: showing compressive stresses in the platens for case 19
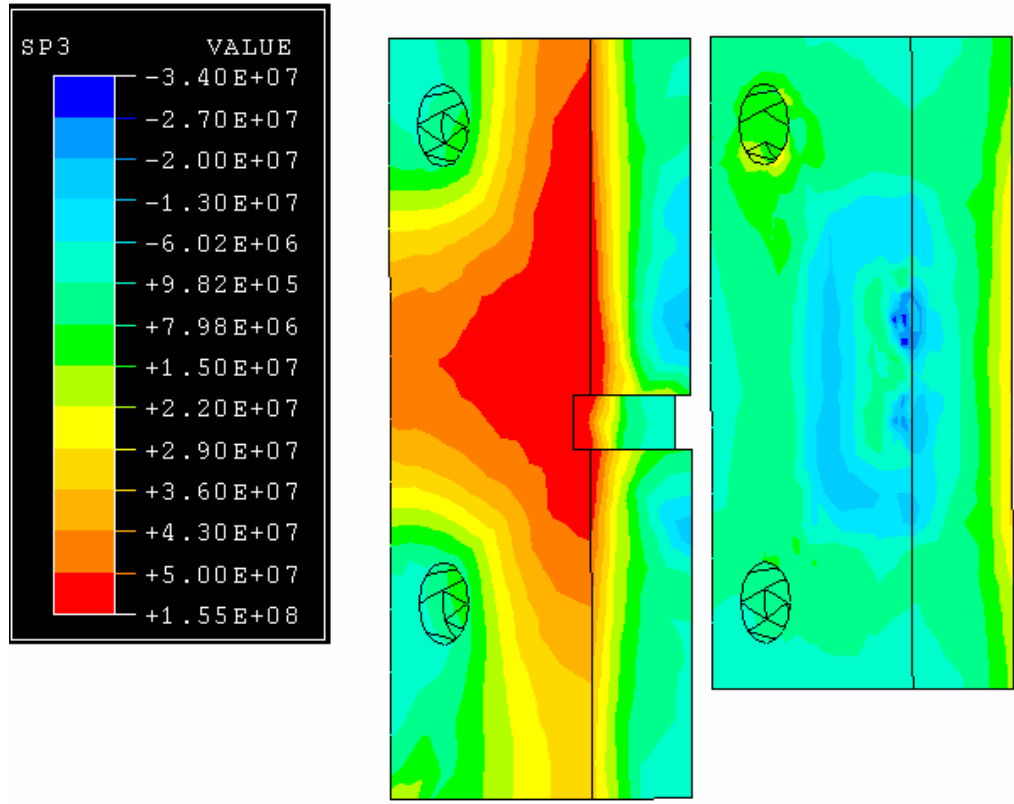

Figure A.19.5: showing compressive stresses in the platens (another view) for case 19 
APPENDIX A.20 Plots for Case 20

\section{Specifications for case 20:}

- $\operatorname{Die}$ size (A): 35.3 "

- Die thickness (B): 10"

- Platen thickness (C): 14.5"

- Thickness ratio (D): 0.43 (Insert thickness: 5.75", Shoulder thickness: 4.25”)

- Die Location (E): Mid-high
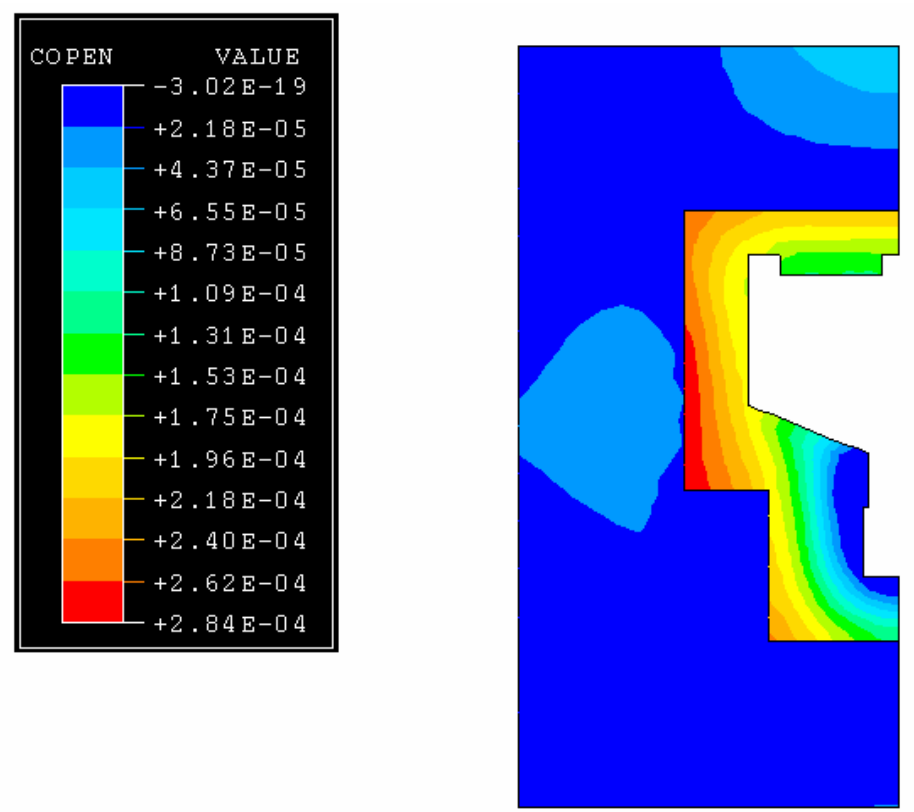

FigureA.20.1: showing parting plane separation for case 20 

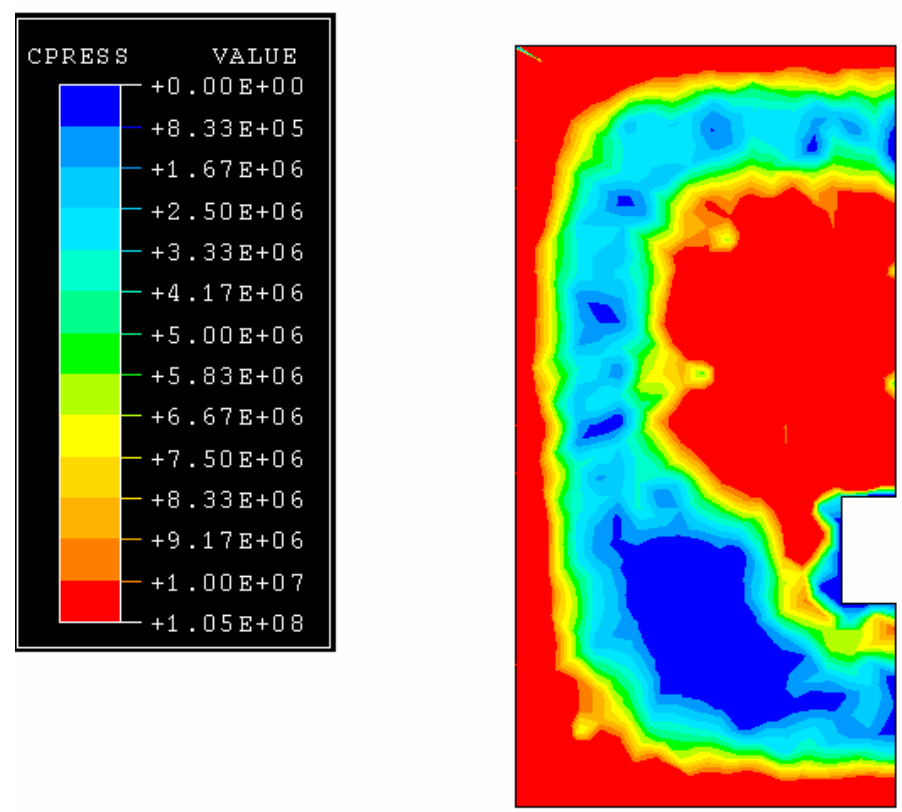

FigureA.20.2: showing contact pressure at the back of the cover die for case 20

\begin{tabular}{|c|c|}
\hline \multirow{15}{*}{ CPRESS } & VALUE \\
\hline & \\
\hline & $+8.33 \mathrm{E}+05$ \\
\hline & $-+1.67 \mathrm{E}+06$ \\
\hline & $-+2.50 \mathrm{E}+06$ \\
\hline & $-+3.33 \mathrm{E}+06$ \\
\hline & $-+4.17 \mathrm{E}+06$ \\
\hline & $-+5.00 \mathrm{E}+06$ \\
\hline & $-+5.83 E+06$ \\
\hline & $-+6.67 \mathrm{E}+06$ \\
\hline & $-+7.50 \mathrm{E}+06$ \\
\hline & $-+8.33 \mathrm{E}+06$ \\
\hline & $-+9.17 \mathrm{E}+06$ \\
\hline & $-+1.00 \mathrm{E}+07$ \\
\hline & $-+8.02 \mathrm{E}+07$ \\
\hline
\end{tabular}

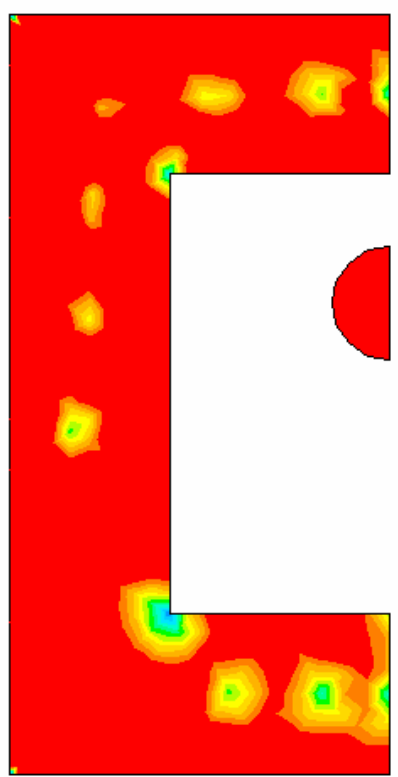

FigureA.20.3: showing contact pressure at the back of the ejector die for case 20 

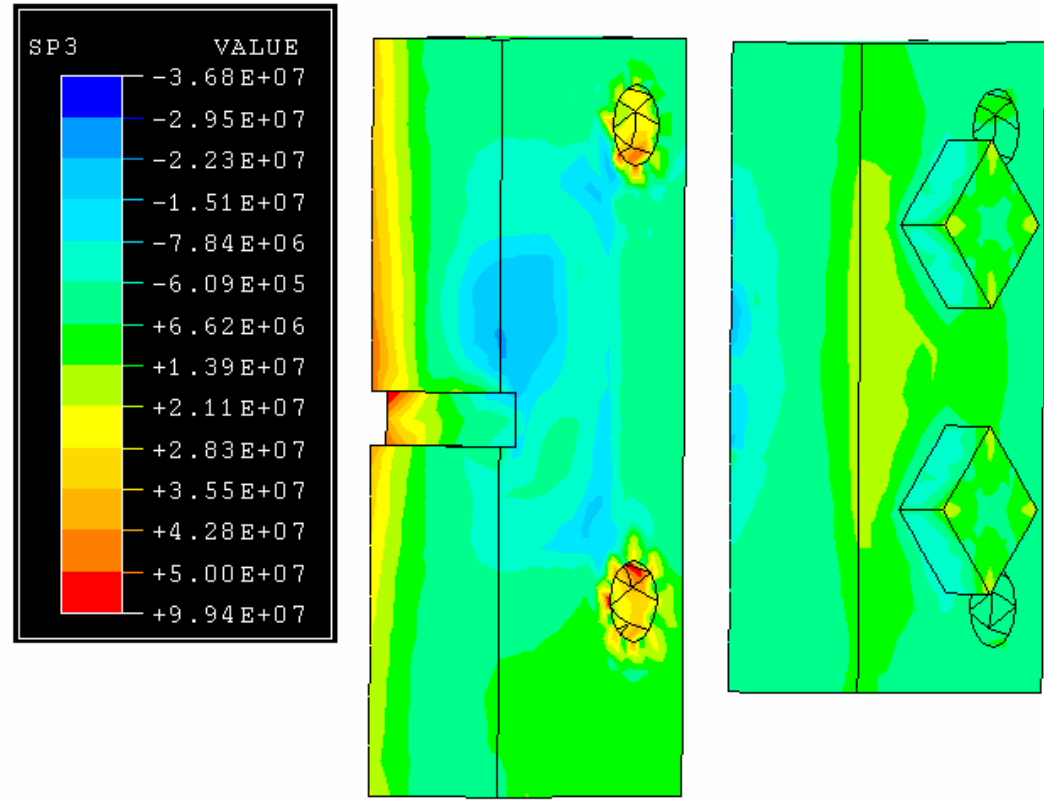

Figure A.20.4: showing compressive stresses in the platens for case 20
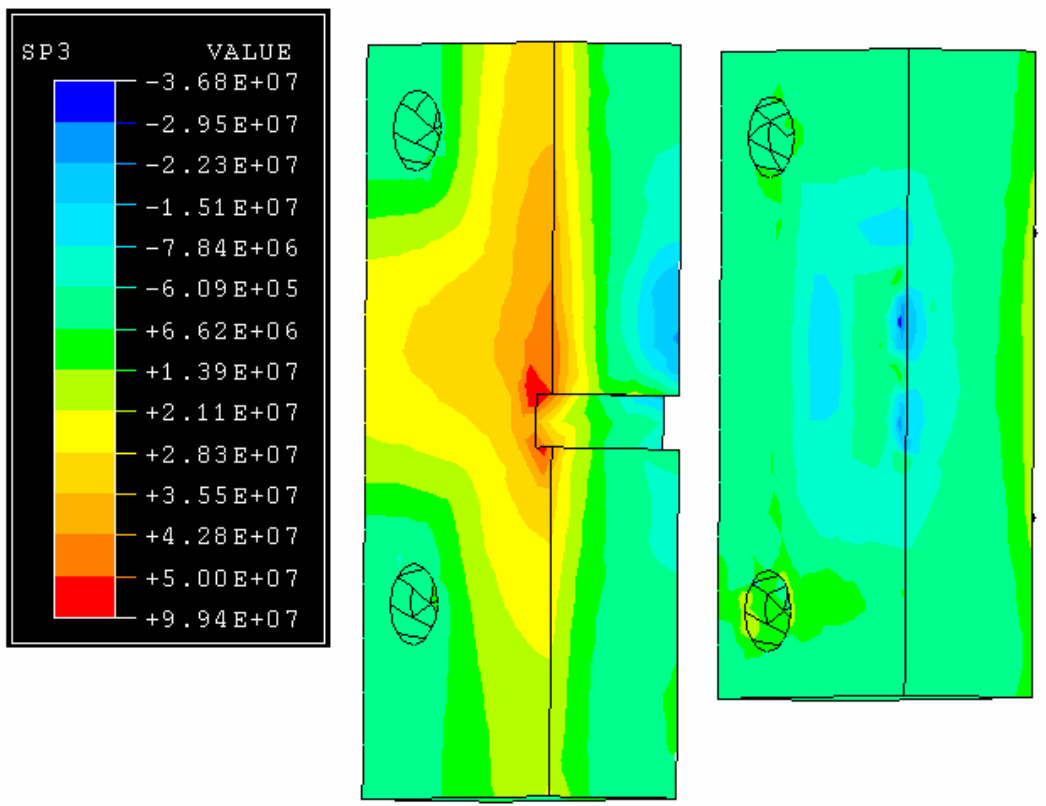

Figure A.20.5: showing compressive stresses in the platens (another view) for case 20 


\section{APPENDIX A.21 Plots for Case 21}

\section{Specifications for case 21:}

- $\operatorname{Die}$ size (A): 35.3"

- Die thickness (B): 5"

- Platen thickness (C): 13.1"

- Thickness ratio (D): 0.43 (Insert thickness: 2.88", Shoulder thickness: 2.13")

- Die Location (E): Mid-high

\begin{tabular}{|c|r|}
\hline \multicolumn{1}{|c|}{ COPEN } & VALUE \\
\hline & $-3.79 \mathrm{E}-19$ \\
$+1.95 \mathrm{E}-05$ \\
$+3.91 \mathrm{E}-05$ \\
$-+5.86 \mathrm{E}-05$ \\
$-+7.82 \mathrm{E}-05$ \\
$-+9.77 \mathrm{E}-05$ \\
$-+1.17 \mathrm{E}-04$ \\
$-1.37 \mathrm{E}-04$ \\
$-+1.56 \mathrm{E}-04$ \\
$-+1.76 \mathrm{E}-04$ \\
$-+1.95 \mathrm{E}-04$ \\
$-+2.15 \mathrm{E}-04$ \\
$-+2.35 \mathrm{E}-04$ \\
$+2.54 \mathrm{E}-04$ \\
\hline
\end{tabular}

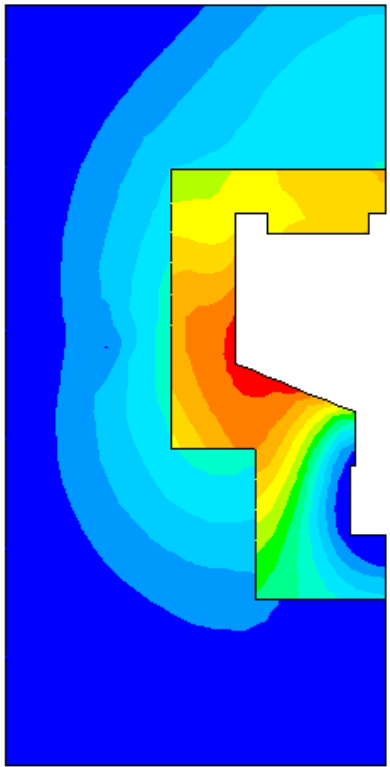

FigureA.21.1: showing parting plane separation for case 21 

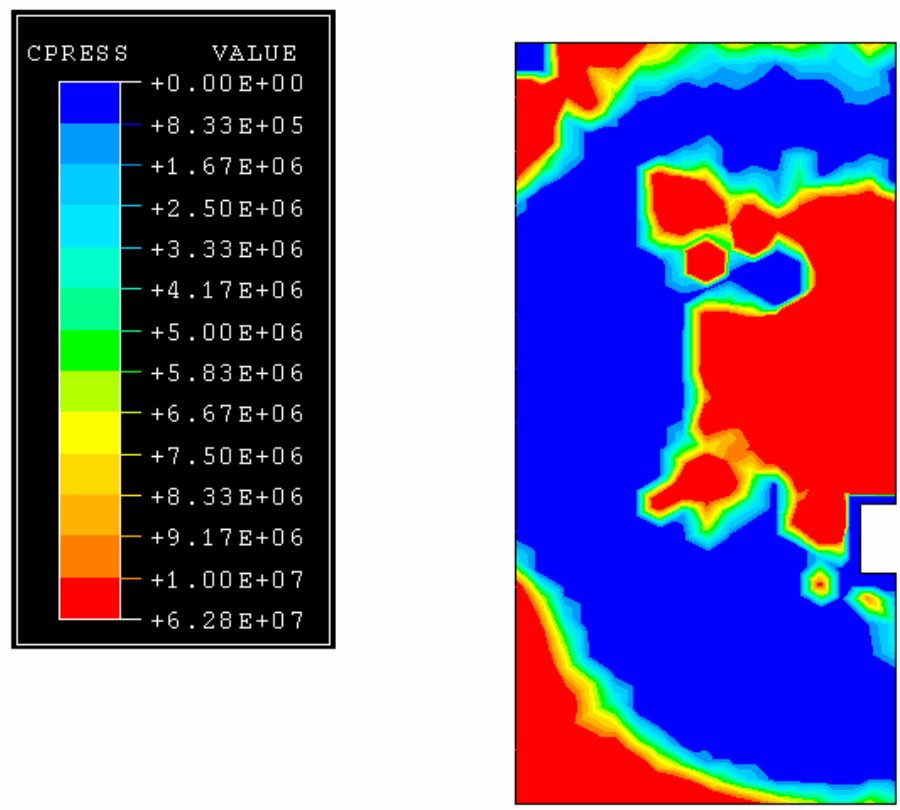

FigureA.21.2: showing contact pressure at the back of the cover die for case 21
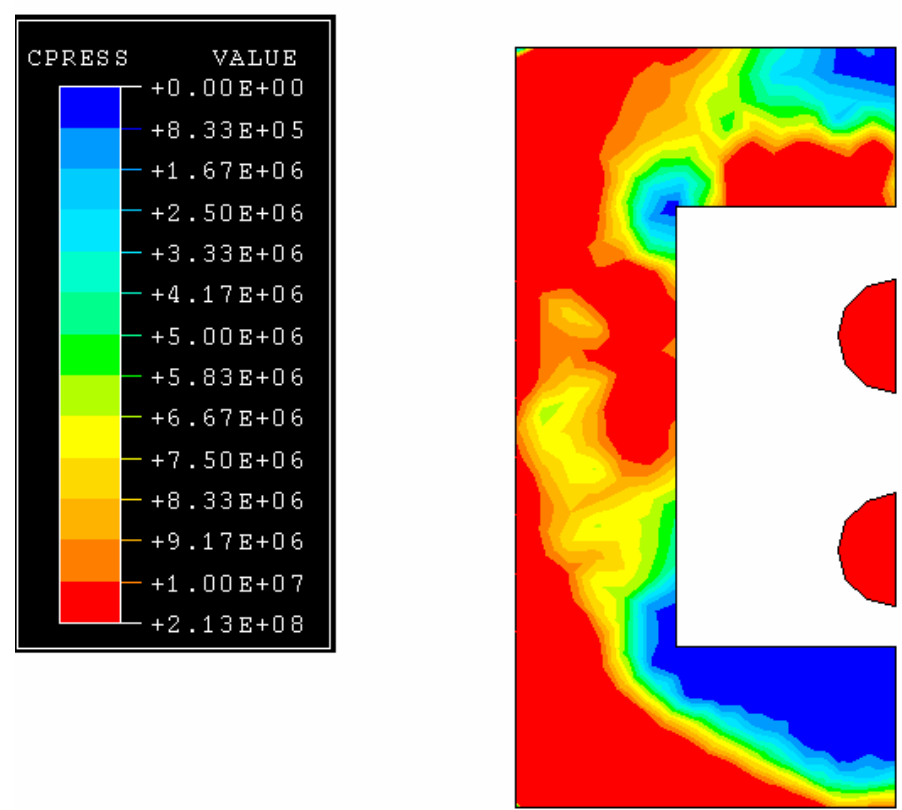

FigureA.21.3: showing contact pressure at the back of the ejector die for case 21 

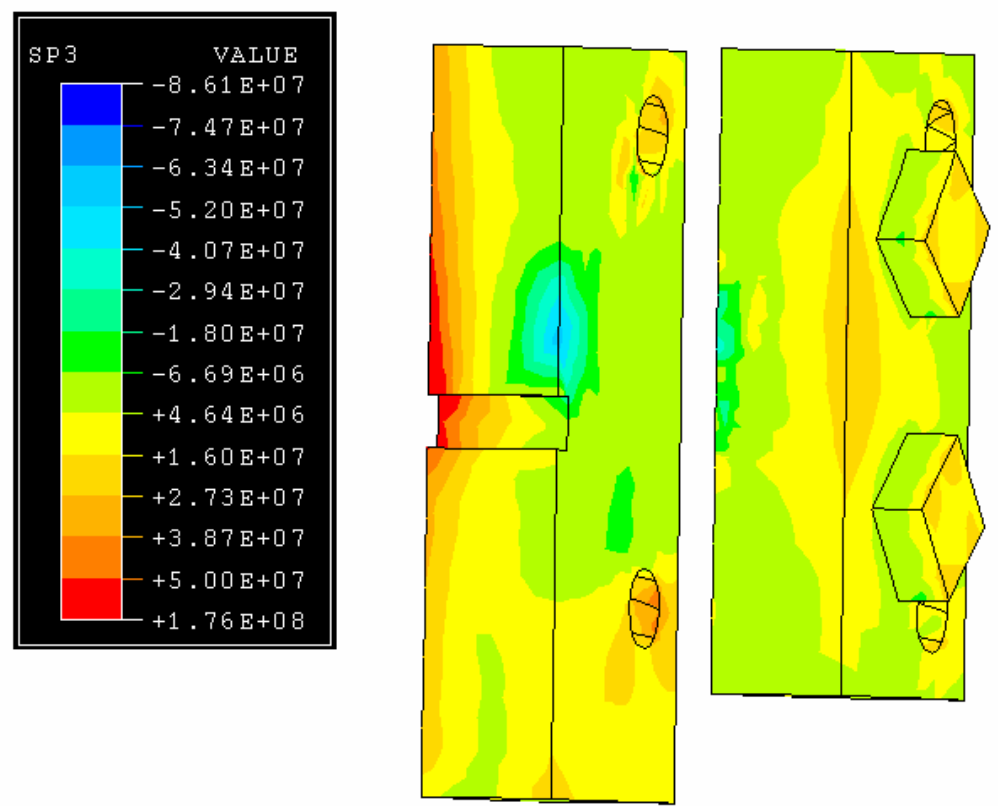

Figure A.21.4: showing compressive stresses in the platens for case 21
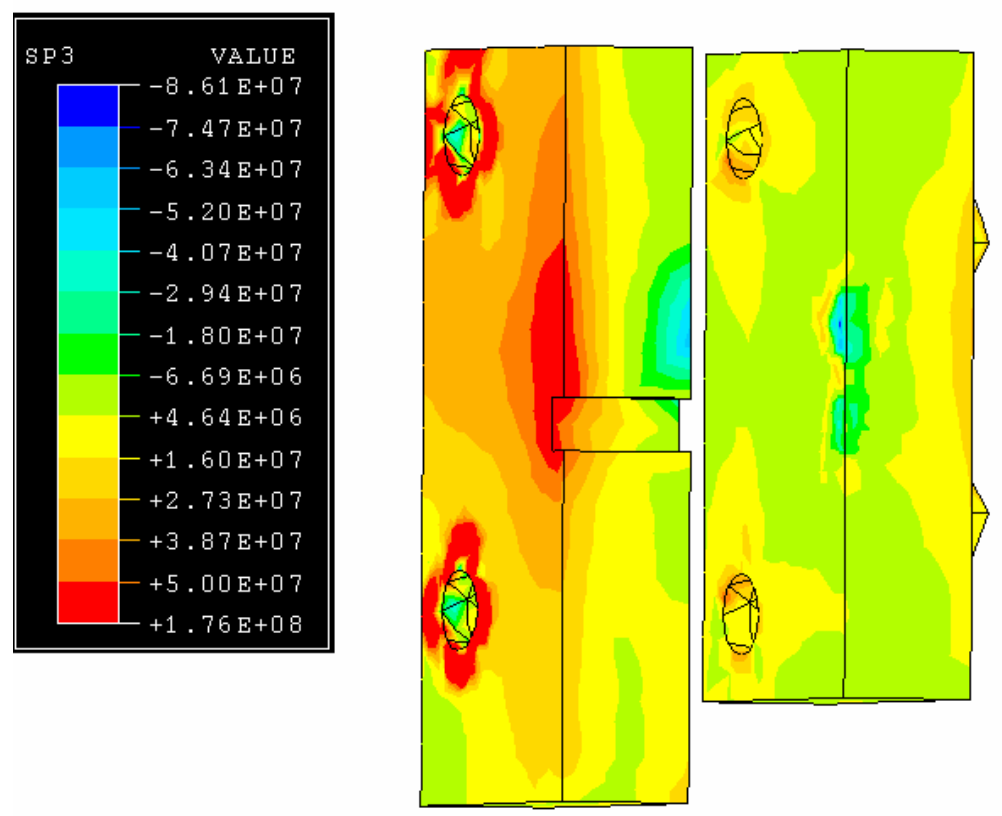

Figure A.21.5: showing compressive stresses in the platens (another view) for case 21 
APPENDIX A.22 Plots for Case 22

\section{Specifications for case 22:}

- $\operatorname{Die}$ size (A): 35.3"

- Die thickness (B): 8.75"

- Platen thickness (C): 13.1"

- Thickness ratio (D): 0.5 (Insert thickness: 4.38", Shoulder thickness: 4.38")

- Die Location (E): Centered

\begin{tabular}{|c|r|}
\hline COPEN & VALUE \\
\hline & $-2.41 \mathrm{E}-19$ \\
& $+2.00 \mathrm{E}-05$ \\
& $+4.00 \mathrm{E}-05$ \\
- & $+6.00 \mathrm{E}-05$ \\
- & $+8.00 \mathrm{E}-05$ \\
- & $+1.00 \mathrm{E}-04$ \\
- & $+2.20 \mathrm{E}-04$ \\
- & $+40 \mathrm{E}-04$ \\
- & $+1.60 \mathrm{E}-04$ \\
- & $+1.80 \mathrm{E}-04$ \\
- & $+2.00 \mathrm{E}-04$ \\
- & $+2.20 \mathrm{E}-04$ \\
- & $+2.40 \mathrm{E}-04$ \\
$+2.60 \mathrm{E}-04$ \\
\hline
\end{tabular}

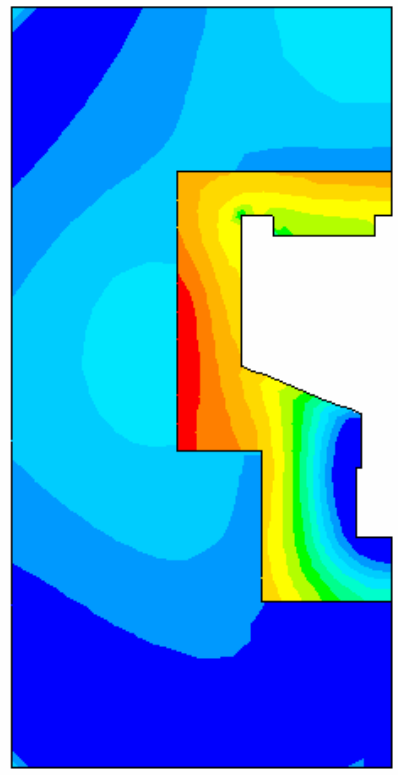

FigureA.22.1: showing parting plane separation for case 22 

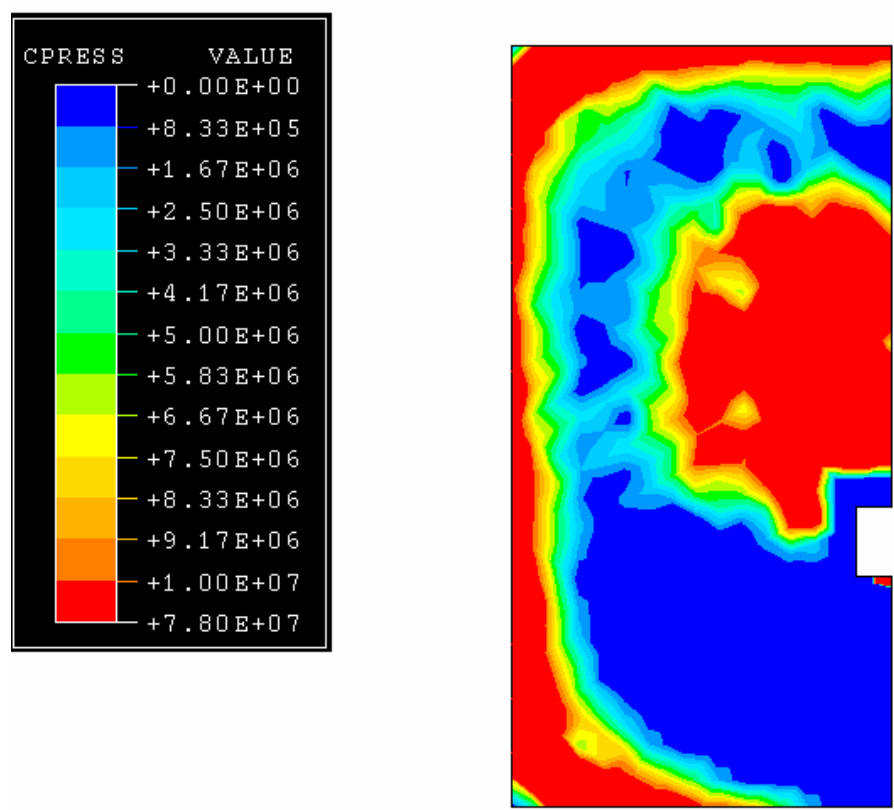

FigureA.22.2: showing contact pressure at the back of the cover die for case 22

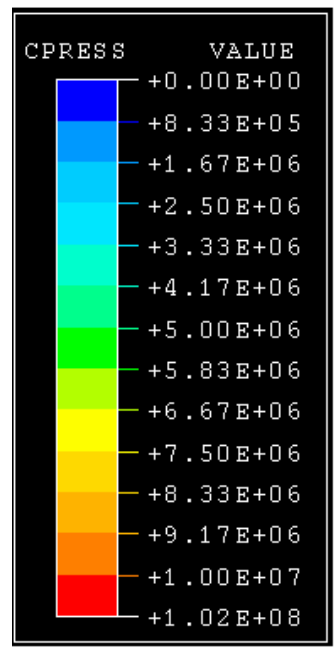

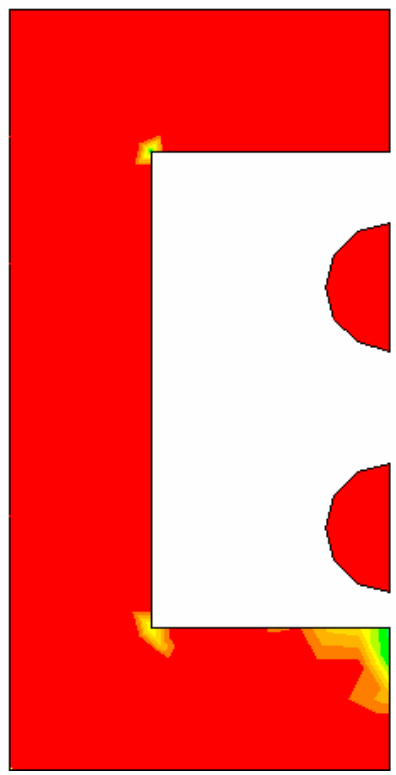

FigureA.22.3: showing contact pressure at the back of the ejector die for case 22 

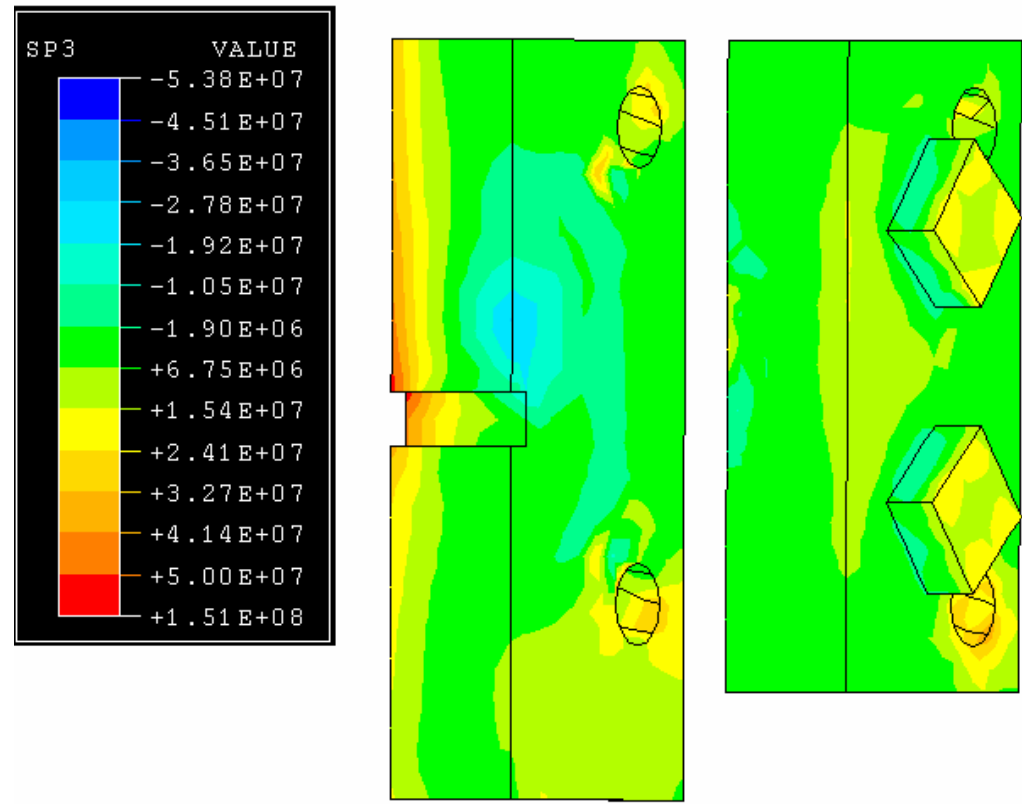

Figure A.22.4: showing compressive stresses in the platens for case 22
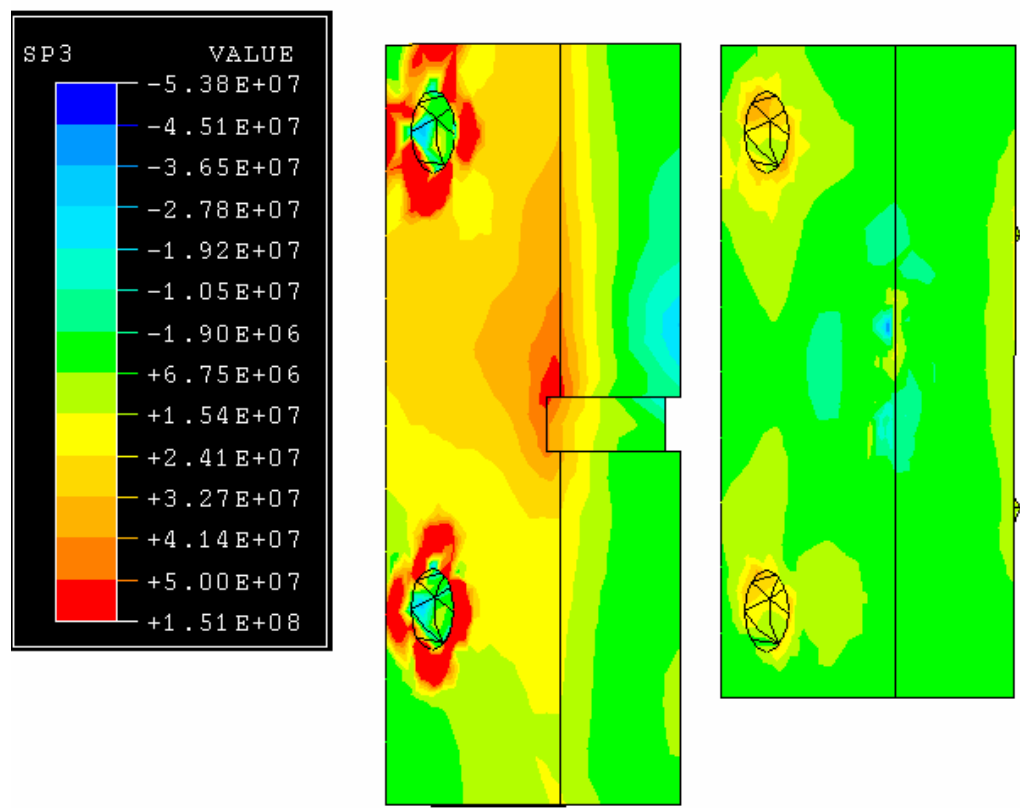

Figure A.22.5: showing compressive stresses in the platens (another view) for case 22 


\section{APPENDIX A.23 Plots for Case 23}

\section{Specifications for case 23:}

- $\operatorname{Die} \operatorname{size}(\mathrm{A}): 31.5$ "

- Die thickness (B): 5"

- Platen thickness (C): 14.5"

- Thickness ratio (D): 0.5 (Insert thickness: 2.5", Shoulder thickness: 2.5")

- Die Location (E): Centered

\begin{tabular}{|r|r|}
\hline \multicolumn{1}{|c|}{ COPEN } & VALUE \\
\hline & $-3.28 \mathrm{E}-19$ \\
$+1.57 \mathrm{E}-05$ \\
$+3.14 \mathrm{E}-05$ \\
$-+4.72 \mathrm{E}-05$ \\
$-6.29 \mathrm{E}-05$ \\
$-+7.86 \mathrm{E}-05$ \\
$-+9.43 \mathrm{E}-05$ \\
$+1.10 \mathrm{E}-04$ \\
$-1.26 \mathrm{E}-04$ \\
$-1.42 \mathrm{E}-04$ \\
$-1.57 \mathrm{E}-04$ \\
$+1.73 \mathrm{E}-04$ \\
$+1.89 \mathrm{E}-04$ \\
$+2.04 \mathrm{E}-04$
\end{tabular}

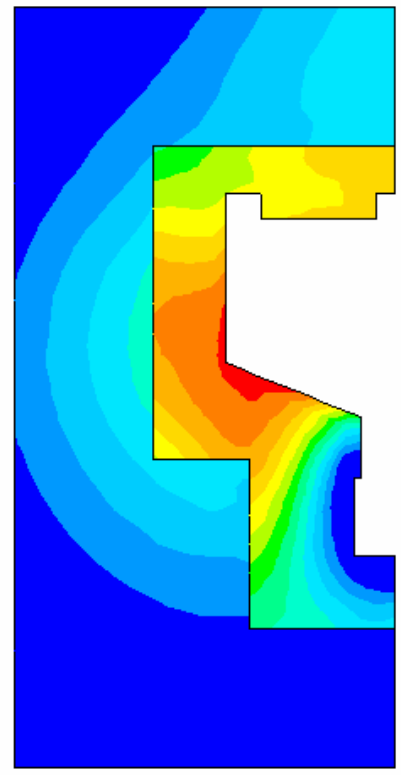

FigureA.23.1: showing parting plane separation for case 23 

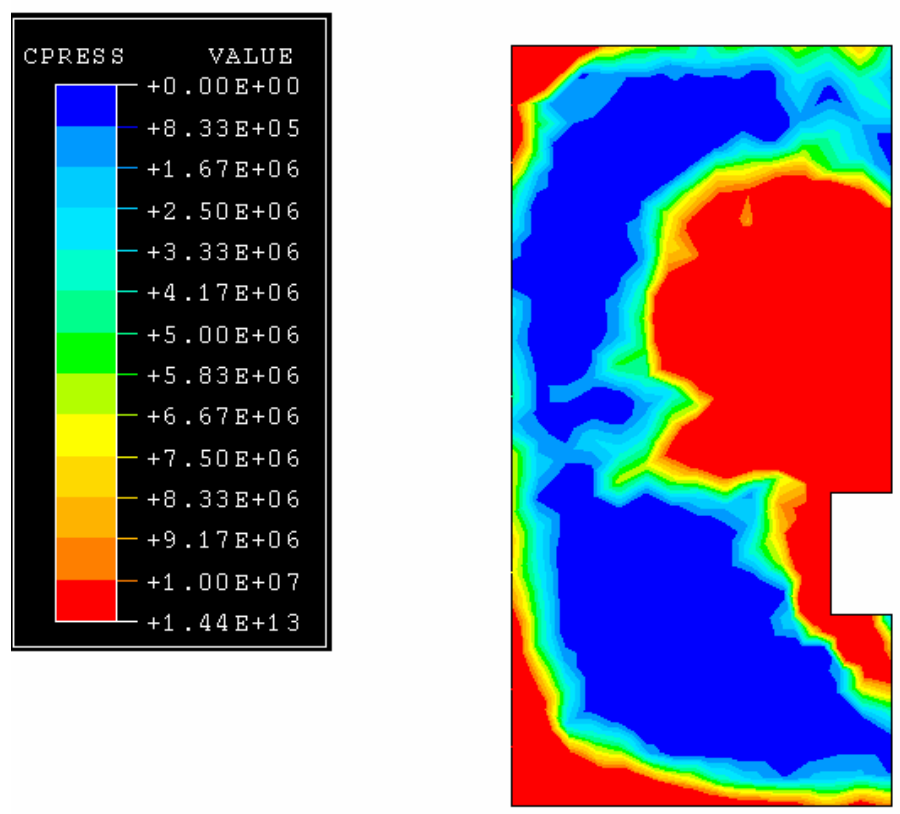

FigureA.23.2: showing contact pressure at the back of the cover die for case 23
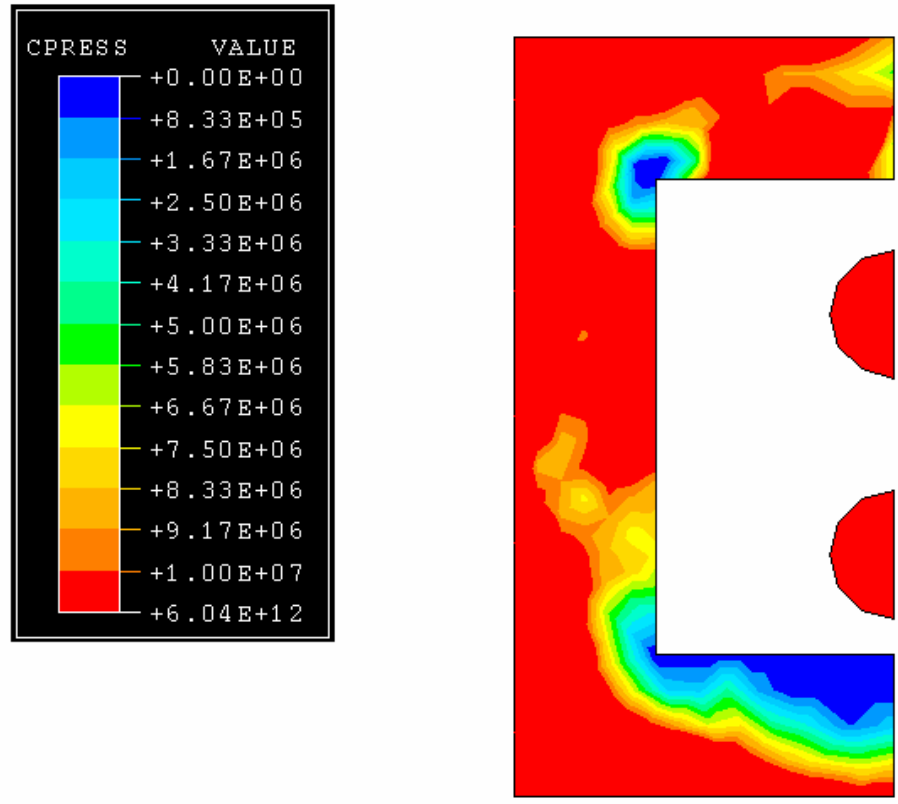

FigureA.23.3: showing contact pressure at the back of the ejector die for case 23 

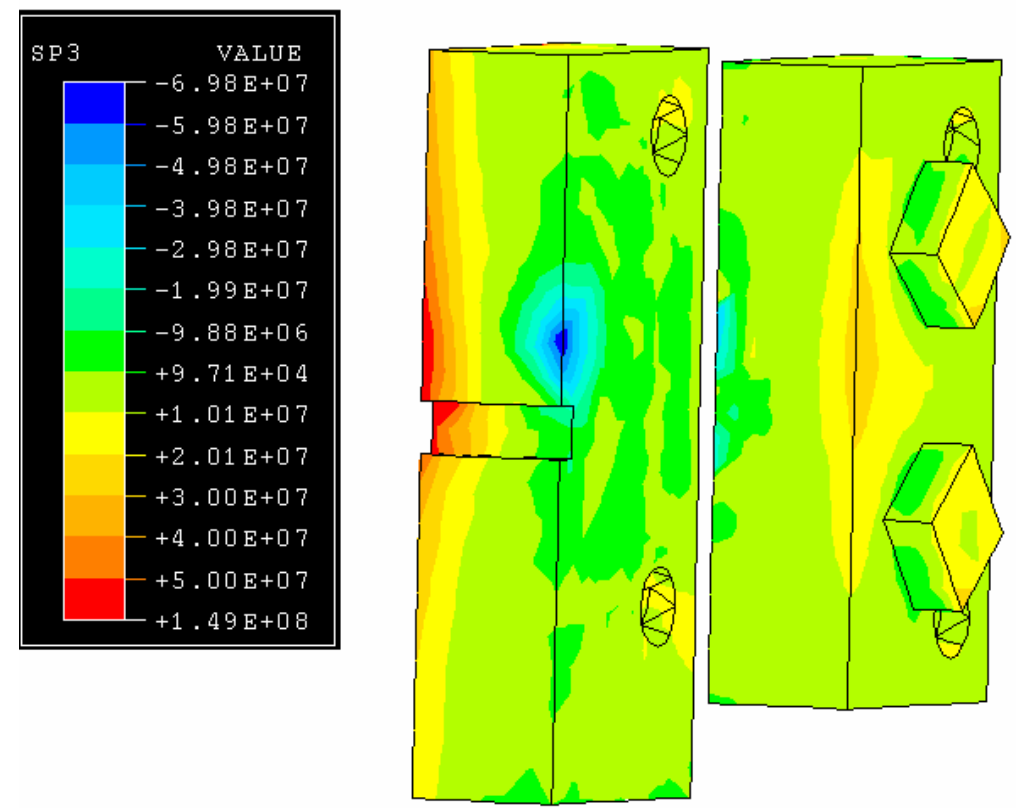

Figure A.23.4: showing compressive stresses in the platens for case 23
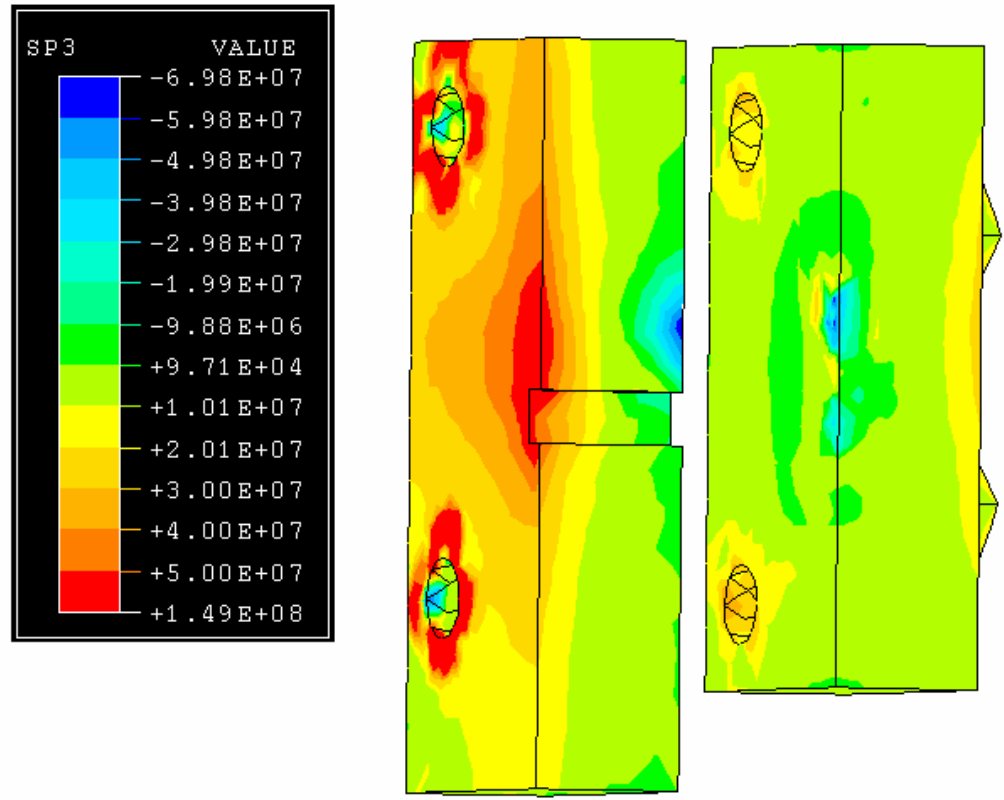

Figure A.23.5: showing compressive stresses in the platens (another view) for case 23 


\section{LIST OF REFERENCES}

[1] H. H. Doehler, "Die Casting”, First Edition, New York, McGraw-Hill Company Inc., 1951.

[2] Chayapati, A., "Study of the Effect of Structural Variables of Die on Die Deflections", Master's Thesis, Mechanical Engineering Department, The Ohio State University, Columbus, Ohio, 1999

[3] Allen, T., Yu, L. and Bernshteyn, M. "Low Cost Response Surface Methods Applied to the Design of Plastic Fasteners"

[4] Axum v 6.0, Release 2, MathSoft, Inc. 2000.

[5] Vittal, M., "Die Casting Part Distortion Prediction", Master's Thesis, Industrial and Systems Engineering Department, The Ohio State University, Columbus, Ohio, 2000

[6] Tewari, A., "Study of The Effect of Structural Variables of Die and Die Casting Machine on Die Deflections," Master's Thesis, Industrial and Systems Engineering, The Ohio State University, Columbus, Ohio, 2000

[7] Kulkarni, Y, "Study of The Effect of Structural Variables of Die and Die Casting Machine on Die Deflections," Master's Thesis, Industrial and Systems Engineering, The Ohio State University, Columbus, Ohio, 2000

[8] H.Ahuett-Garza "Characterization of Loads in Die Casting and Prediction of Die Deflections", Ph.D. Dissertation, Mechanical Engineering Department, The Ohio State University, Columbus, Ohio, 1995. 